\title{
DEVELOPING \\ A TRANSCULTURAL MEASUREMENT \\ SCALE
}

\author{
By \\ Perley-Ann Friedman
}

A thesis submitted to the Faculty of Graduate and Postdoctoral Affairs in partial fulfillment of the requirements for the degree of

\section{Doctor of Philosophy}

in

Management

Sprott School of Business

Carleton University

Ottawa, Ontario

(C) 2012

Perley-Ann Friedman 
Library and Archives

Canada

Published Heritage

Branch

395 Wellington Street

Ottawa ON K1A ON4

Canada
Bibliothèque et

Archives Canada

Direction du

Patrimoine de l'édition

395 , rue Wellington

Ottawa ON K1A ON4

Canada
Your file Votre référence

ISBN: 978-0-494-93671-9

Our file Notre référence

ISBN: 978-0-494-93671-9
NOTICE:

The author has granted a nonexclusive license allowing Library and Archives Canada to reproduce, publish, archive, preserve, conserve, communicate to the public by telecommunication or on the Internet, loan, distrbute and sell theses worldwide, for commercial or noncommercial purposes, in microform, paper, electronic and/or any other formats.

The author retains copyright ownership and moral rights in this thesis. Neither the thesis nor substantial extracts from it may be printed or otherwise reproduced without the author's permission.
AVIS:

L'auteur a accordé une licence non exclusive permettant à la Bibliothèque et Archives Canada de reproduire, publier, archiver, sauvegarder, conserver, transmettre au public par télécommunication ou par l'Internet, prêter, distribuer et vendre des thèses partout dans le monde, à des fins commerciales ou autres, sur support microforme, papier, électronique et/ou autres formats.

L'auteur conserve la propriété du droit d'auteur et des droits moraux qui protege cette thèse. $\mathrm{Ni}$ la thèse ni des extraits substantiels de celle-ci ne doivent être imprimés ou autrement reproduits sans son autorisation.
In compliance with the Canadian Privacy Act some supporting forms may have been removed from this thesis.

While these forms may be included in the document page count, their removal does not represent any loss of content from the thesis.
Conformément à la loi canadienne sur la protection de la vie privée, quelques formulaires secondaires ont été enlevés de cette thèse.

Bien que ces formulaires aient inclus dans la pagination, il n'y aura aucun contenu manquant. 


\section{ABSTRACT}

The research in this dissertation presents the first empirical work with the transcultural construct. The results have clarified the scope of the construct and provided an empirically developed scale, the TMS, for measuring an individual's transcultural ability. The TMS can be used to determine the level of ability a person possesses for understanding a culture combined with their motivation, intent and capability to adapt and act appropriately within the culture - one's transcultural ability. This study also presents support for the predictive validity of the transcultural scale in the foreign assignment selection process with the ability to predict the likelihood of an individual completing an overseas assignment.

The research model was developed from an analysis of the literature and the results from the assessment of a pilot study with expatriates. This analysis identified the possible components of transcultural ability. An on-line survey was developed and completed by 200 expatriates. Data analysis involved a multi-step process that included both exploratory and confirmatory factor analysis, and predictive validity analysis with regression testing. The transcultural construct was found to be comprised of fifteen components that include: facilitator, empathy, observant, open, strategic, adventurous, motivation, education, personal autonomy, emotional resilience, confidence, nonjudgmental, cultural intelligence, flexibility and experience. This research provides a comprehensive base of knowledge for continued conceptual, theoretical and empirical work with the transcultural construct. 
The research results, in addition to empirically defining the transcultural construct and developing the TMS measure, support the use of the TMS as part of the overseas assignment selection process, to mitigate the failure of these assignments. The TMS provides the opportunity to select a candidate for overseas work who is likely to complete the assignment, thereby reducing the risk of the monetary, personal and organizational costs associated with the failure of such assignments. 


\section{ACKNOWLEDGEMENTS}

This dissertation document and doctoral degree were influenced by many individuals, and I sincerely thank them all. I was fortunate to receive tremendous support from family, friends and colleagues and especially from many at Sprott School of Business, who never wavered in their support of my choice to continue to pursue this degree with escalating health issues. There are a few who deserve special recognition. A very sincere and special thank you goes to:

- Sylvia Friedman, my mother, for her unwavering support and encouragement, and for always believing in me even when my reach seemed beyond my grasp;

- Jerry Friedman, my father, the eternal optimist who always saw the cup half full, even when there was no cup to be found;

- Dr. Steven Murphy, my thesis advisor, for his honesty and advice, and especially for encouraging me to not fear challenging the limits;

- Dr. Linda Schweitzer for her invaluable advice and guidance throughout the Ph.D. process;

- Dr. David Cray for his work on Hofstede, and the expatriate and repatriate issues, that helped me find my place in academic research;

- Dr. Andre deCarufel for introducing me to the Ph.D. as an attainable possibility and for encouraging me to pursue this degree;

- Liam Bishop, my life partner who provided endless encouragement, patience and support throughout this process; 
- Bang Bishop and the late Fred Friedman, my present and past feline soul-mates who have kept me down to earth and full of love;

- Koh Lanta (a small island in southern Thailand), my second home, evidence of my passion for other, especially Asian, cultures;

- Distance running that provided me with the many solitary hours for uninterrupted reflection and analysis; and

- Yoga that gives me strength of mind, body and soul to stay focused and able to handle whatever challenges life presents. 


\section{DEDICATION}

\section{Sylvia Sherman Friedman}

\section{4-2010}

This research is dedicated to my Mother. She was my best friend from the time I was old enough to understand the difference between a mother and a best friend. For me that would have been at around two years of age when she taught me to read. I realized that the relationship I had with her was different from the relationship my friends and storybook characters had with their mothers. My mother believed that reading makes everything possible - to read is to learn, to grow and to reach beyond what we think is possible, as there are no limits other than those we impose upon ourselves.

I remember when I was 3 and borrowing books at the Ottawa Public Library. I asked the Librarian if they had this new book. She handed me a book probably thinking I wouldn't know the difference; after all, I was only 3 . I told her not only was it not the right book, but that it was about dogs and I didn't fancy dog stories as I was a cat person. She was quite surprised that I could not only read and had my own library card, but that the pudgy redhead had read enough to have formed opinions on her literary likes and dislikes.

I am always reading - so much to learn and so little time. However, my mother was wrong. There are limits; our time is limited. My mother ran out of time on July 8, 2010. She never wavered in her support of me following my dreams, and was delighted that, in my fifties, I was pursuing a Ph.D. I will miss her terribly for the rest of my life. 


\section{DEVELOPING \\ A TRANSCULTURAL MEASUREMENT \\ SCALE}

Table of Contents

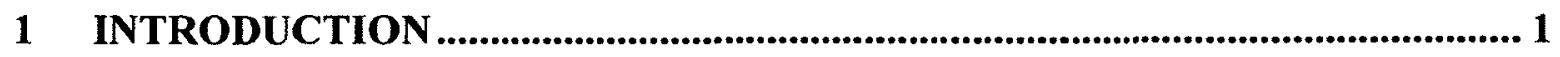

2 LITERATURE REVIEW ......................................................................................... 6

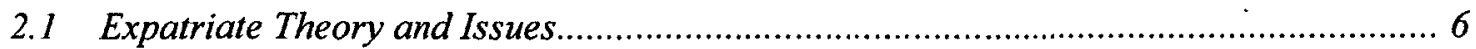

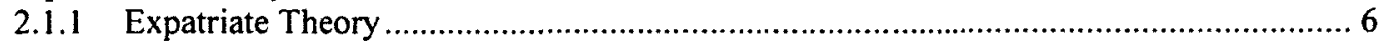

2.1.2 Measuring (Predicting) Expatriate Success ................................................. 10

2.2 Cross-Cultural Business Environment............................................................. 15

2.2.1 Cross Cultural Differences and Impacts ...........................................................16

2.2.2 Cultural Dimensions and Value-Based Cross Cultural Leadership ............................ 18

2.3 Transculturals ............................................................................................. 23

2.3.1 Introducing the Transcultural Construct ..........................................................23

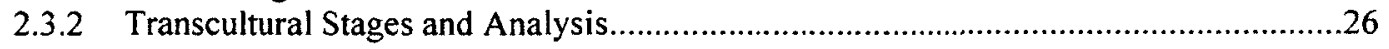

2.3.3 The Evolution of the Transcultural Construct .......................................................33

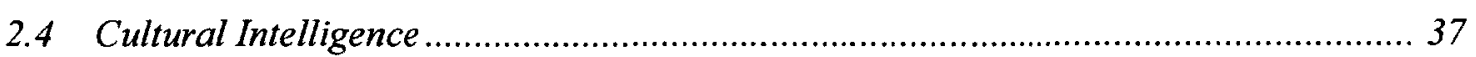

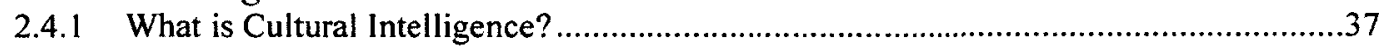

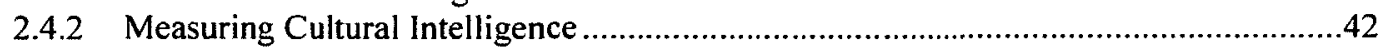

2.4.3 Similarities and Differences with Transcultural Ability ......................................43

2.4.4 The Limitations of the Cultural Intelligence Construct .......................................47

2.5 Contribution of the Literature Review ..................................................5I

3 PILOT STUDY: INTERVIEWS WITH EXPATRIATES...................................58

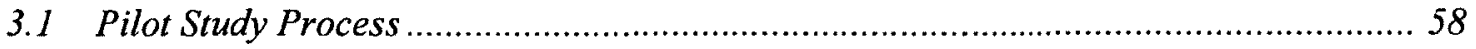

3.2 Pilot Study Content Analysis and Results ............................................................... 62

3.3 Pilot Study Contribution to the Research Model ..................................................... 65

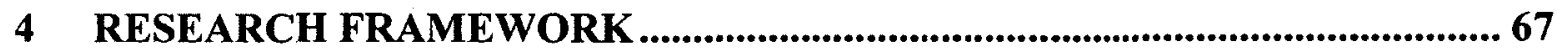

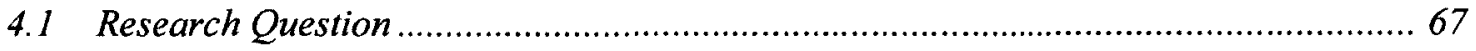

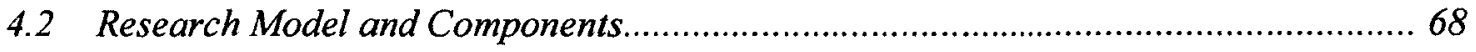

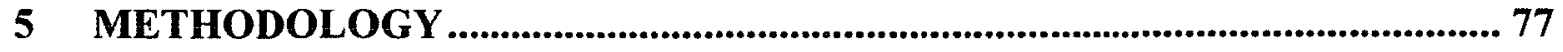

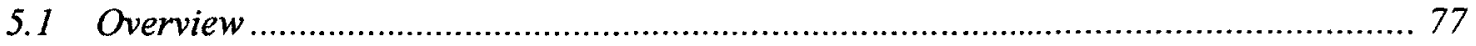

5.2 Factor Analysis for Transcultural Development..................................................... 77

5.3 Research Activities ................................................................................................ 79

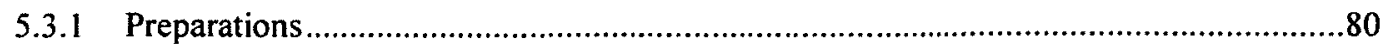

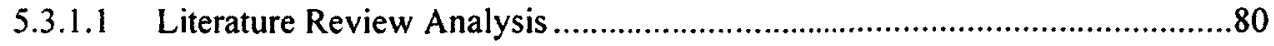

5.3.1.2 Identify Research Components .....................................................81

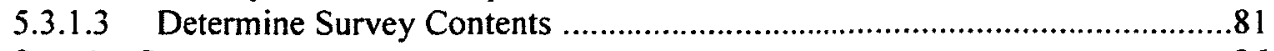

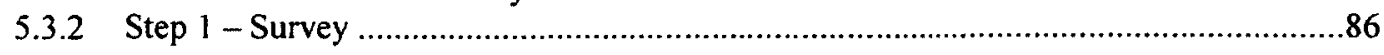




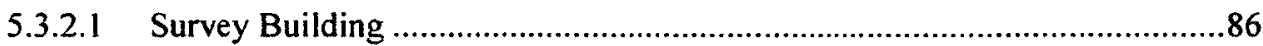

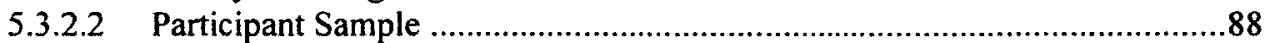

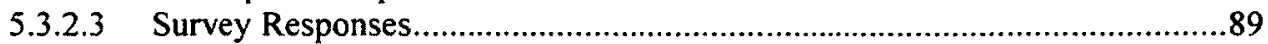

5.3.3 Step 2 - Developing the Transcultural Scale.............................................................

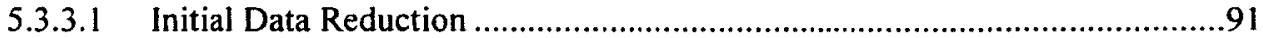

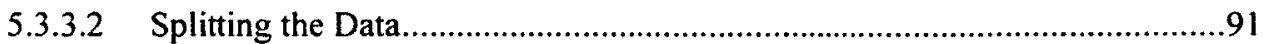

5.3.3.3 Analyze with Exploratory Factor Analysis ..............................................92

5.3.3.4 Develop a Transcultural Measurement Scale ............................................92

5.3.3.5 Analyze with Confirmatory Factor Analysis................................................93

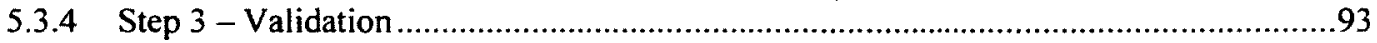

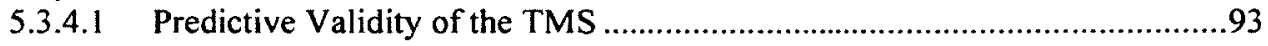

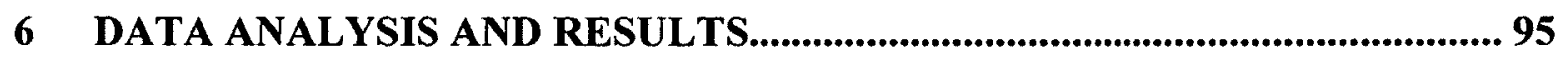

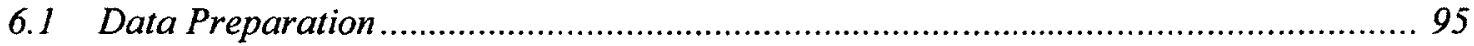

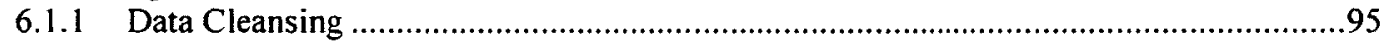

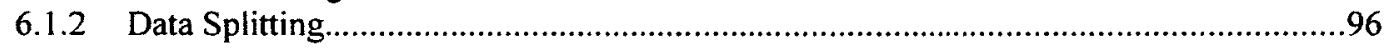

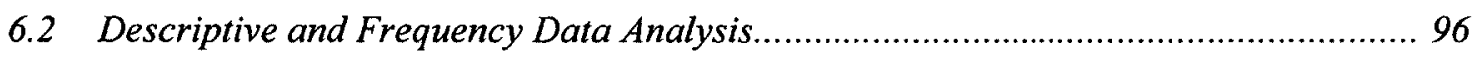

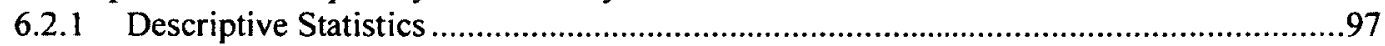

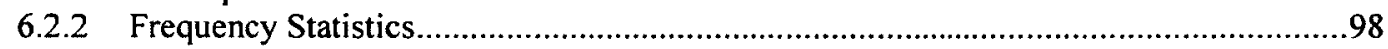

6.2.3 Comparing Frequency and Statistically Significant Statistics ..................................106

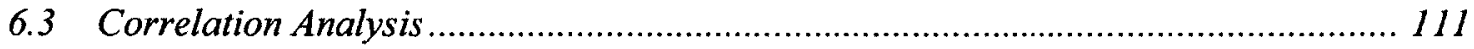

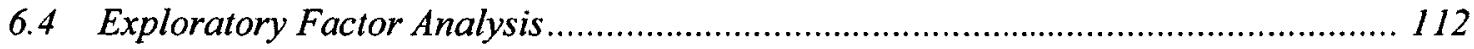

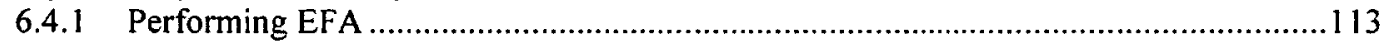

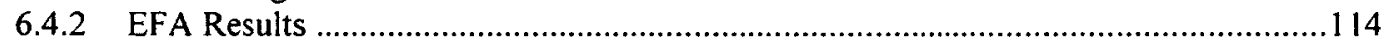

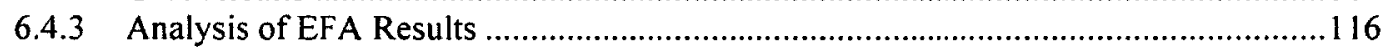

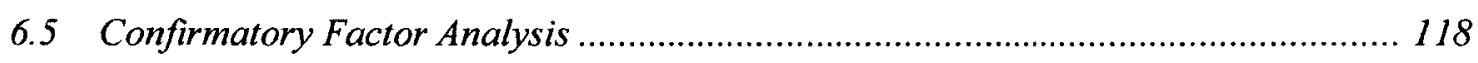

6.6 EFA/CFA Results Produce the TMS Instrument ............................................... 121

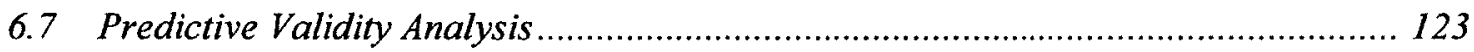

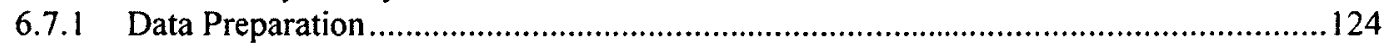

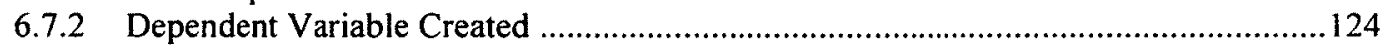

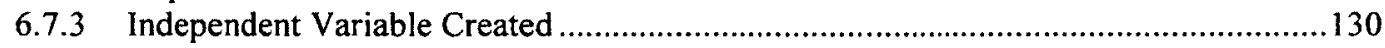

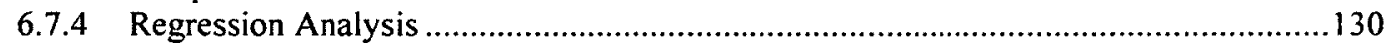

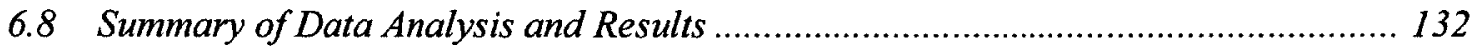

6.9 The Validated Transcultural Measurement Scale ............................................... 133

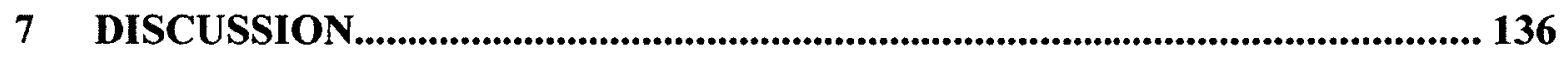

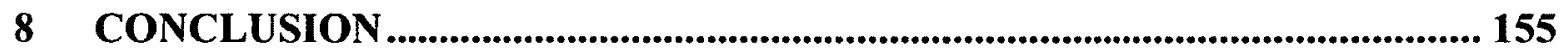

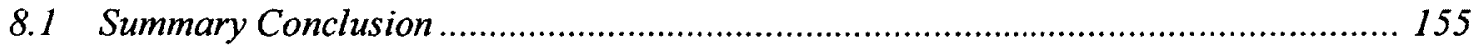

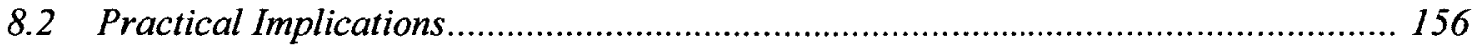

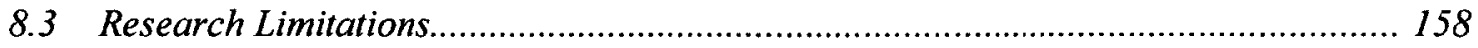

8.4 Suggestions for Future Research .............................................................. 162 


\section{List of Tables}

Table 1: Transcultural Stage and Potential for Overseas Assignments ........................... 30

Table 2: Comparing Transitional Experience with Transcultural Development .............. 34

Table 3: The Cultural Intelligence Framework ................................................................ 40

Table 4: Cultural Intelligence aligned with Transcultural Development.......................... 44

Table 5: Components and Literature Review Section ..................................................... 56

Table 6: Pilot Study Interview Questions Information .................................................. 59

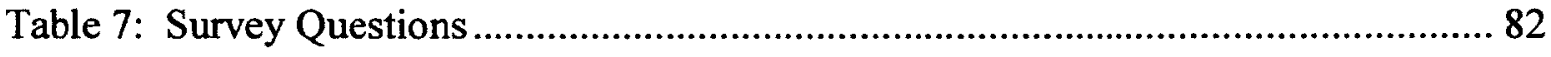

Table 8: Descriptive Statistics for Continuous Variables ................................................. 97

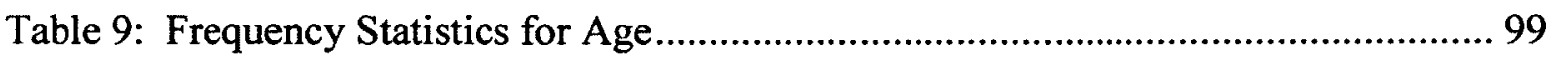

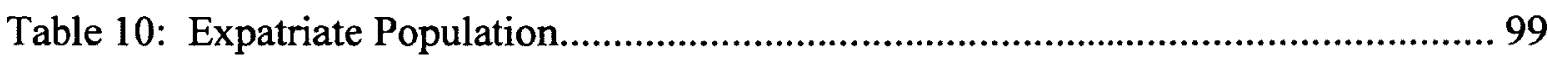

Table 11: Frequency Statistics for Gender.................................................................. 100

Table 12: Frequency Statistics for Highest Level of Education ................................... 100

Table 13: Frequency Statistics for Number of Overseas Jobs ...................................... 102

Table 14: Frequency Statistics for Number of Overseas Jobs Completed...................... 102

Table 15: Frequency Statistics for Number Returned Early by Choice........................... 103

Table 16: Frequency Statistics for Number Returned Early Not By Choice................. 104

Table 17: Frequency Statistics for Seeing Oneself as a Successful Expatriate ............. 105

Table 18: Frequency Statistics for Repatriation Difficult.............................................. 105

Table 19: Comparing Frequency Statistics ................................................................. 107

Table 20: Analyzing Data Sets 1 and 2 for Statistical Significance ............................. 110

Table 21: Criteria for Removing an Item during EFA................................................. 114

Table 22: Final Results of Exploratory Factor Analysis.............................................. 115

Table 23: KMO and Bartlett's Test from EFA with Data Set 1 .................................. 116 
Table 24: CFA with Transcultural Ability Items ..................................................... 119

Table 25: KMO and Bartlett's Test from CFA with Data Set 2 ….............................. 120

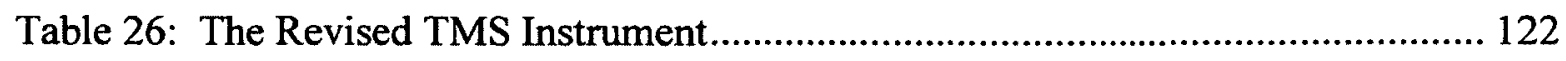

Table 27: Linear Regression Analysis Results of Frequency Dependent Variable Items

Table 28: Logistic Regression Analysis Results of Dichotomous Dependent Variable

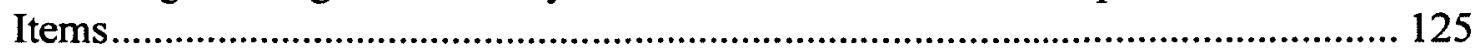

Table 29: Successful Expatriate Dependent Variable Design ........................................ 126

Table 30: Successful Expatriate Dependent Variable Decision Table ........................... 127

Table 31: Dependent Variable Descriptive Statistics .................................................... 129

Table 32: Transcultural Variable Frequency ............................................................. 130

Table 33: Regression Analysis Results.......................................................................... 131

Table 34: Validated Transcultural Measurement Scale Survey.................................... 134 


\section{List of Figures}

Figure 1: Progressive Characteristics of Transculturals ................................................ 27

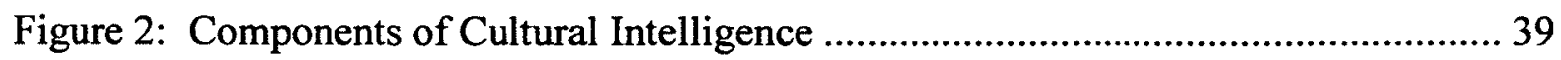

Figure 3: Components of Transcultural Ability (Proposed) ...........................................69

Figure 4: Transcultural Ability and Expatriate Success ............................................. 144 


\section{List of Appendices}

Appendix A: Criteria Considered Relevant to Overseas Adjustment/Success.......... 181

Appendix B: Inter-Item Correlation Matrix Tables............................................... 182

Appendix C: Component Abbreviations ………….................................................... 201

Appendix D: Summary of the Data Analysis Results for the Research Items .......... 202

Appendix E: Transcultural Measurement Scale Survey .......................................... 207 


\section{DEVELOPING \\ A TRANSCULTURAL MEASUREMENT \\ SCALE}

\section{INTRODUCTION}

A transcultural is someone who can easily move between, and function in, any culture through a recognition and understanding of the behavioural equivalents between cultures (Graen, 2006; Graen, Hui, Wakabayashi and Wang, 1997). Transculturals have the ability to adapt their behaviour to cultural environments that are different from their own. Being able to identify the degree to which an individual is a transcultural would provide international businesses with the opportunity of selecting an individual for foreign jobs or assignments who would facilitate interaction and collaboration with the local culture (Graen, Hui and Gu, 2004).

The globalization of business is ever increasing as is the number of employees being sent to foreign work locations (Okpara and Kabongo, 2011) and effective expatriate performance is of prime importance for organizational success overseas (Kim and Slocum, 2008). While $33 \%$ of expatriates believe that foreign experience will lead to faster promotions, $17 \%$ left their company during an overseas assignment and $38 \%$ left within one year of returning home (Brookfield, 2010). Organizations are paying more attention to expatriate selection and development in order to mitigate the high financial and personal costs associated with poor expatriate selections (Chen, Kirkman, Kim, Farh and Tangirala, 2010; Paik, Segaud and Malinowski, 2002; Osman-Gani and Rockstuhl, 2009). Selecting the right individual for a foreign work assignment can be challenging for organizations as success is uncertain and the cost of expatriate failure is substantial 
(Adler, 1997). Failed assignments can also lead to the indirect costs associated with damaged reputations and strained relations with foreign businesses and host governments (Vogel, van Vuuren and Millard, 2008).

Some organizations take great care in selecting the resources to fill these roles, considering both organizational and technical performance (Sanchez, Spector and Cooper, 2000), and the flexibility to culturally adapt to the new environment (Andreason and Kinner, 2005; Black and Gregersen, 1999). There are also some organizations that quickly find a person to ship off overseas without much consideration given to the cultural adjustment challenges (Harvey, 1982; Shin, Morgeson and Campion, 2007). Thorough expatriate selection has been recommended as an effective way to increase the likelihood of expatriate success (Solomon, 1996).

Extensive work has been done on cultural dimensions to determine the mix of characteristics desirable in a cross-cultural employee and leader (Hofstede, 1980; House, Javidan, Hanges and Dortfman, 2002; Trompenaars and Hampden-Turner, 1998). These dimensions are complex and depend on the location of the work as well as on the national culture of the individuals under consideration. By being too focused on the attributes of the target culture, this selection process could exclude those who have not had the opportunity to demonstrate or develop the required or targeted characteristics, but nevertheless, may be good candidates for overseas assignments. While there are many methods used for selecting expatriates, from technical skill sets to cultural awareness and 
adaptation (Black and Gregersen, 1999), there is neither consensus nor consistency for this selection (Vogel et al., 2008).

The characteristics of a transcultural and the stages of transcultural development can be pieced together from the academic literature; however there are gaps in this literature as to measuring exactly what makes up a transcultural. In addition to this lack of clarity, to date there has been no empirical research with the transcultural construct. This dissertation addresses the issue of clarifying the definition of transcultural. In addition to this lack of clarity, there is also no method for determining an individual's transcultural ability. This study also provides an empirically developed scale for measuring an individual's transcultural ability.

The research in this dissertation enhances the theoretical definition of a transcultural and provides an empirically developed measure for determining the degree to which a person is a transcultural. The measure was tested through a validation involving expatriate success in order to link the transcultural construct with expatriate selection and to increase the likelihood of success with overseas assignments. The measure developed, called a Transcultural Measurement Scale (TMS), approaches cultural diversity from an individual perspective, focusing on the individual and his or her ability to understand and adapt to living and working within diverse cultures (Friedman, Dyke and Murphy, 2009). Organizations can use the TMS to facilitate the overseas selection process as it provides them with the possibility of selecting an individual with the appropriate level of 
transcultural ability or cultural knowledge, awareness and ability, for the target assignment (Graen, 2006; Graen et al., 2004; Graen et al., 1999; Selmer, 2004).

The methodology used in this research included a multi-step process for scale development (see Clark and Watson, 1995; Cronbach and Meehl, 1955; Comrey, 1988; Floyd and Widaman, 1955; Loevinger, 1957; Spector, 1992; Stevens, 2009). There were four major steps in the methodology that included: literature review and model development, survey, data analysis and instrument development, and validation.

The theoretical contributions of this study include a review of the transcultural theory that combines the academic knowledge and theory for the transcultural construct, and the first empirical study for measuring a person's transcultural ability. The study also provides a discussion of the expatriate literature and the challenges with overseas placement. The transcultural construct is integrated with the expatriate selection process. The study provides a theoretical framework for defining, utilizing, and continuing research with the transcultural construct.

This research, in addition to contributing theoretically, has contributed practically by providing an empirical scale for measuring individuals who have the ability to adapt their behaviour to cultural environments that are different from their own. This augments current organizational methods for determining an individual's likelihood of completing an overseas job or assignment. 
Chapter 2 presents a review of the academic literature used to develop the model and framework tested in this research. Chapter 3 provides a discussion of the pilot study. Chapter 4 presents the research model and framework. The methodological approach is discussed in Chapter 5. Chapter 6 provides the data analysis and results, and Chapter 7 discusses the research results in the context of this study's contribution to the literature. Chapter 8 provides the conclusions of the research with a summary conclusion, a discussion of the limitations of the research, and suggestions for future research. 


\section{LITERATURE REVIEW}

The literature review is presented in five sections. These include: expatriate theory and issues, the cross-cultural context, the transcultural construct, cultural intelligence theory and the contributions of the literature review to the research study.

\subsection{Expatriate Theory and Issues}

This section provides a detailed discussion of expatriate theory that includes an overview of the current issues and challenges of successful expatriation. The section ends with a review of the literature dealing with measuring or predicting success in this area. The goal of this section is to provide an understanding of the challenge of successful expatriation in order to illustrate the importance of expatriate selection and its impact on expatriate success.

\subsubsection{Expatriate Theory}

For many decades, the growth of international business and the positive benefits of global expansion on an organization's economy have continued to require organizations to send their best personnel on international assignments. International organizations have tended to favour sending home office resources on overseas assignments to complement and supplement the resources in the foreign subsidiaries (Gelfand, Erez and Aycan, 2007). 
Lazarova and Tarique (2005) provide four main reasons for global assignments: to build the organizational structure and framework of the company, to analyze and solve specific problems, to perform an existing organizational role, and to oversee and direct the foreign operation. While these assignments are of strategic importance to organizations, the success of such assignments relies on the appropriateness of individuals assigned to them (Kim and Slocum, 2008).

Sending an individual on foreign assignment is an expensive long-term process involving selection, relocation, support, oversight and repatriation (Brewster, 1996). U.S. corporate relocation costs were estimated at $\$ 25$ billion in 2009 (Worldwide ERC, 2009). This high cost should get the attention of organizations and encourage them to pick the right person for overseas assignments with respect to adjustment, as this directly contributes to the success or failure of the assignment (Jenkins and Mockaitis, 2010). Expatriate selection is taken seriously by some firms (Sanchez et al., 2000), however, many have a poor selection process and a lack of consistency with respect to their procedures (Andreason and Kinner, 2005; Black and Gregersen, 1999). Some selection processes focus on expediency and organizational or technical expertise, thereby ignoring the ability to adapt to the foreign culture (Harvey, 1982; Kim and Slocum, 2008; Shin et al., 2007).

Nankervis and colleagues (1993) attributed "the failure of expatriate assignments ... to the inadequate adaptation of the employee, their partner and family, to unfamiliar, and often threatening, overseas locations" (Nankervis, Compton and McCarthy, 1993, p. 
570). A successful cross-cultural assignment is dependent on the expatriate's ability to adjust to and master the new culture; however, the effects of culture shock can negatively influence the abilities and performance of those on overseas assignments (Oberg, 1960). Culture shock is defined as the occupational disease suffered by people who are suddenly transplanted abroad (Oberg, 1960). It is caused by the absence of the familiar signs and symbols of social interaction with the expatriate experiencing frustration, anxiety and a terrible longing for home (Adler, 1975; Boyacigiller and Adler, 1991; Deng and Gibson, 2008; Furnham and Bochner, 1982).

Culture shock can be broken down into four stages. The first stage is the honeymoon, where the individual is fascinated with the 'new' and is often pampered and looked after by the locals. The crisis stage begins when difficulties are encountered. The individual begins to perceive problems with most aspects of life in the new culture and starts to develop a hostile and aggressive attitude towards the host country. This stage is a turning point and many expatriates return home during the crisis stage (Black and Gregersen, 1999; Kealey, Protheroe, MacDonald, Vulpe, 2006). The crisis stage can last months or years depending on the individual (Oberg, 1960). Those who pass through the crisis stage are able to open themselves up to the new culture and begin the adjustment stage where they learn about the culture and the language, and begin to adapt to their new environment. In the adaptation stage, the fourth and final stage of culture shock, the expatriate has accepted the customs, food, and habits and gets along in the new country. While the expatriate has adapted to the new culture, it does not necessarily mean that they 
understand the nuances or customs, nor does it imply that they are comfortable and feel at home in the culture (Oberg, 1960, Black and Gregersen, 1999, Graen et al., 1997).

The Culture Shock Inventory (Redden, 1975) was designed to identify those who will have problems adjusting due to culture shock. Various characteristics were used to assess individuals that included: ethnocentrism, experience, cognitive and behavioural flexibility, cultural knowledge, and interpersonal sensitivity (Redden, 1975). Those who scored high on all characteristics, except on ethnocentrism where a lower score is preferred, were seen as desirable as they would likely have less difficulty handling culture shock.

In their literature review and synthesis of the expatriate experience, Sims and Schraeder (2004) identify training, demography, disposition, personality, organizational support and technical expertise as salient factors affecting culture shock. They also provide hypotheses for future empirical testing to measure the impact of these factors on the level of culture shock experienced. Sims and Schraeder (2004) conclude their paper by stating that "expatriates do not, cannot, and will not make successful cross-cultural adjustment unless they overcome the potentially debilitating effects of culture shock" (p.84).

Kealey and Rubin (1973) provide what they call a resume of research findings from their literature review focusing on identifying meaningful selection criteria for overseas assignments. Their resume provides approximately eighty (80) items as predictors of overseas success. Kealey and Rubin indicate that while their resume supports the 
conceptual existence of a cross-cultural type of individual, there may be limited use for this type as it is based on an abstraction from the literature (Kealey and Rubin, 1973). A summary of the results of this study can be found in Appendix A.

\subsubsection{Measuring (Predicting) Expatriate Success}

While the employment of expatriates remains operationally and strategically important for organizations, the rate of failure of expatriate assignments does not appear to have significantly decreased over time (Pires, Stanton and Ostenfeld, 2006). Sims and Schraeder (2004) reported that 16-70 percent of expatriate assignments have been estimated to fail, with this figure supported in the academic literature over the past twenty years (Black and Gregersen, 1999; Black and Gregersen, 1991; Naumann, 1992). More

recently, Okapara and Kobongo reported that expatriate failure rates range between 10\%$80 \%$ depending on the country and industry (Okpara and Kabongo, 2011). The wide range of failure rates in the literature may be identifying a lack of precision with the research or it may be indicating that expatriate failure is not really a problem.

Harzing (1995) labels expatriate failure rates a myth due to a strong dependency on academic articles and not on reliable statistical sources. Harzing (2002), in her study of 60 citations of expatriate failure rates, identified that the dependency on academic referencing has distorted the accuracy of the rates. However, recent empirical evidence from the Brookfield Global Relocation Survey for 2010 reports that $17 \%$ of expatriates left their position during an assignment, $38 \%$ left their organization within the first year of returning from an overseas assignment and $23 \%$ left within 2 years of returning home 
(Brookfield, 2010). This empirical evidence tightens the recent failure rate range to between $20-40 \%$.

The average cost of expatriate failure is estimated at $\$ 65,000$ to $\$ 300,000$ US per employee (Worldwide ERC, 2009; Zeira and Banai, 1985) with some firms in excess of $\$ 1$ million (US) annually (Shannonhouse, 1996). Failure rates between $10 \%$ and $80 \%$ are reported to have cost organizations between $\$ 40,000,000$ and $\$ 1$ US billion annually, depending on the scope and the impact of the failure on the organization (Hawley, 2009; Vogel et al., 2008). In 1997, the estimate of total losses for American expatriating firms exceeds $\$ 2$ billion per year (Punnett, Crocker and Stevens, 1997). The current figures and failures rates from Worldwide ERC (2009) and Brookfield (2010) suggest that expatriate failure rates and costs are improving.

Expatriate failure rates and costs were also found to vary between countries and within organizations depending on whether expatriate and repatriate resignations were included in the statistics. This helps to explain the wide-range of rates and costs attributed to expatriate failure (Okpara and Kabongo, 2011).

While success can be measured statistically through the number of failures and lost revenue, it can also be measured from a proactive position. This involves predicting whether an individual will be successful on an overseas assignment. Organizations attempting to predict expatriate success are becoming more aware of the importance of who is sent on overseas assignments (Black and Gregersen, 1999). Initially, skill set was 
an important consideration as it was thought that sending the most skilled would facilitate the overseas assignment (Sanchez et al., 2000). With many expatriates returning home early due to culture shock, the trend moved towards looking at intrapersonal attributes (Black and Gregersen, 1991). It was thought that certain types of people would be able to survive and recover from culture shock. This also proved insufficient as failures rates continued to be high. The focus then combined individual attributes with situational factors such as family and job conditions (Black and Gregersen, 1999). While this may have been an improvement, large percentages of expatriates were still returning home early from assignments (Black and Gregersen, 1999).

Recent decades have seen increasing research in predicting expatriate success and this research has included cross-cultural leadership as a major factor. This is evidenced by the work of Hofstede (e.g., 1980), the Globe Project (House et al., 2002) and other studies that have focused on improving cross-cultural leadership by better understanding and predicting the personal traits and attributes of individuals in these roles. Hawes and Kealey (1980), in attempting to address the measurement issue, found overseas effectiveness to be dependent on an individual's personal and family adjustment and satisfaction, and on their professional competence and range of inter-cultural activities and involvement (Hawes and Kealey, 1980). Ng, Van Dyne and Ang (2009) explored learning capabilities for global leader development and Graen has done extensive research on leadership as an effective approach to intercultural cooperation (Graen, Hui and $\mathrm{Gu}, 2004)$. A 2009 study of expatriate managers in Asia found that self-confidence 
is positively influenced by cross-cultural effectiveness and adjustment (Osman-Gani and Rockstuhl, 2009).

Some individuals are more successful than others in cultural situations (Ang et al., 2007). The following description provides an academically supported typology of five levels of expatriate success. The lowest level of expatriate success would apply to someone who has a low degree of cultural awareness and tends to stereotype and look at other cultures as an adventure (Graen and Hui, 1999; Redden, 1975). These individuals are believed to have difficulties recovering from culture shock (Adler, 1975; Black and Gregersen, 1999, Oberg, 1960).

A medium-low level of expatriate success could include those who can identify behaviours and attitudes of other cultures (Graen and Hui, 1999). While these individuals have difficulties adjusting to a new culture, they often complete some overseas assignments even though they see themselves as unsuccessful expatriates. In addition, these individuals may have some difficulty upon repatriation as they did adjust somewhat overseas, so they would be going through a form of culture shock re-adjusting back home (Hurn, 1999).

The medium level of expatriate success applies to individuals who can perceive similarities and differences between cultures, and who conform to cultures different from their own (Graen and Hui, 1999). Additionally, this level includes expatriates who see 
themselves as successful with little difficulty repatriating (Black, Gregersen and Mendenhall, 1992).

The medium-high level of expatriate success includes those individuals who have successfully completed more than a few overseas assignments without returning home early, and are willing take on more overseas work. These individuals perceive and understand cultural differences and they can successfully function appropriately in other cultural environments (Graen and Hui, 1999). For example, while bowing in Japan would be likened to shaking hands in Canada, this individual understands the nuances of the deepness of the bow and the strength of the handshake. They use this understanding and insight to successfully adapt to new cultures and integrate with the local community.

The high level of expatriate success includes individuals who have completed multiple overseas assignments without returning home early. They have the ability to easily identify the nuances of the functional or behavioural equivalents between cultures. These individuals would also strive to create an atmosphere of mutual cooperation possibly by transforming or combining the cultures together without offending either culture (Graen and Hui, 1999; Graen et al, 2004). They are very comfortable in any culture and tend to become career expatriates. In addition, expatriates at this high level of success see themselves as successful, however they can encounter repatriation problems as these people do not necessarily identify with home as being somewhere specific or where they were raised. In addition, expatriates at a high level of success may be bored without the challenges of new cultural stimulation (Black and Gregersen, 1999). 
Organizations need to consider expatriate success when they assign individuals overseas. Selecting the appropriate individual for the assignment would help organizations reduce the number of expatriates who return home early. However, two major difficulties present themselves to organizations in this regard. The first is the ability of an organization to identify or recognize such individuals, and the second is the capacity of an organization to nurture and encourage the development of such individuals from within their organizations. Resolving both of these challenges hinges on an organization's ability to identify the employees who are, or will be, good candidates for overseas assignments.

The expatriate is functioning in a cross-cultural business environment, often in a lead or senior position. The next section will provide an overview of the cross-cultural business environment and the prominent cross-cultural leadership research on cultural value dimensions.

\subsection{Cross-Cultural Business Environment}

This section provides an overview of culture with respect to cross-cultural business. The goal of the section is to present a picture of the cross-cultural business environment in order to identify the fundamental challenges facing businesses with respect to overseas assignments. It also provides an overview of the popular dimension-based theories for overseas placement selection. 


\subsubsection{Cross Cultural Differences and Impacts}

Economic expansion and the necessity to operate in many countries are introducing organizations to cultures that are inconsistent and often incongruent with local practices and customs. Organizations need to understand the impacts of these cross-cultural differences and recognize that international collaboration is a necessity to reduce the propensity of cultural conflict that can inhibit and prevent organizational growth (Graen et al., 2004). Cultural understanding can also help organizations build cross-cultural relationships and prevent inappropriate behaviour that can threaten international cooperation (Ricks, 1999). Many international organizations are striving to integrate people from various cultures in order to overcome cultural differences through an understanding and accommodating of cultural divergence (Shin et al., 2007). The employees of global companies work with others whose attitudes and values may be very different, as are their goals and expectations (Cray and Mallory, 1998). A lack of cultural awareness can negatively influence cross-cultural interactions from the challenges of cultural differences and a weak understanding of the dynamics of cross-cultural interfaces in domestic and international contexts (Gelfand et al, 2007).

In 1952, Kroeber and Kluckhohn discussed over 164 definitions of culture and concluded "as yet we have no full theory of culture" (Kroeber and Kluckhohn, 1952, p. 357). Two notable academics in the cross-cultural field, Hofstede and Triandis have defined culture, as a collective programming of the mind (Hofstede, 1991) and as different ways of doing things (Triandis, 1994). While there are many definitions, common to most is the sharing of culture and how it is adapted over time and through generations (Gelfand et al., 2007). 
Cultural differences distinguish one culture from another by the way in which they handle relationships with others, view the passage of time, and interact with the environment, amongst other differentiators (Hofstede, 1980; Trompenaars and HampdenTurner, 1998). Cultural behaviour may be the result of problem-solving skills, or of a set of rules and norms that guide behaviour (Harris, 1999). The identification of cultural values can allow for cultural differences to be compared and contrasted. This information can then provide those in cross-cultural situations with an understanding of why people are behaving as they are and what this behaviour means.

Cultural differences can lead to cultural judgments and evaluations. Instead of viewing various cultures as different, they may be seen as wrong if they are different. HampdenTurner and Trompenaars (2000) view cultural differences as different choices to resolve the problems the culture faces. Ethnocentrism is a reaction to foreign cultures whereby the new culture is evaluated by the standards of one's own culture (Hofstede, 1999). Triandis (2006) argues that humans are ethnocentric as they feel that what is normal in their own culture also should be normal in other cultures. Foreign cultures, when seen as mirror images of one's cultural values or reversals in order and sequence, may be frightening and some mistake this as a reversal of value systems and a negation of what one has come to believe in (Hampden-Turner and Trompenaars, 2000).

While cultural values can be compared and contrasted, an understanding of cultural equivalence between the cultures enhances the ability to comprehend the behaviour, and 
provides a means of understanding and appreciating another culture. For example, in Canada we shake hands when we meet business colleagues. By contrast, in Japan people bow, and in Thailand they 'wai' (hold their hands under their chin and bow). In both Japan and Thailand, the deeper the bow, the greater the respect. However, in Canada, a handshake that is too strong or too weak can indicate a lack of respect. This information can help foreigners understand relationships and attitudes of those in the host country. However, such behavioural differences can be evaluated based on cultural knowledge that may be inadequate or out of date. Organizations and individuals need to be aware of the timeliness of their cultural information, as it has been suggested that cultural values and the subsequent behaviour, may not always be stable over longer periods of time (Inglehart, 2008).

\subsubsection{Cultural Dimensions and Value-Based Cross Cultural Leadership}

Leadership theory has evolved from a study of individual traits to leadership styles (Bass, 1990: Stogdill, 1975), and cross-cultural leadership has developed to include the study of cultural dimensions (Hofstede, 1980; House et al., 2002; Trompenaars and HampdenTurner, 1998). Implicit Leadership Theory (ILT) claims that our assumptions, stereotypes, beliefs and structures influence how we view and evaluate leaders. As leadership is considered by some to be universal (Bass, 1990), and people behave differently across cultures, it follows that the view of what makes a good leader would also differ across cultures (House et al., 2002). This section will discuss value-based cross-cultural leadership focusing on the work of Hofstede, the House Project and the influence of other academics examining value-based leadership cross-culturally. 
In the mid-1960's Geert Hofstede explored the differences in the thinking and social action that existed between nations (Hofstede, 1980; Hofstede, 2001). He argues that people have predictable mental programs that contain a component of the individual's national culture expressed through the values that dominate the culture. Hofstede, through theoretical and statistical analysis, empirically developed five value dimensions of national culture (Hofstede, 1980; Hofstede, 2001): power distance; uncertainty avoidance; individualism / collectivism; masculinity / femininity; and long-term / shortterm orientation.

Hofstede scored the nations in the survey by their measurement on each dimension. This dimension measurement serves to highlight the strong potential for cultural clashes involving any mix of countries and cultures. In the half century since Hofstede's study was undertaken, there have been a myriad of studies involving culture, yet his work remains at the forefront of the field (Cray and Mallory, 2007). This is understandable considering that such research is very expensive, extremely time consuming and difficult to administer. As Hofstede's dimensions and research results are widely known and accepted, many researchers still use and analyze these measurements, rankings and clusters in their own research (Ardichvili and Kuchinke, 2002; Goh and Pin, 2009; Leong and Fischer, 2100; Scandura and Dorfman, 2004).

However, it should be mentioned that there is strong criticism of Hofstede's work. The timeliness of the results is one of the obvious problems, as the data was collected 
approximately 50 years ago. Other problems are that the sample of IBM employees was not reflective of national cultures, and that the U.S.-centric nature of the study demonstrated an ethnocentric researcher bias (Javidan, House, Dorfman, Hanges and de Luque, 2006). In addition there has been criticism of the research methodology, as the study was intended to explore employee satisfaction, not identify cultural dimensions.

The Global Leadership and Organizational Behaviour Effectiveness (GLOBE) Project studied the effects of leadership on social and organizational culture to better understand the forces of cultural resistance and change (House and Globe Associates, 2004; House et al., 2002; House and Globe Associates, 1999). The GLOBE Project also attempted to identify and explore aspects of leadership that are universally applicable, with either a positive or a negative connotation, and the different interpretations of leadership attributes across cultures (Chhokar, Brodbeck and House, 2007; Frost and Walker, 2007; Grove, 2005; House and Globe Associates, 2004). The Globe Project has had a major influence on cross cultural relations and leadership with many research projects building on its findings (Frein and Castellanos, 2010; Light, 2003; Raskovic and Krzisnik, 2010; Pellegrini, Scandura and Jayaraman, 2010; Wong, Wong and Li, 2007).

The central proposition of the GLOBE Project is that "the attributes and entities that differentiate a specified culture are predictive of organizational practices, and the leader attributes and behaviours that are most frequently enacted are most effective in that culture" (House et al., 2004, p.17). The Project results supported this central proposition (House et al., 2003) and in addition, found a convergence of, or a similarity between, the 
behavioral practices of cross-cultural leaders (House et al., 1991). Liddell (2005) reasoned that this may be reflective of a universal human desire for meaning and direction from authority figures. Indeed, the confirmation of this universal attribute of convergence would also be an indication of the changing values within societies or nations (Inglehart, 2008).

Inglehart alludes to the challenge of aligning cross-cultural leadership with cultural value dimensions. Since values may not be stable, any expectations that are built on the notion of stable values are also not stable, nor dependable (Inglehart, 2008). If organizations are selecting their cross-cultural leader candidates from the cultural dimension studies, they are facing challenges that stem from trying to find such complex individuals, and from the risk that the dimension values are changing.

Cross-cultural studies have generally concerned themselves with cultural values and measurements of cultural dimensions (Earley and Mosakowski, 2004a; Hofstede, 1980; Hofstede, 1990; House et al., 2004; Hofstede, Van Deusen, Mueller and Charles, 2002; Trompenaars and Hampden-Turner, 1998). The process of preparing managers for foreign work has focused on cultural training, aimed at helping the candidate understand what they will see and experience on their assignment. The problem with this type of approach, as Hofstede pointed out, is the ecological fallacy of attributing the characteristics of a country to the individuals within that country (Hofstede, 1991). It is possible that the locals will demonstrate behaviour incongruent with the country values, 
which would present a challenge to the expatriate who has been selected and received cultural training based on country values.

There are a variety of cross-cultural leadership theories and studies involving values that have been assessed across cultures. Some of the more interesting studies are worth mentioning to illustrate the range of research in the area. One example is a study of paternalistic leadership in non-Western cultures where it is found to be more prevalent and accepted (Pellegrini and Scandura, 2008). In another example, Spreitzer, McCall and Mahoney (1997) took a pragmatic approach and used the term international executive to describe an expatriate in a managerial or very senior position, with a mix of both values and abilities as found in the literature. They argued that there is a lack of academic research on the predictors for expatriate success. Yet another study suggested that global leadership is a process influencing and encouraging cross-cultural cooperation towards a common goal (Osland, Bird, Mendenhall and Osland, 2006). This study focused on the individual leader and not on cultural awareness and adaptation. Finally, Grisham (2006) took a creative approach to cross-cultural leadership by focusing on the impact of poetry and metaphors for building trust, communicating more effectively and inspiring subordinates, focusing on the individual and away from the cultural values.

The more creative cross-cultural leadership studies provide an alternative to the culture and value-based dimension theories for selecting appropriate candidates for overseas opportunities. It is useful to review the value-theories of cross-cultural leadership as this research does help define cross-cultural assignment success. However, it is limiting to 
focus on only those in leadership roles as overseas jobs opportunities include a variety of roles and responsibilities. Current research needs to go beyond simply looking at leadership to focus on the individual and the ability to adapt to a different cultural environment. The following section presents the transcultural construct.

\subsection{Transculturals}

This section will describe the transcultural construct, including its various levels and their characteristics. The section also contains a review of the evolution of the transcultural concept.

The concept of a transcultural is not new. While it has been used theoretically over the years by a range of academics (see Adler, 1984; Graen and Hui, 1999; Lobel, 1990; Trompenaars and Hampden-Turner, 1998), empirical work to better articulate and measure the construct had been lacking. The intent of this section is to highlight the value of the transcultural construct to international business and the expatriate selection process. In addition, this section aims to underscore the importance of continued study and research concerning the transcultural construct.

\subsubsection{Introducing the Transcultural Construct}

A transcultural is defined as "a person who can transcend one's own culture to understand and see the merits of another culture" (Graen et al., 2004, p.233). Graen and colleagues use the term to denote those who are able to transcend different cultures and help bring people of different cultural backgrounds together (Graen et al., 1997). The 
term has been described "as a form of culture created not from within its separate spheres but in the holistic forms of diverse cultures" (Milhouse, Asante and Nwosu, 2000, p.ix). It is about knowing and understanding that there are many types of behaviour patterns and various ways to communicate when different cultures come together. A high level transcultural is described as a special type of person who has moved beyond their own cultural socialization and can recognize, understand and make valid judgments about other cultures (Graen, et al., 1997).

A high level transcultural is someone who can overcome cultural barriers, including their own, by understanding the value and merit of other cultures (Graen, 2006; Graen et al., 1997). Bird and Stevens (2003) describe such people as very educated, connected to others like themselves, relying on technology (e.g., the internet), self-confident, pragmatic, difficult to intimidate, democratic and participatory, as well as flexible and trusting (Bird and Stevens, 2003). They are most often willing and able to change their style of interacting to adapt to a new cultural reality (Lobel, 1990). Transculturals have the ability to adapt their behaviour to cultural environments that are different from their own. Responding to one's own culture is often difficult (Maddox, 1993), yet transculturals can usually adapt to most cultures. Adler (1984) views them as beyond culture or without having an identifiable cultural specificity.

Those with strong transcultural abilities could loosely be compared to a chameleon, as they have the ability to transform as necessary, adapting and acting according to the requirements of the situation. This makes them desirable candidates for international 
assignments, as they can easily adapt and function within a new environment. The challenge for organizations, however, is to be able to identify individuals who are high level transculturals, or those who have the ability to develop and strengthen their transcultural ability.

The concept of the transcultural was developed by Graen and colleagues, building on their leader-member exchange leadership theory and in response to the value theories of cross-cultural leadership of Geert Hofstede and the GLOBE Project (Graen, 2006; Graen et al., 2004; Graen et al., 1997). Transcultural theory takes an individual approach, focusing on the individual's abilities, not on the values of their home country. When measuring an individual with respect to cross-cultural constructs, it is important to ensure that the measure does not suffer from either the ecological or the reverse ecological fallacy; in other words, the inaccurate assumption that individual characteristics can be assumed by those of a society, or the assumption that the characteristics of a society also apply to each individual in that society.

The research in this study supports the concept of the transcultural as an ability-based construct. The transcultural literature suggests that transcultural ability can change over time (Graen et al., 1997). This support for change implies that the characteristics of the transcultural are ability not value-based, as abilities are subject to change. Austin's (2002) ability-based work with the MSCEIT (a measure of emotional intelligence) concentrated on distinguishing traits from abilities. The ability-based research of Leping (2006) and Rode and Associates (2007) involved looking at skills, not traits or values, in 
their ability-based scales and measurement analysis. Transcultural ability can be improved (Graen et al., 1997), which supports the ability-based nature of the construct.

Abilities involve means and capabilities, which are changeable over time (House, 1971). In contrast, traits and values are stable, reflecting an individual's mode of conduct (Rokeach, 1973). Values and traits are innate qualities that are relatively stable, whereas abilities are skills acquired through experience and training, and can be constantly evolving (Strang, 2007; Zaccaro, 2007). Transcultural ability is not composed of values that are stable and enduring over time. Each component of transcultural ability may be subject to change (Graen et al., 1997); however, a change in an individual's transcultural ability does not mean that their values have changed. While values are stable, they can impact our decisions and influence a wide range of behaviour that contributes to our skills and abilities.

Transculturals, as a result of their ability to recognize cultural equivalence, can positively influence intercultural interactions by facilitating the building of relationships between those of different cultures. Specifically, transculturals in higher stages are valuable assets for international placements. Organizations are faced with the challenge of identifying such individuals. The next section will present the five stages of transcultural ability.

\subsubsection{Transcultural Stages and Analysis}

A five-stage process model has been identified to describe transcultural ability. These stages involve: cultural adventurer, cultural sensitizer, discrepant culture insider, 
comparative culture judge and socializing synthesizers (Graen et al., 1997; Graen and Hui, 1999). This model is solely theoretical as Graen and colleagues never empirically measured nor operationalized it. The following figure illustrates the hierarchy of the transcultural stages.

\section{Figure 1: Progressive Characteristics of Transculturals}

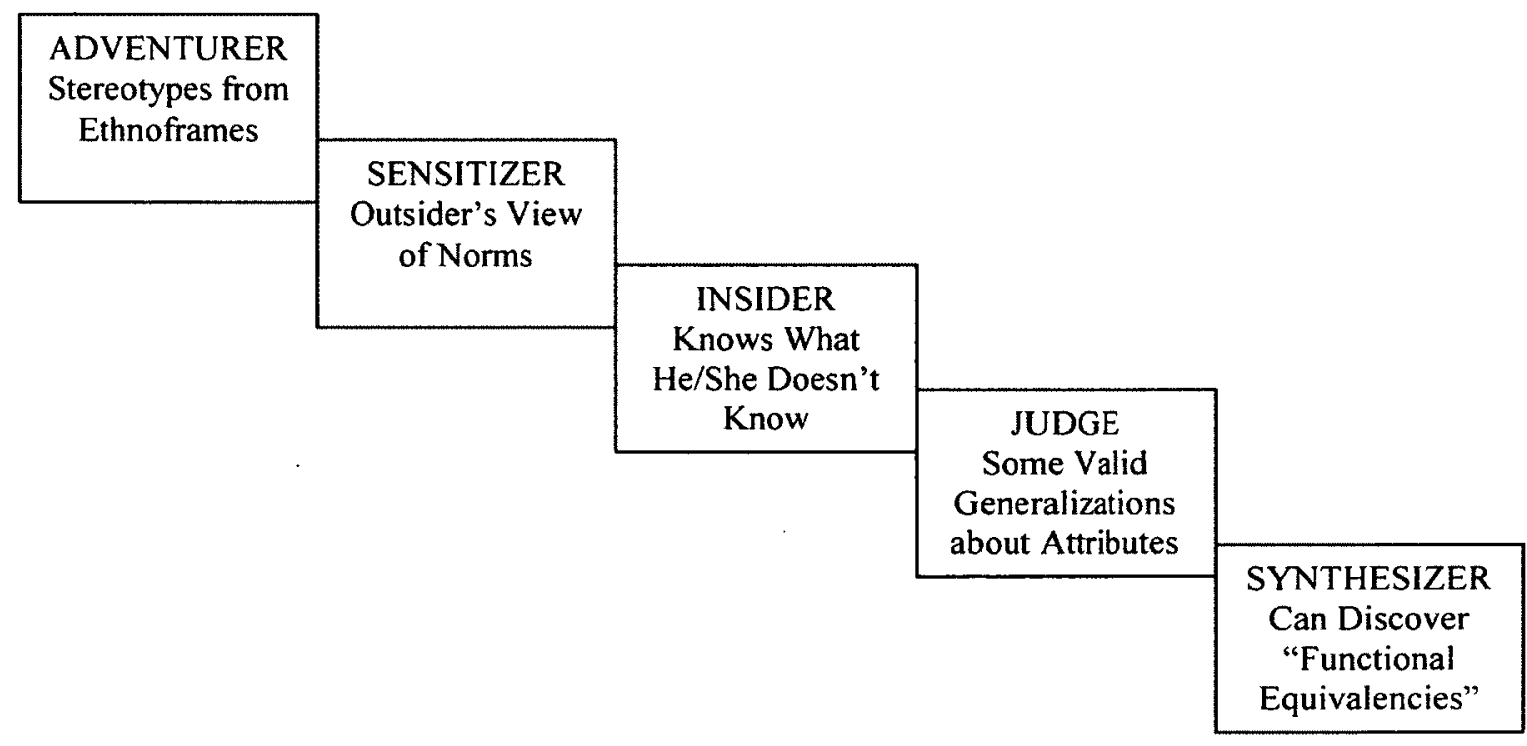

Source: Graen and Hui, 1999, p. 21.

The five progressive or successive stages of becoming a transcultural are described as follows (Graen et al., 1997):

1. Cultural Adventurer - This is the first level of the transcultural. It involves an adventurer's mentality towards cultures other than one's own. This is the lowest degree to which we are aware of other cultures; a product of our lifestyle, past experience and our interactions with others professionally and socially. The cultural 
interest is similar to that of a tourist who employs stereotyping due to limited cultural knowledge and/or disinterest in learning more about other cultures.

2. Cultural Sensitizer - At this level, the individual can attune their behaviours and attitudes to a culture other than their own. In order to be able to perceive a culture from that culture's perspective, individuals need to read and conform to the social and behavioural cues and norms of that culture.

3. Discrepant Culture Insider - Individuals at this stage are insiders in cultures that are vastly different from their own, and they can read and conform to the different culture. This involves the possession of the affective and behavioural knowledge to perceive similarities and differences between cultures. They possess an increasing curiosity with respect to their surroundings, and become more observant, open and optimistic in their interactions with the new culture.

4. Comparative Culture Judge - This stage defines those who are able to identify relevant and useful cultural differences and similarities, and make appropriate cultural comparisons. They can perceive the variety of cultural phenomena by being able to see beyond their own cultural boundaries and by possessing authentic, not superficial, knowledge of the cultures.

5. Socializing Synthesizers - This final stage is reserved for those who have been socialized into many different cultures and have the unique ability to identify 
constructs with functional equivalence between cultures. These individuals can create or facilitate the development of third cultures that can be understood by residents in both cultures. They are essentially bridging the transformation of the two cultures into a third culture, without offending either culture.

While the various levels of transcultural ability are defined above, no metric has ever been developed to measure an individual's transcultural development. While everyone may have some degree of transcultural ability, there is no method for determining if an individual is a socializing synthesizer or is behaving at one of the other stages of transcultural ability.

Transcultural effectiveness can be understood as an individual's ability to successfully transcend their childhood culture combined with a high level of curiosity for their surroundings, as well as respect and empathy for others, especially involving individuals of different cultural backgrounds (Graen and Hui, 1999). As a high performing transcultural can easily adapt to any culture, they may be ideal candidates for overseas assignments. Higher level transculturals can also build strong relations of mutual trust and shared obligation with individuals from different cultures. Conflicts can be resolved with solutions created from their combined knowledge of both cultures. This new form of cultural understanding brings different cultures together in a way that allows them to function more effectively (Graen et al., 2004). 
While a cultural adventurer (a lower level transcultural) is not an ideal candidate for overseas assignments due to their lack of interest and ethnocentric frames of reference, individuals identified at the other four stages of transcultural ability may be of value to the organization with respect to international assignments (Graen et al., 1997). The following table identifies the value and potential of individuals at each of the five transcultural stages for foreign work.

Table 1: Transcultural Stage and Potential for Overseas Assignments

\begin{tabular}{|l|l|}
\hline \multicolumn{1}{|c|}{ Transcultural Stage } & \multicolumn{1}{c|}{ Potential for Overseas Assignments } \\
\hline 1. Cultural Adventurer & $\begin{array}{l}\text { - Candidate for remaining local or for brief } \\
\text { assignments with other expatriates as a buffer } \\
\text { between the cultures }\end{array}$ \\
\hline 2. Cultural Sensitizer & $\begin{array}{l}\text { - Candidate for brief cross-cultural interactions such } \\
\text { as short trips and cross-cultural meetings }\end{array}$ \\
\hline 3. Discrepant Culture Insider & $\begin{array}{l}\text { - Candidate for short term foreign assignments with } \\
\text { large expatriate community overseas } \\
\text { - Potential to strengthen transcultural ability over time } \\
\text { through training and nurturing }\end{array}$ \\
\hline $\begin{array}{l}\text { 4. Comparative Culture } \\
\text { Judge }\end{array}$ & $\begin{array}{l}\text { - Candidate for foreign assignments } \\
\text { 5. Socializing Synthesizer }\end{array}$ \\
$\begin{array}{l}\text { - Ideal candidate for overseas assignment especially } \\
\text { in a lead role }\end{array}$ \\
\hline
\end{tabular}

Adapted from: Graen et al., 1997; Graen et al., 2004; Graen and Hui, 1999.

The cultural adventurer, as defined by Graen and associates (1997), is an adventurer insofar as they are interested in other cultures in a manner similar to how tourists experience other cultures as an act of leisure, rarely experiencing the local way of life.

These individuals are aware that there are cultural differences, but they neither 
understand nor accept these differences as other ways of living. They see the behaviour as a novelty and not an appropriate form of behaviour. They are prime candidates for extreme culture shock (Oberg, 1960), which would render them unable to function appropriately in a new culture. They therefore have the potential to somewhat damage cross-cultural relations. An individual at this stage could be sent on an overseas assignment with other expatriates to provide support and direction, thereby protecting the individual from uncomfortable and challenging situations with the locals.

The cultural synthesizer may recognize other behaviours as different. However, this individual does not yet understand the new culture from a functional perspective and thus needs assistance. These people can function in a cross-cultural environment for short periods of time and should likely not be placed in a lead role with those from another culture. As these individuals are learning about the target culture, they could function on a team, possibly for short assignments or overseas trips, in order to limit or manage the impact of culture shock.

The discrepant cultural insider is observant, recognizes different cultures, and can understand the similarities and differences between their own culture and the new culture. While this individual may not be considered a strong transcultural, they are capable of functioning within a foreign culture with available support from a local expatriate community and organizational resources. These individuals are also potential candidates for training, nurturing and mentoring programs, as they could develop and strengthen their transcultural skills over time. 
The comparative cultural judge may be an ideal candidate for both expatriation and repatriation. Their ability to not only perceive cultural differences, but also to understand those differences, facilitates their ability to function appropriately in cross-cultural environments. These individuals can successfully adapt to new cultures and begin to find ways to allow for mutual co-existence with the locals.

The socializing synthesizer, with the ability to identify functional equivalence between cultures, can assimilate easily into a new culture and can also facilitate the development of third cultures without offending those in either of the bridged cultures. A third culture is defined as a synthesized culture which has cultural values and practices that are acceptable to the people of the different cultural groups involved (Graen et al., 1997). This new culture takes advantage of the strengths and minimizes the weakness of both cultures. It strives to avoid offending either culture as it develops a merged culture that is acceptable to all members (Graen et al., 2004).

The concept of a synthetic culture may help explain how such third cultures are created and legitimized. Synthetic cultures, often used for cultural training simulations, are developed through an integration of Hofstede's value dimensions (Hofstede and Pedersen, 1999; Hofstede, Pedersen and Hofstede, 2002). Bhawuk (1998) found that training based on theory facilitates the learner's ability to absorb content and integrate this content with new situations. Synthetic cultures strategically focus on the manifestations of a culture. Rodriguez (2005) found that US-Mexican strategic alliance 
success was positively influenced by the emergence of third cultures. These third or virtual cultures were shaped by the intercultural fit of the management styles of the two cultures. The development of such cultures was found to promote high levels of cooperation and improve group effectiveness (Rodriguez, 2005).

The transcultural is also creating a culture based on interpretations of cultures and merging cultures into a virtual or synthetic culture that is a product of the mind. Individuals at the high transcultural stage may be strategic, open, optimistic, and experienced enough to facilitate the creation of third cultures due to their cultural confidence and their motivation to meet the challenges of international relations.

\subsubsection{The Evolution of the Transcultural Construct}

This section will provide a discussion of the evolution of the transcultural construct. It is important to include this discussion to illustrate the growing importance of the construct and how it has emerged and grown simultaneously from various academic studies. Over time, the construct has gained strength with the growing importance of cross-cultural interactions (Graen et al., 1997).

In 1937, Stonequist led the field in the study of those individuals who oscillate between cultural boundaries. His book, The Marginal Man, describes people who are neither accepted by, nor belong to, a specific culture group because they are moving in and out of various cultures (Stonequist, 1937). Kealey and Ruben (1973) identified a cross-cultural or overseas type of individual based on their literature review of overseas placement 
selection criteria. However, they cautioned that this type of individual was an ideal derived from the literature and may have limited usefulness as the nature and environment of the task was not considered. Also in 1973, Aitken described a multinational man however his discussion focused on adjustment with respect to lifestyle and did not consider organizational effectiveness (Aitken, 1973). Peter Adler (1975) defined the transitional experience with reference to recovering from culture shock. He saw a movement from a state of low self and cultural awareness to a state of high self and cultural awareness (Adler, 1975, p. 15).

The following table compares Adler's five stages of the transitional experience with the five stages of transcultural development, identifying their similarities and differences.

Table 2: Comparing Transitional Experience with Transcultural Development

\begin{tabular}{|c|l|l|l|}
\hline$\#$ & \multicolumn{1}{|c|}{$\begin{array}{c}\text { Transitional } \\
\text { Experience }\end{array}$} & \multicolumn{1}{c|}{$\begin{array}{c}\text { Transcultural } \\
\text { Development }\end{array}$} & Similarities/ Differences \\
\hline 1. & $\begin{array}{l}\text { Contact - views new } \\
\text { culture from own } \\
\text { cultural ethnocentrism, } \\
\text { attuned to differences }\end{array}$ & $\begin{array}{l}\text { Cultural Adventurer - has } \\
\text { an adventurer's mentality } \\
\text { towards cultures other than } \\
\text { one's own }\end{array}$ & $\begin{array}{l}\text { Similarities } \\
\text { - Differences are seen } \\
\text { as interesting } \\
\text { A sense of excitement } \\
\text { with curiosity }\end{array}$ \\
\hline 2. & $\begin{array}{l}\text { Disintegration - a } \\
\text { period of confusion } \\
\text { with isolation and } \\
\text { frustration increasing }\end{array}$ & $\begin{array}{l}\text { Cultural Sensitizer - can } \\
\text { attune their behaviours and } \\
\text { attitudes to a culture other } \\
\text { than their own }\end{array}$ & $\begin{array}{l}\text { Similarities } \\
\text { - Cultural differences } \\
\text { recognized } \\
\text { Differences }\end{array}$ \\
\hline $3 . \begin{array}{l}\text { Sensitizer not } \\
\text { frustrated with the } \\
\text { new culture }\end{array}$ \\
\hline $\begin{array}{l}\text { Reintegration - } \\
\text { rejection and hostility } \\
\text { towards second culture }\end{array}$ & $\begin{array}{l}\text { Discrepant Culture Insider } \\
\text { - can read and conform to } \\
\text { the different culture }\end{array}$ & $\begin{array}{l}\text { Differences } \\
\text { - Sensitizer not } \\
\text { rejecting nor hostile } \\
\text { towards new culture }\end{array}$ \\
\hline
\end{tabular}




\begin{tabular}{|c|c|c|c|}
\hline \# & $\begin{array}{l}\text { Transitional } \\
\text { Experience }\end{array}$ & $\begin{array}{l}\text { Transcultural } \\
\text { Development }\end{array}$ & Similarities/ Differences \\
\hline 4. & $\begin{array}{l}\text { Autonomy - sensitivity } \\
\text { and skills developing } \\
\text { along with the ability } \\
\text { to cooperate in the new } \\
\text { culture }\end{array}$ & $\begin{array}{l}\text { Comparative Culture } \\
\text { Judge - can now recognize } \\
\text { the relevant and useful } \\
\text { cultural differences and } \\
\text { similarities in order to } \\
\text { make appropriate cultural } \\
\text { comparisons }\end{array}$ & $\begin{array}{l}\text { Similarities } \\
\text { - Recognize norms of } \\
\text { new culture } \\
\text { - Ability to behave } \\
\text { appropriately in the } \\
\text { new culture }\end{array}$ \\
\hline 5. & $\begin{array}{l}\text { Independence - } \\
\text { attitudes and } \\
\text { behaviours that are } \\
\text { independent of cultural } \\
\text { influence and ability to } \\
\text { explore diversity and } \\
\text { experience new facets } \\
\text { and cultural } \\
\text { dimensions }\end{array}$ & $\begin{array}{l}\text { Socializing Synthesizers - } \\
\text { have been socialized into } \\
\text { many different cultures } \\
\text { and have the unique ability } \\
\text { to identify constructs with } \\
\text { functional equivalence } \\
\text { between cultures }\end{array}$ & $\begin{array}{ll}\text { Similarities } \\
\text { - High level of comfort } \\
\text { in new culture } \\
\text { - Highest level of } \\
\text { growth } \\
\text { - Evolutionary stages } \\
\text { - Open to new cultures }\end{array}$ \\
\hline
\end{tabular}

In 1977, Adler evolved his theory into the multicultural man, defined as "a human being whose identification and loyalties transcend the boundaries of nationalism and whose commitments are pinned to a vision of the world as a global community" (Adler, 1977, p. 24). The multicultural man is seen as fluid and dynamic, susceptible to change and more importantly, not belonging to a culture, living instead on the boundaries. Adler sees this individual as one who aims to create "a third area beyond the bounded territories" (Adler, 1977, p. 26). This reference to a third area is similar to the transcultural who facilities the creation of a third culture. The reference, along with Adler's progressive stages, suggests that Adler's multicultural man was an early version of the transcultural.

As Adler was advancing his theory of the multicultural man, Bochner (1977) was developing his theory of the mediating man, someone who can link cultures. Like Adler, Bochner attributes this type of individual with cultural flexibility and membership in 
international social networks. It is interesting that while Adler and Bochner suggest that these individuals may exhibit superior levels of social and cultural assimilation, Dinges (1983) sees these individuals as not something anyone would strive towards, due to their shaky grounding from being in a constant state of flux between dynamic growth and personal disintegration. He suggests that those who appear to be models of intercultural competency may really be culture dropouts who do not fit into any specific cultural group (Dinges, 1983).

Cosmopolitans are those that can grow beyond their own cultural boundaries (Harris and Moran, 1991). These people are not identified by region but, rather, as worldwide or global, with interest and experience in many parts of the world. Black and Gregersen (1999) support the better managing of expatriates by selecting those individuals with a cosmopolitan orientation for foreign assignments. They differentiate such persons who intuitively understand different cultural values and their meanings, as well as respect different views and attitudes (Black and Gregersen, 1999).

More recently, Bird and Stevens (2003) suggested that national cultures are becoming obsolete due to the impact of globalization. They see cultures converging into one commonly accepted global culture with an identifiable and homogeneous group. This group shares a common set of values, attitudes, norms and behaviours and are members of a distinct emerging global culture with "a common lens through which the world is understood" (Bird and Stevens, 2003, p. 400). These people are described as seeking out others like themselves who are educated, connected through travel and the internet, self- 
confident, pragmatic, democratic, flexible and open to new experiences. These are all characteristics that could be used to describe a high level transcultural, someone approaching or at the socializing synthesizer stage of transcultural development.

Cultural intelligence is a construct that has been aligned with the overseas selection process. The following section presents an overview of cultural intelligence, identifies similarities and differences with the transcultural theory and provides a discussion of its limitations.

\subsection{Cultural Intelligence}

This section discusses the concept of cultural intelligence, including how it is measured. The goal of this section is to provide an understanding of individuals that have increased levels of cultural behaviour, cultural strategic thinking and cultural motivation. This section includes a discussion of the similarities and differences between cultural intelligence and transcultural ability, and concludes with a discussion of the limitations of cultural intelligence.

\subsubsection{What is Cultural Intelligence?}

Cultural intelligence has been defined "as a person's capability for successful adaptation to new cultural settings" (Earley, Ang and Tan, 2006, p.5). It includes how one thinks and solves problems, how motivated they are, and their ability to behave suitably in any situation (Earley, 2006). The construct was developed by combining psychological 
concepts of culture with cross-cultural management thought (Earley and Mosakowski, 2004a). A culturally intelligent person can identify relevant information, make appropriate judgments and integrate relevant information to determine the behaviour appropriate to a specific situation (Triandis, 2006).

Earley has taken a new approach to the study of cultural differences through the construct of cultural intelligence (Earley, 2006). This construct, like the transcultural concept, is at the individual level. It focuses on how individuals adapt to different cultural environments based on "facets of cognitive and meta-cognitive processing, motivational mechanisms and behavioral adaptation ... an individual's capabilities to adapt in a cultural setting as a driver of behavior" (Earley, 2006, p.292). However, this does not include the deep understanding of culture that allows the transcultural to become socialized into the new culture by making cultural comparisons at the system level, not just at the behavioural level (Graen et al, 1997). There is a strong emphasis on cultural training and exposure for improving one's cultural intelligence.

Cultural intelligence does have some commonalities with transcultural ability. However, cultural intelligence shifts focus away from the importance of developing an intuitive cognition and of assimilation with other cultures (Graen et al., 1997) to "a person's capability for successful adaptation to new cultural settings" (Earley et al., 2006, p.5). This is in contrast to the high functioning transcultural who recognizes the cultural cues and nuances with culturally equivalent behaviour flowing from this knowledge. The distinction lies with the transcultural being able to cognitively understand the cultural 
environment, as opposed to the culturally intelligent person who is assessing and making judgment calls on appropriate behaviour based on training and previous cultural exposure. Transcultural ability goes beyond the capability to function (Ang, Van Dyne, $\mathrm{Koh}, \mathrm{Ng}$, Templer, Tay and Chandrasekar, 2007). The transcultural is not behaving from training and cultural exposure; rather she/he has a deep cultural understanding that includes the ability to interpret fine distinctions in situations and behave based on these interpretations.

Cultural intelligence incorporates three components, (Earley et al., 2006) as illustrated in the following diagram.

\section{Figure 2: Components of Cultural Intelligence}

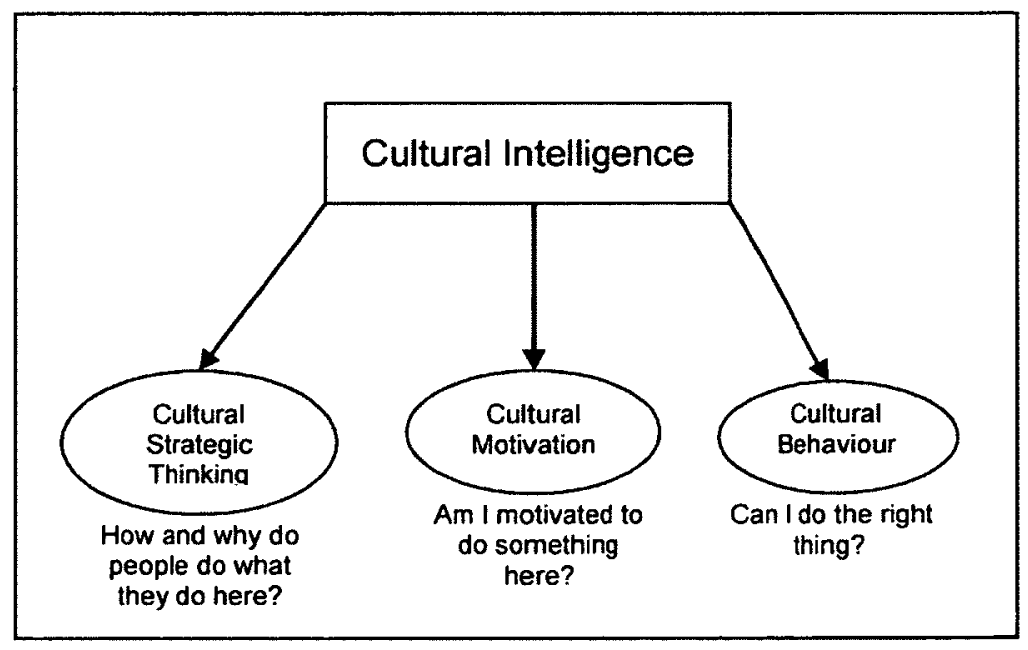

Source: Earley et al., 2006.

In order to be a successful global leader or manager, one needs to function in a continuously changing environment. Cultural intelligence requires high levels of cultural strategic thinking, motivation and behaviour (Earley et al., 2006; Earley and 
Mosakowski, 2004a). These three elements provide for cultural adaptation. While some elements may be stronger in some individuals than others, taken together they complement and support each other (Earley et al., 2006).

Cultural intelligence can be explained through a framework of five cumulative characteristics or levels that describe how people adapt to new and culturally diverse work assignments (Earley and Mosakowski, 2004a). The local focuses on her/his own cultural environment, and is considered the lowest or weakest level of cultural intelligence. The second level is the analyst who observes and learns from new cultural situations, followed by the confident who has high levels of perseverance and focused goals. The mimic, the fourth level, has control of actions and behaviour and is able to comfortably adopt cultural mannerisms and styles. The fifth or highest level of cultural intelligence is the cultural chameleon with higher levels of all three elements of cultural intelligence: cultural strategic thinking, motivation and cultural behavioural adaptation. The following table presents the 5 characteristics of Cultural Intelligence.

\section{Table 3: The Cultural Intelligence Framework}

\begin{tabular}{|l|l|}
\hline \multicolumn{1}{|c|}{ Characteristic } & \multicolumn{1}{c|}{ Description } \\
\hline 1. The Provincial & $\begin{array}{l}\text { Effective only when working with people of similar } \\
\text { background }\end{array}$ \\
\hline 2. The Analyst & $\begin{array}{l}\text { Methodically deciphers a culture's rules and expectations, } \\
\text { realizes quickly he/she is in alien territory, observes and } \\
\text { learns from others how to interact }\end{array}$ \\
\hline 3. The Natural & $\begin{array}{l}\text { Relies entirely on his intuition rather than on a systematic } \\
\text { learning style }\end{array}$ \\
\hline 4. The Ambassador & $\begin{array}{l}\text { May not know much about the culture but communicates that } \\
\text { she/he belongs there with the confidence and humility to } \\
\text { recognize the known and how to avoid cultural mistakes }\end{array}$ \\
\hline
\end{tabular}




\begin{tabular}{|l|l|}
\hline \multicolumn{1}{|c|}{ Characteristic } & \multicolumn{1}{c|}{ Description } \\
\hline 5. The Mimic & $\begin{array}{l}\text { Control over actions and behavior, but not always insightful } \\
\text { of the significance of the cultural cues, however mimicry } \\
\text { puts locals at ease, facilitates communication, builds trust }\end{array}$ \\
\hline 6. The Chameleon & $\begin{array}{l}\text { High levels of CQ components, (uncommon with only 5\% of } \\
\text { those surveyed at this level) and can be mistaken for a local }\end{array}$ \\
\hline
\end{tabular}

Source: Early and Mosakowski, 2004a; Early and Mosakowski, 2004b.

Cultural intelligence does not focus on cultural values, but rather on the individual's ability to adapt to different cultural environments. Behavioural solutions are based on situational context instead of a strategy based on values and dimensions devoid of context (Hofstede, 1980; House et al., 2004, Trompenaars and Hampden-Turner, 1998). As cultural experiences are unique, past experiences do not necessarily provide proven solutions. A culturally intelligent person pays close attention to situations, is able to select important and relevant information, and then analyze and integrate this information to make correct judgements (Triandis, 2006). An individual with high cultural intelligence has the ability to handle culturally-specific situations and to take appropriate cultural action.

While natural cultural chameleons are rare (Earley and Mosakowski, 2004a), individuals at any level of cultural intelligence can be trained in an effort to improve their cultural intelligence. In addition, organizations can select new employees and managers based on target levels of cultural intelligence to reduce training efforts and costs. However, cultural training does not necessarily mean that the individuals can behave appropriately, as there is a distinction between knowing and doing. Transculturals at higher levels (not only at the highest level) will, through deep analysis and knowledge of cultural 
equivalents, behave more like the locals, not as actors following a script. A good example of understanding cultural equivalents involve the behavioural habits in Thailand of laughing when stressed and the inability to answer a question in the negative. Cultural knowledge alone may not identify an appropriate behavioural response required by the situation. The culturally intelligent may understand that the local is stressed and they may or may not realize the information provided by the local is inaccurate. In contrast, the transcultural will quickly attempt to mitigate the situation, knowing what an appropriate response might be to alleviate the stress and receive accurate information.

Cultural intelligence has its roots in psychology and was developed from the concept of emotional intelligence, originally seen as a trait-based measure (Goleman, 1995). However the literature on cultural intelligence and the more recent work with emotional intelligence focuses on an ability-based approach to the construct (Earley et al., 2006). Caruso, Mayer and Salovey (2002), in their ability-based work on emotional intelligence, focused on the skills, not the values or traits, of the individual and found that abilities can be enhanced over time through socialization, training and experience. Cultural intelligence is also seen as an ability-based measure, as it can be improved through training and experience (Earley et al., 2006). The next section provides a discussion on the measurement of cultural intelligence.

\subsubsection{Measuring Cultural Intelligence}

Cultural intelligence is measured with a self-assessment questionnaire containing 54 dichotomous response questions (Earley et al., 2006). These responses are opposites or 
contradictory of each other and do not provide for a response somewhere between the two choices, such as a neutral position. For example, the choice is between: "often" and "never," or "experienced" and "entry-level," which does not allow the respondent to select an option in the middle such as "sometimes" or "some experience".

The purpose of the self-assessment questionnaire is to provide the user with an indication of their level of cultural intelligence in order to determine potential success in crosscultural working environments. Early and colleagues suggest that a successful crosscultural manager will have a high level of cultural intelligence, measured by the degree to which cultural encounters are planned for and implemented, and how the person focuses energy and attention to overcome the challenges of working in a cross-cultural environment (Early, Ang and Tan, 2006).

\subsubsection{Similarities and Differences with Transcultural Ability}

The cultural intelligence framework can be aligned with the stages of transcultural development, as there are some clear similarities. While both concepts facilitate cultural adaptation, cultural intelligence focuses more on demonstrating appropriate behaviour, whereas transculturals can develop deep cultural understanding. Transcultural theory could be described as incorporating cultural intelligence theory, however it does include additional elements not identified in cultural intelligence. The following table presents the six profiles of cultural intelligence (Earley and Mosakowski, 2004a; Earley and Mosakowski, 2004b) aligned with the five stages of transcultural development (Graen et al., 1997): 
Table 4: Cultural Intelligence aligned with Transcultural Development

\begin{tabular}{|c|c|}
\hline Cultural Intelligence & Transcultural Development \\
\hline $\begin{array}{l}\text { 1. The Provincial - effective only when } \\
\text { working with people of similar } \\
\text { background }\end{array}$ & $\begin{array}{l}\text { 1. Cultural Adventurer - has an } \\
\text { adventurer's mentality of basic interest } \\
\text { towards cultures other than one's own }\end{array}$ \\
\hline $\begin{array}{l}\text { 2. The Analyst - methodically deciphers a } \\
\text { culture's rules and expectations, realizes } \\
\text { quickly he/she is in alien territory, then } \\
\text { determines the patterns and how to } \\
\text { interact }\end{array}$ & $\begin{array}{l}\text { 2. Cultural Sensitizer - can attune their } \\
\text { behaviours and attitudes to a culture } \\
\text { other than their own }\end{array}$ \\
\hline $\begin{array}{l}\text { 3. The Natural - relies entirely on his } \\
\text { intuition rather than on a systematic } \\
\text { learning style }\end{array}$ & $\begin{array}{l}\text { 3. Discrepant Culture Insider - can read } \\
\text { and conform to the different culture }\end{array}$ \\
\hline $\begin{array}{l}\text { 4. The Ambassador - may not know much } \\
\text { about the culture but communicates that } \\
\text { she/he belongs there with the confidence } \\
\text { and humility needed to recognize the } \\
\text { known and how to avoid cultural } \\
\text { mistakes }\end{array}$ & $\begin{array}{l}\text { 4. Comparative Culture Judge - can now } \\
\text { recognize the relevant as well as the } \\
\text { useful cultural differences and } \\
\text { similarities in order to make appropriate } \\
\text { cultural comparisons }\end{array}$ \\
\hline $\begin{array}{l}\text { 5. The Mimic - control over actions and } \\
\text { behavior, but not always insightful of } \\
\text { the significance of the cultural cues, } \\
\text { however mimicry puts locals at ease, } \\
\text { facilitates communication, builds trust }\end{array}$ & No alignment \\
\hline $\begin{array}{l}\text { 6. The Chameleon - high levels of CQ } \\
\text { components, often mistaken for a local } \\
\text { due to insider's skills and outsider's } \\
\text { perspective }\end{array}$ & $\begin{array}{l}\text { 5. Socializing Synthesizers - has been } \\
\text { socialized into many different cultures } \\
\text { and has the unique ability to identify } \\
\text { constructs with functional equivalence } \\
\text { between cultures, possesses an intuitive } \\
\text { ability for deep cultural understanding of } \\
\text { the nuances and norms, often without } \\
\text { prior training and experience in the } \\
\text { culture, able to facilitate the development } \\
\text { of an environment of mutual cooperation } \\
\text { across cultures }\end{array}$ \\
\hline
\end{tabular}

A comparison between the cultural intelligence profiles (Earley and Mosakowski, 2004b) and the transcultural development stages (Graen et al., 1997) highlights the differences between the two theories. The first stage of cultural intelligence, the Provincial, is 
similar to the first stage of transcultural development, the Cultural Adventurer, insofar as both are comfortable with their own culture and uncomfortable with other cultures. The transcultural Cultural Adventurer is not uncomfortable with other cultures, as is the Provincial, due to their curiosity and interest towards other cultures. This means that there is willingness, from the low level transcultural, to learn about and experience other cultures with an openness that is not found in the low level of cultural intelligence.

The cultural intelligence Analyst and the transcultural Cultural Sensitizer are at the second level of the theories. Both levels can identify cultural differences and analyze behaviour, however only the transcultural can recognize and adjust to other cultures without experiencing the sense of alienation experienced by the Analyst. This distinction means that a transcultural at this level has a degree of emotional resilience that prevents feelings of alienation that could negatively impact cross-cultural business relations.

The third level compares the Natural with the Discrepant Cultural Insider. At this level, neither is dependent on being taught about the new culture to understand it. The Natural uses intuition, which may or may not provide an accurate assessment of the culture or of the appropriate behaviour required. In contrast to the Natural, the Insider understands and conforms to the culture through non-judgemental observation and may mimic behaviour to ensure appropriateness. The transcultural is flexible, observant and employs a strategy of mimicry as necessary to ensure that cultural blunders are avoided. 
The fourth level of cultural intelligence is the Ambassador, aligned with the transcultural Comparative Cultural Judge. Both know how to behave and how to not offend the locals by avoiding cultural errors. The distinction lies in a more comprehensive understanding of the culture by the transcultural that provides the nuances and subtleties inherent in cultural interaction, as opposed to only understanding the surface, or observable, behaviour. The implication here is that the transcultural will, through assessments and cultural comparisons, adapt, adjust and behave more appropriately, especially in situations that are complex and vague.

While both theories contain a fifth level, the transcultural level does not align with the fifth cultural intelligence level, the Mimic. This level is somewhat comparable with the third transcultural level where some mimicry can occur, as well as comparable with the fourth transcultural level where there is an understanding of the significance of the behaviour. The Mimic implies that the behaviour itself is not understood; only the need to exhibit the behaviour is realized.

The sixth and highest level of cultural intelligence is the Chameleon, aligned with the Socializing Synthesizer, the fifth and highest level of transcultural development. Both of these levels include those who are socialized in the new culture and behave appropriately, however the Chameleon, with insider skills, does have an outsider's perspective that can cloud recognition of new cultural norms and behaviours. The Synthesizer is more attuned to the culture and can easily recognize changes and new developments. At this level, an additional distinction differentiates the two theories. It is the ability and strategy 
of the Synthesizer to facilitate the development of an environment of cooperation across cultures, thereby creating a third culture to facilitate socialization between cultures. This is achievable at this level, only because the Synthesizer has a deep cultural integration with the cultures, not just behavioural understanding. A transcultural would be more likely to build more meaningful and stable business (and personal) relationships with locals than the culturally intelligent equivalent.

To summarize the distinction between the two theories, while there is an apparent alignment between the cultural intelligence and transcultural stages, transcultural theory goes beyond being able to identify when to exhibit known behaviour. The transcultural develops a deep understanding of the new culture based on an identification of cultural and functional equivalents. The implication for the organization is that while both concepts provide for the likelihood of an individual behaving appropriately; the transcultural development theory also provides for an individual that has a deeper level of cultural understanding that is not necessarily derived from previous cultural knowledge and training.

Analysis and current academic research have identified some limitations with cultural intelligence theory. These limitations are presented in the following section.

\subsubsection{The Limitations of the Cultural Intelligence Construct}

The cultural intelligence construct has applications in the area of cultural adaptation; however it also does have limitations. The construct is useful for application in a 
multicultural environment with respect to determining an individual's level of cultural awareness and as an indicator for training and support needs. Individuals entering a multicultural workforce find diversity challenging, possibly due to the novelty of encountering people from other cultures, religions and/or lifestyle orientations. The measure of an individual's cultural intelligence could be used by organizations as an indicator of a person's cultural motivation, strategic thinking and behaviour which, in turn, can be used to assess an individual's suitability for diverse work environments and the level of support required by the individual.

While cultural intelligence is useful in some applications, it has important limitations in cross-cultural or foreign situations. It does present a challenge for use as a measure of cultural adaptation with respect to expatriate application. As cultural intelligence is based on an individual's cultural experience and training, it does not account for those individuals with an ability to adapt to whatever culture environment they find themselves in, without prior history or training in such environments. Such an individual would be demonstrating transcultural ability, even though they would be seen have having lower cultural intelligence. Cultural intelligence does not differentiate between having cultural intelligence and knowing how and when to use that intelligence.

Cultural intelligence integrates constructs that previously had received little attention $(\mathrm{Ng}$ and Earley, 2006). The integration includes cultural behaviour, cultural strategic thinking and cultural motivation with cognitive intelligence into one theory (Ang, Van Dyne, Koh and $\mathrm{Ng}, 2004)$. There had been a lack of empirical work on cultural intelligence until the 
work on convergent, discriminate and incremental validity by Ward and associates (Ward, Fischer, Lam and Hall, 2009).

The multi-part study by Ward et al. (2009) examines the structure of cultural intelligence, as well as its emotional intelligence, personality and cognitive ability components. In specifically studying the relationship between cultural and emotional intelligence the focus was on the incremental validity of the intelligence. The study found no support for the argument that cultural intelligence and emotional intelligence are distinct, which could be interpreted as implying that they are similar. This study also examined the concepts of convergent and discriminate validity to support how cultural intelligence accounts for variance in cultural adaptation. Unfortunately this part of the study also failed to show the incremental validity of cultural intelligence, as the convergent and discriminate validity scores were not significant.

The overall findings of the study "cast doubt on the measures of cultural intelligence" (Ward et al., 2009, p.103) as "the findings seriously challenge (the) suggestion that (cultural intelligence) can make a novel contribution to the prediction of cross-cultural adaptation and expatriate effectiveness" (Ward et al., 2009, p. 102). These findings do limit the applicability, relevance and relationship of cultural intelligence with the expatriate selection and development processes.

The cultural intelligence self-assessment questionnaire provided in 'CQ: Developing Cultural Intelligence at Work' (Earley et al., 2006) has inherent challenges. Many of the 
questions are vague and open to misinterpretation, others need to be modified, and additional questions are necessary in order to encompass the full description of the cultural intelligence stages. The dichotomous nature of the questionnaire assumes that if one answer is not appropriate, the remaining answer is. Specific examples of these problem questions include selecting from either "experience" or "novice", or selecting between "unsure" and "energized" (Earley et al., 2006). The underlying assumption that one of the responses is correct may force a respondent to make an inappropriate selection, which may compromise the appropriateness and validity of the survey findings.

Someone just entering the workforce can have advanced transcultural abilities without any previous cultural exposure, which is in contrast to the cultural intelligence requirement for exposure to other cultures through education and employment experience (Crowne, 2008). Crowne argues that cultural intelligence is a critical skill of global leaders for mitigating cultural blunders. Her analysis focuses on the relationship between cultural exposure, from experience and training, and cultural intelligence. She contends that the more exposure an individual has with other cultures, the higher the individual's cultural intelligence will be (Crowne, 2008). Furthermore, Crowne argues that those who were in another culture for work or schooling have higher cultural intelligence than those who were merely exposed while on vacation. This research supports the importance of work exposure and cultural training with respect to higher levels of cultural intelligence.

Unlike the concept of cultural intelligence, the transcultural construct is not dependent on cultural exposure and training. The transcultural construct is focused on an individual's 
ability to move beyond their own cultural socialization, and to recognize, understand and make valid judgments about other cultures (Graen et al., 1997), without a focused or primary dependency on any previous cultural exposure or training. The open attitude and flexibility of the transcultural can be contrasted with the culturally intelligent, whose behaviour is learned and then repeated.

Transcultural ability goes beyond cultural intelligence. The high level transcultural is not just behaving appropriately; this individual also possesses a deep contextual understanding of the culture and behaviours they are experiencing. Organizations do not have to undertake costly and lengthy cultural training and development initiatives in order to provide the required information and knowledge to these individuals.

The previous sections in this chapter presented a review of the academic literature that was used to develop the research framework for this study. The following section presents a discussion of the contribution of this literature review to the research and analysis undertaken in the present study.

\subsection{Contribution of the Literature Review}

This section will discuss the contributions of the previous sections in this chapter to the research in this dissertation. Expatriate theory and issues were presented first to situate the research in the area of expatriate study. This area of study focuses on the challenges and issues associated with selecting the right individual to send on overseas assignments. The selection process is of strategic importance to organizations as the success of such 
assignments can depend on the individual selected (Kim and Slocum, 2008; Jenkins and Mockaitis, 2010). Culture shock can negatively impact the success of such assignments due to the difficulties some people experience adapting to new cultural environments (Oberg, 1960). Being better able to handle the effects of culture shock may mitigate its negative influence (Sims and Schraeder, 2004). Many studies have focused on identifying the characteristics of individuals in an attempt to be able to predict overseas assignment success (Black and Gregersen, 1999; Graen and Hui, 1999; Kealey and Rubin, 1973; Osman-Gani and Rockstuhl, 2009).

The links in the literature between overseas assignment success, overcoming culture shock and the expatriate selected for the assignment, directly influenced the research in this study. The expatriate theory review introduced many of the components used in the development of the research model. In addition, the expatriate analysis provided direction for the data analysis of the research study. The literature has also provided information and discussion analyzing the characteristics and factors desirable for overseas assignment success. The five levels of expatriate success developed in the analysis include: high, medium-high, medium, medium-low and low. Six variables were used in this analysis and they included: number of overseas jobs, number of overseas jobs completed, number of early returns, number of early returns by choice, seeing one-self as a successful expatriate and finding repatriation difficult. These variables have directly contributed to the research survey as the items for assessing expatriate success. In addition to providing research components and the items for analyzing levels of expatriate success, the expatriate literature has also provided clarity for the execution of 
the predictive validity analysis in the current study. Specifically, this refers to the development of a proxy measure for expatriate success.

The cross cultural context is presented second as it provides an overview of the business environment of the expatriate. The discussion of culture and cultural differences illustrates culture shock and situates the expatriate in their foreign environments where things are done differently (Triandis, 1994). The ability of the expatriate to adapt and adjust to the new surroundings and to people behaving differently, stresses the importance of the expatriate being able to understand and appreciate a new culture. In addition to situating the expatriate in a challenging environment and highlighting the importance of overcoming culture shock, this section introduces the value-based theories for expatriate selection.

The value-based theories of Hofstede (1990), the Globe Project (2004) and HampdenTurner and Trompenaars (2000) focus on the values of a country's culture, and can be used for expatriate selection for cross-cultural leaders. These theories are value-based in nature and attempt to match individuals with country values. The country focus suggests that an individual may be desirable for one country, but not for another. While the valuebased theories are widely known and accepted, the focus on the country culture, not on the individual, seems to disregard the skills and abilities that individuals develop throughout their life and career. 
The literature on cross-cultural leadership is potentially useful, as those who are selected for overseas work have traditionally been assumed to be taking on leadership roles. However, due to the need to send technical and support resources abroad as well the realities of cross-cultural placement begs a wider scope for expatriates. This gap in the value-based theories, and their inability to incorporate non-leadership abilities, motivated the current research.

The importance of the individual in a cross-cultural environment and the need to identify those who can overcome culture shock leads to the limited transcultural literature; which is presented in the third section of the literature review. Building on the two previous sections, and their importance and contribution to the research, the transcultural provides an individual who can overcome cultural barriers by understanding and seeing the merits of another culture (Graen et al, 1997). The transcultural theory analysis provides the characteristics of transculturals. These individuals, at higher levels of transcultural ability, may be better able to recover from culture shock and adapt to a new culture. This suggests that they may be desirable for expatriate selection. The characteristics or components identified in this section were used in the development of the transcultural model and the research survey used in this study.

The few articles on the transcultural provide a discussion of a theory that is somewhat vague as it does not provide a detail description of the components of transcultural ability. In addition, there is no method for determining an individual's level of transcultural ability. These omissions in the literature directly influenced the research in 
this study, which is attempting to fill these gaps. The transcultural section of the literature review contributed to the purpose of the study, and to the analysis and development of the research model and components. It confirmed and clarified the need for the inclusion of the seventeen components of the research model that were introduced in the literature review sections. In addition the transcultural literature review identified the need for empirical research to confirm the transcultural construct components and to provide a measure for transcultural ability. As well, it also identified the application of the transcultural construct in the expatriate selection process.

The fourth section of the literature review presents and analyzes cultural intelligence theory. This is a theory that, like the transcultural theory, focuses on the individual. The comparison of these two theories helps identify the limitations of the cultural intelligence construct, and the issues associated with using it for expatriate selection. The difference between having cultural intelligence, and knowing how and when to use that intelligence, highlighted and supported the distinction between the theories. However, the research did support cultural intelligence as a useful option for the expatriate selection process, even though it does have limitations. This contributed to the current research by helping to shape the mix of items in the transcultural model with the inclusion of cultural intelligence as one piece of the much larger model.

The following table presents the components of transcultural ability that were identified in the literature review. The table identifies each component and its corresponding source section(s) in the literature review. 
Table 5: Components and Literature Review Section

\begin{tabular}{|c|c|c|}
\hline Component & $\begin{array}{l}\text { Literature Review } \\
\text { Section(s) }\end{array}$ & Major Academic Source(s) \\
\hline Adventurous & $\begin{array}{l}\text { Expatriate Theory, } \\
\text { Transculturals }\end{array}$ & $\begin{array}{l}\text { Graen et al., 1977; Harris and Moran, } \\
\text { 1991; Oberg, } 1960 .\end{array}$ \\
\hline Confidence & $\begin{array}{l}\text { Expatriate Theory, } \\
\text { Transculturals, } \\
\text { Cultural Intelligence }\end{array}$ & $\begin{array}{l}\text { Adler, 1975; Deng and Gibson, 2008; } \\
\text { Earley et al., 2006; Fritz and Mollenbert, } \\
\text { 2001; Furnham and Bochner, 1982; } \\
\text { Graen et al., 1977; Harris and Moran, } \\
\text { 1991; Oberg, 1960; Pilot Study Analysis; } \\
\text { Ruben, } 1989 .\end{array}$ \\
\hline $\begin{array}{l}\text { Cultural } \\
\text { Intelligence }\end{array}$ & $\begin{array}{l}\text { Expatriate Theory, } \\
\text { Transculturals, } \\
\text { Cultural Intelligence }\end{array}$ & $\begin{array}{l}\text { Earley, 2006; Graen et al., 1977; } \\
\text { Triandis, 2006. }\end{array}$ \\
\hline Education & $\begin{array}{l}\text { Expatriate Theory, } \\
\text { Transculturals, } \\
\text { Cultural Intelligence }\end{array}$ & Earley et al., 2006; Graen and Hui, 1999. \\
\hline $\begin{array}{l}\text { Emotional } \\
\text { Resilience }\end{array}$ & Transculturals & Earley et al., 2006; Graen and Hui, 1999. \\
\hline Empathy & $\begin{array}{l}\text { Expatriate Theory, } \\
\text { Transculturals }\end{array}$ & $\begin{array}{l}\text { Black and Gregersen, 1999; Graen et al., } \\
\text { 1997; Kealey and Rubin, } 1973 .\end{array}$ \\
\hline Experience & $\begin{array}{l}\text { Expatriate Theory, } \\
\text { Transculturals }\end{array}$ & $\begin{array}{l}\text { Adler, 1975; Black and Gregersen, 1999; } \\
\text { Graen et al., 1997; Hawkes and Kealey, } \\
\text { 1980; Maddox, 1993; Oberg, } 1960 .\end{array}$ \\
\hline Facilitator & $\begin{array}{l}\text { Expatriate Theory, } \\
\text { Transculturals }\end{array}$ & $\begin{array}{l}\text { Graen and Hui, 1999; Graen et al., 1997; } \\
\text { Graen et al., 2004; Kealey and Rubin, } \\
1973 .\end{array}$ \\
\hline Flexibility & $\begin{array}{l}\text { Expatriate Theory, } \\
\text { Transculturals }\end{array}$ & $\begin{array}{l}\text { Bird and Stevens, 2003; 2006; Graen et } \\
\text { al., 1999; Graen and Hui, 1999; Harris } \\
\text { and Moran, 1991; Lobel, 1990. }\end{array}$ \\
\hline Motivation & $\begin{array}{l}\text { Expatriate Theory, } \\
\text { Transculturals, } \\
\text { Cultural Intelligence }\end{array}$ & $\begin{array}{l}\text { Earley et al., 2006; Graen et al., 1997; } \\
\text { Graen et al., 2004; Graen and Hui, 1999; } \\
\text { Harris and Moran, 1991; Lobel, } 1990 .\end{array}$ \\
\hline Non-Judgmental & $\begin{array}{l}\text { Expatriate Theory, } \\
\text { Transculturals, } \\
\text { Cultural Intelligence }\end{array}$ & $\begin{array}{l}\text { Black and Gregersen, 1999; Graen et al., } \\
\text { 1997; Graen et al., 2004; Graen and Hui, } \\
\text { 1999. }\end{array}$ \\
\hline Observant & $\begin{array}{l}\text { Transculturals, } \\
\text { Cultural Intelligence }\end{array}$ & $\begin{array}{l}\text { Earley et al., 2006; Graen et al., 1997; } \\
\text { Graen et al., 2004; Graen and Hui, } 1999 .\end{array}$ \\
\hline Open & $\begin{array}{l}\text { Expatriate Theory, } \\
\text { Transculturals }\end{array}$ & $\begin{array}{l}\text { Black and Gregersen, 1999; Earley et al., } \\
\text { 2006; Graen et al., 19971 Kealey et al., } \\
\text { 2006; Oberg, 1960; Rubin, } 1989 .\end{array}$ \\
\hline
\end{tabular}




\begin{tabular}{|c|c|c|}
\hline Optimistic & $\begin{array}{l}\text { Expatriate Theory, } \\
\text { Transculturals }\end{array}$ & $\begin{array}{l}\text { Maddox, 1993; Oberg, 1960; } \\
\text { Trompenaars and Hampden-Turner, } \\
1998 \text {. }\end{array}$ \\
\hline $\begin{array}{l}\text { Personal } \\
\text { Autonomy }\end{array}$ & \begin{tabular}{|l} 
Transculturals \\
\end{tabular} & $\begin{array}{l}\text { Graen } \text { et al., 1997; Graen } \text { et al., 2004; } \\
\text { Graen and Hui, 1999 }\end{array}$ \\
\hline Respectful & $\begin{array}{l}\text { Expatriate Theory, } \\
\text { Transculturals }\end{array}$ & $\begin{array}{l}\text { Graen } \text { et al., 1997; Graen et al., 2004; } \\
\text { Graen and Hui, 1999. }\end{array}$ \\
\hline Strategic & \begin{tabular}{|l|} 
Transculturals, \\
Cultural Intelligence \\
\end{tabular} & $\begin{array}{l}\text { Earley et al., 2006; Graen et al., 1997; } \\
\text { Graen et al., 2004; Graen and Hui, } 1999 .\end{array}$ \\
\hline $\begin{array}{l}\text { Expatriate } \\
\text { Success }\end{array}$ & $\begin{array}{l}\text { Expatriate Theory, } \\
\text { Cross-Cultural } \\
\text { Business } \\
\text { Environment, } \\
\text { Transculturals }\end{array}$ & $\begin{array}{l}\text { Black and Gregersen, 1999; Graen et al., } \\
\text { 1997; Hawkes and Kealey, 1980; Hurn, } \\
\text { 1999; Okpara and Kabongo, 2011; } \\
\text { Redden, 1975; Sims and Schraeder, } \\
\text { 2004. }\end{array}$ \\
\hline
\end{tabular}

The next section of this dissertation presents the results of a pilot study that was undertaken prior to the TMS research to facilitate the development of the TMS. The pilot study was built on the components that flowed from the literature review in order to clarify and confirm their inclusion in the research model and in the survey questionnaire. 


\section{PILOT STUDY: INTERVIEWS WITH EXPATRIATES}

This section provides a discussion of the pilot study involving convenience interviews with self-reported successful expatriates. The goal of this section is to discuss the process and results of the pilot study, and to outline the ways in which it provided insight and contributed to the development of the research model and items for the main body of research.

Preliminary research was undertaken to investigate the transcultural construct with a group of successful expatriates. The purpose of this pilot study was to address the gaps identified in the academic literature and to gain information from real-world expatriates regarding the characteristics and attributes they believe to be critical to success. The pilot study was undertaken to help the researcher analyze and confirm the components for the research model flowing from the literature review, and to supplement items not well covered in the literature.

\subsection{Pilot Study Process}

With over twenty years of Management Consulting experience, most of which has been in the area of international business and global expansion, the author has a network of acquaintances, colleagues and peers from a broad range of industries, organizations, cultures and countries. A convenience sample of twelve individuals was selected for the pilot study. These individuals were chosen because they had completed more than one overseas assignment in their career. 
A set of eighteen questions was designed to investigate the characteristics, attitudes and attributes of these self-identified, successful expatriates. These questions are provided in Table 5. Due to logistics and availability, eight of the selected individuals participated in the study. A one-hour telephone interview was conducted with each individual. The participants did not have any advance copy of the questions, nor did they know the content or purpose of the study.

The following table contains the interview questions, the literature sources and a discussion of the purpose of each question. These questions were developed based on a critical analysis of the literature and the components that were identified during that analysis.

Table 6: Pilot Study Interview Questions Information

\begin{tabular}{|l|l|l|}
\hline \multicolumn{1}{|c|}{ Interview Questions } & \multicolumn{1}{|c|}{ Literature Source } & \multicolumn{1}{c|}{ Purpose } \\
\hline $\begin{array}{l}\text { 1. Describe the culture you } \\
\text { grew up in compared to } \\
\text { the one you now live in? }\end{array}$ & $\begin{array}{l}\text { Graen } \text { et al., 1997, } \\
\text { Hampden-Turner and } \\
\text { Trompenaars, 2000, } \\
\text { Hui and Triandis, 1985. }\end{array}$ & $\begin{array}{l}\text { To determine if the participant } \\
\text { has experienced many cultures } \\
\text { and understands their } \\
\text { similarities and differences } \\
\text { without judgment or bias. }\end{array}$ \\
\hline $\begin{array}{l}\text { 2. How many cultures have } \\
\text { you lived in? Briefly } \\
\text { discuss. }\end{array}$ & $\begin{array}{l}\text { Earley } \text { et al., 2006, } \\
\text { Oberg, 1960. }\end{array}$ & $\begin{array}{l}\text { To investigate if exposure to } \\
\text { cultures helped to mitigate } \\
\text { future culture shock and } \\
\text { facilitate future cultural } \\
\text { adjustment. }\end{array}$ \\
\hline
\end{tabular}




\begin{tabular}{|c|c|c|c|}
\hline & Interview Questions & Literature Source & Purpose \\
\hline & $\begin{array}{l}\text { Based on your cultural } \\
\text { experience, which } \\
\text { culture was most } \\
\text { comfortable, and which } \\
\text { was the most } \\
\text { uncomfortable? }\end{array}$ & $\begin{array}{l}\text { Bird and Stevens, } 2003, \\
\text { Lobel, 1990, Ruben } \\
1989 .\end{array}$ & $\begin{array}{l}\text { To gain an understanding of } \\
\text { comfort levels. Transcultural } \\
\text { are comfortable in many } \\
\text { cultures, so they may not } \\
\text { necessarily select their home } \\
\text { culture as most comfortable. } \\
\text { The most challenging culture } \\
\text { may be difficult to select if no } \\
\text { culture is considered very } \\
\text { challenging. }\end{array}$ \\
\hline & $\begin{array}{l}\text { Which culture is your } \\
\text { preference and why? }\end{array}$ & $\begin{array}{l}\text { Hampden-Turner and } \\
\text { Trompenaars, } 2000 .\end{array}$ & $\begin{array}{l}\text { To understand if they based } \\
\text { cultural preference on their } \\
\text { home culture. }\end{array}$ \\
\hline & $\begin{array}{l}\text { Describe your circle of } \\
\text { friends with respect to } \\
\text { their culture and } \\
\text { location? }\end{array}$ & $\begin{array}{l}\text { Earley et al., 2006; } \\
\text { Earley and } \\
\text { Mosakowski, 2004a. }\end{array}$ & $\begin{array}{l}\text { To see if they are limited by } \\
\text { geography, etc. or do they have } \\
\text { friends around the world. }\end{array}$ \\
\hline 6. & $\begin{array}{l}\text { How do you approach a } \\
\text { new culture? (Generally, } \\
\text { both when you are in a } \\
\text { new place and/or } \\
\text { experiencing a new } \\
\text { culture.) }\end{array}$ & $\begin{array}{l}\text { Earley et al., 2006; } \\
\text { Earley and } \\
\text { Mosakowski, 2004a, } \\
\text { Graen and Hui, 1999, } \\
\text { Triandis, 2006. }\end{array}$ & $\begin{array}{l}\text { To understand if they are } \\
\text { systematic about how they } \\
\text { approach a new culture. }\end{array}$ \\
\hline & $\begin{array}{l}\text { How do you approach } \\
\text { those from } \\
\text { unknown/new cultures } \\
\text { in a work and in a social } \\
\text { situation? }\end{array}$ & $\begin{array}{l}\text { Earley et al., 2006; } \\
\text { Earley and } \\
\text { Mosakowski, 2004b. }\end{array}$ & $\begin{array}{l}\text { To determine if they are } \\
\text { methodical when presented } \\
\text { with an unknown culture. }\end{array}$ \\
\hline 8. & $\begin{array}{l}\text { What is your norm with } \\
\text { respect to your IT } \\
\text { orientation - PC, } \\
\text { Internet, mobile, text, } \\
\text { videophone, Skype, } \\
\text { etc.? }\end{array}$ & $\begin{array}{l}\text { Bird and Stevens, 2003, } \\
\text { Harris and Moran, } \\
\text { 1991, Lobel, 1990. }\end{array}$ & $\begin{array}{l}\text { To see if they utilize available } \\
\text { means of communication and } \\
\text { are open to new ideas and } \\
\text { ways. }\end{array}$ \\
\hline & $\begin{array}{l}\text { Do you adapt easily } \\
\text { when confronted with } \\
\text { (rapid) change? Explain. }\end{array}$ & $\begin{array}{l}\text { Earley et al., 2006; } \\
\text { Earley and } \\
\text { Mosakowski, 2004b. }\end{array}$ & $\begin{array}{l}\text { To understand if they adapt as } \\
\text { required to new situations. }\end{array}$ \\
\hline
\end{tabular}




\begin{tabular}{|c|c|c|}
\hline Interview Questions & Literature Source & Purpose \\
\hline $\begin{array}{l}\text { 10. Have you ever } \\
\text { experienced a situation } \\
\text { where you had no idea } \\
\text { what was transpiring } \\
\text { due to unknown cultural } \\
\text { norms and/or } \\
\text { expectations? How did } \\
\text { you handle yourself? }\end{array}$ & $\begin{array}{l}\text { Earley et al., 2006; } \\
\text { Earley and } \\
\text { Mosakowski, 2004b, } \\
\text { Fritz and Mollenberg, } \\
\text { 2001, Hampden-Turner } \\
\text { and Trompenaars, 2000, } \\
\text { Triandis, 2006. }\end{array}$ & $\begin{array}{l}\text { To determine if they look for } \\
\text { behaviour cues and patterns, } \\
\text { use this information to } \\
\text { determine cultural equivalency } \\
\text { between new and home } \\
\text { cultures. }\end{array}$ \\
\hline $\begin{array}{l}\text { 11. How you do deal with } \\
\text { two valid yet } \\
\text { contradictory } \\
\text { alternatives, such as } \\
\text { 'look before you leap' } \\
\text { and 'he who hesitates } \\
\text { gets lost', a common } \\
\text { paradox. }\end{array}$ & $\begin{array}{l}\text { Bird and Stevens, 2003, } \\
\text { Earley et al., 2006; } \\
\text { Earley and } \\
\text { Mosakowski, 2004a, } \\
\text { Lobel, 1990, Ruben, } \\
\text { 1990. }\end{array}$ & $\begin{array}{l}\text { To see if they are deterred by } \\
\text { cultural mysteries. }\end{array}$ \\
\hline $\begin{array}{l}\text { 12. What limitations are you } \\
\text { under with respect to } \\
\text { work and location? (e.g. } \\
\text { family constraints, } \\
\text { financial obligations, } \\
\text { credentials, etc.). }\end{array}$ & $\begin{array}{l}\text { Earley et al., 2006; } \\
\text { Earley and } \\
\text { Mosakowski, 2004a. }\end{array}$ & $\begin{array}{l}\text { To find if they can deal with } \\
\text { limitations. }\end{array}$ \\
\hline $\begin{array}{l}\text { 13. How much control do } \\
\text { you feel you have on } \\
\text { your career path? }\end{array}$ & $\begin{array}{l}\text { Black and Gregersen, } \\
\text { 1999, Graen et al., } \\
1997 .\end{array}$ & $\begin{array}{l}\text { To understand if they feel that } \\
\text { they have control and } \\
\text { autonomy in their lives. }\end{array}$ \\
\hline $\begin{array}{l}\text { 14. What were your biggest } \\
\text { cultural 'faux pas' in } \\
\text { work and social } \\
\text { situations? } \\
\text { When and how did you } \\
\text { realize your errors? }\end{array}$ & $\begin{array}{l}\text { Earley et al., 2006; } \\
\text { Earley and } \\
\text { Mosakowski, 2004a, } \\
\text { Hampden-Turner and } \\
\text { Trompenaars, } 2000 .\end{array}$ & $\begin{array}{l}\text { To analyze how they handle } \\
\text { cultural complexities and if } \\
\text { they have a problem admitting } \\
\text { their cultural mistakes. Also, } \\
\text { to find out if they see the } \\
\text { experience as a learning } \\
\text { opportunity. }\end{array}$ \\
\hline $\begin{array}{l}\text { 15. How do you handle } \\
\text { making (cultural) } \\
\text { mistakes, both when you } \\
\text { realize you made them } \\
\text { and when you are told } \\
\text { by others that you have? }\end{array}$ & $\begin{array}{l}\text { Earley et al., 2006; } \\
\text { Earley and } \\
\text { Mosakowski, 2004a, } \\
\text { Ruben, } 1989 .\end{array}$ & $\begin{array}{l}\text { To see if they are culturally } \\
\text { open and honest, and if they } \\
\text { have struggled with repairing } \\
\text { their cultural mistakes. }\end{array}$ \\
\hline
\end{tabular}




\begin{tabular}{|c|c|c|}
\hline Interview Questions & Literature Source & Purpose \\
\hline $\begin{array}{l}\text { 16. Would someone from a } \\
\text { foreign culture describe } \\
\text { you differently when } \\
\text { they have known you for } \\
\text { a while, compared to } \\
\text { their impressions after a } \\
\text { first encounter? Explain. }\end{array}$ & $\begin{array}{l}\text { Earley et al., 2006; } \\
\text { Earley and } \\
\text { Mosakowski, 2004a, } \\
\text { Graen et al., 1997, Hui } \\
\text { and Triandis, 1985, } \\
\text { Triandis, 2006. }\end{array}$ & $\begin{array}{l}\text { To investigate how they assess } \\
\text { new cultural situations in order } \\
\text { to determine the norms. At } \\
\text { first they may be quiet or aloof, } \\
\text { and once they understand how } \\
\text { to behave appropriately they } \\
\text { may be more forthcoming. }\end{array}$ \\
\hline $\begin{array}{l}\text { 17. How do you handle } \\
\text { conflict or } \\
\text { disagreements in a } \\
\text { foreign cultural setting? }\end{array}$ & $\begin{array}{l}\text { Earley et al., 2006; } \\
\text { Earley and } \\
\text { Mosakowski, 2004a, } \\
\text { Fritz and Mollenberg, } \\
\text { 2001, Graen et al., } \\
1997 .\end{array}$ & $\begin{array}{l}\text { To determine if they feel they } \\
\text { know how to behave } \\
\text { appropriately in cultural } \\
\text { situations, e.g. if intervening is } \\
\text { appropriate and how to do this. }\end{array}$ \\
\hline $\begin{array}{l}\text { 18. Do you believe in the } \\
\text { notion of bridging } \\
\text { cultures, as in creating a } \\
\text { common or "third" } \\
\text { culture? Discuss. }\end{array}$ & Graen et al., 1997. & $\begin{array}{l}\text { To understand the extent to } \\
\text { which they may strive to } \\
\text { bridge cultures into a third or } \\
\text { common culture in order to } \\
\text { facilitate understanding and } \\
\text { cooperation between all } \\
\text { parties. }\end{array}$ \\
\hline
\end{tabular}

\subsection{Pilot Study Content Analysis and Results}

The analysis of the responses involved comparing and contrasting the information provided by the participants to discover patterns and linkages, and emerging themes and associations. The Cultural Intelligence Tests were assessed in accordance with the scoring instructions provided with the test (Earley et al., 2006, p. 223-225). All eight participants scored relatively high on the dichotomous cultural intelligence test, which further supports their appropriateness for this pilot study. Indeed, despite its limitations, cultural intelligence has been positively related to overseas adjustment (Early $e t$ al. 2006). 
An interesting result of the transcultural stage analysis revealed that not only are different people currently at different stages, but that a person's stage was not dependent on their overseas job experience or on their exposure to other cultures. This suggests that the level of transcultural ability is not solely dependent on training and/or cultural experience. Most of the participants described growing up in a homogeneous, closed society, and they were not exposed to other cultures until their late teens. The youngest participant did discuss growing up in many cultures and found it difficult to relate to one specific culture as his own.

All participants described their cultural comfort in terms of relationships and interactions with the locals. Their cultural comfort levels were influenced by positive relationships with coworkers and peers, and not by assessments or judgments of the local culture's customs and traditions. The notion of bridging cultures was strongly supported as a way to facilitate working within a cross-cultural environment. Some described this as a process of mutual cooperation, acceptance and tolerance of each other. One respondent mentioned that this blending of cultures can happen naturally when people are open to new ideas and new ways of doing things. Four of the participants specifically mentioned that they welcomed change, with one identifying him/herself as a change initiator.

The themes and characteristics identified in the analysis strongly support flexibility and openness with other peoples and situations. The participants all exhibited a pragmatic and realistic approach to their life and career opportunities. Additionally, they demonstrated openness, optimism and confidence in their personal situation. They all 
expressed empathy for others and a respect for all cultures, especially when a new culture is experienced. Two participants mentioned that using caution mitigated cultural blunders and another said that observation helps them to decipher complex cultural situations.

Only two of the participants were uncomfortable with information technology (IT) tools, while the others saw IT as a way of life. All the participants were highly educated and most felt in control of their lives. Each participant expressed optimism towards the future and displayed personal strength and resilience, which they identified as a necessity in order to deal with life's challenges.

Through a process of comparing and contrasting the responses of the eight participants, a pattern emerged in ranking the participants from high to low. Those high in the ranking were the ones that were the most comfortable and flexible with overseas jobs and more open to change and new experiences. In contrast, those lower in the ranking were not as open or flexible to adaptation and change. All participants were comfortable with the cultural aspects of their overseas jobs, even those with previously limited cultural exposure and training.

The participants were aligned with the higher transcultural levels. The levels ranged from high to medium, with no participants aligning with the lower two transcultural levels. This result was expected as all participants were initially identified as repeat expatriates having successfully completed overseas work assignments. In addition, none 
of the participants identified the challenges and difficulties that someone at the lower two transcultural levels would experience; such as discomfort with other cultures due to a lack of awareness, knowledge and/or understanding of cultural behavioural cues (Graen et al, 1997).

\subsection{Pilot Study Contribution to the Research Model}

The analysis of the pilot study responses identified a group of successful expatriates that exemplified both similar and contrasting characteristics. The participant responses were then aligned with the transcultural stages, resulting in positions from the middle to high level. This back translation indicated a positive relationship between transcultural stages and successful expatriates.

The pilot study contributes to the overarching project by providing rich qualitative examples of individuals who have been successful with respect to completing overseas assignments. The respondent data provided clarity and detail to the literature by confirming the attributes and characteristics of successful expatriates. The pilot study process provided valuable insight and complimented the literature by clarifying the gaps with practical experience. The pilot confirmed the seventeen components that were identified in the literature as the participants had these characteristics in common. It also added value by confirming the distinction between transcultural ability and cultural intelligence, as all of the participants identified that their expatriate success was not solely the result of cultural training and knowledge. In fact, most of the participants mentioned that they had no such training and exposure prior to their first overseas 
assignment. This insight contributed to the analysis of the research model components and the selection of items for the research survey questionnaire.

The following section presents the framework for the research completed in this dissertation. It includes the research model and a discussion of the model components with respect to their theoretical relationships. 


\section{RESEARCH FRAMEWORK}

This section provides theoretical support for the research that was undertaken in this study. The first part identifies the research question that was addressed, and the second part provides the research model, including a discussion of its components.

\subsection{Research Question}

This research addressed the question, "how do we determine an individual's transcultural level?" The answer to this question was sought through the design of a scale that incorporated an identification and confirmation of the components of the transcultural construct.

The research in this dissertation contributes to the expatriate literature by identifying the components of the transcultural construct and compiling them in a Transcultural Measurement Scale (TMS), which provides a means to measure an individual's transcultural ability. Previous to this study there was no empirical study concerning the transcultural construct, as Graen and colleagues only provided a theoretical description of the abilities required of a transcultural. The TMS provides a way to determine where an individual ranks, or is positioned, with respect to transcultural ability level or stage. This construct has been defined within a five-stage model.

At the bottom or low end of the transcultural scale you will find a 'cultural adventurer', an individual with an adventurer's mentality towards other cultures, and at the top or high 
end of the scale, you will find a 'socializing synthesizer', an individual who is a developed transcultural who can bridge two different cultures into a new culture that is congruent with other cultures (Graen et al., 1997). Between these two stages are three other levels that depict and identify an individual evolving towards becoming a fully developed transcultural. This information can be used to facilitate the selection of individuals for overseas assignments. The following section presents and discusses the research model.

\subsection{Research Model and Components}

The research model has been developed from an analysis of the literature review and from the results of the assessment of the pilot study interviews with expatriates. This analysis identified many possible components of transcultural ability. The components were narrowed down to seventeen by consolidating them, removing redundancies and clearly focusing on the intent of the model.

The following diagram presents the research model and identifies the seventeen proposed components of transcultural ability. 


\section{Figure 3: Components of Transcultural Ability (Proposed)}

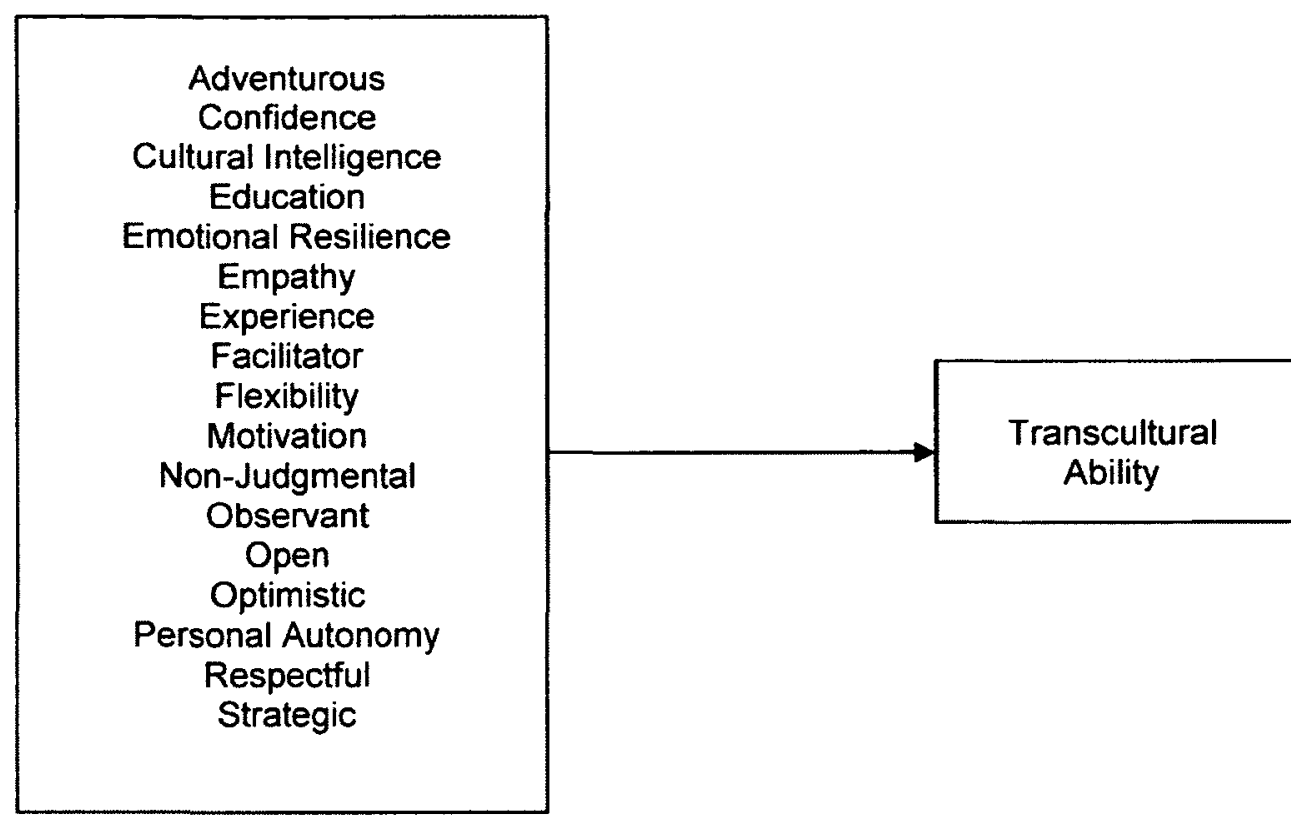

A discussion of these components, which includes a working definition of the component and the reason for which the component is important to transcultural ability and measurement, is provided below:

Adventurous - the ability to willingly partake in new activities that have an element of risk. Being adventurous is important to the transcultural measure because transculturals are open to new experiences and situations, and need to be willing to experience new and often difficult situations (Graen at al., 1977).

Confidence - the ability to maintain positive certainty about one's decisions and actions. Confidence is an important component for measuring transcultural ability; as individuals pass through the transcultural stages their confidence is strengthened (Graen et al., 1977). Confidence has been found to positively influence cross-cultural effectiveness and 
adjustment (Osman-Gani and Rockstuhl, 2009). Confidence is also strengthened when an individual is recovering from culture shock (Adler, 1975; Deng and Gibson, 2008; Furnham and Bochner, 1982), especially in the later stages, where they feel they can function within the new culture (Oberg, 1960).

Cultural Intelligence - the ability to successfully adapt to new cultural settings. Cultural intelligence is an important component for transculturals, as those with a high level of cultural intelligence are likely to be at an advanced stage of transcultural development (Graen et al., 1997). It includes how one thinks and solves problems, how motivated they are and their ability to behave suitably in a new cultural situation (Earley, 2006).

Education - formal and informal education. Transculturals are described as highly educated (Bird and Stevens, 2003; Graen et al., 1999). Self-improvement and curiosity motivate the transcultural to engage in various learning activities, such as undertaking many hobbies and other leisure activities, and learning about the cultural phenomena that they encounter. This knowledge base develops and contributes to additional cognitive tools for analyzing their cultural experiences (Graen and Hui, 1999). With a broader range of knowledge and increased exposure, the individual will facilitate cultural analysis (Earley et al., 2006). The interview results found that all participants held graduate degrees and had a broad range of interests and hobbies. 
Emotional Resilience - the ability to quickly recover from emotional challenges.

Emotional resilience is an important component for transculturals, as they have to be able to accept that cultural differences are not to be taken personally (Graen et al., 1997). The interview process also identified this component, as most of the participants described how they were quick to apologize for their behaviour when they offended the locals. One mentioned that offering food was a good tool for handling cultural mistakes. It is interesting that only one participant mentioned feeling embarrassed when they made cultural errors.

Empathy - the ability to identify and deeply understand the feelings of others. Empathy is a component of importance to transculturals, as it allows them to understand the perspectives and attitudes of others as they assess cultural behaviour (Graen et al., 1997). This component also assumes an attitude free from pre-existing bias or prejudice towards others. In their literature review, Kealey and Rubin (1973) found that across all research studies "empathy" had been agreed upon as a predictor of overseas success.

Experience - exposure to foreign cultures from travel and overseas work. The more experience an individual has with different cultures, the more cultural ability they possess. The interview process supported this component, as all participants indicated that moving from culture to culture became easier and easier with each new culture encountered. This notion is also reflected in the expatriate and transcultural literature (Adler, 1975; Black and Gregersen, 1999; Graen et al., 1997; Hawkes and Kealey, 1980; Maddox, 1993). 
Facilitator - the ability to function as a catalyst in a neutral way, bringing two or more diverse people/cultures together to foster mutual cooperation. The transcultural theory describes how high level transculturals seek to create bridging or "third" cultures. This creation or change implies that these individuals encourage, welcome and facilitate change. This component is especially relevant to the higher level transculturals who strive to facilitate cultural interactions by creating an environment where people from different cultures can comfortably work together (Graen et al., 1997; Graen et al., 2004; Graen and Hui, 1999).

Flexibility - the ability to quickly change behaviour according to the circumstances. Being flexible is an important component for transculturals as they need to assess and modify their behaviour continuously, as they become integrated into new cultures, and as they move between cultures (Bird and Stevens, 2003; Graen et al., 1999; Graen and Hui, 1999; Kealey and Rubin, 1973; Lobel, 1990).

Motivation - the ability to maintain an intensity, direction and persistence of effort. An important component for transcultural measurement is motivation from a cultural and personal perspective. While cultural motivation is one of the three cultural intelligence components (Earley et al., 2006), this component for transcultural measurement is not limited to cultural pursuits. For the transcultural it also involves personal and professional endeavours (Graen et al., 1997; Graen et al., 2004; Graen and Hui, 1999; Harris and Moran, 1991; Lobel, 1990). 
Non-Judgmental - the ability to resist judging and criticizing the conduct of others. Cross-cultural understanding stems from viewing different cultures as simply different, without prejudice or judgment (Early et al., 2004), and from viewing them neither as right nor as wrong because they are different from the home culture. A higher-level transcultural does not judge cultures or cultural behaviour. This individual is very accepting of other cultures and strives to understand a culture in order to integrate into that culture (Graen et al., 1997; Graen et al., 2004; Graen and Hui, 1999; Kealey and Rubin, 1973).

Observant - the ability to be aware of the behaviour of others from watching how they function, what they do, when they do it and to whom they do it with/to. It is important that a transcultural, especially one at a higher stage of development, be observant of the behaviour of others (Graen et al., 1997; Graen et al., 2004; Graen and Hui, 1999). Crosscultural understanding requires an identification of relevant information to understand the components and merit of another culture. This enables transculturals to identify and understand appropriate behaviour in the new culture.

Open - the ability to be ready and willing to accept new ideas and experiences. Being open to new cultures, people and experiences is an important component of a transcultural. Openness provides transculturals with the opportunity to be able to experience new cultures with honesty and respect (Graen et al., 1997). This quality is also required by higher levels of cultural intelligence as the individual has to be open to 
the new culture in order to accurately understand the nuances and norms and to be able to adapt to it (Earley et al., 2006). Being closed to new experiences negatively impacts an individual's ability to recover from culture shock (Black and Gregersen, 1999; Kealey et al., 2006; Oberg, 1960; Rubin, 1989).

Optimistic - the ability to maintain a positive, hopeful view of the future. An important transcultural component is being optimistic, as this provides individuals with the encouragement to continue through the unknown. This includes attempting to understand situations and behaviours that may not initially make sense (Maddox, 1993; Oberg, 1960; Trompenaars and Hampden-Turner, 1998). Transculturals are not as likely to get stuck in the crisis stage of cultural shock (Oberg, 1960), as their strong optimism tends to keep them focused on resolving their situation.

Personal Autonomy - the ability to have personal independence and a sense of control. Being in control or feeling that one is in control of one's life, both professionally and personally, is an important component of transcultural measurement. Transculturals need this autonomy in order to be able to quickly assess situations and make decisions regarding appropriate behaviour (Earley et al., 2006; Graen et al., 1997; Graen et al., 2004; Graen and Hui, 1999). This autonomy provides them with the independence to make decisions and the liberty to enact them.

Respectful - the ability to have an attitude of admiration and consideration towards others. An important component of transculturals is that they are respectful of other 
cultures. They find value in the norms and admire the people. This allows them to earn the respect of those from other cultures, which provides them with the opportunity to learn about and deeply understand other cultures as if they were from that culture (Earley et al., 2006; Graen et al., 1997; Graen et al., 2004; Graen and Hui, 1999; Kealey and Rubin, 1973;).

Strategic - the ability to develop a plan of action for all goals/activities. Strategic ability is an important component for transculturals as they deliberately focus and learn from cultural situations in order to be able to analyze and understand how to transform their behaviour (Graen and Hui, 1999). Transculturals, when presented with new cultures, strategically focus their energy on the new culture in order to identify the differences and learn the behaviour (Earley et al., 2006; Graen et al., 1997; Graen et al., 2004). Being strategic is an important component for a transcultural as they need to adapt to a new culture with a practical and sensible attitude, and not ignore or disregard the importance of the norms and nuances of the culture. This approach facilitates adaptation and their ability to bring people together in an environment of multi-cultural cooperation (Graen et al., 1997; Graen and Hui, 1999; Graen et al., 2004).

This research framework chapter has presented the overarching research question "how do we determine an individual's transcultural level?" A research model proposing seventeen components of transcultural ability was also presented. These components were identified during the analysis of the literature review and clarified in the pilot study. The following chapter presents the methodology for the research in this dissertation. The 
sections in the chapter include an overview, a discussion of factor analysis for scale development, and an identification and detailed discussion of the preparations and the methodology designed for this research study. 


\section{METHODOLOGY}

\subsection{Overview}

The methodology for the development of the Transcultural Measurement Scale (TMS) included the basic principles for scale development (Stevens, 2009; Clark and Watson, 1995), including an examination of the predictive validity of the measure (Clark and Watson, 1995; Cronbach and Meehl, 1995).

The following section presents a discussion of factor analysis for transcultural development. The four steps of the research methodology are then presented with a discussion of the activities, processes and procedures that were completed within each of these four steps.

\subsection{Factor Analysis for Transcultural Development}

Factor analysis is a common and popular procedure for developing and evaluating new constructs (Floyd and Widaman, 1995). The goal of the research was to determine the variable importance of the items in the proposed TMS. This was an exploratory procedure as there was no existing measure to compare results against. Therefore exploratory factor analysis was selected as an appropriate initial tool for building the TMS.

In a research endeavour it is important to confirm at the outset that there is harmony between the items analyzed by showing that they are from the same set of variables 
(Cronbach and Meehl, 1955). This reassures the researcher that the test will adequately measure the construct. The use of content followed by construct validation, prior to analysis with exploratory factor analysis, will confirm the existence of a relationship between the variables (Clark and Watson, 1995). Content validity is a necessary prerequisite for establishing the construct validity of a measure (Rossiter, 2008). This view is supported in the classic article by Haynes, Richard and Kubany (1995, p. 238) that defines construct validity as "the degree to which elements of an assessment instrument are relevant to and representative of the targeted construct". The assessment of the literature review and the results of the pilot study were designed to provide the content validity for the research items.

Exploratory factor analysis uses the matrix of correlations, or co-variances, of the measured variables to identify a predictive latent variable (Clark and Watson, 1995; Floyd and Widaman, 1995). Not all variables tend to have successful results and some have to be dropped (Comrey, 1988). The intent is to reduce the set of variables, as necessary, to a smaller but reliable set. Many studies (e.g., Comrey, 1988; $\mathrm{Ng}$, Wang, Kim and Bodenhorn, 2010: Nguyen, Biderman and McNary; 2010; Stevens, 2009) have looked at the best or correct number of factors, however it may be better to consider factors in terms of their reliability or appropriateness to the construct at hand (de Winter, Dodou and Wieringa, 2009).

With this process, a factor structure is hypothesized and tested for fit. A model is produced that depicts whether the model loads significantly, which would confirm the 
model. This result can be referred to as "goodness of fit". The goal here is to find the best fit, not necessarily a perfect fit. This fit can be described as an "adequate representation of the data (or) is at best an approximation of reality" (Floyd and Widaman, 1995, p. 294).

Once a statistically significant set of variables has been determined, confirmatory factor analysis and predictive validity can be used to test and confirm the results of the exploratory factor analysis (Stevens, 2009). This latter analysis focuses on determining the links between the predictor and the outcome variables in order to confirm the predictive validity of the scale (Cronbach and Meehl, 1955; Swann, Chang-Schneider and Larsen McClarty, 2007).

In summary, the research for this dissertation involved developing a measurement scale for identifying an individual's transcultural ability. As there is no existing measure for transcultural ability, an exploratory procedure is required. Factor analysis, both exploratory and confirmatory, and predictive validity analysis was selected for the research data analysis. The following section of this paper presents a discussion of the research steps that were undertaken for the development of the TMS.

\subsection{Research Activities}

The research activities included preparations and three steps in the methodology:

- Preparations - literature review and pilot study analysis, and item or survey question development. 
- Step 1: Survey -survey creation, distribution and data gathering.

- Step 2: Instrument Development -data analysis and scale construction with factor analysis.

- Step 3: Validation - confirmation of the research with validation using regression analysis.

The preparation and each step of the methodology are discussed in detail in the following sections.

\subsubsection{Preparations}

This activity focused on designing and preparing to administer the research survey. Clark and Watson (1995) provide some basic principles of scale development in their classic paper on creating reliable and valid assessment instruments. In order to begin with a clear conceptualization of the target construct, Clark and Watson support not only reviewing the relevant literature, but also including a review of similar and related constructs (Clark and Watson, 1995). Comrey (1988) and Cronbach and Meehl (1955) also support that the initial step of any research should be to gain a thorough understanding of the theoretical concepts and their interaction with other constructs.

\subsubsection{Literature Review Analysis}

The literature review and pilot study results were thoroughly analyzed to identify key components for the development of the research model and survey questions for this research. 


\subsubsection{Identify Research Components}

A set of components and an item pool were developed from both the analysis of the literature review and also the results from the pilot study interviews with successful expatriates. This analysis identified seventeen components that influence transcultural ability. The following section identifies the survey questions that were drawn from the identified components.

\subsubsection{Determine Survey Contents}

This section created the survey questions that were designed to capture information on topics such as demography, transcultural ability and expatriate success. The demographic questions involved the participant's age, gender, education level and a dichotomous yes/no question to qualify participants as having foreign work experience.

The questions pertaining to transcultural ability were distributed through the survey to ensure that there was no acquiescence bias from a perceived pattern of response. The items were developed for each component from the theory and are all in the form of a statement. A Likert scale response style was used that required participants to select from a range scale (Likert, 1932). The responses were issued on a 7-point scale ranging from "strongly agree" (1) to "strongly disagree" (7).

The survey also contained questions related to expatriate success. Success on a foreign assignment is defined for the purposes of this research as including an individual 
remaining in the foreign position/posting for the original timeframe or intent associated with the posting. It also recognizes that factors beyond the individual's control are exceptions to be considered with respect to successful completion of an assignment. The results of these questions, along with questions regarding the number of foreign work positions, were used in the assessment of the predictive validity of the survey to confirm that an individual's transcultural measurement can be used to determine the likelihood of this individual completing a foreign assignment. Table 7 presents the 60 survey questions by component and the six questions pertaining to expatriate success (questions that were reverse scored are labeled with an ' $R$ '). This table also provides academic sources to support the questions.

\section{Table 7: Survey Questions}

\begin{tabular}{|l|l|}
\hline \multicolumn{1}{|c|}{ Survey Questions } & \multicolumn{1}{|c|}{ Source } \\
\hline Adventurous & \\
\hline 1. I tend to seek out local foods as my first choice when & $\begin{array}{l}\text { Graen } \text { et al., 1977; Harris } \\
\text { and Moran, 1991; Oberg, }\end{array}$ \\
2. I want to experience different cultures as much as & 1960; Pilot Study \\
possible in both my personal and professional life. & Analysis. \\
3. I prefer to socialize with other expatriates on a foreign & \\
assignment. R & \\
4. I get bored when things are stagnant or consistent. \\
5. I am secure in my own skin (I know my abilities, \\
strengths and limits). \\
6. I prefer a job in a culture different from my own. \\
7. I eagerly use new technology as soon as it is available. \\
\hline
\end{tabular}




\begin{tabular}{|c|c|}
\hline Survey Questions & Source \\
\hline \multicolumn{2}{|l|}{ Confidence } \\
\hline $\begin{array}{l}\text { 1. In terms of knowing how to navigate new cultures, I } \\
\text { see myself as highly experienced. } \\
\text { 2. In keeping a conversation going with someone from } \\
\text { another culture, I deal successfully with ambiguity and } \\
\text { differences. } \\
\text { 3. I think along the lines of live and let live even if it goes } \\
\text { against my core values. }\end{array}$ & $\begin{array}{l}\text { Adler, 1975; Deng and } \\
\text { Gibson, 2008; Earley et } \\
\text { al., 2006; Fritz and } \\
\text { Mollenbert, 2001; } \\
\text { Furnham and Bochner, } \\
\text { 1982; Graen et al., 1977; } \\
\text { Harris and Moran, 1991; } \\
\text { Oberg, 1960; Pilot Study } \\
\text { Analysis; Ruben, 1989. }\end{array}$ \\
\hline \multicolumn{2}{|l|}{ Cultural Intelligence } \\
\hline $\begin{array}{l}\text { 1. I can easily integrate myself into a new culture. } \\
\text { 2. When it comes to knowing how to cope with cultural } \\
\text { diversity, others say I am very knowledgeable. } \\
\text { 3. I look for cultural cues when I encounter those from } \\
\text { another culture. } \\
\text { 4. I see myself has having a lot of cultural expertise. }\end{array}$ & $\begin{array}{l}\text { Earley, 2006; Graen et al., } \\
\text { 1997; Triandis, } 2006 .\end{array}$ \\
\hline \multicolumn{2}{|l|}{ Education } \\
\hline $\begin{array}{l}\text { 1. I try to learn the basics of the languages I encounter. } \\
\text { 2. I consider myself to be well educated. } \\
\text { 3. I actively keep abreast of global issues and concerns. } \\
\text { 4. I have many hobbies and interests. }\end{array}$ & $\begin{array}{l}\text { Earley et al., 2006; Graen } \\
\text { and Hui, 1999; Pilot Study } \\
\text { Analysis. }\end{array}$ \\
\hline \multicolumn{2}{|l|}{ Emotional Resilience } \\
\hline $\begin{array}{l}\text { 1. I am intimidated by new experiences. } R \\
\text { 2. I am not easily offended. }\end{array}$ & $\begin{array}{l}\text { Graen and Hui, 1999, Pilot } \\
\text { Study Analysis. }\end{array}$ \\
\hline \multicolumn{2}{|l|}{ Empathy } \\
\hline 1. I empathize with people from other cultures. & $\begin{array}{l}\text { Black and Gregersen, } \\
\text { 1999; Graen } \text { et al., 1997; } \\
\text { Kealey and Rubin, 1973; } \\
\text { Pilot Study Analysis. }\end{array}$ \\
\hline
\end{tabular}




\begin{tabular}{|c|c|}
\hline Survey Questions & Source \\
\hline \multicolumn{2}{|l|}{ Experience } \\
\hline $\begin{array}{l}\text { 1. Culture shock has been a difficult challenge for me. } R \\
\text { 2. I want to experience living in many cultures. }\end{array}$ & $\begin{array}{l}\text { Adler, 1975; Black and } \\
\text { Gregersen, 1999; Graen et } \\
\text { al., 1997; Hawkes and } \\
\text { Kealey, 1980;, Maddox, } \\
\text { 1993; Oberg, 1960; Pilot } \\
\text { Study Analysis. }\end{array}$ \\
\hline \multicolumn{2}{|l|}{ Facilitator } \\
\hline $\begin{array}{l}\text { 1. I see myself as a change agent, helping others with } \\
\text { change. } \\
\text { 2. I often play a liaison role bringing those from other } \\
\text { cultures together. }\end{array}$ & $\begin{array}{l}\text { Graen and Hui, 1999; } \\
\text { Graen } \text { et al., 1997; Graen } \\
\text { et al., 2004; Kealey and } \\
\text { Rubin, 1973; Pilot Study } \\
\text { Analysis. }\end{array}$ \\
\hline \multicolumn{2}{|l|}{ Flexibility } \\
\hline $\begin{array}{l}\text { 1. I am flexible, not predictable. } \\
\text { 2. I can easily 'go with the flow' in cultural situations. } \\
\text { 3. I am a good actor, not reserved. } \\
\text { 4. I am willing to take risks } \\
\text { 5. My partner/family is supportive of my career and has } \\
\text { an open attitude toward other cultures. } \\
\text { 6. My family is very flexible with my job relocations; } \\
\text { they do not 'hold me back' from opportunities. } \\
\text { 7. I can operate/live in a state of flux and confusion. }\end{array}$ & $\begin{array}{l}\text { Bird and Stevens, 2003; } \\
\text { 2006; Graen et al., 1999; } \\
\text { Graen and Hui, 1999; } \\
\text { Harris and Moran, 1991; } \\
\text { Lobel, 1990; Pilot Study } \\
\text { Analysis. }\end{array}$ \\
\hline \multicolumn{2}{|l|}{ Motivation } \\
\hline $\begin{array}{l}\text { 1. I am involved, not indifferent. } \\
\text { 2. I tend to extend my visits home as long as possible. } \mathrm{R} \\
\text { 3. I am sometimes reluctant to return abroad after a home } \\
\text { visit. R } \\
\text { 4. When on assignment I tend to look for any opportunity } \\
\text { to return home for a visit. } \mathrm{R} \\
\text { 5. I look forward to the end on an assignment so I can } \\
\text { return home. } \mathrm{R} \\
\text { 6. I am energized, not lethargic. }\end{array}$ & $\begin{array}{l}\text { Earley et al., 2006; Graen } \\
\text { et al., 1997; Graen } \text { et al., } \\
\text { 2004; Graen and Hui, } \\
\text { 1999; Harris and Moran, } \\
\text { 1991; Lobel, 1990; Pilot } \\
\text { Study Analysis. }\end{array}$ \\
\hline \multicolumn{2}{|l|}{\begin{tabular}{|l} 
Non-Judgmental \\
\end{tabular}} \\
\hline $\begin{array}{l}\text { 1. I never assume to understand a new culture. } \\
\text { 2. I sometimes think my (native) culture is superior to } \\
\text { other cultures. R }\end{array}$ & $\begin{array}{l}\text { Black and Gregersen, } \\
\text { 1999; Graen } \text { et al., 1997; } \\
\text { Graen et al., 2004; Graen } \\
\text { and Hui, 1999; Pilot Study } \\
\text { Analysis. }\end{array}$ \\
\hline
\end{tabular}




\begin{tabular}{|c|c|}
\hline Survey Questions & Source \\
\hline \multicolumn{2}{|l|}{ Observant } \\
\hline $\begin{array}{l}\text { 1. I tend to be inquisitive and research many topics. } \\
\text { 2. I tend to see cultures in groupings, e.g. Western, } \\
\text { Oriental and African. } R \\
\text { 3. I am confident in my ability to interpret cultural } \\
\text { behavioural cues. }\end{array}$ & $\begin{array}{l}\text { Earley et al., 2006; Graen } \\
\text { et al., 1997; Graen et al., } \\
\text { 2004; Graen and Hui, } \\
\text { 1999; Pilot Study } \\
\text { Analysis. }\end{array}$ \\
\hline \multicolumn{2}{|l|}{ Open } \\
\hline $\begin{array}{l}\text { 1. I prefer to work with people who are technically very } \\
\text { competent rather than those from a different culture. } \mathrm{R} \\
\text { 2. I would rather work with someone who is from a } \\
\text { culture very different from my own culture. } \\
\text { 3. I have friends from many cultural backgrounds. }\end{array}$ & $\begin{array}{l}\text { Black and Gregersen, } \\
\text { 1999; Earley et al., 2006; } \\
\text { Graen et al., 19971 Kealey } \\
\text { et al., 2006; Oberg, 1960; } \\
\text { Rubin, 1989, Pilot Study } \\
\text { Analysis. }\end{array}$ \\
\hline \multicolumn{2}{|l|}{ Optimistic } \\
\hline $\begin{array}{l}\text { 1. People are all basically the same, no matter where they } \\
\text { are from. }\end{array}$ & $\begin{array}{l}\text { Maddox, 1993; Oberg, } \\
\text { 1960; Pilot Study } \\
\text { Analysis; Trompenaars } \\
\text { and Hampden-Turner, } \\
1998 .\end{array}$ \\
\hline \multicolumn{2}{|l|}{ Personal Autonomy } \\
\hline $\begin{array}{l}\text { 1. I feel I am in control of my life and career. } \\
\text { 2. I accept responsibility for my life/career decisions. }\end{array}$ & $\begin{array}{l}\text { Graen } \text { et al., 1997; Graen } \\
\text { et al., 2004; Graen and } \\
\text { Hui, 1999; Pilot Study } \\
\text { Analysis. }\end{array}$ \\
\hline \multicolumn{2}{|l|}{ Respectful } \\
\hline $\begin{array}{l}\text { 1. When I have to meet strangers from another culture, I } \\
\text { carefully plan my conversation in advance. } \\
\text { 2. I approach new cultures with caution. } \\
\text { 3. I plan what I say when I am with a person from a } \\
\text { different culture. } \\
\text { 4. Generalizations are often desirable when dealing with } \\
\text { cultural differences. } \mathrm{R} \\
\text { 5. I tend to become somewhat formal in culturally } \\
\text { ambiguous situations. } \\
\text { 6. Stereotyping helps me view others in some cultural } \\
\text { situations. R }\end{array}$ & $\begin{array}{l}\text { Graen } \text { et al., 1997; Graen } \\
\text { et al., 2004; Graen and } \\
\text { Hui, 1999; Pilot Study } \\
\text { Analysis. }\end{array}$ \\
\hline
\end{tabular}




\begin{tabular}{|c|c|}
\hline Survey Questions & Source \\
\hline \multicolumn{2}{|l|}{ Strategic } \\
\hline $\begin{array}{l}\text { 1. I set clear goals before I start working with others from } \\
\text { different cultures. } \\
\text { 2. I always have a Plan B as an alternative plan in case } \\
\text { things do not work out as anticipated. } \\
\text { 3. I intentionally seek out foreign work assignments. } \\
\text { 4. I consider myself to be very sensible and not ruled by } \\
\text { my emotions. } \\
\text { 5. I change the way I interact depending on the cultural } \\
\text { backgrounds of those around me. }\end{array}$ & $\begin{array}{l}\text { Earley et al., 2006; Graen } \\
\text { et al., 1997; Graen et al., } \\
\text { 2004; Graen and Hui, } \\
\text { 1999; Pilot Study } \\
\text { Analysis. }\end{array}$ \\
\hline \multicolumn{2}{|l|}{ Expatriate Success } \\
\hline $\begin{array}{l}\text { 1. Number of overseas jobs. } \\
\text { 2. Number of completed overseas jobs } \\
\text { 3. Number of times you returned home early by choice. } \\
\text { 4. Number of times you returned home early due to issues } \\
\text { beyond your control. } \\
\text { 5. Do you see yourself as a successful expatriate? } \\
\text { 6. Was returning home a difficult transition? }\end{array}$ & $\begin{array}{l}\text { Black and Gregersen, } \\
\text { 1999; Graen et al., 1997; } \\
\text { Hawkes and Kealey, 1980, } \\
\text { Pilot Study Analysis, } \\
\text { Redden, 1975, Sims and } \\
\text { Schraeder, 2004. }\end{array}$ \\
\hline
\end{tabular}

Note: Items that were reverse scored are labeled with an "R".

The next steps in the methodology involve the activities pertaining to the research survey and are presented in the following section.

\subsubsection{Step 1 - Survey}

The first step in the methodology involved the various activities associated with the research survey itself including building the survey, identifying the sample, administering or distributing the survey, and gathering the responses.

\subsubsection{Survey Building}

The first step in the methodology involved building the research survey. A self-reporting survey, the most common data collection method, was used (Stone, 1978). While self- 
reporting may be seen to include bias or be perceived as self-serving (Buhrmester, Furman, Wittenbert and Reis, 1988), a recent study found that self-views do matter (Swann et al., 2007) based on the impressive relationships found between social outcomes and self-views.

The survey was built electronically using QuestionPro, an internet based survey provider. This facilitated the creation, distribution and response gathering activities. The survey used a seven-point Likert scale for responses (Likert, 1932), with an agreement style ranging from strongly agree to strongly disagree. A seven point, instead of a five point, Likert scale was selected to achieve a more specific data set with which to analyze and determine the various levels of transcultural ability. The survey began with a statement of purpose, then provided the demographic questions and questions pertaining to expatriate success. This section was then followed with the sixty questions identified from the literature review and pilot study.

In order to finalize the survey build and to ensure clarity and straightforwardness of the questions, the survey was pre-tested. The survey was completed by ten people for this pre-test to ensure that it was designed and built accurately and also that it took approximately twenty minutes to complete. The pre-test feedback was analyzed and all required modifications were made to the survey prior to widespread distribution and use. These modifications involved text edits to eliminate perceived ambiguities and to ensure that the statement questions were clear and straightforward. These changes did not change the substance of the questions nor their order. 


\subsubsection{Participant Sample}

Participants for this research were sourced using three methods. The first method involved contacting Human Resource (HR) departments of organizations that regularly send their employees on foreign work assignments. The second method identified expatriates and repatriates, and contacting them directly to invite them to complete the on-line questionnaire. The third method involved providing paper copies of the survey to organizations and individuals who did not have access to the on-line survey. While any of these methods could have resulted in participants that were not appropriate, the survey also included a question that confirmed participant suitability in the form of a dichotomous yes/no question asking the participant if they have foreign work experience.

The HR departments involved in the participant identification process were from organizations that operate internationally. They represented investment firms, engineering and technology firms, associations for overseas workers (for example, the Canadian Chambers of Commerce in various Asian countries were involved) and a selection of branches from Canadian Government departments. These HR departments, or another suitable representative, were asked to participate in the research by providing their current and past overseas employees or members with the necessary information to participate in the survey.

The second method of sourcing participants was direct contact with individuals who are on foreign work assignments and others who have completed such work. This was done 
through snowball sampling; participants contacted other people they know who are/were working in a foreign location. This method was selected as it would likely provide access to qualified individuals, as they are being peer selected by other expatriates and repatriates. The lead researcher has a database of many expatriates/repatriates that has been collected over an extensive career of international work. This database led to the identification of the individuals that were interviewed in the pilot study. The people in the database were contacted with a request to participate in the survey and to contact their network of other expatriates and repatriates in order to request that they also complete the survey.

The third method, using a paper copy of the survey, was necessary due to the security policies and procedures of some firms that may have prevented participants from accessing the on-line survey site. Additionally, several participants requested a paper copy of the survey because of the unreliability of the internet in some locations. Paper copies were distributed to participating organizations and to individuals for manual completion of the survey.

The sample target audience was focused on individuals with a Western upbringing (e.g. those born and raised in Canada or the United States).

\subsubsection{Survey Responses}

The final activity in the survey was the generation and reception of the survey responses. The quality of received data is highly important with factor analysis (Comrey, 1988). 
Factor analysis is often performed with large sample sizes, however the literature in this area has been analyzed for the impact of sample size on factor recovery (MacCallum, Widaman, Zhang and Hong, 1999; Veilicer and Fava, 1998). These researchers concluded that there are no absolute thresholds for sample size minimums, only rules of thumb. Along these lines, it is recommended that 5-10 participants per variable be used (Floyd and Widaman, 1995) and it is suggested that 200 participants is suitable for up to 40 variables (Comrey, 1988). Therefore, a sample size of 200 was selected to support the seventeen components of transcultural ability.

The researcher was provided with completed paper copies of the survey from various firms and individuals that did not have access to the survey on-line. The researcher entered these responses into the on-line survey and reviewed the entries to ensure data accuracy and completeness.

As the survey questions were provided on-line with the response data entered directly into QuestionPro, the researcher monitored the participant count and determined when the target of 200 complete response sets was reached. After accounting for spoiled and incomplete survey response sets, a total of 285 response sets was actually required to reach the target of 200 complete response sets. The data from the complete response sets was then downloaded from the QuestionPro Web site into the SPSS statistical application software for analysis. The next step in the methodology involves developing the transcultural scale. 


\subsubsection{Step 2-Developing the Transcultural Scale}

The second step in the methodology involved the activities associated with analyzing the data and developing the TMS. The analysis activities treated all questions as separate items, not grouped by component. This was to allow flexibility in the grouping of items during factor analysis and to prevent the components from guiding the study.

\subsubsection{Initial Data Reduction}

The analysis activities began with correlation analysis to understand the item relationships (Cronbach and Meehl, 1955). This analysis reduces multi-collinearity; the occurrence of items with multiple correlations (Freund and Minton, 1979). That is, when a correlation between two items is very high, with 1 signifying an exact equal relationship (Anderson, Sweeney and Williams, 1996), as highly correlated items ( $r>0.900)$ may be measuring the same phenomenon (Tabachnick and Fidell (2001).

\subsubsection{Splitting the Data}

The sample ( $\mathrm{n}=200)$ was randomly split in half (Stevens, 2009; Yoo and Chon, 2008). The random selection minimized any selection bias and uniqueness between the data sets. The splitting provided two files of 100 data records. One half of the data records, referred to as data set $1(n=100)$, was used with EFA for the initial analysis activities to develop the TMS instrument. The second half of the data, referred to as data set 2 ( $\mathrm{n}=100$ ), was used for confirming the TMS instrument with CFA, and predictive validity analysis with regression (DeVellis, 1991). 


\subsubsection{Analyze with Exploratory Factor Analysis}

Factor analysis, beginning with exploratory factor analysis, was the scale development process used for this research. This tool was selected based on its strong support for use in scale development (Clark and Watson, 1995; Cronbach and Meehl, 1955; Comrey, 1988; Floyd and Widaman, 1995; Han and Ki, 2010; Hinkin, 1995; Loevinger, 1957;

Reise, Waller and Comrey, 2000; Wood, Linley, Maltby, Baliousis and Joseph, 2008). Factor analysis groups the data into factors that logically interpret the patterns and relationships in the data (Schilderinch, 1977). Interpretation of the results through loadings, which are component-variable correlations, provides for the identification and removal of insignificant data, thereby reducing the items under analysis (Stevens, 2009). Such reductions produce a cleaner factor structure and a better fit of the data (Costello and Osborne, 2005). A cut-off point was used to determine if an item is retained or removed from the analysis. This is an iterative process with oblique selected as the rotation method, as it allows the manifest variables to co-vary to the greatest extent possible in order to find the underlying structure of the data (Gerbing and Hamilton, 1996).

\subsubsection{Develop a Transcultural Measurement Scale}

This stage involved the initial generation of the TMS from the results of the exploratory factor analysis process. The scale items were modified based on the factor analysis results. Changes to the original items included removing questions due to insignificant loadings in the factor analysis results. 


\subsubsection{Analyze with Confirmatory Factor Analysis}

Confirmatory factor analysis was used to confirm the structure of the TMS. This tool, following exploratory factor analysis, has also been used by many researchers in scale development (Gerbing and Hamilton, 1996; Han and Ki, 2010; Yoo and Chon, 2008; Zhang, Bi and $\mathrm{Yu}, 20100$ ). The analysis used data set 2 to confirm the results of the factor structure provided by the exploratory factor analysis. The factor structure is considered confirmed if it is supported with a different set of data (Stevens, 2009).

The third and final step in the methodology involved the validation of the instrument and is presented in the following section.

\subsubsection{Step 3 - Validation}

The final step of the analysis validated the TMS. Predictive validity testing with regression analysis was used to validate the predictive power of the TMS.

\subsubsection{Predictive Validity of the TMS}

The final analysis of the research results involved regression analysis. This activity focused on determining the links between the predictor (TMS) and outcome variables in order to confirm the predictability of the scale (Cronbach and Meehl, 1955; Swann et al., 2007). Regression analysis was employed for this final measure of the TMS tool with a 
dependent variable developed for expatriate success and an independent variable created from the confirmatory factor analysis structure.

This chapter has presented the research methodology for the development of the TMS.

The preparations were discussed along with the research steps, which included preparing the research survey, developing the TMS with factor analysis and validating the measure to ensure its predictive power. The following chapter in this dissertation presents the data analysis and results of the research described in this chapter. 


\section{DATA ANALYSIS AND RESULTS}

This chapter is presented in nine sections. Section 6.1 discusses the data preparation that was required prior to statistical analysis. Section 6.2 presents the descriptive data analysis of the research. Section 6.3 provides the correlation analysis of the data. Section 6.4 provides the results of the exploratory factor analysis (EFA), with Section 6.5 providing the confirmatory factor analysis (CFA). Section 6.6 presents the confirmed TMS. Section 6.7 presents the predictive validity analysis and Section 6.8 provides a summary of the data analysis and results. To conclude this chapter, Section 6.9 presents the validated Transcultural Measurement Scale (TMS).

\subsection{Data Preparation}

This section provides a discussion of the various activities that were undertaken to prepare the data for the statistical analysis procedures. These data preparation activities include data cleansing and data splitting.

\subsubsection{Data Cleansing}

Several activities were required to clean and prepare the data for statistical analysis. The survey data consisted of 285 records. Of these, 85 were not usable: 50 records were without data due to technical difficulties from transmission speed variations and internet provider outages while the respondents were completing the survey, and 35 records were without data. These 85 records were identified and removed. 200 records $(n=200)$ remained after data cleansing and were used in the data analysis. 


\subsubsection{Data Splitting}

The sample data $(\mathrm{n}=200)$ was randomly split in half in preparation for the data analysis process and procedures, creating data set $1(n=100)$ and data set $2(n=100)$. This provided three data sets (full set, data set 1 , and data set 2) for the analysis activities. All three data sets were used in the descriptive and frequency data analysis. The full data set was used for correlation analysis. Data set 1 was used for EFA, and data set 2 was used for CFA and for the predictive validity analysis with regression.

The following section presents the results of the descriptive, frequency and statistical significance analysis of the participant data.

\subsection{Descriptive and Frequency Data Analysis}

This section presents a descriptive and frequency statistical analysis of the demographic research data for the full data set $(n=200)$. The frequency analysis is also presented for data sets $1(n=100)$ and $2(n=100)$, along with a comparison of the results between these two data sets and the full data set. A discussion of similarities and any significant differences between the three data sets follows. This section also presents an analysis of the statistical significance between data set 1 and 2 . 


\subsubsection{Descriptive Statistics}

Data on two characteristics were collected with continuous variables that included the number (of foreign assignments) that were not completed both by choice and due to factors beyond the respondent's control. The descriptive statistics for these variables are presented in Table 8, and include measures of mean, standard deviation, variance, skewness and kurtosis, and standard error of these variables, as appropriate. This analysis was completed on the full data set $(n=200)$.

\section{Table 8: Descriptive Statistics for Continuous Variables}

\begin{tabular}{|l|c|c|c|c|c|c|c|c|c|}
\hline Variables & n & Mean & $\begin{array}{c}\text { Std. } \\
\text { Error } \\
\text { of } \\
\text { Mean }\end{array}$ & $\begin{array}{c}\text { Std. } \\
\text { Dev. }\end{array}$ & Var. & Skew. & $\begin{array}{c}\text { Std. } \\
\text { Error of } \\
\text { Skew. }\end{array}$ & Kurt. & $\begin{array}{c}\text { Std. } \\
\text { Error } \\
\text { of } \\
\text { Kurt. }\end{array}$ \\
\hline \# Returned By Choice & 200 & 1.210 & .033 & .473 & .224 & 2.577 & .172 & 7.808 & .342 \\
\hline \# Returned Not Choice & 200 & 1.090 & .023 & .320 & .102 & 3.771 & .172 & 14.844 & .342 \\
\hline
\end{tabular}

The low mean for the two variables reflect that returning home early, whether by choice or not by choice, is not a common occurrence with the sample population.

Skewness and kurtosis scores provide information about the normal distribution of the data, a requirement for statistical analysis (Muthen and Kaplan, 1985; Zikmund, 2003). It has been suggested that absolute values of skewness greater than 3.0 and of kurtosis greater than 10 indicates a problem with the normal distribution of the data (Hair, Anderson, Tatham and Black, 2002; Kline, 2005). The standard error for skewness is equal for all variables, as is the standard error for kurtosis. The skewness and kurtosis values for the items in this research are within the non-problematic range and indicate 
that the distribution is relatively normal with the exception of one item, the variable "\# Returned Not Choice."

An analysis of the exception item explains the problematic values. The exception item, “\# Returned Not Choice," received a skewness value of 3.771 and a kurtosis value of 14.844, both problematic values with respect to normal distribution. This item refers to the number of times an expatriate returned to the home country due to a situation out of their control. This is a rare occurrence as it signifies a potential job loss or possibly a firm closing its foreign office. The mean score for this variable at 1.09 , with a very low standard error of .023 , indicates that most respondents provided the same answer to this question. Even though it was not expected that many respondents would have been forced to leave their jobs, the variable was included so respondents could stipulate about their reason for returning home early. It is not surprising that this value is problematic in producing an exceptional thickness to one side of the distribution tail (Ko and Jun, 2009) resulting in a non-symmetrical distribution curve (Zigmund, 2003).

The next section provides the results of the frequency analysis of the demographic data provided by the participants.

\subsubsection{Frequency Statistics}

The frequency statistics provide information that can be used to build a profile of the survey sample. This section contains the frequency statistic tables and discussions for 
age, gender, education and for the fields pertaining to overseas jobs. The frequency statistics for age are presented in Table 9.

Table 9: Frequency Statistics for Age

\begin{tabular}{|c|c|c|}
\hline Age Selections & $\begin{array}{c}\text { Frequency } \\
\mathbf{N = 2 0 0}\end{array}$ & Percent \\
\hline Below 25 & 2 & $1 \%$ \\
\hline $26-35$ & 18 & $9 \%$ \\
\hline $36-45$ & 70 & $35 \%$ \\
\hline $46-55$ & 70 & $35 \%$ \\
\hline Over 55 & 40 & $20 \%$ \\
\hline
\end{tabular}

Seventy percent of participants were between the ages of 36 and 55, with twenty percent over 55 . The respondent profile shows only $10 \%$ under the age of 35 . This distribution is very close to the expatriate population at all age levels (Brookfield, 2010), which is presented in Table 10. The expatriate and the survey populations both find the bulk of the expatriates in the $30-50$ age range and both have approximately $20 \%$ over 50 years of age. It should be noted that the survey was not distributed specifically by age.

\section{Table 10: Expatriate Population}

\begin{tabular}{|c|c|}
\hline Age Selections & Percent \\
\hline $20-29$ & $10 \%$ \\
\hline $30-39$ & $32 \%$ \\
\hline $40-49$ & $40 \%$ \\
\hline $50-59$ & $16 \%$ \\
\hline 60 and over & $2 \%$ \\
\hline
\end{tabular}

The frequency statistics for gender are presented in Table 11 . 
Table 11: Frequency Statistics for Gender

\begin{tabular}{|c|c|c|}
\hline Gender Selections & $\begin{array}{c}\text { Frequency } \\
\mathbf{N = 2 0 0}\end{array}$ & Percent \\
\hline Female & 68 & $34 \%$ \\
\hline Male & 132 & $66 \%$ \\
\hline
\end{tabular}

The majority of the respondents were male. The frequency results for gender identify a one-third / two-third split between female and male respondents respectively. This is in contrast to the 2009 expatriate population that was made up of only $17 \%$ women, down from $20 \%$ in 2008, and at its lowest level since 2001 (Brookfield, 2010). The frequency statistics for education are presented in Table 12.

Table 12: Frequency Statistics for Highest Level of Education

\begin{tabular}{|l|c|c|}
\hline \multicolumn{1}{|c|}{ Highest Level of Education Selections } & $\begin{array}{c}\text { Frequency } \\
\mathbf{N = 2 0 0}\end{array}$ & Percent \\
\hline High School & 14 & $7.0 \%$ \\
\hline Some University & 1 & $0.5 \%$ \\
\hline Undergraduate & 92 & $46.0 \%$ \\
\hline Masters & 49 & $24.5 \%$ \\
\hline PhD & 8 & $4.0 \%$ \\
\hline $\begin{array}{l}\text { Professional (MD, Nurse, Engineer, Lawyer, } \\
\text { CA) }\end{array}$ & 24 & $12.0 \%$ \\
\hline College (including Trade School) & 12 & $6.0 \%$ \\
\hline
\end{tabular}

The participants were highly educated with $93 \%$ having continued their education postHigh-School, and nearly one quarter held a Master's degree. A high $87 \%$ of the sample attended university and $40.5 \%$ completed a graduate degree or received a professional designation. Only $6 \%$ attended college or completed their education at trade school. The 
large percentage of highly educated expatriates is in line with the trend that expatriates, especially those from developed countries, tend to be highly educated (Just Landed, 2011).

The above frequency statistics provide a participant profile that describes the average participant as a male over 36 . He is highly educated with a strong likelihood of a degree or professional designation beyond a Bachelor's degree.

There were six items in the survey asking about the participant's overseas job experience. These items required the participants to select the number of overseas jobs they had undertaken, the number of overseas jobs they had completed, and the number of times they had returned early from an overseas job, either by choice, or by necessity (i.e., factors outside of their control). Two of these six items asked whether the participants saw themselves as successful expatriates and whether or not they found the repatriation process to be difficult.

The following table presents the frequency statistics for the number of overseas jobs. 
Table 13: Frequency Statistics for Number of Overseas Jobs

\begin{tabular}{|c|c|c|c|}
\hline Overseas Jobs Variable & Response & $\begin{array}{c}\text { Frequency } \\
\mathbf{n = 2 0 0}\end{array}$ & Percentage \\
\hline \# of overseas jobs & 0 & 0 & $0.0 \%$ \\
\hline \multirow{3}{*}{} & 1 & 43 & $21.5 \%$ \\
\cline { 2 - 4 } & 2 & 50 & $25.0 \%$ \\
\cline { 2 - 4 } & 3 & 51 & $25.5 \%$ \\
\cline { 2 - 4 } & 4 & 34 & $17.0 \%$ \\
\cline { 2 - 4 } & $4+$ & 22 & $11.0 \%$ \\
\hline
\end{tabular}

The frequency of overseas jobs is relatively tight between one and three jobs, ranging from $21.5 \%$ to $25.5 \%$. The overall sample provides a fairly wide range of expatriate experience. Seventeen percent indicated four overseas jobs completed and eleven percent of the participants responded with more than four jobs, which provides for twenty-eight percent of the respondents being highly experienced in overseas assignments.

Table 14 presents the frequency statistics for the number of overseas jobs completed.

Table 14: Frequency Statistics for Number of Overseas Jobs Completed

\begin{tabular}{|c|c|c|c|}
\hline Overseas Jobs Variable & Response & $\begin{array}{c}\text { Frequency } \\
\mathbf{n = 2 0 0}\end{array}$ & Percentage \\
\hline \# of overseas jobs completed & 0 & 22 & $11.0 \%$ \\
\hline \multirow{3}{*}{} & 1 & 37 & $18.5 \%$ \\
\cline { 2 - 4 } & 2 & 51 & $25.5 \%$ \\
\cline { 2 - 4 } & 3 & 46 & $23.0 \%$ \\
\cline { 2 - 4 } & 4 & 22 & $11.0 \%$ \\
\cline { 2 - 4 } & $4+$ & 22 & $11.0 \%$ \\
\hline
\end{tabular}


The frequency statistics for the number of overseas jobs completed is in line with the number of overseas jobs, taking into account that some respondents were on an overseas job when they participated in the survey (i.e., it is important to note that all eleven percent who reported no overseas jobs completed were deployed overseas at the time of the survey). Nearly half the sample (48.5\%) had completed two or three overseas assignments.

Table 15 presents the frequency statistics for the number of times the respondent returned home early, by choice, from an overseas job.

Table 15: Frequency Statistics for Number Returned Early by Choice

\begin{tabular}{|c|c|c|c|}
\hline Overseas Jobs Variable & Response & $\begin{array}{c}\text { Frequency } \\
\mathbf{n = 2 0 0}\end{array}$ & Percentage \\
\hline \# returned early by choice & 0 & 164 & $82.0 \%$ \\
\hline \multirow{3}{*}{} & 1 & 32 & $16.0 \%$ \\
\cline { 2 - 4 } & 2 & 3 & $1.5 \%$ \\
\cline { 2 - 4 } & 3 & 1 & $0.5 \%$ \\
\hline
\end{tabular}

An overwhelming number of respondents $(82 \%)$ did not return home early from an assignment. At 18\%, a small percentage of respondents indicated that they returned home early from a job by their own choice. The vast majority of these, at $16 \%$, indicated that they returned home early from a single assignment. Expatriate failure rates range between 10\%-80\% depending on the country and industry (Okpara and Kabongo, 2011); however a failure rate of $30 \%-40 \%$ is often cited (Black and Gregersen, 1999; Black and Gregersen, 1999; Vogel et al., 2008). While there is controversy regarding empirical 
evidence of expatriate failure (Harzing, 2002), a 2009 study of US multinational corporations reported that $17 \%$ of expatriates left the company during assignments that year (Brookfield, 2010). This is very much in line with the survey statistics.

Table 16 presents the frequency statistics for the number of times the respondent returned home early from an overseas job not by choice.

Table 16: Frequency Statistics for Number Returned Early Not By Choice

\begin{tabular}{|c|c|c|c|}
\hline Overseas Jobs Variable & Response & $\begin{array}{c}\text { Frequency } \\
\mathbf{n = 2 0 0}\end{array}$ & Percentage \\
\hline $\begin{array}{c}\text { \# returned early not by } \\
\text { choice }\end{array}$ & 0 & 184 & $92.0 \%$ \\
\hline & 1 & 14 & $7.0 \%$ \\
\cline { 2 - 4 } & 2 & 2 & $1.0 \%$ \\
\hline
\end{tabular}

Only $8 \%$ of respondents indicated that they returned home early, not by choice. This means that a situation beyond the control of the expatriate forced her/him to return home early. Examples of this would be a medical or family emergency, political or civic strife in the foreign country or an organizational change that terminated the position overseas.

Table 17 presents the frequency statistics for seeing oneself as a successful expatriate. 
Table 17: Frequency Statistics for Seeing Oneself as a Successful Expatriate

\begin{tabular}{|c|c|c|}
\hline $\begin{array}{c}\text { Seeing Oneself as a Successful } \\
\text { Expatriate Selection }\end{array}$ & $\begin{array}{c}\text { Frequency } \\
\mathbf{N = 2 0 0}\end{array}$ & Percent \\
\hline Yes & 162 & $\mathbf{8 1 . 0 \%}$ \\
\hline No & 38 & $19.0 \%$ \\
\hline
\end{tabular}

A high $81 \%$ of respondents see themselves as successful expatriates, with $19 \%$ seeing themselves as the contrary. This statistic is very close to the $17 \%$ of expatriates that returned home early (Brookfield, 2010), and is comparable to the $18 \%$ of survey participants that returned home early by choice. This suggests that there may be a possible relationship between returning home early and seeing oneself as an unsuccessful expatriate.

Table 18 presents the frequency statistics for finding repatriation difficult.

Table 18: Frequency Statistics for Repatriation Difficult

\begin{tabular}{|c|c|c|}
\hline Repatriation Difficult Selections & $\begin{array}{c}\text { Frequency } \\
\mathbf{N = 2 0 0}\end{array}$ & Percent \\
\hline Yes & 63 & $31.5 \%$ \\
\hline No & 130 & $65.0 \%$ \\
\hline Missing & 7 & $3.5 \%$ \\
\hline
\end{tabular}

While $31.5 \%$ of the survey respondents indicated that they experienced difficulty upon repatriation, the majority of respondents $(65 \%)$ did not experience any such difficulty when they returned home after an overseas job. The academic literature on repatriation 
describes high rates (25-50\%) of repatriates leaving their companies within the first year of repatriation (Black and Gregersen, 1999; Hurn, 2007; Lee and Liu, 2006). An empirical study by Brookfield (2010) found that $38 \%$ left their organization within the first year of returning from an overseas assignment and $23 \%$ left within 2 years of returning home (Brookfield, 2010). The $31.5 \%$ of survey participants finding repatriation difficult is in line with the expatriate population.

To summarize the overseas jobs variables, the majority of participants completed 2 or more overseas jobs. Only $18 \%$ of the respondents indicated that they returned home by choice from an overseas job. Additionally, $8 \%$ of the respondents returned home early out of necessity, not by choice. Eighty one percent of participants saw themselves as successful expatriates, while $31.5 \%$ found repatriation challenging.

The respondent profile describes the average participant as a Canadian male over 36 , highly educated and probably working in a senior management or professional role. It also includes completion of approximately two to three overseas jobs without any early returns, either by choice or by necessity, and includes a self-perception of being a successful expatriate without any difficulties upon repatriation.

\subsubsection{Comparing Frequency and Statistically Significant Statistics}

This section presents frequency and statistically significant statistics for data sets 1 and 2 . The frequency statistics are presented in a table format aligned with the frequency statistics for the sample data collected in this research (as provided in the previous 
section). The purpose of such a table is to allow the frequency statistics to be compared for similarities and differences between the data sets.

The frequency statistics for each data set are equal or similar within $5 \%$ for most variables. However, six fields have differences greater than $10 \%$ between the split data sets. It should be noted that the frequency differences between the data sets and the full sample data is $8 \%$ or less for all fields.

Table 19 presents and aligns the frequency statistics for the sample data and data sets 1 and 2.

\section{Table 19: Comparing Frequency Statistics}

\begin{tabular}{|c|c|c|c|c|c|c|}
\hline & $\begin{array}{c}\text { All Sample } \\
\text { Data } \\
\text { Frequency } \\
\mathbf{N = 2 0 0}\end{array}$ & $\%$ & $\begin{array}{c}\text { Data Set 1 } \\
\text { Frequency } \\
\mathbf{N}=\mathbf{1 0 0}\end{array}$ & $\begin{array}{c}\text { Data Set 2 } \\
\text { Frequency } \\
\mathbf{N = 1 0 0}\end{array}$ & $\%$ \\
\hline Age & 2 & $1 \%$ & 0 & $0 \%$ & 2 & $2 \%$ \\
\hline Below 25 & 18 & $9 \%$ & 12 & $12 \%$ & 6 & $6 \%$ \\
\hline $26-35$ & 70 & $35 \%$ & 29 & $29 \%$ & 41 & $41 \%$ \\
\hline $36-45$ & 70 & $35 \%$ & 40 & $40 \%$ & 30 & $30 \%$ \\
\hline $46-55$ & 40 & $20 \%$ & 19 & $19 \%$ & 21 & $21 \%$ \\
\hline Over 55 & & & & & & \\
\hline Gender & 68 & $34 \%$ & 40 & $40 \%$ & 28 & $28 \%$ \\
\hline Female & 132 & $66 \%$ & 60 & $60 \%$ & 72 & $72 \%$ \\
\hline Male & & & & & & \\
\hline & & & & & & \\
\hline Highest Level of & & & & & \\
\hline Education & 14 & $7 \%$ & 8 & $8 \%$ & 6 & $6 \%$ \\
\hline High School & 1 & $.5 \%$ & 1 & $1 \%$ & 0 & $0 \%$ \\
\hline Some University & 92 & $46 \%$ & 38 & $38 \%$ & 54 & $54 \%$ \\
\hline Undergrad & 49 & 24.5 & 23 & $23 \%$ & 26 & $26 \%$ \\
\hline Masters & & & & & \\
\hline
\end{tabular}




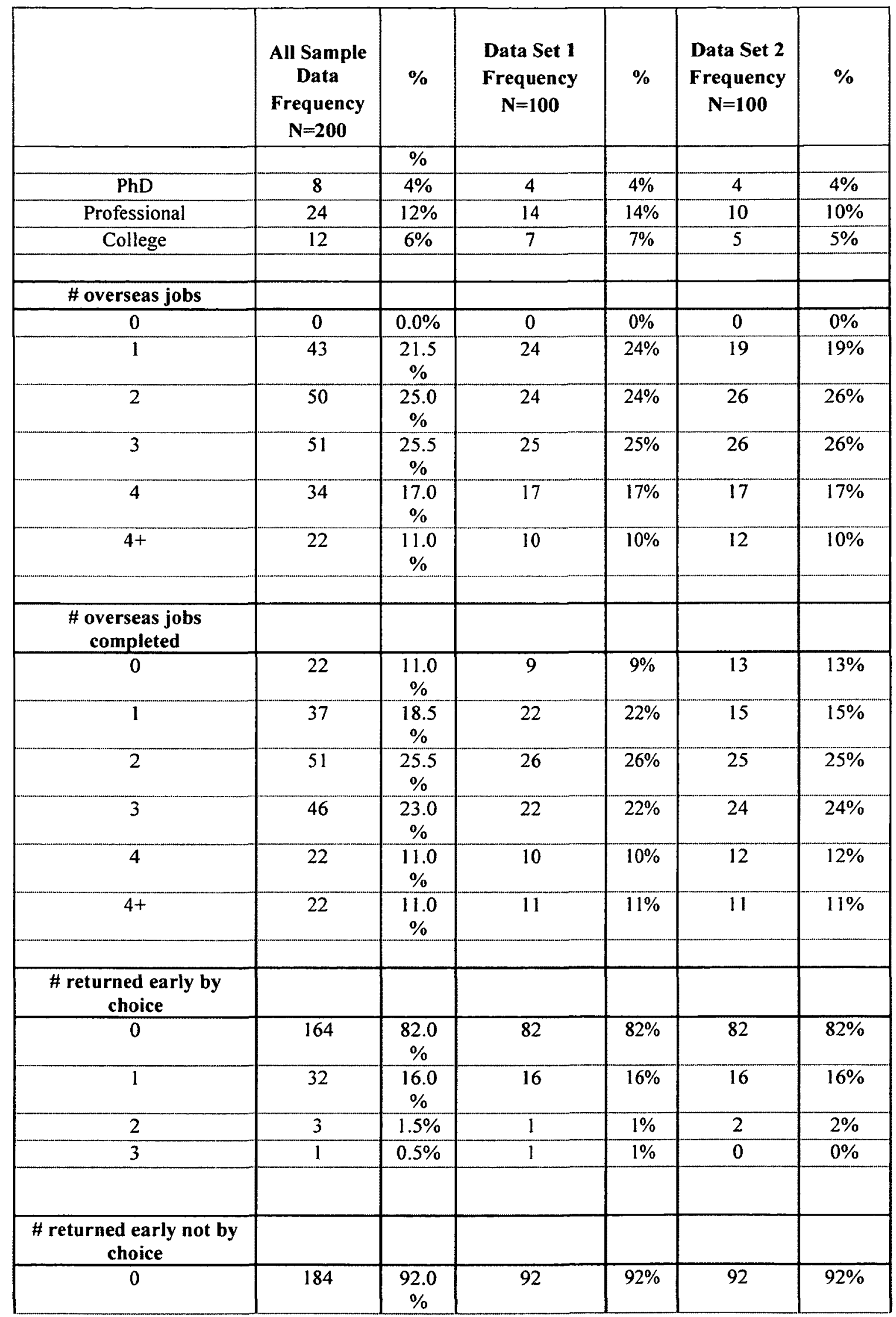




\begin{tabular}{|c|c|c|c|c|c|c|}
\hline & $\begin{array}{l}\text { All Sample } \\
\text { Data } \\
\text { Frequency } \\
\mathbf{N}=\mathbf{2 0 0}\end{array}$ & $\%$ & $\begin{array}{c}\text { Data Set } 1 \\
\text { Frequency } \\
\quad \mathbf{N}=100\end{array}$ & $\%$ & $\begin{array}{c}\text { Data Set } 2 \\
\text { Frequency } \\
\quad \mathrm{N}=100\end{array}$ & $\%$ \\
\hline 1 & 14 & $7.0 \%$ & 7 & $7 \%$ & 7 & $7 \%$ \\
\hline 2 & 2 & $1.0 \%$ & 1 & $1 \%$ & 1 & $1 \%$ \\
\hline \multicolumn{7}{|c|}{$\begin{array}{c}\text { See self as successful } \\
\text { expatriate }\end{array}$} \\
\hline Yes & 162 & $\begin{array}{c}81.0 \\
\%\end{array}$ & 80 & $80 \%$ & 82 & $82 \%$ \\
\hline No & 38 & $\begin{array}{c}19.0 \\
\% \\
\end{array}$ & 20 & $20 \%$ & 18 & $18 \%$ \\
\hline \multicolumn{7}{|c|}{ Repatriation Difficult } \\
\hline Yes & 63 & $\begin{array}{c}31.5 \\
\%\end{array}$ & 25 & $25 \%$ & 38 & $38 \%$ \\
\hline No & 130 & $\begin{array}{c}65.0 \\
\%\end{array}$ & 71 & $71 \%$ & 59 & $59 \%$ \\
\hline Missing & 7 & $3.5 \%$ & 4 & $4 \%$ & 3 & $3 \%$ \\
\hline
\end{tabular}

The nine demographic variables were analyzed for significant differences across the two data sets. The null hypothesis was that there is no difference or $\mathrm{H}_{0}$ : Data Set $1=$ Data Set 2. The alternate hypothesis was that there are significant differences or $\mathrm{H}_{1}$ : Data Set $1<$ $>$ Data Set 2.

This significance testing was evaluated by variable. As there was a mix of categorical and continuous variables: cross tab analysis was used with the categorical variables, and t-test analysis was used with the continuous variables. The null hypothesis was supported as the difference between the means of the variables in the data sets was not statistically significant for $\mathrm{p}<.05$. However, two variables were very close at .073 for gender and .052 for found repatriation difficult. It can be concluded that the random splitting of the full data set produced statistically similar data sets except for the gender and found 
repatriation difficult variables. There were slightly fewer respondents who reported finding repatriation difficult in data set 2 . The found repatriation difficult variable was used in the calculation of the dependent variable used in regression analysis with data set 2. Table 20 presents the analysis for statistically significant differences between data sets 1 and 2.

Table 20: Analyzing Data Sets 1 and 2 for Statistical Significance

\begin{tabular}{|c|c|c|c|c|}
\hline Cross-Tab Analysis & $\begin{array}{l}\text { Pearson } \\
\text { Chi Value }\end{array}$ & df & p-value & $\begin{array}{c}\text { Significant } \\
p<0.05\end{array}$ \\
\hline Gender & 3.209 & 1 & 0.073 & No \\
\hline $\begin{array}{l}\text { Highest Level of } \\
\text { Education }\end{array}$ & 46.061 & 50 & 0.632 & No \\
\hline $\begin{array}{l}\text { See oneself as a } \\
\text { successful expatriate }\end{array}$ & 0.13 & 1 & 0.718 & No \\
\hline $\begin{array}{l}\text { Found repatriation } \\
\text { difficult }\end{array}$ & 3.785 & 1 & 0.052 & No \\
\hline T-Test Analysis & t-value & df & Sig & $\begin{array}{l}\text { Significant } \\
\text { Sig }<0.05\end{array}$ \\
\hline Age & 0.302 & 198 & 0.701 & No \\
\hline \# expatriate jobs & -0.711 & 198 & 0.667 & No \\
\hline $\begin{array}{l}\text { \# expatriate jobs } \\
\text { completed }\end{array}$ & -0.24 & 198 & 0.695 & No \\
\hline \# left early by choice & 0.149 & 198 & 0.728 & No \\
\hline $\begin{array}{l}\text { \# left early not by } \\
\text { choice }\end{array}$ & 0 & 198 & 1 & No \\
\hline
\end{tabular}

The following section provides the correlation analysis that was performed with the research data. 


\subsection{Correlation Analysis}

An inter-item correlation matrix was run with the entire data set $(n=200)$ with all 60 items (questions) and is presented in the Inter-item Correlation Matrix (First Iteration) table of Appendix B. This analysis was included in the research to facilitate data reduction. While factor analysis also provides for data reduction, it was decided to perform this activity with an inter-item correlation matrix at the outset to provide a cleaner data set going into the factor analysis activities (Cronbach and Meehl, 1955; Hinkin, 1995). By reducing the variables prior to exploratory factor analysis, the number of iterations of this analysis was reduced, as a portion of the insignificant data had already been removed.

The inter-item correlation matrix was analyzed to identify items that were highly associated with each other (Zikmund, 2003). When a correlation between two items is very high, with 1 signifying an exactly equal relationship (Anderson et al., 1996), the items are both measuring and/or influenced by the same phenomenon. As both items are providing the same information, one of these items is redundant and can be removed. Tabachnick and Fidell (2001) stated that highly correlated variables ( $>0.900)$ may be measuring the same construct. Potential redundant variables could increase the likelihood of increased error due to these variables contributing very little to the explanation of variance. Therefore, all items with correlations were analyzed for such redundancies.

The inter-item correlation matrix was analyzed to identify items with high correlations of approximately .900 and higher. These high correlations, and their item labels, are grey- 
shaded in the Inter-item Correlation Matrix (First Iteration) table of Appendix B. The items with high correlations were further analyzed in order to determine the complexity of any multiple relationships. This was done to ensure that when items were selected for removal, the related item was retained. The correlation matrix was then re-run to determine if the problematic high correlation relationships were resolved.

Iterative runs of the inter-item correlation matrix were completed to facilitate the analysis. The iterative runs allowed items to be removed slowly, in stages, with the subsequent results providing information on relationships that continued to be, or were no longer, highly correlated.

In total, four iterations of the inter-item correlation matrix were run and a total of 14 items were removed from the data set. The final inter-item correlation matrix contains 46 items and can be found in the Inter-item Correlation Matrix (Final Iteration) table of Appendix B. The components with their corresponding abbreviations used in the matrix item labels can be found in Appendix C. Appendix D presents a summary of the results for each research items including an identification of items that were removed.

The next section will present the data analysis and results from the EFA process.

\subsection{Exploratory Factor Analysis}

Exploratory factor analysis (EFA) is the first step in the scale development process used for this research. It was selected on an analysis of the scale development literature (Clark 
and Watson, 1995; Cronbach and Meehl, 1955; Comrey, 1988; Floyd and Widaman, 1995; Han and Ki, 2010; Hinkin, 1995; Loevinger, 1957). Factor analysis provides a grouping of the data into factors and loadings that logically interpret the patterns and relationships in the data (Schilderinch, 1977). Interpretation of the results through loadings, which are component-variable correlations, provides for insignificant data to be identified and removed, thereby reducing the items under analysis (Stevens, 2009). Such reductions produce a cleaner factor structure and a better fit of the data (Costello and Osborne, 2005).

\subsubsection{Performing EFA}

EFA was performed on data set 1 . This data set contains 100 records that were randomly split from the original data set of 200 records. While varimax is the most common choice for rotation, oblique was selected as this method allows items to more freely correlate (Costello and Osborne, 2005; Netemeyer, Bearden and Sharma 2003; Stevens, 2009). Oblique rotation has been found to better reflect the underlying structure of the data and may produce higher loadings (Gerbing and Hamilton, 1996). An eigen value of greater than 1 was used as a cutoff for determining the number of factors retained in each iteration.

Stevens (2009) suggests that, for oblique rotation, both the factor structure matrix and the factor pattern matrix be assessed. The former contains the factor loadings; the latter indicates the importance of the items to their factor. With each of the iterations of EFA, the output factor structure matrix was reviewed and assessed to determine which items 
should be removed due to weak or insignificant loadings (Comrey, 1988; Costello and Osborne, 2005; Hair et al., 2002; Stevens, 2009; Tabachnick and Fidell, 2001; Van Der Veen and Song, 2010; Yoo and Chon, 2008). The factor structure was also used to confirm any removals. If there was no agreement between the matrices, the item was retained and re-assessed after subsequent iterations of EFA. Table 21 presents the three criteria for removing an item from EFA processing.

\section{Table 21: Criteria for Removing an Item during EFA}

\section{Criteria for Removing an Item during EFA}

1. Loadings of close to .500 or less (in all factors);

2. A lack of significance in any one factor; and

3. Loadings in more than one factor (cross-loadings) with a difference greater than two. The item with the lowest loading is removed.

Source: Comrey, 1988; Costello and Osborne, 2005; Hair et al., 2002; Stevens, 2009, Tabachnick and Fidell, 2001; Van Der Veen and Song, 2010; Yoo and Chon, 2008.

The next section presents the results of the EFA.

\subsubsection{EFA Results}

This section provides the results and a discussion of the EFA activities. EFA was an iterative process that provided for the identification of items that could be trimmed from the structure due to their weak loadings (Yoo and Chon, 2008). Nine iterations of analysis were performed and 15 items were eliminated, as they met the theoretically supported statistical criteria for insignificance. Table 22 contains the results of the final 
EFA run. The negative (-) sign in the load result indicates questions that were negatively phrased and the insignificant loadings are presented in grey.

Table 22: Final Results of Exploratory Factor Analysis

\begin{tabular}{|l|c|c|c|}
\hline \multicolumn{1}{|c|}{ Component } & Item & Factor 1 & Factor 2 \\
\hline Adventurous & AD_Q1 & $\mathbf{. 7 9 0}$ & .063 \\
& AD_Q19 & $\mathbf{. 9 4 7}$ & .247 \\
& AD_Q29 & $\mathbf{. 7 6 0}$ & .368 \\
& AD_Q40 & $\mathbf{. 8 6 2}$ & .239 \\
\hline Cultural Intelligence & CI_Q38 & $\mathbf{. 8 7 3}$ & .439 \\
\hline Confidence & CO_Q25 & $\mathbf{. 8 4 5}$ & .399 \\
\hline Education & ED_Q28 & $\mathbf{. 7 7 1}$ & .395 \\
& ED_Q60 &. $\mathbf{7 9 1}$ & .336 \\
\hline Empathy & EM_Q4 & $\mathbf{. 8 7 4}$ & .330 \\
\hline Emotional Resilience & ER_Q20 & $\mathbf{. 8 5 4}$ & -.157 \\
& ER_Q46 & $\mathbf{. 7 8 8}$ & .463 \\
\hline Experience & EX_Q5 & $\mathbf{. 7 5 3}$ & .137 \\
\hline Facilitator & FA_Q24 & $\mathbf{. 9 2 8}$ & .401 \\
\hline Flexibility & FL_Q31 & $\mathbf{. 8 0 9}$ & .493 \\
& FL_Q41 & $\mathbf{. 8 3 8}$ & .235 \\
& FL_Q51 & $\mathbf{. 7 7 1}$ & .215 \\
\hline Motivation & MO_Q22 & $\mathbf{. 7 7 3}$ & -.118 \\
& MO_Q27 & $\mathbf{. 8 8 8}$ & -.023 \\
& MO_Q34 & $\mathbf{. 8 3 4}$ & -.005 \\
& MO_Q58 & $\mathbf{. 8 6 9}$ & .352 \\
& MO_Q7 & $\mathbf{. 8 4 4}$ & .517 \\
\hline Non-Judgmental & NJ_Q52 & $\mathbf{. . 8 1 3}$ &. .159 \\
\hline Observant & OB_Q3 & $\mathbf{. 8 5 2}$ & .377 \\
\hline Open & OP_Q42 & $\mathbf{. 7 8 2}$ & .068 \\
& OP_Q53 & $\mathbf{. 9 0 7}$ & .103 \\
\hline Personal Autonomy & PA_Q36 & $\mathbf{. 8 7 4}$ & .269 \\
\hline Respectful & RE_Q11 & .364 & $\mathbf{. 8 7 7}$ \\
& RE_Q13 & .144 & $\mathbf{. 8 9 3}$ \\
& RE_Q14 & .340 & $\mathbf{. 9 2 5}$ \\
& RE_Q23 & .389 & $\mathbf{. 8 3 9}$ \\
\hline Strategic & ST_Q48 & $\mathbf{. 8 2 4}$ & .371 \\
\hline
\end{tabular}

The KMO and Bartlett's Test results are presented in Table 23. The strength of the twofactor solution is supported by a strong KMO measure that confirms an accurate number 
of factors (Stevens, 2009). The results of Bartlett's Test of Sphericity, with a significance level of .000 , provides additional support for the strength of the relationship between the variables (Davis, 1996; Stevens, 2009). The amount of variance explained in the latent construct was $62.55 \%$ for factor 1 and $9.43 \%$ for Factor 2 .

Table 23: KMO and Bartlett's Test from EFA with Data Set 1

\begin{tabular}{|c|c|c|}
\hline \multicolumn{3}{|c|}{ KMO and Bartlett's Test } \\
\hline \multicolumn{2}{|c|}{ Kaiser-Meyer-Olkin Measure of Sampling Adequacy. } & .936 \\
\hline \multirow[t]{3}{*}{ Bartlett's Test of Sphericity } & Approx. Chi-Square & 2965.070 \\
\hline & Df & 465 \\
\hline & Sig. & .000 \\
\hline
\end{tabular}

To summarize, the EFA process involved nine iterations of analysis. The final run produced a distinct two-factor result, with strong showings for each item in the factors without any cross-loading items. Factor 1 contained 27 items and Factor 2 contained 4 items. Each factor contains more than three items, which supports a strong and stable factor solution (Costello and Osborne, 2005). Seven items were determined insignificant during the EFA iteration runs, as they met the theoretically supported statistical criteria for insignificance and were removed. Both the KMO and Bartlett's Test results support the two-factor solution and the strong relationship between the 31 remaining items.

\subsubsection{Analysis of EFA Results}

The EFA produced a two-factor solution with 27 items in Factor 1, and 4 items in Factor 2. The "optimistic" component was eliminated from the research model, as the question corresponding to this component was deemed insignificant. The Factor 1 items are 
aligned with fifteen of the sixteen remaining components that have been theoretically identified as compromising transcultural ability. The Factor 2 items are aligned with "respectful"; the sixteenth component. While some items have been removed from the EFA analysis due to weak loadings, it is important to note that all but one ("optimistic") of the original components remain with at least one item.

The Factor 2 items are all aligned with the "respectful" component. This component involves respect for other cultures including the ability to admire the people of, and find value in, other cultures (Earley et al, 2006; Graen et al., 1997; Graen et al., 2004, Graen and Hui, 1999). The absence of any "respectful" component items in Factor 1 supports the strength of Factor 2 as both statistically and theoretically distinct from Factor 1.

With respect to the transcultural research undertaken in this study, the results of the EFA have isolated the items in Factor 2 as distinct from those in Factor 1. The Factor 1 items are theoretically based and EFA has provided empirical support for their strong loadings on the same factor (Stevens, 2009). This evidence suggests that the Factor 1 items alone provide a measure for transcultural ability.

The Factor 2 items were theoretically based, however empirically they have been shown to be distinct from transcultural ability as measured in the Factor 1 items. This distinctness questions the appropriateness of Factor 2 for measuring transcultural ability. The Factor 2 items all aligned with the "respectful" component. The literature has identified the complexity and variability associated with how respect is conceptualized 
(Langdon, 2007), which offers a potential explanation of why these items were isolated in their own factor. Langdon (2007) suggests that respect is difficult to measure as there are a variety of interpretations for, and assumptions of, respectful behaviour. Montgomery, Kane and Vance (2004) proposed that norms of respect can vary between individuals and may not even be shared within an organization. Van Quaquebeke and Eckloff (2010) have suggested that the difficulty of measuring respect may be because research has not yet identified which behaviours are understood as indicators of respect. It is possible that the "respectful" component was found to be insignificant as the respondents understood its meaning from multiple perspectives. Due to the absence of any items from the "respectful" component in Factor 1, the Factor 2 items were removed from the model and were no longer included in the research.

The following section presents the next step in the data analysis, the CFA process.

\subsection{Confirmatory Factor Analysis}

Confirmatory factor analysis (CFA) was the second step in the process used for developing the TMS (Gerbing and Hamilton, 1996; Han and Ki, 2010; Yoo and Chon; Zhang, Bi and $\mathrm{Yu}, 20100)$. CFA "rests on a solid theoretical or empirical base," (Stevens, 2009, pg. 326) with the researcher providing the theoretical and methodological foundation for the analysis. With CFA, the items are generally forced onto a specific structure in order to confirm the results (Stevens, 2009). While the factor structure from EFA is utilized for CFA; the data for this analysis is different from that used in EFA. The second data set, data set 2, $(\mathrm{n}=100)$ was used for this analysis. An eigen value of 
greater than 1 was used as a cutoff for determining the number of factors retained in each iteration.

The CFA process includes the items identified in EFA as belonging in Factor 1, labeled as transcultural ability. These 27 items were forced into one factor; which prevents rotation processing as there is no opportunity for movement between factors. Table 24 presents these results and the EFA results for Factor 1. The results of the CFA are extremely similar to those from the EFA for Factor 1 with the differences ranging from .000 to .107 between the two loadings.

\section{Table 24: CFA with Transcultural Ability Items}

\begin{tabular}{|l|c|c|c|}
\hline \multicolumn{1}{|c|}{ Component } & Item & CFA Loadings & EFA Loadings \\
\hline Adventurous & AD_Q1 & .718 & .790 \\
& AD_Q19 & .941 & .947 \\
& AD_Q29 & .859 & .760 \\
& AD_Q40 & .870 & .862 \\
\hline Cultural Intelligence & CI_Q38 & .771 & .873 \\
\hline Confidence & CO_Q25 & .795 & .845 \\
\hline Education & ED_Q28 & .878 & .771 \\
& ED_Q60 & .810 & .791 \\
\hline Empathy & EM_Q4 & .881 & .874 \\
\hline Emotional Resilience & ER_Q20 & -.829 & -.854 \\
& ER_Q46 & .788 & .788 \\
\hline Experience & EX_Q5 & -.747 & -.753 \\
\hline Facilitator & FA_Q24 & .901 & .928 \\
\hline Flexibility & FL_Q31 & .766 & .809 \\
& FL_Q41 & .741 & .838 \\
& FL_Q51 & .764 & .771 \\
\hline Motivation & MO_Q22 & -.794 & -.773 \\
& MO_Q27 & -.801 & -.888 \\
& MO_Q34 & -.883 & -.834 \\
& MO_Q58 & .881 & .869 \\
& MO_Q7 & .872 & .844 \\
\hline Non-Judgmental & NJ_Q52 & -.784 & -.813 \\
\hline
\end{tabular}




\begin{tabular}{|l|c|c|c|}
\hline \multicolumn{1}{|c|}{ Component } & Item & CFA Loadings & EFA Loadings \\
\hline Observant & OB_Q3 & .869 & .852 \\
\hline Open & OP_Q42 & .822 & .782 \\
& OP_Q53 & .890 & .907 \\
\hline Personal Autonomy & PA_Q36 & .843 & .874 \\
\hline Strategic & ST_Q48 & .851 & .824 \\
\hline
\end{tabular}

Cronbach's Alpha is used to measure consistency between the items in a factor with a value greater than .7 as the standard for reliability (Han and Ki, 2010; Shapiro, Giannoulakis, Drayer and Want, 2010). The Cronbach Alpha at .982 indicates very high reliability for the consistency of the items. The $\%$ of variance explained in the latent construct by Factor 1 was $68.81 \%$.

The strength of the solution is also supported by a strong KMO measure at .923 with a significance level of .000 , which provides additional support for the strength of the relationship between the variables (Davis, 1996; Stevens, 2009). Table 25 presents the results of the KMO and Bartlett's Test for the CFA.

Table 25: KMO and Bartlett's Test from CFA with Data Set 2

\begin{tabular}{|ll|r|}
\hline \multicolumn{2}{|c|}{ KMO and Bartlett's Test } \\
\hline Kaiser-Meyer-Olkin Measure of Sampling Adequacy. & .923 \\
Bartlett's Test of Sphericity $\quad$ Approx. Chi-Square & 352.796 \\
& Df & 595 \\
& Sig. & .000 \\
\hline
\end{tabular}

The Factor 1 items belong to fifteen of the seventeen components that have been theoretically identified as composing transcultural ability. The "optimistic" component was eliminated during the EFA when the item corresponding to this component was 
eliminated due to similar loadings in multiple factors. The "respectful" component and associated items were eliminated due to the isolation of Factor 2 from Factor 1 in EFA.

The CFA analysis provided strong support for the solution provided by the EFA. This support was found in a Cronbach Alpha at .982, a KMO at .923, and statistical significance in Bartlett's Test. The following section presents the contents of the TMS instrument flowing from the EFA/CFA analysis.

\subsection{EFA/CFA Results Produce the TMS Instrument}

EFA was used as an exploratory process for generating the TMS, and CFA was used as a confirmatory process to test the TMS (Stevens, 2009). The TMS instrument, as determined with EFA/CFA analysis, contains 27 items from the original 60 questions that were proposed in this research. To summarize the EFA and CFA activities, a multi-step process was utilized, involving both EFA and CFA on a randomly split data set. The EFA produced a 31 item two-factor solution. Factor 1 contained 27 items and Factor 2 contained 4 items. The Factor 2 items aligned with the "respectful" component, a concept that the research suggests is highly complex and challenging to measure. As the Factor 2 items were distinct from those in Factor 1, and because of the difficulties identified with measuring respect, these items were removed and not included in CFA processing.

The CFA activities involved running factor analysis for the Factor 1 items identified during EFA analysis. The CFA produced strong loadings in the first iteration of CFA. 
The Cronbach Alpha, KMO, and Bartlett tests provided strong support for the CFA model. These results tested, confirmed and supported the 27 items in the TMS instrument (Ralston and Pearson, 2010; Stevens, 2009).

Table 26 presents the 27 items in the TMS instrument. The data label, containing the component and original survey question sequence number, is provided for information only and is not part of the TMS survey instrument.

Table 26: The Revised TMS Instrument

\begin{tabular}{|c|l|c|}
\hline$\#$ & \multicolumn{1}{|c|}{ Question/Item } & Data Label \\
\hline 1 & $\begin{array}{l}\text { I tend to seek out local foods as my first choice when I'm in } \\
\text { foreign countries. }\end{array}$ & AD_Q1 \\
\hline 2 & I tend to be inquisitive and research many topics. & OB_Q3 \\
\hline 3 & I empathize with people from other cultures. & EM_Q4 \\
\hline 4 & Culture shock has been a difficult challenge for me & EX_Q5 \\
\hline 5 & I am involved, not indifferent. & MO_Q7 \\
\hline 6 & $\begin{array}{l}\text { I want to experience different cultures as much as possible in both } \\
\text { my personal and professional life. }\end{array}$ & AD_Q19 \\
\hline 7 & I am intimidated by new experiences. & ER_Q20 \\
\hline 8 & I am sometimes reluctant to return abroad after a home visit. & MO_Q22 \\
\hline 9 & $\begin{array}{l}\text { I often play a liaison role bringing those from other cultures } \\
\text { together. }\end{array}$ & FA_Q24 \\
\hline 10 & $\begin{array}{l}\text { I think along the lines of live and let live even if it goes against my } \\
\text { core values. }\end{array}$ & CO_Q25 \\
\hline 11 & $\begin{array}{l}\text { When on assignment, I tend to look for any opportunity to return } \\
\text { home for a visit. }\end{array}$ & MO_Q27 \\
\hline 12 & I try to learn the basics of the languages I encounter. & ED_Q28 \\
\hline 13 & I get bored when things are stagnant or consistent. & AD_Q29 \\
\hline 14 & I am a good actor, not reserved. & FL_Q31 \\
\hline 15 & I look forward to the end of an assignment so I can return home. & MO_Q34 \\
\hline 16 & I accept responsibility for my life/career decisions. & PA_Q36 \\
\hline
\end{tabular}




\begin{tabular}{|c|l|c|}
\hline$\#$ & \multicolumn{1}{|c|}{ Question/Item } & Data Label \\
\hline 17 & $\begin{array}{l}\text { I look for cultural cues when I encounter those from another } \\
\text { culture }\end{array}$ & CI_Q38 \\
\hline 18 & I prefer a job in a culture different from my own. & AD_Q40 \\
\hline 19 & $\begin{array}{l}\text { My partner/family is supportive of my career and has an open } \\
\text { attitude toward other cultures. }\end{array}$ & FL_Q41 \\
\hline 20 & $\begin{array}{l}\text { I would rather work with someone who is from a culture very } \\
\text { different from my own culture. }\end{array}$ & OP_Q42 \\
\hline 21 & I am not easily offended. & ER_Q46 \\
\hline 22 & $\begin{array}{l}\text { I always have a Plan B as an alternative plan in case things do not } \\
\text { work out as anticipated. }\end{array}$ & ST_Q48 \\
\hline 23 & $\begin{array}{l}\text { My family is very flexible with my job relocations; they do not } \\
\text { 'hold me back' from opportunities. }\end{array}$ & FL_Q51 \\
\hline 24 & I sometimes think my (native) culture is superior to other cultures. & NJ_Q52 \\
\hline 25 & I have friends from many cultural backgrounds. & OP_Q53 \\
\hline 26 & I am energized, not lethargic. & ED_Q58 \\
\hline 27 & I have many hobbies and interests. & ED_Q60 \\
\hline
\end{tabular}

The next step in the analysis process focused on assessing whether the TMS-confirmed items had the predictive power necessary to determine expatriate success. The following section provides the data analysis and results from the predictive validity activities.

\subsection{Predictive Validity Analysis}

Predictive validity analysis was performed to determine if the model flowing from the EFA/CFA analysis had the power to predict expatriate success (Mosteller and Tukey, 1977; Seber and Lee, 2003). Regression analysis was the methodological tool selected for testing predictive validity (Schilderinck, 1977). Prior to performing the regression analysis, the data needed to be prepared. This activity involved orienting the questions the same way for high or low agreement (i.e., inverting negatively phrased questions). 
As well, the dependent and independent variables were built from the respondent data. The various activities involved with preparing the data, building the dependent and independent variables, performing a correlation analysis with the regression data and the regression analysis results are provided in this section.

\subsubsection{Data Preparation}

The original 60 items (represented as questions in the survey) were prepared to discourage acquiescence bias, which can occur when the participants provide the same answer to all questions and when they agree with all statements (Comrey, 1988). The questions or statements were worded in such a way as to prevent a 'pattern of agreement' with high or low scale selections. However, the aggregation or summing of the variables for preparing the independent variable requires that all questions be oriented the same way (DeCoster, 2004, Spector, 1992). An analysis of the remaining 27 questions/items found that six questions needed to be re-oriented.

\subsubsection{Dependent Variable Created}

Regression analysis requires a dependent variable for the independent variable(s) to be explained and judged (Davis, 1996; Zikmund, 2003). In this research, the independent variable represents transcultural ability and the dependent variable represents the level of expatriate success of the respondents. The latter variable identifies the ability of the respondent to successfully complete overseas jobs. This proxy measure was constructed from an analysis of six item responses from the descriptive data provided in the survey. These six responses included four frequency questions asking the number of overseas 
jobs, the number of overseas jobs completed, the number of early returns and the number of early returns that were not by choice, and two dichotomous yes/no questions asking if the respondent saw themselves as successful expatriates, and if they found repatriation difficult.

Separate regression analyses were performed with each of the six response variables to determine their appropriateness in the proxy measure for expatriate success. The following tables present the regression analysis for each variable. Table 27 presents the results of the linear regression analysis for the frequency variables, and Table 28 presents the logistic regression for the dichotomous variables.

Table 27: Linear Regression Analysis Results of Frequency Dependent Variable $\underline{\text { Items }}$

\begin{tabular}{|l|c|c|c|c|}
\hline \multicolumn{1}{|c|}{ DV Item Variables } & $\mathbf{R}^{2}$ & $\mathbf{F}$ & $\begin{array}{c}\text { Standardized } \\
\mathbf{B}\end{array}$ & Sig. \\
\hline \# Overseas Jobs & .325 & 38.489 & .570 & .000 \\
\hline \# Completed & .385 & 50.044 & .620 & .000 \\
\hline $\begin{array}{l}\text { \# Returned Home Early } \\
\text { By Choice }\end{array}$ & .320 & 37.573 &. .565 & .000 \\
\hline $\begin{array}{l}\text { \# Returned Home Early } \\
\text { Not Choice }\end{array}$ & .012 & .976 & .110 & .326 \\
\hline
\end{tabular}

Note: Grey highlight indicates insignificant variable

Table 28: Logistic Regression Analysis Results of Dichotomous Dependent Variable Items

\begin{tabular}{|l|c|c|c|c|c|}
\hline \multicolumn{1}{|c|}{ DV Item Variables } & $\mathbf{R}^{2}$ & $\mathbf{F} / \mathbf{x}^{2}$ & $\mathbf{E x p}(\mathbf{B})$ & $\mathbf{B}$ & Sig. \\
\hline $\begin{array}{l}\text { See self as successful } \\
\text { expatriate }\end{array}$ & .424 & $45.199^{+}$ & 1.079 & .764 & .000 \\
\hline Found repatriation difficult & .012 & $.961^{+}$ & 1.007 & .007 & .334 \\
\hline
\end{tabular}

Note: Grey highlight indicates insignificant variable 
The results of the regression analyses on the six variable items found two of the variables to be insignificant. The frequency variable '\# returned home early not by choice' was insignificant at $\mathrm{p}=.326$, and the dichotomous variable 'found repatriation difficult' was also insignificant at $p=.334$. These two variables were removed from any further analysis, while the remaining four variables were used to create a more robust proxy measure of expatriate success.

Table 29 presents the Successful Expatriate Variable Design Table. This table contains the four response fields from the survey that were analyzed for the dependent variable, and the possible responses for each field.

\section{Table 29: Successful Expatriate Dependent Variable Design}

\begin{tabular}{|c|l|c|c|c|c|c|c|}
\hline$\#$ & \multicolumn{1}{|c|}{ Response Fields } & \multicolumn{5}{|c|}{ The Possible Responses } \\
\hline 1 & \# Overseas Jobs & 0 & 1 & 2 & 3 & 4 & $4+$ \\
\hline 2 & \# Overseas Jobs Completed & 0 & 1 & 2 & 3 & 4 & $4+$ \\
\hline 3 & Return Early By Choice & 0 & 1 & 2 & 3 & 4 & $4+$ \\
\hline 4 & See Self Successful Expat & Y & N & & & & \\
\hline
\end{tabular}

The dependent variable was constructed based on support from the literature review and the pilot study, and confirmed with regression analysis. Four variables were used in the analysis to prepare the proxy dependent variable. Table 30 is the decision table that was used to create the dependent variables. This table was used to assess each data point, from low to high. The paragraphs following the table provide a discussion of the decisions steps for the creation of each of the five categories in this variable. 


\section{Table 30: Successful Expatriate Dependent Variable Decision Table}

\begin{tabular}{|c|l|c|c|c|c|c|}
\hline$\#$ & \multicolumn{1}{|c|}{$\begin{array}{c}\text { Successful Expatriate } \\
\text { Response Fields }\end{array}$} & $\begin{array}{c}\mathbf{5} \\
\text { Low }\end{array}$ & $\begin{array}{c}\mathbf{4} \\
\text { Med-Low }\end{array}$ & $\begin{array}{c}\mathbf{3} \\
\text { Medium }\end{array}$ & $\begin{array}{c}\mathbf{2} \\
\text { Med- } \\
\text { High }\end{array}$ & High \\
\hline 1 & \# Overseas Jobs & 1 & 1,2 & 2,3 & 3 & $4,4+$ \\
\hline 2 & \# Overseas Jobs Completed* & 0 & At least l & All -1 & $\begin{array}{c}\text { All or all } \\
-1\end{array}$ & $\begin{array}{c}\text { All or all } \\
-1\end{array}$ \\
\hline 3 & Return Early By Choice & 1 & Any & Any & 0 & 0 \\
\hline 4 & See Self Successful Expat & $\mathrm{N}$ & $\mathrm{N}$ & $\mathrm{Y}^{* *}$ & $\mathrm{Y}^{* *}$ & $\mathrm{Y}^{* *}$ \\
\hline
\end{tabular}

* Some respondents were on an overseas job when they completed the survey.

** If respondents with 3 or more overseas jobs saw themselves as unsuccessful expatriates, a lower category (to the left) was selected and if respondents with 1 or 2 overseas jobs saw themselves as successful expatriates, a higher category (to the right) was selected

The decision table was used in a step-wise fashion from left to right (low to high) and working iteratively downwards from row 1 through to row 4 . The first decision is to select the first instance of \# of overseas jobs, then work down the table, moving to the appropriate lower or upper next for the decisions that fit. For example, an individual with 1 overseas job that was completed would be a ' 4 ' if they saw themselves as unsuccessful, or a ' 3 ', if they saw themselves as successful.

The lowest level of a successful expatriate is someone who has had one overseas job and has not completed it. The individual does not see themselves as a successful expatriate. This individual may not easily agree to another overseas job, as their previous experience with such work was not favourable. 
The medium-low level of successful expatriate has had one or two overseas jobs and has completed at least one of them. They have returned home early for any reason and do not see themselves as successful expatriates. They may be reluctant to accept another foreign opportunity.

The medium level of successful expatriate included respondents indicating up to three overseas jobs, with up to only one early return by choice. They may be returning home early when they are faced with difficult challenges. This level sees themselves as successful with no difficulties.

The medium-high level of successful expatriate included up to four overseas jobs with no returns early. In addition, these respondents saw themselves as successful expatriates. This level is differentiated from the medium level as the expatriate does remain on assignment.

The high level of successful expatriate includes individuals who are very comfortable in any culture and tend to be career expatriates so the difference here is that they have held 4 or more overseas jobs. This level includes respondents seeing themselves as successful.

The analysis for the dependent variable involved assessing the data set responses using the decision table. Data set 2 was used for regression analysis as this analysis concerns the confirmation and validation of the TMS. This step is aligned with principles for scale 
development that use one half of the data for developing the scale and the other half for its validation (Stevens, 2009; Clark and Watson, 1995). The mix and positioning of the responses in the decision table provided the appropriate value for the transcultural variable for each response set in data set 2 .

Once the analysis and decisions were complete and the dependent variables were built, the variables' descriptive statistics were produced. Table 31 presents these statistics.

\section{Table 31: Dependent Variable Descriptive Statistics}

\begin{tabular}{|c|c|c|c|c|c|}
\hline Information & $\mathbf{N}$ & Mean & $\begin{array}{c}\text { Std. Error of } \\
\text { Mean }\end{array}$ & Std. Dev. & Var. \\
\hline Successful Expatriate & 100 & 2.68 & .141 & 1.413 & 1.998 \\
\hline
\end{tabular}

The mean at 2.68 places the average respondent within the medium to medium-high level of successful expatriate.

Table 32 presents the frequency distribution of the transcultural dependent variable. The successful expatriate variable profile of data set 2 has the highest level of success with a strong showing of $28 \%$. The Level 2 (medium-high) had a frequency of $20 \%$ and the medium Level 3 was strong at $24 \%$. The lowest frequency of successful expatriate was at the med-low level 4 at $12 \%$ with the low Level 5 with a frequency of $16 \%$. The majority of the respondents were tightly clustered in the high, medium-high and medium levels of successful expatriate. 
Table 32: Transcultural Variable Frequency

\begin{tabular}{|c|c|c|}
\hline $\begin{array}{c}\text { Successful Expatriate } \\
\text { Variable }\end{array}$ & $\begin{array}{c}\text { Frequency } \\
\mathbf{n = 1 0 0}\end{array}$ & $\begin{array}{c}\text { Percentage of } \\
\text { Respondents }\end{array}$ \\
\hline 1 & 28 & $28 \%$ \\
\hline 2 & 20 & $20 \%$ \\
\hline 3 & 24 & $24 \%$ \\
\hline 4 & 12 & $12 \%$ \\
\hline 5 & 16 & $16 \%$ \\
\hline
\end{tabular}

\subsubsection{Independent Variable Created}

An independent variable was created from the respondent data based on the CFA results.

This variable was created from the summed average of the 27 items in Factor 1 and was labeled as TMS for "Transcultural Measurement Scale".

The next section presents the regression analysis performed on data set 2 .

\subsubsection{Regression Analysis}

Regression analysis procedures were performed on the survey data to test for predictive validity and for examining any potential mediation or moderation with age or gender. The first regression analysis tested for predictive validity. This involved data set 2 , the dependent variable successful expatriate, and the independent variable, TCA. Table 33 presents the results of the regression analysis. 


\section{Table 33: Regression Analysis Results}

\begin{tabular}{|c|c|}
\hline $\mathrm{R}$ & .668 \\
\hline $\mathrm{R}^{2}$ & .446 \\
\hline $\mathrm{F}$ & 64.455 \\
\hline Pearson & .027 \\
\hline Standardized B & .668 \\
\hline $\mathrm{T}$ & 8.028 \\
\hline Sig. & .000 \\
\hline
\end{tabular}

An $\mathrm{R}$ value of .668 provided strong support for the predictive validity of the Transcultural Ability independent variable with respect to the Successful Expatriate dependent variable (Stalans, 1995). $\mathrm{R}^{2}$ with possible values between 0 and 1 , explains how much variance is accounted for by the model. The $R^{2}$ value is .446 , which explains that almost half of the variation of the dependent variable is attributable to transcultural ability. This high value provides support for the predictive validity of the model (Anderson et al, 1996). The F-value indicates the total variation explained by the model, which is high at 64.455 . This strong $\mathrm{F}$ value also reflects the model's statistically significant predictive capacity (Anderson et al., 1996).

The standardized Beta, at .668, indicates a strong and robust relationship between the dependent and independent variables. This means that there is a direct relationship between the two variables; as transcultural ability increases the likelihood of expatriate success also increases, and conversely, as the likelihood of expatriate success decreases, transcultural ability also decreases. Standardized Beta allows for a fair comparison of the 
effects of change on the variables by measuring unit change in standard deviations for the variables (Stevens, 2009).

Reliability analysis was conducted to assess the consistency of the results across the items in the scale. This was done to compliment the strong predictive validity of the scale. The average inter-item correlation estimate was used as it is the appropriate reliability estimate for a one-time administration of a survey. The reliability score was .685 which is close to the recommendations of Nunnally and Bernstein (1994) who suggest that reliability values should be approaching .700 or higher.

As age and gender have been the topic of some discussion in the expatriate literature, final data analysis procedures were run to check if age or gender moderated or mediated the relationship between transcultural abilities and expatriate success. The results found significance between age and expatriate success, however it did not find a significant moderating or mediating relationship between age or gender and transcultural ability.

The following section presents a summary of the data analysis and results presented in this chapter.

\subsection{Summary of Data Analysis and Results}

In summary, the data analysis and results involved a multi-step process utilizing various statistical procedures. The respondent data was cleaned and split into two databases of equal size. Correlation analysis was performed to reduce the data in order to provide 
cleaner data sets for statistical analysis. EFA was performed with data set 1 resulting in a two-factor solution for the TMS model. CFA was executed with data set 2, which confirmed the single factor structure of the ability-based transcultural measure.

The predictive validity of the TMS model was established through regression analysis. An independent variable was created from the summed average of the 27 items in Factor 1 as identified during EFA, and confirmed with strong CFA results. A dependent variable was built from the respondent data in data set 2 . The regression results provided strong support for the predictive power of TMS in helping to explain expatriate success.

Appendix D presents a summary of the statistical data results analysis for the research items. The following section presents the TMS Instrument as validated by this study.

\subsection{The Validated Transcultural Measurement Scale}

The data analysis activities and results completed in this research support a 27 -item TMS survey. This survey instrument, as determined and confirmed with EFA/CFA analysis, was validated with predictive validity testing using regression analysis.

Table 34 contains the questions for the TMS survey that have been successfully validated in this dissertation. A 7-point Likert scale is used for the responses. 
Table 34: Validated Transcultural Measurement Scale Survey

\begin{tabular}{|c|c|}
\hline$\#$ & Question \\
\hline 1 & I tend to seek out local foods as my first choice when I'm in foreign countries. \\
\hline 2 & 1 tend to be inquisitive and research many topics. \\
\hline 3 & I empathize with people from other cultures. \\
\hline 4 & Culture shock has been a difficult challenge for me. $R$ \\
\hline 5 & I am involved, not indifferent. \\
\hline 6 & $\begin{array}{l}\text { I want to experience different cultures as much as possible in both my personal and } \\
\text { professional life. }\end{array}$ \\
\hline 7 & I am intimidated by new experiences. $R$ \\
\hline 8 & I am sometimes reluctant to return abroad after a home visit. $R$ \\
\hline 9 & I often play a liaison role, bringing those from other cultures together. \\
\hline 10 & I think along the lines of "live and let live" even if it goes against my core values. \\
\hline 11 & When on assignment, I tend to look for any opportunity to return home for a visit. $R$ \\
\hline 12 & I try to learn the basics of the languages I encounter. \\
\hline 13 & I get bored when things are stagnant or consistent. \\
\hline 14 & I am a good actor, not reserved. \\
\hline 15 & I look forward to the end of an assignment so I can return home. $\mathrm{R}$ \\
\hline 16 & I accept responsibility for my life/career decisions. \\
\hline 17 & I look for cultural cues when I encounter those from another culture. \\
\hline 18 & 1 prefer a job in a culture different from my own. \\
\hline 19 & My partner/family is supportive of my career and has an open attitude toward other cultures. \\
\hline 20 & I would rather work with someone who is from a culture very different from my own culture. \\
\hline 21 & I am not easily offended. \\
\hline 22 & I always have a Plan B as an alternative plan in case things do not work out as anticipated. \\
\hline 23 & $\begin{array}{l}\text { My family is very flexible with my job relocations; they do not 'hold me back' from } \\
\text { opportunities. }\end{array}$ \\
\hline 24 & I sometimes think my (native) culture is superior to other cultures. $R$ \\
\hline 25 & I have friends from many cultural backgrounds. \\
\hline 26 & I am energized, not lethargic. \\
\hline 27 & I have many hobbies and interests. \\
\hline
\end{tabular}

Note: Items that were/are to be reverse scored are labeled with an " $R$ ". 
Appendix E presents the Transcultural Measurement Survey that includes the 27 questions with the 7-point Likert response column grid. The next section of this dissertation provides a discussion of the research results in the context of the contributions made to the transcultural and expatriate literatures. 


\section{DISCUSSION}

This dissertation is the first study to analyze the transcultural literature and assemble the concepts together into a transcultural construct. While the concept of a transcultural has been found in the literature since the mid-1980's (Adler, 1984), the discussion has been vague, without any formal description of the construct. In 1997, Graen and colleagues (1997) provided a more detailed discussion of the construct that included a description of five stages of transcultural development. The transcultural continued to appear in the literature linked with cross-cultural leadership and expatriate theory; however, the content continued to be purely conceptual. This theoretical discussion consisted of describing transcultural ability in terms of stages of development and the benefits of such individuals for multinational corporations to meet the challenges of managing crosscultural differences (Graen et al., 1997; Graen and Hui, 1999). However, the discussion did not include an overall description of the concept, nor a method or process for determining transcultural ability. The research in this study addressed these shortcomings in the literature.

The present study was undertaken to address the challenge of moving from conceptual to empirical by enhancing our knowledge of the transcultural with an analysis of its components, and by providing a measure for transcultural ability through empirical research. The development of the Transcultural Measurement Scale (TMS) provides more depth to our understanding of transculturals, both theoretically and empirically. This theoretical understanding expands our knowledge of the concept into a construct for 
determining, assessing and generalizing the implications of transcultural ability, supported by the empirical results that confirmed the construct.

The research results are generalizable to the expatriate population in North America. The participant sample was statistically similar to the US expatriate population in a major study by Brookfield Global with US multinationals (Brookfield, 2010). The demographic and self-perception results of this study matched the expatriate population in terms of age, education, perceptions of expatriate failure, seeing oneself as successful and repatriation difficulties (Brookfield, 2010). However, transcultural ability may or may not apply across cultures. That is, it is possible that this concept and theory only applies to Western cultures, as it was developed theoretically and empirically by Western researchers, and with a predominantly Western sample. It is also possible that other concepts are more appropariate in other cultures for expatriate selection and assignment success.

The research in this study achieved a valid transcultural measure by using a methodology that included a two-step factor analysis for scale development. The factor structure of the scale appeared robust with the EFA showing a factor structure supported by CFA with a Cronbach Alpha of .981 and a KMO at .923. There was strong support for the predictive validity of the measure with respect to expatriate success with an $R$ value of .668 , an $R$ square value of .446 and a standardized Beta value of .668 . 
The model of transcultural ability, flowing from the empirically confirmed factor structure, contained fifteen components. These components support some of the facets introduced by Graen and colleagues $(1997,2004)$, as well as some in the expatriate literature. The fifteen components of transcultural ability found in this study include: adventurous, confidence, education, emotional resiliency, empathy, experience, facilitator, flexibility, motivation, non-judgmental, observant, open, personal autonomy and strategic. Each component can be present in varying strengths, with the mix of these strengths determining transcultural ability.

Two components, "optimistic" and "respectful", were removed during the data analysis procedures. "Optimistic" was deemed insignificant during EFA. This component was included in the research model due to support from the literature (Maddox, 1993; Oberg, 1960). Optimism is closely aligned with emotional stability, a value in the Big Five Personality Model of values (Digman, 1990), which identifies a positive relationship between emotional stability and an optimistic outlook. Optimism could be seen as a traitlike component and this may help to explain the lack of support it received for inclusion in the ability-based model. It is also possible that the optimistic component was insignificant as it may have been explained by other abilities, such as being open and flexible.

The "respectful" component was removed from the transcultural model as the items associated with this component were isolated in Factor 2 during EFA. Their distinctness from the Factor 1 items suggests that they are measuring something different from the 
Factor 1 items. Langdon (2007) suggests that measuring for respect is challenging due to varied interpretations of the term and the invalid assumptions made by a universal definition. He explains that respectful behaviour varies by context, which makes it deceivingly complex. Montgomery, Kane and Vance (2004) proposed that norms of respect can vary between individuals and may not even be shared within an organization. They suggest that these variations may be affected by race, sex and expectations of mutual respect. Van Quaquebeke (2010) observes that research has not yet identified which behaviours are understood as indicators of respect. This can be attributed to the notion that there is a "perceiver" and a "perceived" when it comes to respect, which further complicates our understanding of the concept (Langdon, 2007). It is possible that the respondents were approaching what was meant by respect from multiple perspectives, rendering it insignificant.

The lack of support for "respectful" within the Factor 1 items suggests that respectful is distinct from Factor 1. This component may have been separated from the other components as it could also be considered strongly value-based. Values have been defined as "basic convictions that a specific mode of conduct or end-state of existence is personally or socially preferable to an opposite or converse mode of conduct or end-state of existence" (Rokeach, 1973, pg. 5). Values influence people's perceptions and behaviour and more importantly, they are fairly stable over time (Meglina and Ravlin, 1998). A person's abilities involve their means and capabilities which are subject to change over time, like experience, exposure, training and influence from one's manager (House, 1971). It is possible that the strong value connotation of the "respectful" 
component influenced its isolation from the Factor 1 components. Like "optimistic", the value-based nature of this component may make it incongruent with the ability-based nature of the transcultural measure.

While an individual's transcultural ability depends on their standing with all TMS components, the hierarchy of loadings does suggest that some components have more influence than others. This hierarchy is also noteworthy as it can be aligned with the transcultural development stages described in the literature.

The research in this study found strong support for the facilitator component as a key component of transcultural ability due to its high loading. This strong loading suggests that this component, and the other higher loading components, are the most central to transcultural ability. Conceptually supported by Graen and colleagues (1997), especially at the higher stages of transcultural ability, this component describes the individual as striving to facilitate cultural interactions by creating a culture where people can work together in an atmosphere of harmonious interaction and cooperation with mutual respect and trust (Graen et al., 1997; Graen et al., 2004). In essence, the facilitation ability enables cultural diversity to be handled in an active manner, unlike passive approaches that do not directly address the challenges of multi-cultural work environments. This latter approach is exemplified by expatriates behaving as if they were in their home environment, which can create an atmosphere of frustration, anxiety and mistrust that could result in expatriate and business failures (Black and Gregersen, 1999; Deng and Gibson, 2008; Kealey et al., 2006). The literature describes this passive approach as 
inadequate due to the high opportunity costs, especially in crisis situations (Graen and Hui, 1999).

The inclusion of the facilitator component, and its high loading, also strengthens and empirically supports the conceptual fifth and highest stage of transcultural development, the socializing synthesizer. This individual is described as transcending cultures, including their native culture, by understanding the value and merit of other cultures and by actively creating a working environment that incorporates the values and practices of both cultures (Graen et al., 1997).

The other four high loading components (ranging from .881 to .851 ), include "empathy," "observant," "open," and "strategic," and can be aligned with the higher transcultural stages where bridging or facilitating cultural cooperation through cultural understanding and comparisons are of key importance (Graen et al., 1997; Graen et al., 2004; Graen and Hui, 1999). Individuals who exhibit empathy have the ability to see themselves in the situations of others, and therefore are better able to understand the cultural implications of these situations. People that are more observant have a higher awareness of their environment and surroundings. Those that are more open tend to experience new cultures with honesty and respect without assumptions and expectations clouding the experience (Graen et al., 1997). Expatriates that are more strategic are focused on devising a plan to achieve an end result, which in cross-cultural situations includes identifying differences and analyzing behaviour (Earley et al., 2006; Graen et al., 2004; Graen and Hui, 1999). Taken together, these high loading components complement the 
ability to facilitate in cross-cultural situations. High transculturals, or individuals with high rankings with the mix of facilitator, empathy, observant, open and strategic components are more likely to be highly focused on successfully and strategically creating a working environment where different cultures can co-exist with mutual respect and cooperation.

The strength of influence from the three components, cultural intelligence, flexibility and experience was found at the bottom of the loading range with a tight grouping from 0.771 to .0747 . These three components can be aligned with the lower stages of transcultural development that involve an identification and recognition of other cultures. The low loadings of these components are in contrast to the literature, which suggests that each are of major importance with respect to the overseas selection process. Jenkins and Mockaitis (2010) suggest that flexibility is a major contributor to successful overseas adjustment. Earley and colleagues (2006) assert that both cultural intelligence and experience are major factors in the selection process. However, the research in this study, with lower loadings on these components, suggests that while these components are necessary and are core items for assessing transcultural ability, they are not sufficient in and of themselves for becoming a higher-level transcultural.

In addition to repositioning components that had previously received major importance in the expatriate selection process literature, the transcultural ability construct and model, as defined in this study, places prime importance on components which had not previously received such elevated distinction. The components of empathy, observant and open 
have received little attention in the expatriate literature. These components were included in the research model based on an analysis of the transcultural literature (Graen et al., 1997; Graen and Hui, 1999; Graen et al., 2004). They concern the individual and their approach and attitude towards their environment. Their inclusion in the model provides a fresh and innovative view of the overseas candidate with a more complex and contemporary mix of relevant components.

Figure 4 provides the empirically developed transcultural ability model with the components of transcultural ability influencing expatriate success. In the model, as suggested by the research in this study, the components are ordered by strength. It should be noted that the loading strength refers to the components that may be more central to the latent construct, and does not mean that they have stronger predictive power for expatriate success. The research model is a simplified representation of reality. It is possible that there are both moderating and mediating influences on the model, however identifying influential variables was beyond the scope of the current study. 
Figure 4: Transcultural Ability and Expatriate Success

$$
\begin{gathered}
\text { Transcultural Ability } \\
\hline \text { Facilitator } \\
\text { Empathy } \\
\text { Observant } \\
\text { Open } \\
\text { Strategic } \\
\text { Adventurous } \\
\text { Motivation } \\
\text { Education } \\
\text { Personal Autonomy } \\
\text { Emotional Resilience } \\
\text { Confidence } \\
\text { Non-Judgmental } \\
\text { Cultural } \\
\text { Intelligence } \\
\text { Flexibility } \\
\text { Experience }
\end{gathered}
$$

The transcultural ability model derived from of the research contributes to the body of academic theory by identifying, clarifying and validating the components of the construct. Previously, there was no clear understanding of the components of the construct, nor was there any indication that there may be differing levels of influence from these components.

The data analysis in this dissertation created a Transcultural Measurement Scale (TMS) and linked the scale with a proxy measure of expatriate success. The challenge that presented itself at the outset of this research was how to use transcultural theory to measure an individual's transcultural ability. The literature proposed that the transcultural was a valuable asset to cross-cultural leadership (Graen and Hui, 1999), but it did not include how to determine someone's transcultural ability. The TMS not only 
provides such a measure, it brings attention to the transcultural construct by linking it empirically with the expatriate literature. This linkage can benefit the area of expatriate study by providing an alternative tool (one that goes beyond cultural intelligence) for the overseas assignment selection process and for improving the likelihood of overseas success.

The results of this study can be used to address various expatriate issues, such as the selection process and expatriate failure rates that are challenging international organizations (Black and Gregersen, 1999; Black and Gregersen, 1991; Harzing, 2002; Pires et al., 2006). The literature suggests that overseas success is dependent on the appropriateness of the individual selected for a specific assignment (Jenkins and Mockaitis, 2010; Kim and Slocum, 2008). The TMS may contribute to the success of overseas assignments as the research in this study has demonstrated that transcultural ability is positively linked to overseas success through predictive validity. This link suggests that there is a higher likelihood of overseas assignment success with a higher level of transcultural ability.

This study of transculturals does not focus on specific cultures or on the characteristics of cultures, as transcultural ability is about knowing and understanding that there are many types of behaviour patterns and many ways to communicate, interact and cooperate (Milhouse $e t$ al., 2000; Graen $e t$ al., 1997). The focus is on identifying one's ability to move beyond their cultural socialization into another cultural environment (Graen $e t$ al., 1997). In other words, the focus is on the individual, not with the target culture, nor with 
a specific type of culture. Transcultural theory does not differentiate cultures nor classify or group them, as in many of the older large studies (Hofstede, 1980; House et al., 2004; Inglehart, 2008; Trompenaars and Hampden-Turner, 1998).

The transcultural construct is centered on the individual and on the mix of characteristics as identified in the transcultural model. A high level transcultural can move in and out of any culture, whether the culture is similar or different from the home culture (Graen et al., 1997). The key here is to identify the transcultural score of an individual in order to provide them with an overseas position that best suits their transcultural ability. This does not mean that only high transculturals are desirable for overseas assignments; it means that there can be a better match between the individual with the requirements of the overseas role. For example, a high level transcultural would likely be more desirable for launching a new initiative in a small African country, and a middle level transcultural may be more suited to a team effort in a major foreign city. Major cities around the world, especially in country capitals, have a large expatriate community and an international atmosphere including sports, dining and entertainment selections similar to many North American cities. Working with a team in an international environment would provide the middle-level transcultural support to help them adjust and adapt in the foreign country. The lower level transculturals may be candidates for assignments involving less cross-cultural exposure, possibly involving less contact with locals, especially if their technical skills are critical to the overseas effort. The TMS results could be used to select an overseas assignment where expatriate success may be more likely. 
The use of the TMS for determining an individual's transcultural ability does not suggest that such individuals will be immune to cultural shock, as cultural shock is experienced by all who experience a new culture (Oberg, 1960). However, higher levels of transcultural ability may provide for an easier recovery from the crisis stage and these people may not return home early (Black and Gregersen, 1999, Kealey and Rubin, 1973; Kealey et al, 2006; Sims and Schraeder, 2004). The implication is that the individual will move through the crisis stage into the adaptation stage more quickly (Black and Gregersen, 1999; Harvey, 1982; Kim and Slocum, 2008; Shin et al., 2007). For example, those with higher levels of transcultural ability can better empathize with others, and with their ability to openly observe, they can quickly identify cultural cues and nuances and understand cultural equivalents (Graen et al., 1997). They strategically determine how to behave and are motivated and flexible enough to alter their behavior appropriately. This helps them become comfortable in, and ultimately adapt to, the new culture, which eases their culture shock recovery (Black and Gregersen, 1999).

The results of this study also identified distinctions between cultural intelligence and transcultural ability. The most notable distinction is the loading of the cultural intelligence component near the bottom of the loading hierarchy in the TMS scale. This indicates that this component is not of prime importance to transcultural ability. This minor role for cultural intelligence in the transcultural model also illustrates that it is but one of fifteen components of the transcultural construct. In other words, cultural intelligence is necessary, but not sufficient on its own, for transcultural ability. 
The literature strongly supports those with cultural intelligence as prime candidates for overseas opportunities (Earley et al., 2006). However, the research in this study has shown that cultural intelligence is only one component of transcultural ability. It should be noted that the final TMS has only one item for the cultural intelligence component. It is possible that cultural intelligence does play a larger role in transcultural ability and may be represented by various items in the developed scale.

The distinction here between transcultural ability and cultural intelligence lies in the differentiation between having cultural intelligence, and knowing how and when to use that intelligence. The cultural intelligence literature includes discussions on establishing standards for behaviour on international work teams (Earley et al., 2006), and deploying cross-cultural training and knowledge ( $\mathrm{Ng}$ et al., 23009). This implies that one needs to be told or instructed on how to behave and function in relation to context. This is in sharp contrast with the transcultural who has the ability to behave appropriately in a foreign work environment without formal knowledge of the culture and its established standards of behaviour (Graen et al., 1997).

The theory behind cultural intelligence supports experience as a major influence for improving one's cultural intelligence (Earley et al., 2006). This is in contrast to transcultural ability where experience has been shown to be one of fifteen components that impact the construct. Transcultural theory allows for a situation where an individual demonstrates appropriate cultural behaviour without prior experience in the culture 
(Graen et al., 1999). Experience alone may not necessarily be enough to improve transcultural ability, as all the components are of importance when assessing the strength of the construct.

This distinction between transcultural and cultural intelligence theories could be interpreted as suggesting that an individual with low cultural intelligence could have high levels of transcultural ability. This could be due to strong influences from the other components. While experience may be a major factor in improving cultural intelligence (Crowne, 2008; Earley and Mosakowski, 2004a), it may not be as strong an influence on transcultural ability.

Another distinction between transcultural ability and cultural intelligence stems from their different conceptual roots. Cultural intelligence has roots in psychology (Earley and Mosakowski, 2004a) and focuses on the individual, whereas transcultural ability stems from cross-cultural adaptation and leadership (Graen et al., 1997) and focuses on the individual within the organization. While both theories focus on the individual, the transcultural theory includes the importance of the organization and the impact of the individual within an organizational context (Graen et al., 2004). This is seen through the importance of the socializing synthesizer's ability to facilitate relationships and cooperation between cultures, which allows the individuals from these cultures to function together effectively (Graen et al., 2004). The high loading of the "facilitator," "empathy" and "observant" components provide the individual with the characteristics to strengthen and support cultural interactions and organizational cooperation. This 
suggests that higher-level transculturals could influence successful cross-cultural relationships. Strong cross-cultural relationships have been demonstrated, in the literature, to be positively associated with organizational success at an international level (Hofstede, 1980; Trompenaars and Hampden-Turner, 1998).

The expatriate literature suggests that those who are flexible are better able to modify their behaviour as they become integrated into new cultures (Graen et al., 1999; Graen and Hui, 1999; Bird and Stevens, 2003; Lobel, 1990). The literature also suggests that flexibility is relative to the situation, as those that are considered flexible in one situation or culture may not be as flexible in another (Andreason and Kinner, 2005). The research in this study suggests a clarification of these positions through the lower comparative ranking of the flexibility component. The suggestion is that while flexibility is a component of transcultural ability; it has less strength than the other higher-ranking components and therefore should not be of prime consideration for expatriate selection. The notion in the literature that those with higher flexibility are better able to modify their behaviour according to necessity does not necessarily translate to cross-cultural situations due to the highly complex cultural nuances that can be present in these situations (Oberg, 1960). In order to be flexible with change, one has to know what is required for the change to occur. Flexibility alone does not provide this information. The required information is determined through careful observation and a respect for what is being observed, in combination with an open, non-judgmental attitude. In addition, the context needs to be taken into account, as the observed actions may have a different significance depending on the specific situation (Maddox, 1993). The 
contrasting support for flexibility can be explained in two ways based on the results of this study and the literature. Firstly, flexibility is not of prime importance, as there are many other components that comprise transcultural ability, and secondly, it is the context of the situation that may be highly complex and require more influence from the other components of the transcultural model, not just the influence from flexibility. In sum, the importance of flexibility in cross-cultural situations may be reduced as the complexity of the situation increases.

The research in this study did not specifically investigate how malleable transcultural ability is to change however the literature suggests that transcultural ability can, indeed, be influenced (Graen et al., 1997; Graen and Hui, 1999; Graen et al., 2004). This supports the possibility of improving transcultural ability. As individuals develop their organizational and interpersonal abilities, they can become more desirable as candidates for expatriate positions. This development is not limited to cultural exposure and experience, as other interpersonal abilities are included in the transcultural construct. Abilities including facilitating, emotional resilience and strategic ability can be developed and improved over the course of a career.

It is interesting to note that the concept of overseas success should not only imply improvement in one's transcultural ability. It is possible that for some, international assignments may become less attractive. This line of thinking contrasts with the current literature, which focuses on identifying characteristics of the individual with respect to indicators of overseas success and how to improve them (Black and Gregersen, 1999; 
Osman-Gani and Rockstuhl, 2009; $\mathrm{Ng}$ et al., 2009). The literature base has not investigated nor analyzed reductions in these indicators. The research in this study does support the idea that, over time, transcultural ability can change, and therefore it can be reduced or improved. For example, if an individual becomes disillusioned with their organization or with their job, they could become less motivated and possibly less open or flexible (Andreason and Kinner, 2005; Paik et al., 2002). This study provides the literature with an alternative view of overseas success as it suggests that change in an individual's transcultural abilities can be multi-directional.

The complexities associated with expatriate function over time highlights the possible inadequacy of cultural intelligence as an indicator of overseas success. Someone could have in-depth knowledge and experience in a culture, but potential changes to their situation with their organization and/or their family may not be accurately reflected in cultural intelligence. As cultural intelligence is just one component of transcultural ability, changes to the other components, possibly stemming from job dissatisfaction, family and personal obligations and health issues, could influence the individual's transcultural ability. An individual, who is a good candidate for overseas assignments due to their high transcultural ability (Earley et al., 2006), may or may not have the same level of transcultural ability in the future, even if their cultural intelligence remains stable.

The description of the transcultural construct, with respect to its components, follows the format of much of cross-cultural leadership theory. The work of Geert Hofstede, the 
Globe Project, and Trompenaars and Hampden-Turner, for example, describe their theory with the use of multiple dimensions (Hofstede, 1980; House et al., 2002; Trompenaars and Hampden-Turner, 1998). These theories use dimensions, similar to how the research in this study used components, to allow for a range or span of content to be combined in order to identify an individual's position within the particular theory. Similar to the other dimension-based theories, changes in the components can impact the overall positioning of the individual as determined by the theory. However, transcultural ability is different from these dimension-based theories as it is centered on an individual, not on a culture. For example, Hofstede's dimensions are based on national cultural values in an attempt to identify individuals who would be best suited to a specific culture based on having similar values (Hofstede, 1980). The value-based theories rely on the stability of the national values and the matching of the individual with a specific set of cultural values. Another difference between transcultural ability and the value-based dimension theories is that transcultural ability focuses on the abilities of the individual, regardless of the target culture (Graen et al., 1997). The older dimension theories are attempting to align an individual with a culture based on the value rankings for overseas success; whereas transcultural ability focuses solely on the individual's abilities as the indicator of such success. Another difference between transcultural ability and the value-based theories is that transcultural ability is not stable. Individuals who may not be desirable for overseas positions at one point in time could be highly desirable in the future.

The research in this study has refined and reshaped the transcultural literature through the empirical findings. The concept of the transcultural now has the possibility of being 
reverse-engineered. That is, the components of the scale can and should be used to develop more holistic theory.

In summary, this research provides both a definition of the transcultural construct and a tool for measuring transcultural ability. The model derived from the research clarifies our understanding of the construct with a loading hierarchy of the model's fifteen components. Transcultural development is an ability-based model and therefore transcultural ability can change over time. Predictive validity has linked transcultural development with expatriate success and suggests that the higher the transcultural ability, the more likely that the expatriate will successfully complete their overseas assignment. Transcultural ability, while incorporating cultural intelligence, has been shown to be distinct from it, as it incorporates a more complex and comprehensive mix of abilities than cultural intelligence alone. This suggests that transcultural ability may be a more robust construct for predicting expatriate success than cultural intelligence.

The next and final chapter in this dissertation provides the conclusion to the research, including the practical implications and limitations of the study, and suggestions for future research. 


\section{CONCLUSION}

The first section in this chapter provides a summary conclusion of the research undertaken, followed by a discussion of the practical implications of the research. The research limitations are then presented. The final section in this chapter offers recommendations for future research with the transcultural construct.

\subsection{Summary Conclusion}

This dissertation has clarified the definition of transcultural and provided an empirically developed scale, the TMS, for measuring an individual's transcultural ability. The modest amount of academic literature that was available on transculturals was purely conceptual. The research in this dissertation broadens our knowledge of the transcultural construct by providing fifteen components that have been empirically linked to expatriate success.

This study has also provided support for the use of the transcultural scale in the foreign assignment selection process. Organizations need a better way to predict expatriate success and are paying more attention to expatriate selection and development (Chen $e t$ al, 2010; Paik et al., 2002; Osman-Gani and Rockstuhl, 2009). Each year, an increasing number of employees are being sent to foreign work locations (Okpara and Kabongo, 2011). While the number of employees being sent overseas is increasing, the success rates are not favourable. In $2009,17 \%$ of expatriates left their company during an overseas assignment and $38 \%$ left within one year of returning home (Brookfield, 2010). The costs are not only monetary for organizations as the indirect costs of unsuccessful 
assignments include damaged relations and reputations with foreign businesses and host governments (Vogel et al., 2008). Organizations may be able to increase the likelihood of overseas success by selecting those that score high on the TMS for their foreign assignments.

The distinction between transcultural ability and cultural intelligence was clarified and reinforced. Transcultural ability was shown to be a more comprehensive construct for achieving expatriate success than cultural intelligence alone. The research indicated that cultural intelligence holds an important, but relatively minor role in transcultural ability.

In summary, the research in this dissertation not only enhances our knowledge of the transcultural construct, it also provides a means for measuring transcultural ability. This research has also shown the predictive strength of the transcultural ability measure for increasing the likelihood of expatriate success.

The following section presents the practical implications flowing from the research in this dissertation.

\subsection{Practical Implications}

The TMS and the ability to identify an individual's stage of transcultural development could aid an organization's interview and selection process for both local and global employment opportunities. Those who score higher on the measure are more likely to 
complete the overseas job and facilitate cross-cultural relations than those who score lower on the measure.

In addition to identifying an individual's transcultural ability level, organizations can use this information to help develop appropriate transcultural improvement programs for the individuals it wants to send on foreign assignments. Such training programs could then be assigned according to the identified needs of an individual. Employees with lower levels of transcultural ability could be offered alternative assignments (better aligned with home country norms), or be provided with specialized training based on the components that need improvement. The effectiveness of the training could be measured by administering the TMS at multiple points in time with the results compared. This provides organizations with a process and procedure for identifying and improving the transcultural ability of their staff.

As the TMS provides organizations with an expectation of reliability for overseas employees, it could reduce the effort spent mitigating expatriate failures. The cost of failure is not only monetary, as corporate knowledge and experience is lost when the expatriate resigns. The overseas initiative may also suffer, depending on the authority and control of the expatriate.

Expatriate failure impacts the return on investment (ROI) of the foreign assignment, and the candidate selection process has been identified as the top initiative to improve ROI (Brookfield, 2010). The TMS could provide organizations with a method of identifying 
individuals who will have a greater likelihood of completing their overseas assignment. Assignment success would mitigate the high costs associated with expatriate failure which could improve the ROI from foreign assignments.

The TMS could aid organizations with their employee career planning, which is the second most popular initiative for improving expatriate assignment ROI (Brookfield, 2010). Many organizations focus exclusively on current opportunities and skills when selecting those for overseas work without planning for future needs with employee development initiatives (Harvey, 1982; Kim and Slocum, 2008; Shin et al., 2007). A TMS provides organizations with the possibility of selecting employees for overseas placements with a measure that could be incorporated into the organization's globalization strategy and in the career development path offered to their employees (Gelfand et al, 2007; Lazarova and Tarique, 2005).

The following section presents the research limitations of this study.

\subsection{Research Limitations}

While the research findings contribute to the theoretical and practical body of knowledge, there are limitations that need to be acknowledged. There are seven limitations with the current research.

The first limitation concerns the generalizability of the results. This limitation is based on two facts: the majority of the participants were from North America, and the potential 
Western-bias of the researcher. Participants from Canada and the United States accounted for approximately $80 \%$ of the survey population. This over-representation is not surprising as the research was based in Canada with a Canadian researcher, however, it does caution against generalizing the results across non-North American (Western) cultures. Further research is required to determine if the TMS is generalizable across cultures.

The generalizability limitation also concerns researcher bias from a cultural perspective. This is similar to Hofstede's concerns of Western bias in his survey questions based on a 1980 cross-nation study, the Chinese Value Survey (Chinese Culture Connection, 1987). Hofstede's survey was designed by Chinese researchers, and some of the questions appeared very strange from a Western perspective. Hofstede realized that he needed to add a fifth dimension to his original four to account for both Eastern and Western values in his dimension set (Hofstede, 2001). While the TMS questions were designed to be straightforward, some of the questions could be interpreted differently by someone from a non-Western culture.

The second limitation of the study is the reliability of a self-report survey. While this type of survey is common, self-perceptions can be self-serving and inaccurate. The tendency for such behaviour may be situational and dependent on many factors (Buhrmester et al., 1988). This research acknowledges the possibility that some participants may have been less than honest with their responses. Some may even have tried to determine the "correct answer". Self-reporting surveys are also subject to self- 
serving bias, which refers to a person's tendency to promote their strengths and downplay any weaknesses (Wolosin, Sherman, and Till, 1973). This theory suggests that a person claims more responsibility for an outcome when the outcome is positive (Campbell and Sedikides, 1999). In a study by Bendapudi and Leone (2003), customers took more responsibility for their actions than was warranted when they participated in a selfreporting study. In order to mitigate inclinations towards self-serving responses, the survey instructions indicated that the responses were anonymous and that the data was confidential. It was hoped that an inability to trace the data to the participant would encourage honest and truthful responses and thereby reduce both inaccuracy and any selfserving tendencies.

The third limitation of the research is that it was cross-sectional and does not assess an individual's transcultural ability over time. The research focused on an initial measurement as opposed to tracking an individual's transcultural growth through a segment of their career. TMS results showing a lower level of transcultural ability cannot be interpreted as an indication of the individual's future abilities in this area. Change in transcultural ability, from either experience or training, was not included in this research. Longitudinal research is needed to identify whether transcultural ability changes over time and how transcultural ability might be malleable to training.

The fourth limitation of this study is common source bias. This is centrally concerned with using only one sample for the data collection (Kammeyer-Mueller, Stell and Rubenstein, 2010). In this study the factor analysis process for scale development and 
validation used a split data-set, as opposed to data collected from two different samples. The random splitting of data was selected as it is supported by notable academics (Gerbing and Anderson, 1988; Stevens, 1999), and has been successfully used in scale development research (see Yoo and Chou, 2008).

The fifth limitation is the presence of common-method bias in the research. Common method bias is perceived when using a single method to collect all of the data (King, Liu, Haney and He, 2007). In this study, the same survey was used by all participants. It has been suggested that different samples and methods should be used for the scale development activities to mitigate bias from sample and method specific factors and to enhance the reliability of the study (Anderson et al., 1996; Hinkin, 1995).

The sixth limitation is the large discrepancy with gender frequencies, but this may be due to the survey distribution method. The survey participants were $34 \%$ female, whereas the expatriate population was only $17 \%$ female in 2009 , with a close $20 \%$ in 2008 (Brookfield, 2010). This gender imbalance may be because the survey was not distributed to a specific gender mix. As the survey was anonymous, it was not possible to control the respondents generated by Human Resource departments and those resulting from snowball sampling. It is possible that those distributing the survey link were gender imbalanced and provided the link to a disproportionate number of women and men than the expatriate population. 
The seventh and final limitation of this study is the existence of statistically significant differences between two of the demographic variables in the split data sets. The gender and the found repatriation difficult variables were significant at $p<.10$. The analysis found a p-value of .073 for gender and .052 for found repatriation difficult. The gender data was collected from the participants principally to analyze the generalizability of the full data set with the expatriate population. The found repatriation difficult variable was used in the construction of the dependent variable for regression testing. However, it should be noted that this last variable was dropped from the final construction of the dependent variable due to insignificance.

The following section presents recommendations for future research with respect to the TMS and the transcultural construct.

\subsection{Suggestions for Future Research}

In providing a measure for determining an individual's transcultural ability, this study raises questions and possibilities that require further research. The transcultural construct is in the nascent stages of theoretical and methodological development. This section provides a discussion of suggestions for future research.

Continuing research with the TMS is necessary to verify the generalizability of the measure beyond Western cultures. This research would involve non-Western participants and the translation of the TMS questions into a variety of languages from both a literal and a cultural perspective. Ideally this research would be undertaken in liaison with 
locals in the research target cultures to ensure non-bias in the methodology with respect to cultural differences and language.

Longitudinal research would build on the current research and provide an avenue for monitoring change in transcultural ability over time. Individuals on foreign assignments could complete the TMS at various points, such as the beginning, middle and end of the assignment (especially in the case of fixed assignment dates). This would provide insight towards identifying change in transcultural ability, and whether specific components change in importance over the course of an expatriate assignment.

Longitudinal research focusing on transcultural ability could be aligned with cultural exposure and/or training initiatives to determine their specific influence on the TMS. This research would include the use of the TMS prior to and post cultural exposure and/or training to determine the effectiveness of such exposure/training with respect to changes in transcultural ability. Controls would be required when repeating the TMS to ensure that there was a reasonable length of time between taking the test to help mitigate any learning behaviour associated with taking the TMS many times. This longitudinal research is valuable as the results of such studies could provide ways to strengthen transcultural ability, both before and during overseas assignments.

This research involved a sample set of participants with a range of education levels, types of work and nationalities. Future research, controlling the participant sample for specific demographic attributes, could be conducted to determine any further moderating or 
mediating influences on the TMS. Additional demographic research could also consider sourcing participants from a mix of cultures. This would provide researchers with a better understanding of the way transcultural ability develops between those with more varied cultural backgrounds.

There is also value for research with cultural intelligence due to the redundancy that eliminated all but one cultural intelligence component. This research would focus on how cultural intelligence may fit with the established transcultural abilities. The results of such research would strengthen and improve our knowledge of these two concepts.

The respect component was removed from the transcultural model due to its isolation in a factor distinct from transcultural ability. While there are explanations based on multiple interpretations of the nature of respect and on how this component may be more value than ability based, its isolation does merit future research.

Further validity testing should include convergent validity tests to confirm whether related constructs are significantly related to TMS, and discriminant validity checks to confirm that constructs that should have no relationship with the TMS do not.

Further research including the concept of self-monitoring may help to better understand the daily functioning of transculturals at all levels. High-self monitors can better adjust their behaviour to their situation than low self-monitors, which does imply that there may be a relationship between high self-monitors and high transcultural ability. Research 
should also address whether high-self monitors are better at adapting in cross-cultural situations than low self-monitors.

Future research should also address the common source and common method bias present in the current study. The TMS research should consider new methodologies to help validate the measure and address reducing common source bias by using more than one source of participants for the analysis (e.g., include expatriates, their immediate supervisor, and a client/customer). In addition, common method bias can be addressed by methodologies that include multiple methods, such as combining the collection of both survey and interview data in the data analysis activities

In closing, this research took an important step towards providing a more holistic picture of the abilities of successful expatriates. Previous research had touched upon these dimensions conceptually; however, empirical research had focused solely on cultural intelligence. This research situates $\mathrm{CI}$ as one important component of a larger transcultural measure. The Transcultural Measurement Scale (TMS) undoubtedly requires further testing, refinement and validity checks, but the scale provides a valuable starting point for researchers and firms interested in exploring a more comprehensive treatment of expatriate abilities. 


\section{REFERENCES}

Adler, N.J. (1983) Cross-Cultural Management Research: The Ostrich and the Trend. Academy of Management Review, 8(2), 226-232.

Adler, N.J. (1984) Understanding the Ways of Understanding: Cross-cultural Management Methodology Reviewed. Advances in International Comparative Management, 1, 31-67.

Adler, N.J. (1997) International dimensions of organizational behavior. Cincinnati, OH: South-Western College Publishing.

Adler, P.S. (1975) The Transitional Experience: An alternative view of culture shock. Journal of Humanistic Psychology, 15(4), 13-23.

Adler, P.S. (1977) Beyond Cultural Identify: Reflection upon Cultural and Multicultural Man. In R.W. Brislin (Ed.), Cultural Learning: Concepts, Applications and Research, The East-West Center, Hawaii.

Aitken, T. (1973) The multinational man: The role of the manager abroad. New York, NY: Wiley.

Anderson, D.R., Sweeney, D.J. and Williams, T.A. (1996) Statistics for Business and Economics. St. Paul, MN: West Publishing Company.

Andreason, A. and Kineer, K. (2005) Repatriation Adjustment Problems and the Successful Reintegration of Expatriates and Their Families. Journal of Behavioral and Applied Management, 6(2), 109-126.

Ang, S., Van Dyne, L., Koh, C. and Ng, K.Y. (2004) The measurement of cultural intelligence. Paper presented at the Academy of Management Meeting's Symposium on Cultural Intelligence in the 21 st Century, New Orleans, LA.

Ang, S., Van Dyne, L., Koh, C., Ng, K., Templer, K., Tay, C. and Chandrasekar, N. (2007) Cultural Intelligence: Its Measurement and Effects on Cultural Judgment and Decision Making, Cultural Adaptation and Task Performance. Management and Organizational Review, 3(3), 335-371.

Ardichvili, A. and Kuchinke, K.P. (2002) Leadership styles and cultural values among managers and subordinates: a comparative study of four countries of the former Soviet Union, Germany, and the US. Human Resource Development International, 5(1), 19-21.

Austin, E.J. (2010) Measurement of Ability Emotional Intelligence: Results for Two New Tests. British Journal of Psychology, 101, 563-578. 
Bass, B.M. (1990) Bass \& Stogdill's Handbook of Leadership, 3rd Edition. New York, NY: Free Press (MacMillians Inc.).

Bendapudi, N. and Leone, R. (2003) Psychological Implications of Customer Participation in Co-Production. Journal of Marketing, 67, 14-28.

Bhawuk, D.P. (1998) The role of culture Theory in Cross-Cultural Training: A Multimethod Study of Culture-Specific, Culture-General and Culture-Theory-Based Assimilators. Journal of Cross-Cultural Psychology, 29, 630-655.

Bird, A. and Stevens M.J. (2003) Toward an emergent global culture and the effects of globalization on obsolescing national cultures. Journal of International Management, 9, 395-407.

Black J. and Gregersen, H. (1999) The right way to manage expatriates. Harvard Business Review, March-April, 52-62.

Black, J. and Gregersen, H. (1991) When Yankee Comes Home: Factors Related to Expatriate and Spouse Repatriation Adjustment. Journal of International Business Studies, 22, 671-693.

Bochner, S. (1977) The mediating man and cultural diversity. In R. Brislin (Ed.) Cultural Learning: Concepts, Applications \& Research, The East-West Center, Hawaii.

Boyacigiller, N.A. and Adler, N.J. (1991) The Parochial Dinosaur: Organizational Science in a Global Context. Academy of Management Review, 16(2), 262-290.

Brewster, C. (1996) Foreign Affairs: Human Resource Management Expatriates: Chris Brewster on Coping with Overseas Employees, Financial Times, October 18, p. 15.

Brookfield (Global Relocation Services) (2010) Global Relocation Trends 2009, www.brookfieldgrs.com, downloaded February 25, 2011.

Brown, F. (2007) The Global Business Leader. Palgrave MacMillan: NY

Buhrmester, D., Furman, W., Wittenbert, M.T. and Reis, H.T. (1988) Five Domains of Interpersonal Competence in Peer Relationships. Journal of Personality and Social Psychology, 55(6), 991-1008.

Campbell, W. and Sedikides, C. (1999) Self-Threat Magnifies the Self-Serving Bias: A Meta-Analytic Integration. Review of General Psychology, 3(1), 23-43.

Caruso, D.R., Mayer, J.D. and Salovey, P. (2002) Relation of an Ability Measure of Emotional Intelligence to Personality. Journal of Personality Assessment, 79(2), 306320. 
Chen, G., Kirkman, B.L., Kim, K., Farh, C.I. and Tangirala, S. (2010) When does crosscultural motivation enhance expatriate effectiveness? A multilevel investigation of the moderating roles of subsidiary support and cultural distance. Academy of Management, 53(5), $1110-1130$.

Chhokar, J.S., Brodbeck, F.C. and House, R.J. (2007) Culture and Leadership Across the World: The GLOBE Book of In-Depth Studies of 25 Societies. Mahwah, NJ: Lawrence Erlbaum Associates.

Chinese Culture Connection (1987) Chinese values and the search for culture-free dimensions of culture. Journal of Cross-Cultural Psychology, 18(2), 143-174.

Clark, L.A. and Watson, D. (1995) Constructing Validity: Basic Issues in Objective Scale Development. Psychological Assessment, 7(3), 309-319.

Comrey, A.L. (1988) Factor-Analytic Methods and Scale Development in Personality and Clinical Psychology. Journal of Consulting and Clinical Psychology, 56(5), 754-761.

Comrey, A.L. (1988) Factor-Analytic Methods of Scale Development in Personality and Clinical Psychology. Journal of Consulting and Clinical Psychology, 56(5), 754-761

Costello A.B. and Osborne, J.W. (2005) Best practices in Exploratory Factor Analysis: Four Recommendations for Getting the Most from Your Analysis, Practical Assessment Research \& Evaluations, 10(7). Available online: $\mathrm{http}: / /$ pareonline.net/getvn.asp?v=10\&n=7.

Cray, D. (2007) The Four or Five Barred Cage: The Consequences of Hofstede's View of Culture. (Sprott Scholl of Business, Research, Sprott Letters) http://www.business.carleton.ca/research_dev/documents/letters/SL07-004.pdf.

Cray, D. and Mallory, G.R. (1998) Making Sense of Managing Culture. London, UK: International Thomson Business Press.

Cronbach, L.J. and Meehl, P.E. (1955) Construct Validity in Psychological Tests.

Psychological Bulletin, 52(4), 281-302

Crowne, K.A. (2008) What leads to cultural intelligence? Business Horizons, 51, 391399.

Davis, D. (1996) Business Research for Decision Making. Belmont, CA: Wadsworth Publishing Company.

de Winter, J.C., Dodou, D. and Wieringa, P.A. (2009) Exploratory Factor Analysis with Small Sample Sizes. Multivariate Behavioral Research, 44(2), 47-181. 
DeCoster, J. (2004). Data Analysis in SPSS. Retrieved September 8, 2010 from http://www.stat-help.com/notes.html.

DeVellis, R.F. (1991) Scale Development. Newbury Park, CA: Sage Publications.

Deng, L. and Gibson, P. (2008) A Qualitative Evaluation on the Role of Cultural Intelligence in Cross-Cultural Leadership Effectiveness. International Journal of Leadership Studies, 3(2), 181-197.

Digman, J.M. (1990) Personality Structure: Emergence of the Five-Factor Model. Annual Review of Psychology, 41, 417-440.

Dinges, N. (1983) Intercultural Competence. In Landis D. and Bahagat, R.S. (Eds.) Handbook of Intercultural Training, Volume 1, Issues in Theory and Design. Elmsford, NY: Pergamon Press Inc. 176-202.

Earley, P.C. (2006). Leading cultural research in the future: A matter of paradigms and taste. Journal of International Business Studies, 37(6), 922-931.

Earley, P.C. and Mosakowski, E. (2004a) Toward culture intelligence: Turning cultural differences into a workplace advantage. Academy of Management Executive, 18(3), 151-157.

Earley, P.C. and Mosakowski, E. (2004b) Cultural Intelligence. Harvard Business Review, (October), 139-146.

Earley, P.C., Ang, S. and Tan, J.S. (2006) CQ: Developing Cultural Intelligence at Work. Stamford, CA: Stamford University Press.

Floyd, F.J. and Widaman, K.F. (1995) Factor Analysis in the Development and Refinement of Clinical Assessment Instruments. Psychological Assessment, 7(3), 286299.

Frein, M. and Castellanos, J.F. (2010) Leading Across Cultures. Leadership Excellence, 27(12), 18 .

Friedman, P.A., Dyke, L.S. and Murphy, S.A. (2009) Expatriate Adjustment from the Inside Out: An Autoethnographic Account. International Journal of Human Resource Management, 20(2), 252-268.

Fritz, W. and Mollenberg, A. (2001) Measuring Intercultural Sensitivity in different Cultural Context. Conference Paper, International Association for Intercultural Communication Studies, July 24-29, 2001, Hong Kong. 
Freund R.J. and Minton, P.D. (1979) Regression Methods: A Tool for Data Analysis. New York, NY: Marcel Dekker, Inc.

Frost, J. and Walker, M. (2007) Cross cultural leadership. Engineering Management, 17(3), 27-29.

Fulkerson, J.R. (1999). Global Leadership Competencies for the Twenty-First Century: More of the same or a new paradigm for what leaders really do? In William H. Mobley (Ed.), Advances in Global Leadership, Vol. 1 (pp. 27-48). Stamford, Connecticut: Jai Press Inc.

Furnham, A. and Bochner, S. (1982) Social difficulty in a foreign culture: an empirical analysis of culture shock, Cultures in Contact: Studies in Cross-Cultural Interaction. Ed. Bochner, S. Pergamon Press, Oxford England.

Gelfand, M.J., Erez, M. and Aycan, Z. (2007) Cross-Cultural Organizational Behaviour. Annual Review of Psychology, 58, 479-514.

Gerbing, D.W. and Hamilton, J.G. (1996) Viability of exploratory factor analysis as a precursor to confirmatory factor analysis. Structural Equation Modeling: A Multidisciplinary Journal, 3(1), 62-72.

Graen, G.B. (2006) In the Eye of the Beholder: Cross-Cultural Lesson in Leadership from Project GLOBE. Academy of Management Perspectives, November, 95-101.

Graen, G.B. and Hui, C. (1999) Transcultural global leadership in the 21st century. In Mobley, W.H., Arnold, V. and Gessner, J. (Eds), Advances in Global Leadership, 1, 926. Stamford, CT: JAI Press.

Graen, G.B., Hui, C. and Gu, Q.L. (2004) A new approach to intercultural cooperation. In Graen, G.B. (Ed.), New frontiers of leadership, LMX Leadership: The series, Vol. 2, 225-246.

Graen, G.B., Hui, C., Wakabayashi, M. and Wang, Z.M. (1997) Cross-Cultural Research Alliances in Organizational Research: Cross-cultural partnership-making in action. In Earley C. and Erez M. (Eds.), New Perspectives on International/Industrial/ Organizational Psychology, (p.75-129). San Francisco, CA: Jossey-Bass Inc.

Gerbing, D.W. and Anderson, J.C. (1988) An Updated Paradigm for Scale Developing Incorporating Unidimensionality and Its Assessment. Journal of Marketing Research, $25(2), 186-92$

Goh, J. and Pin, W. (2009) Parallel leadership in an 'unparallel' world - cultural constraints on the transferability of Western educational leadership theories across cultures. International Journal of Leadership in Education, 12(4), 319-345. 
Goleman, D. (1995) Emotional Intelligence: Why it can matter more than IQ. New York: Bantam.

Graf, A. and Harland, L.K. (2005) Expatriate Selection: Evaluating the Discriminant, Convergent, and Predictive Validity of Five Measures of Interpersonal and Intercultural Competence. Journal of Leadership and Organizational Studies, 11(2), 46-62.

Grisham, T. (2006) Metaphor, poetry, storytelling and cross-cultural leadership. Management Decision, 44(4), 486-503.

Grove, C. (2005) Introduction to the GLOBE Leadership Project Worldwide. Retrieved from http://www.grovewell.com/pub-GLOBE-intro.html.

Hair, J.F., Anderson, R.E. and Black, W.C. (2002). Multivariate Data Analysis. 6th Edition, Upper Saddle River, NJ: Prentice Hall.

Hampden-Turner, C.M. and Trompenaars, F. (2000) Building Cross-Cultural Competence. New Haven, Conn: Yale University Press.

Han, E. and Ki, E.J. (2010) Developing a measure of celebrity reputation. Public Relations Review, 36, 199-201.

Harris, M. (1999) Theories of Culture in Post-Modern Times. Walnut Creek, CA: Alta Mira Press.

Harris, P. and Moran, R. (1991) Managing Cultural Differences. Gulf Publishing Company, Houston, TX.

Harzing, A.W. (2002) Are our referencing errors undermining our scholarship and credibility? The case of expatriate failure rates. The Journal of Organizational Behaviour, 23, 127-148.

Harzing, A.W. (1995) The persistent myth of high expatriate failure rates. The International Journal of Human Resource Management, 6, 457-475.

Harvey, M. (1982) The Other Side of Foreign Assignments. Columbia Journal of World Business, 17(1), 53-61.

Hawley, K. (2009) Developing your Global Workforce: Expatriate management in Africa - Not so easy; no room for complacency. HRM Magazine Retrieved June 20, 2009 from http://www.expatworld.co.za/journal_article_2.html.

Hawes, F. and Kealey, D. (1980) Canadians In Development. Ottawa, Canada: Canadian International Development Agency. 
Haynes, S.N., Richard, D.C. and Kubany, E.S. (1995) Content validity in psychological assessments: a functional approach to concepts and methods. Psychological Assessment, $7,238-247$.

Hinkin, T.R. (1995) A review of scale development practices in the study of organizations. Journal of Management, 21(5), 967-988.

Hofstede, G. (1980) Culture's Consequences: International Differences in Work-Related Values. 1st Edition, Thousand Oaks, CA: Sage.

Hofstede, G. (1991) Cultures \& Organizations. Maidenhead, England UK, Mc-Graw Hill Book Company.

Hofstede, G. (2001) Culture's Consequences: Comparing Values, Behaviors, Institutions and Organizations across Nations. 2nd Edition, Thousand Oaks, CA: Sage.

Hofstede, G. (2009) Retrieved July 16, 2009 from http://www.geert-hofstede.com/.

Hofstede, G.J. and Pedersen, P. (1999) Synthetic Cultures: Intercultural Learning Through Simulation Gaming. Simulation and Gaming, 30(4), 415-440.

Hofstede, G.J., Pedersen, P. and Hofstede, G. (2002) Exploring Culture, Exercise, Stories and Synthetic Cultures. Yarmouth, Maine: Intercultural Press.

Hofstede, G., Van Deusen, C.A., Mueller, C.B. and Charles, T.A. (2002) What goals do business leaders pursue? A study in fifteen countries. Journal of International Business Studies, 33(4), 785-803.

House, R.J. (1971) A Path-Goal Theory of Leadership Effectiveness. Administrative Science Quarterly, 321-338.

House, R., Javidan, M., Hanges, P. and Dortfman, P. (2002) Understanding cultures and implicit leadership theories across the globe: An introduction to project GLOBE. Journal of World Business, 37, 3-10.

House, R.J., Hanges, P.J., Javidan, M., Dorfman, P.W., Gupta, V. and GLOBE Associates (2004) Culture, Leadership, culture and organizations: The GLOBE study of 62 societies. Thousand Oaks, CA: Sage.

House, R.J., Hanges, P.J., Ruiz-Quintanilla, S.A., Javidan, M., Dorfman, P.W., Dickson, M. and Gupta, V. (1999) Project Globe. In W.H. Mobley, V. Arnold and J. Gessner (Eds.). Advances in Global Leadership. Volume 1 (pp. 171-233). Stamford, CT: JAI Press.

Hui, C. and Graen, G. (1997) Guanxi and Professional Leadership in Contemporary SinoAmerican Joint Ventures in Mainland China. Leadership Quarterly, 8(4), 451-468. 
Hui, C.H. and Triandis, H.C. (1985) Measurement in Cross-Cultural Psychology: A Review and Comparison of Strategies. Journal of Cross-Cultural Psychology, 16(2) 131152.

Hurn, B. (1999) Repatriation - the toughest assignment of all. Industrial and Commercial Training, 31, 224-228.

Inglehart, R.F. (2008) Changing Values among Western Publics from 1970-2006. West European Politics, 31, 130-146.

Javidan, M., House, R.J., Dorfman, P.W., Hanges, P.J. and de Luque, M.S. (2006) Conceptualizing and measuring cultures and their consequences: a comparative review of GLOBE's and Hofstede's approaches. Journal of International Business Studies, 37, 897-914.

Jenkins, E.M. and Mockaitis, A.I. (2010) You're from where? The influence of distance factors on New Zealand expatriates' cross-cultural adjustment. The International Journal of Human Resource Management, 21(15), 2694-2715.

Kammeyer-Mueller, J., Stell, P.D. and Rubenstein, A. (2010) The Other Side of Method Bias: The Perils of Distinct Source Research Designs. Multivariate Behavioral Research, 45, 294-311.

Kealey, D.J. (1989) A study of cross-cultural effectiveness: Theoretical issues, practical applications. International Journal of Intercultural Relations, 13, 387-428.

Kealey, D.J. (1996) The Challenge of International Personnel Selection. In D. Landis and R.S. Bhagat (Eds.), Handbook of Intercultural Training, 2nd Edition, Thousand Oaks, CA, Sage Publications.

Kealey, D.J. and Protheroe, D.R. (1996) The effectiveness of cross-cultural training for expatriates: an assessment of the literature on the issue. International Journal of Intercultural Relations, 20(2), 141-165.

Kealey, D.J. and Ruben, B.D. (1983) Cross-Cultural Personnel Selection Criteria, Issues and Methods. In Landis D. and Bahagat, R.S. (Eds.) Handbook of Intercultural Training, Volume 1, Issues in Theory and Design. Elmsford, NY: Pergamon Press Inc. 155-175.

Kealey, D.J., Protheroe, D.R., MacDonald, D. and Vulpe, T. (2006) International Projects: Some lesson on avoiding failure and maximizing success. Performance Improvement, 45(3), 38-46.

Kim, K. and Solocum, J.W. (2008) Individual differences and expatriate assignment effectiveness: The case of U.S.-based Korean expatriates. Journal of World Business, 43, 109-126. 
King, W.R., Liu, C.Z., Haney, M.H. and He, J. (2007) Method Effects in IS Survey Research: An Assessment and Recommendations. Communications of the Association for Information Systems, 20, 457-482.

Kline, R. (2005) Principles and Practice of Structural Equation Modeling. 2nd Edition. New York, NY: The Guilford Press.

Ko, Y.H. and Jun, C.H. (2009) Use of reference distributions when dealing with unknown regression errors. Journal of Statistical Computation \& Simulation, 79(10), 1195-1204.

Kroeber, A.L. and Kluckhohn, C. (1952) Culture: A Critical Review of Concepts and Definitions. New York, NY: Vintage Books.

Langdon, S.W. (2007) conceptualizations of Respect: Qualitative and Quantitative Evidence of Four (Five) Themes. The Journal of Psychology, 141(5), 469-484.

Lazarova, M. and Tarique, I. (2005) Knowledge transfer upon repatriation. Journal of World Business, 40, 361-373.

Lee, H. and Liu, C. (2006) The Determinants of Repatriate Turnover Intentions: An Empirical Analysis. International Journal of Management, 23, 751-762.

Leong, L.Y. and Fischer, R. (2011) Is Transformational Leadership Universal? A MetaAnalytical Investigation of Multifactor Leadership Questionnaire Means Across Cultures. Journal of Leadership \& Organizational Studies, 18(2), 164-174.

Light, D.A. (2003) Cross-Cultural Lessons in Leadership. MIT Sloan Management Review, 45(1), 5-6.

Likert, R.A. (1932) A technique for the measurement of attitudes. Archives of Psychology, 40, pp. 5-52.

Lobel, S. A. (1990) Global leadership competencies: Managing to a different drumbeat. Human Resource Management, 29(1), 39-47.

Loevinger, J. (1957) Objective tests as instruments of psychological theory. Psychology Reports, 3, 635-694.

MacCallum, R.C., Widaman, K.F., Zhang, S. and Hong, S. (1999) Sample size in factor analysis. Psychological Methods, 4, 84-99.

Maddox, R.C. (1993) Cross-Cultural Problems in International Business. Westport, CT: Quorum Books, Greenwork Publishing Group. 
Meglina, B.M. and Ravlin, E.C. (1998) Individual Values in Organizations: Concepts, Controversies and Research. Journal of Management, 24(3), p.355-375.

Milhouse, V.H., Asante, M.K. and Nwosu, P.O. (2000) Transcultural Realities. Thousand Oaks, CA: Sage.

Montgomery, K., Kane, K. and Vance, C. (2004) Accounting for Differences in Norms of Respect. Group \& Organizational Management, 29(2), 248-268.

Moore, K.A., McCabe, M.P. and Stockdale, J.E. (1998) Factor analysis of the Personal Assessment of Intimacy in Relationships Scale (PAIR): engagement, communication and shared friendships. Sexual and Martial Therapy, 13(4), 361-368.

Mosteller, R. and Tukey, J.W. (1977) Data Analysis and Regression. Reading MA: Addison-Wesley Publishing Company.

Muthen, B. and Kaplan, D. (1985) A Comparison of Methodologies for the Factor Analysis of Non-Normal Likert Variables. British Journal of Mathematical and Statistical Psychology, 38(1), 171-189.

Nankervis, A., Compton, R. and McCarthy, T. (1993) Strategic Human Resource Management. Thomas Nelson Australia, South Melbourne.

Naumann, E. (1992) A conceptual model of expatriate turnover. Journal of International Business Studies, 23(3), 499-531.

Netemeyer, R.G. Bearden, W.O. and Sharma, S. (2003) Scaling Procedures: Issues and Applications. London: Sage.

Ng, K.Y. and Earley, P.C. (2006) Culture + Intelligence: Old Constructs, New Frontiers. Group \& Organization Management, 31(1), 4-19.

Ng, K.M, Wang, C., Kim, D.H. and Bodenhorn, N. (2010) Factor Structure Analysis of the Schutte Self-Report Emotional Intelligence Scale on International Students. Educational and Psychological Measurement, 70(4), 695-709.

Ng, K.Y., Van Dyne, L. and Ang. S. (2009) From Experience to Experiential Learning: Cultural Intelligence as a Learning Capability for Global Leader Development. Academy of Management Learning \& Education, 8(4), 511-526.

Nguyen, N.T., Biderman, M.D. and McNary, L.D. (2010) A validation study of the Cross-Cultural Adaptability Inventory. International Journal of Training and Development, 14(2), 112-129. 
Nunnally, J.C. and Bernstein, I.H. (1994) Psychometric Theory. New York: McGrawHill.

Oberg, K. (1960) Cultural Shock: Adjustment to New Cultural Environments. Practical Anthropology, 7, 177-182.

Okpara, J.O. and Kabongo, J.D. (2011) Cross-cultural training and expatriate adjustment: A study of western expatriates in Nigeria. Journal of World Business, 46, 22-30.

Osman-Gani, A.M. and Rockstuhl, T. (2009) Cross-cultural training, expatriate selfefficacy, and adjustments to overseas assignments: An empirical investigation of managers in Asia. International Journal of Intercultural Relations, 33, 277-290.

Osman-Gani, A.M. and Rockstuhl, T. (2008) Consequences of Social Network Characteristics for Expatriate Adjustment and Performance in Overseas Assignments: An Empirical Investigation of Managers in Asia. Academy of Management Annual Meeting Proceedings, 1-6.

Osland, J.S., Bird, A., Mendenhall, M. and Osland, A. (2006) Developing Global Leadership Capabilities and Global Mindset: A Review. Northampton, MA: Edwad Elgar Publishing.

Paik, Y., Segaud, B., and Malinowski, C. (2002) How to improve repatriation management. International Journal of Manpower, 23(7), 635-648.

Pellegrini, E. K., and Scandura, T. A. (2008) Paternalistic leadership: A review and agenda for future research. Journal of Management, 34(3), 566-593.

Pellegrini, E. K., Scandura, T. A. and Jayaraman, V. (2010) Cross-cultural generalizability of paternalistic leadership: An expansion of leader-member exchange theory. Group \& Organization Management, 35(4), 391-420.

Pires, G., Stanton, J. and Ostenfeld, S. (2006) Improving Expatriate Adjustment and Effectiveness in Ethically Diverse Countries. Cross Cultural Management, 1(2), 156170.

Punnett, B.J., Crocker, O. and Stevens, M.A. (1992) The Challenge for Women Expatriates and Spouses: Some Empirical Evidence. International Journal of Human Resource Management, 3(3), 585-92.

Ralston, D.A and Pearson, A. (2010) the Cross-Cultural Evolution of the Subordinate Influence Ethics Measure. Journal of business Ethics, 96, 149-168.

Raskovic, M. and Krzisnik, S. (2010) Cross-cultural comparison of leadership practices from Slovenia and Portugal using the Globe Research Progama Methodology. Portuguese Journal of Management Studies, 15(2), 13-33. 
Redden, W. (1975) Culture Shock Inventory. Fredericton, NB, Canada, Organizational Texts Ltd.

Reise, S.P., Waller, N.G. and Comrey, A.L. (2000) Factor Analysis and Scale Revision. Psychological Assessment, 12(3), 287-297.

Ricks, D.A. (1999) Blunders in International Business. 3rd Edition, Malden, MA: Blackwell Publishers Inc.

Rode, C.J., Mooney, C.H., Arthaud-Day, M.L., Near, J.P., Baldwin, T.T., Rubin, R.S. and Boomer, W.H. (2007) Emotional intelligence and individual performance: evidence of direct and moderated effects. Journal of Organizational Behaviour, 28, 399-421.

Rodriquez, C.M. (2005) Emergence of a third culture: shared leadership in international strategic alliances. International Marketing Review, 22(1), 67-95.

Rokeach, M. (1973) The Nature of Human Values. New York, NY: The Free Press.

Rossiter, J.R. (2002) C-OAR-SE Procedures for Scale Development. International Journal of Research in Marketing, 19, 305-335.

Rossiter, J.R. (2008) Content Validity of Measures of Abstract Constructs in Management and Organizational Research. British Journal of Management, 19, 380-388.

Ruben, B.D. (1976) Assessing Communication Competency for Intercultural Adaptation. Group \& Organization Studies, 1(3), 334-354.

Ruben, B.D. (1989) The Study of Cross-Cultural Competence: Traditions and Contemporary Issues. International Journal of Intercultural Relations, 13, 229-240.

Sanchez, J., Spector, P. and Cooper, C. (2000) Adapting to a boundaryless world: A developmental expatriate model. Academy of Management Executive, 14, 96-106.

Scandura, T. and Dorfman, P. (2004) Leadership research in an international and crosscultural context. Leadership Quarterly, 15, 277-307.

Schilderinck, J.H. (1977) Regression and factor analysis applied in econometrics. Netherlands: Intercontinental Graphics Dordrecht.

Seber, G.A and Lee, A.J. (2003) Linear Regression Analysis. 2nd Edition, Hoboken, NJ: John Wiley \& Sons.

Selmer, J. ((2004) Psychological barriers to adjustment of Western business expatriates in China: newcomers vs long stayers. International Journal of Human Resource Management, 15(4), 794-813. 
Shannonhouse, R. (1996) Overseas-assignment failures. USA Today International, November, 8.

Shapiro, S.L., Giannoulakis, C., Drayer, J. and Want, C.H. (2010) An examination of athletic alumni giving behavior: Development of the Former Student-Athlete Donor Constraint Scale. Sport Management Review, 13, 283-295.

Shin, S., Morgeson, F.P. and Campion, M.A. (2007) What you do depends on where you are: understanding how domestic and expatriate work requirements depend upon the cultural context. Journal of International Business Studies, 38, 64-83.

Sims, R. and Schraeder, M. (2004) An examination of salient factors affecting expatriate culture shock. Journal of Business and Management, 10(1), 73-88.

Smith, P.B. (2006) When elephants fight, the grass gets trampled: The GLOBE and Hofstede projects. Journal of International Business Studies, 37, 915-921.

Solomon, C. (1994) Success abroad depends on more than job skills. Personnel Journal, 4, 51-59.

Spector, P.E. (1992) Summated Rating Scale Construction: An Introduction. Newbury Park, CA: Sage Publications.

Spreitzer, G. M., McCall Jr., M. W. and Mahoney, J. D. (1997) Early Identification on International Executive Potential. Journal of Applied Psychology, 82(1), 6-29.

SPSS Statistics Users Guide - Retrieved September 9, 2010 from http://www.spss.com.

Stalans, L.J. (1995) Multidimensional Scaling. In Grimm, L.G. and Yarnold, P.R. (Eds.), Reading and Understanding Multivariate Statistics, (p.137-168), Washington, DC:

American Psychological Association.

Stevens, J.P. (2009) Applied Multivariate Statistics for the Social Sciences. 5th Edition, New York, NY: Routledge.

Stevens, S.S. (1946) On the theory of scales of measurement. Science, 103, 677-680.

Strang, K.D. (2007) Examining effective technology project leadership traits and behaviours. Computers in Human Behavior, 23, 424-462.

Stogdill, R.M. (1975) The Evolution of Leadership Theory. In Academy of Management Proceedings, 1975 (pp. p.4-6).

Stonequist, E.V. (1937) The Marginal Man. New York, NY: Scribner. 
Swann, W.B. Jr., Chang-Schneider, C. and Larsen McClarty, K.L. (2007) Do people's self-views matter? Self-concept and self-esteem in everyday life. American Psychologist, 62(2), 84-89.

Tabachnick, B.G. and Fidell, L.S. (2001) Using Multivariate Statistics. Boston, MA: Allyn and Bacon.

Triandis, H.C. (2006) Cultural intelligence in organizations. Group \& Organization Management, 31(1), 20-26.

Trompenaars, F. and Hampden-Turner, C. (1998) Riding the Waves of Culture. New York, NY: McGraw-Hill.

Van Der Veen, R. and Song, H. (2010) Exploratory Study of the Measurement Scales for the Perceived Image and Advertising Effectiveness of Celebrity Endorsements in a Tourism Context. Journal of Travel \& Tourism Marketing, 27, 460-473.

Van Quaquebeke, N. and Eckloff, T. (2010) Defining Respectful Leadership: What It Is, How It Can Be Measured, and Another Glimpse at What It Is Related to. Journal of Business Ethics, 91, 343-358.

Vogel, A.J., van Vuuren, J.J. and Millard, S.M. (2008) Preparation, support and training requirements of South African expatriates. South African Journal of Business Management, 39(3), 33-48.

Veilicer, W.F. and Fava, J.L. (1998) Effects of variable and subject sampling on factor pattern recovery. Psychological Methods, 3, 231-251.

Ward, C., Fischer, R., Lam, F.S. and Hall, L. (2009) The Convergent, Discriminate, and Incremental Validity of Scores on a Self-Report Measure of Cultural Intelligence. Educational and Psychological Measurement, 69(1), 85-105.

Wong, J., Wong, P.N. and Li, H. (2007) An investigation of leadership styles and relationship cultures of Chinese and expatriate managers in multinational construction companies in Hong Kong. Construction Management \& Economics, 25(1), 95-106.

Wood, A.M., Linley, P.A., Maltby, J., Baliousis, M. and Joseph, S. (2008) The Authentic Personality: A Theoretical and Empirical Conceptualization and Development of the Authenticity Scale. Journal of Counseling Psychology, 55(3), 385-399.

Williams, G. and Bent, R. (1996) Developing Expatriate Managers for Southeast Asia, Eds. Landis, D. and Bhagat, R.S. Handbook of Intercultural Training, 2nd Ed. Sage Publications, Thousand Oaks, CA. 
Wolosin, R., Steven, J. and Till, A. (1973) Effects of Cooperation and Competition on Responsibility Attribution After Success and Failure. Journal of Experimental Social Psychology, 9(3), 220-235.

Worldwide ERC (2009) Facts and Statistics. Downloaded from www.worldwideerc.org/ Resources/Research/Pages/Facts-and-Statistics.aspx on January 16, 2011.

Yoo, J.E. and Chon, K. (2008) Factors Affecting Convention Participation DecisionMaking: Developing a Measurement Scale. Journal of Travel Research, 47, 113-122.

Zaccaro, S.J. (2007) Trait-Based Perspectives of Leadership. American Psychologist, 62(1), 6-16.

Zeira, Y. and Banai, M. (1985) Selection of expatriate managers in MNCs. International Studies of Management and Organization, 15(1), 33-51.

Zhang, B., Bi, Y.L. and Yu, G. (2010) Factor Analysis of a Scale to Assess State SelfMonitoring in Adolescents During Interview. Psychological Reports, 106(3), 721-730.

Zikmund, W.G. (2003) Business Research Methods, 7th Edition. Mason, OH: SouthWestern. 


\section{Appendix A: Criteria Considered Relevant to Overseas Adjustment/Success}

The following table contains a summary of the selection criteria results from a 1973 literature review on cross-cultural personnel selection. In this study, Kealey and Rubin analyzed cross-cultural personnel selection processes and identified the criteria used for predicting overseas success and adjustment (Kealey and Rubin, 1973). The following table provides this criteria listed by the type of study where it was found.

\section{Criteria Considered Relevant to Overseas Adiustment/Success}

\begin{tabular}{|c|c|c|c|}
\hline Peace Corps & $\begin{array}{l}\text { Overseas } \\
\text { Business }\end{array}$ & $\begin{array}{l}\text { Technical } \\
\text { Assistance }\end{array}$ & Military \\
\hline $\begin{array}{l}\text { Empathy } \\
\text { Courtesy } \\
\text { Interest in nationals } \\
\text { Flexibility } \\
\text { Patience } \\
\text { Tolerance } \\
\text { Technical Knowledge } \\
\text { Initiative } \\
\text { Openness } \\
\text { Extrovert } \\
\text { Positive self-image } \\
\text { Perseverance } \\
\text { Reliability } \\
\text { Intelligence } \\
\text { Service orientation }\end{array}$ & $\begin{array}{l}\text { Empathy } \\
\text { Respect } \\
\text { Interest in host culture } \\
\text { Flexibility } \\
\text { Adaptability } \\
\text { Tolerance } \\
\text { Technical skill } \\
\text { Initiative } \\
\text { Maturity } \\
\text { Independence } \\
\text { Sincerity } \\
\text { Integrity } \\
\text { Political sensitivity } \\
\text { Organizational ability } \\
\text { Motivation } \\
\text { Experience } \\
\text { Past performance } \\
\text { Managerial ability } \\
\text { Language skills } \\
\text { Emotional stability } \\
\text { Wives'opinion } \\
\text { Desire to go abroad } \\
\text { Overseas experience }\end{array}$ & $\begin{array}{l}\text { Empathy } \\
\text { Respect } \\
\text { Interest in nationals } \\
\text { Relationship building } \\
\text { Flexibility } \\
\text { Tolerance } \\
\text { Technical skill } \\
\text { Initiative } \\
\text { Non-judgemental } \\
\text { Open-mindedness } \\
\text { Outgoing } \\
\text { Positive self-image } \\
\text { Perseverance } \\
\text { Non-ethnocentricism } \\
\text { Honesty } \\
\text { Frankness }\end{array}$ & $\begin{array}{l}\text { Empathy } \\
\text { Respect } \\
\text { Interest in local culture } \\
\text { Adaptability } \\
\text { Acceptance } \\
\text { Technical skill } \\
\text { Non-judgemental } \\
\text { Open-mindedness } \\
\text { Sociability } \\
\text { Non-ethnocentricism } \\
\text { Intellectual curiosity } \\
\text { Morality }\end{array}$ \\
\hline
\end{tabular}

Source: Kealey and Ruben, 1973, p.166. 


\section{Appendix B: Inter-Item Correlation Matrix Tables}

The following pages contain the Inter-Item Correlation Matrix Tables. The first table presents the correlation results for the full data set gathered from the respondents. The second table presents the final data set used in the dissertation research. The final data set does not include the variables that were removed during the correlation analysis. 


\section{Appendix B - Table 1: Inter-Item Correlation Matrix}

Note: First iteration with all 60 Items

\begin{tabular}{|c|c|c|c|c|c|c|c|c|c|c|c|c|}
\hline ITEMS & $A D \_Q 1$ & $\mathrm{CO}_{\mathrm{Q} 2}$ & OB_Q3 & EM_Q4 & EX_Q5 & $F L Q 6$ & MO_Q7 & NJ_Q8 & OB_Q9 & PA_Q10 & RE_Q11 & MO_Q12 \\
\hline$\overline{A D Q 1}$ & 1.000 & 0.759 & 0.691 & 0.767 & -0.730 & 0.657 & 0.603 & 0.557 & -0.299 & 0.612 & 0.122 & -0.452 \\
\hline 0 Q2 & 0.759 & 1.000 & 0.850 & 0.893 & -0.696 & 0.818 & 0.762 & 0.590 & -0.221 & 0.729 & 0.316 & -0.557 \\
\hline $\mathrm{OB} Q \mathrm{Q3}$ & 691 & 0.850 & 1.000 & 0.865 & -0.596 & 0.778 & 0.787 & 0.623 & -0.079 & 0.679 & .356 & -0.494 \\
\hline EM_Q4 & 0.767 & 0.893 & 0.865 & 1.000 & -0.663 & 0.783 & 0.774 & 0.688 & -0.191 & 0.654 & .393 & -0.607 \\
\hline EX_Q5 & -0.730 & -0.696 & -0.596 & -0.663 & 1.000 & -0.574 & -0.506 & -0.540 & 0.372 & -0.479 & 0.003 & 0.510 \\
\hline$\overline{F L} Q 6$ & 657 & 0.818 & 0.778 & 0.783 & -0.574 & 1.000 & 0.825 & 0.506 & -0.182 & 0.732 & 0.357 & -0.551 \\
\hline MO Q7 & 603 & 762 & 0.787 & 0.774 & -0.506 & 0.825 & 1.000 & 0.609 & -0.045 & 0.643 & 0.447 & -0.513 \\
\hline NJQ8 & 0.557 & 0.590 & 0.623 & 0.688 & -0.540 & 0.506 & 0.609 & 1.000 & -0.080 & 0.514 & 0.361 & -0.728 \\
\hline OB_Q9 & -0.299 & -0.221 & -0.079 & -0.191 & 0.372 & -0.182 & -0.045 & -0.080 & 1.000 & 0.003 & 0.397 & 0.083 \\
\hline PAQ10 & 612 & 29 & 79 & 654 & $\overline{-0 .}$ & 0.732 & 43 & $\overline{14}$ & 0.003 & 1.000 & 24 & 2.455 \\
\hline RE Q11 & 0.122 & 316 & 0.356 & 393 & 0.003 & 357 & .447 & .361 & 0.397 & .424 & 00 & -0.260 \\
\hline $\mathrm{MOQ12}$ & -0.452 & 557 & -0.494 & -0.607 & 0.510 & -0.551 & -0.513 & -0.728 & 0.083 & -0.455 & 60 & 1.000 \\
\hline RE_Q13 & 101 & 099 & 0.240 & 183 & 0.212 & 0.166 & 0.376 & 0.281 & 0.437 & 0.084 & $\overline{94}$ & 0.153 \\
\hline RE_Q14 & 075 & 327 & 458 & 441 & 0.042 & 0.349 & 0.503 & .418 & 0.409 & .354 & 26 & 0.296 \\
\hline$F L Q 15$ & 0.740 & 0.863 & 0.852 & 0.829 & -0.650 & 0.860 & 0.792 & 0.551 & -0.205 & 0.745 & .323 & -0.486 \\
\hline REQQ16 & -0.541 & -0.409 & -0.307 & -0.415 & 0.570 & -0.441 & -0.338 & -0.391 & 0.502 & -0.258 & 0.201 & 0.371 \\
\hline FA Q17 & 0.725 & 838 & 0.769 & 0.789 & -0.685 & 0.792 & 0.765 & 0.623 & -0.248 & 0.707 & 0.329 & -0.463 \\
\hline $\mathrm{CO} Q 18$ & 0.754 & 0.924 & 0.833 & 0.845 & -0.662 & 0.877 & 0.783 & 0.580 & -0.123 & 0.750 & 0.390 & -0.500 \\
\hline AD_Q19 & 0.822 & 0.885 & 0.796 & 0.844 & -0.726 & 0.847 & 0.792 & 0.583 & -0.224 & 0.732 & 0.305 & -0.520 \\
\hline ER_Q20 & .638 & -0.829 & -0.773 & -0.785 & 0.710 & -0.752 & -0.666 & -0.529 & 0.277 & -0.584 & -0.185 & 0.517 \\
\hline $\mathrm{Cl} \mathrm{Q21}$ & 0.768 & 0.869 & 0.844 & 0.804 & -0.721 & 0.817 & 0.797 & 0.577 & -0.214 & 0.717 & 0.255 & -0.496 \\
\hline $\mathrm{MO}$ Q22 & -0.672 & -0.655 & -0.612 & -0.707 & 0.725 & -0.641 & -0.628 & -0.677 & 0.225 & -0.536 & -0.133 & 0.726 \\
\hline RE Q23 & 0.148 & 0.300 & 0.439 & 0.409 & -0.011 & 0.427 & 0.593 & 0.434 & 0.368 & 0.355 & 0.737 & -0.378 \\
\hline FA Q24 & 0.715 & 0.867 & 0.827 & 0.810 & -0.632 & 0.825 & 0.843 & 0.598 & -0.024 & 0.741 & 0.427 & -0.465 \\
\hline COQ25 & 0.693 & 0.721 & 0.726 & 0.760 & -0.615 & 0.630 & 0.778 & 0.533 & 0.030 & 0.572 & 0.447 & -0.317 \\
\hline AD Q26 & -0.734 & -0.602 & -0.500 & -0.574 & 0.745 & -0.586 & -0.423 & -0.521 & 0.432 & -0.500 & 0.134 & 0.494 \\
\hline$\widehat{\mathrm{MO} Q 27}$ & -0.791 & -0.767 & -0.682 & -0.749 & 0.801 & -0.786 & -0.720 & -0.637 & 0.262 & -0.613 & -0.126 & 0.640 \\
\hline$\overline{E D \_Q 28}$ & 0.639 & 0.698 & 0.676 & 0.725 & -0.561 & 0.783 & 0.685 & 0.489 & -0.243 & 0.561 & 0.351 & -0.415 \\
\hline$A D \_$Q29 & 0.604 & 654 & 0.691 & 0.686 & -0.460 & 0.753 & 0.654 & 0.568 & -0.088 & 0.717 & 0.417 & -0.511 \\
\hline $\mathrm{Cl} Q \mathbf{Q} 30$ & 0.720 & 0.903 & 0.823 & 0.832 & -0.661 & 0.876 & 0.802 & 0.517 & -0.171 & 0.748 & 0.338 & -0.471 \\
\hline FL Q31 & 0.533 & 0.792 & 0.743 & 0.705 & -0.490 & 0.782 & 0.723 & 0.449 & -0.032 & 0.677 & 0.512 & -0.485 \\
\hline
\end{tabular}


Appendix B - Table 1: Inter-Item Correlation Matrix

\begin{tabular}{|c|c|c|c|c|c|c|c|c|c|c|c|c|}
\hline ITEMS & $A D Q 1$ & $\mathrm{CO} \mathrm{Q} 2$ & OB_Q3 & EM Q4 & EX_Q5 & $\mathrm{FL} Q 6$ & MO_Q7 & NJ_Q8 & OB_Q9 & $\mathrm{PA} Q \mathrm{Q10}$ & RE_Q11 & MO_Q12 \\
\hline NJ Q32 & -0.523 & -0.292 & -0.174 & -0.293 & 0.576 & -0.190 & -0.095 & -0.290 & 0.602 & -0.066 & 0.453 & 0.205 \\
\hline $\mathrm{OP} Q 33$ & -0.537 & -0.331 & -0.236 & -0.334 & 0.558 & -0.326 & -0.299 & -0.272 & 0.435 & -0.231 & 0.235 & 0.339 \\
\hline MO_Q34 & -0.770 & -0.752 & -0.623 & -0.652 & 0.715 & -0.701 & -0.654 & -0.535 & 0.233 & -0.555 & -0.142 & 0.545 \\
\hline OT_Q35 & 0.636 & 0.698 & 0.730 & 0.698 & -0.557 & 0.727 & 0.723 & 0.565 & -0.111 & 0.594 & 0.392 & -0.448 \\
\hline PA Q36 & 0.639 & 0.802 & 0.773 & 0.762 & -0.624 & 0.789 & 0.788 & 0.605 & -0.278 & 0.703 & 0.279 & -0.508 \\
\hline FL Q Q37 & 0.618 & 0.811 & 0.773 & 0.802 & -0.564 & 0.849 & 0.776 & 0.599 & -0.204 & 0.717 & 0.348 & -0.544 \\
\hline $\mathrm{Cl}$ Q38 & 0.590 & 0.827 & 0.790 & 0.818 & -0.538 & 0.835 & 0.786 & 0.548 & -0.151 & 0.619 & 0.411 & -0.503 \\
\hline$A D \_$Q39 & 0.634 & 0.860 & 0.790 & 0.797 & -0.569 & 0.823 & 0.785 & 0.558 & -0.240 & 0.720 & 0.346 & -0.491 \\
\hline$A D Q Q 40$ & 0.781 & 0.764 & 0.739 & 0.748 & -0.627 & 0.720 & 0.649 & 0.546 & -0.203 & 0.609 & 0.319 & -0.410 \\
\hline$F L Q 41$ & 0.667 & 0.762 & 0.728 & 0.745 & -0.643 & 0.813 & 0.644 & 0.500 & -0.097 & 0.690 & 0.273 & -0.448 \\
\hline OP_Q42 & 0.750 & 0.710 & 0.690 & 0.755 & -0.642 & 0.633 & 0.598 & 0.468 & -0.233 & 0.531 & 0.133 & -0.351 \\
\hline ST Q43 & 0.423 & 0.620 & 0.615 & 0.619 & -0.286 & 0.586 & 0.586 & 0.398 & 0.150 & 0.623 & 0.440 & -0.365 \\
\hline ST Q44 & 0.491 & 0.608 & 0.676 & 0.632 & -0.358 & 0.707 & 0.770 & 0.467 & -0.007 & 0.581 & 0.447 & -0.318 \\
\hline ST Q45 & 0.396 & 0.601 & 0.703 & 0.653 & -0.201 & 0.570 & 0.726 & 0.415 & 0.179 & 0.470 & 0.651 & -0.342 \\
\hline ER_Q46 & 0.535 & 0.720 & 0.757 & 0.705 & -0.464 & 0.705 & 0.815 & 0.505 & 0.028 & 0.624 & 0.464 & -0.397 \\
\hline $\mathrm{Cl} Q 47$ & 0.566 & 0.838 & 0.788 & 0.789 & -0.545 & 0.743 & 0.821 & 0.478 & 0.008 & 0.634 & 0.407 & -0.453 \\
\hline ST Q48 & 0.575 & 0.737 & 0.753 & 0.692 & -0.503 & 0.815 & 0.826 & 0.529 & -0.044 & 0.692 & 0.392 & -0.448 \\
\hline AD_Q4 & 0.384 & 0.534 & 0.565 & 0.589 & -0.299 & 0.642 & 0.596 & 0.327 & 0.120 & 0.491 & 0.329 & -0.410 \\
\hline ST Q50 & 0.734 & 0.850 & 0.771 & 0.793 & -0.684 & 0.848 & 0.824 & 0.542 & -0.102 & 0.653 & 0.356 & -0.505 \\
\hline FL_Q51 & 0.532 & 0.706 & 0.678 & 0.663 & -0.572 & 0.734 & 0.625 & 0.440 & -0.122 & 0.481 & 0.180 & -0.438 \\
\hline NJ_Q52 & -0.704 & -0.733 & -0.702 & -0.720 & 0.617 & -0.723 & -0.663 & -0.586 & 0.185 & -0.675 & -0.257 & 0.511 \\
\hline OPQ53 & 0.721 & 0.809 & 0.722 & 0.783 & -0.712 & 0.828 & 0.751 & 0.472 & -0.272 & 0.608 & 0.157 & -0.462 \\
\hline ED_Q54 & 0.466 & 0.598 & 0.604 & 0.617 & -0.538 & 0.466 & 0.516 & 0.582 & -0.167 & 0.461 & 0.208 & -0.575 \\
\hline EX Q55 & 0.800 & 0.857 & 0.798 & 0.840 & -0.765 & 0.846 & 0.769 & 0.554 & -0.212 & 0.696 & 0.235 & -0.489 \\
\hline FL Q56 & 0.693 & 0.838 & 0.800 & 0.820 & -0.645 & 0.824 & 0.818 & 0.607 & -0.152 & 0.750 & 0.407 & -0.582 \\
\hline ED_Q57 & 0.616 & 0.740 & 0.762 & 0.800 & -0.621 & 0.705 & 0.754 & 0.696 & -0.147 & 0.617 & 0.318 & -0.621 \\
\hline MO Q58 & 0.655 & 0.779 & 0.783 & 0.779 & -0.597 & 0.837 & 0.812 & 0.642 & -0.100 & 0.745 & 0.341 & -0.572 \\
\hline OB Q59 & 0.727 & 0.891 & 0.821 & 0.833 & -0.667 & 0.840 & 0.813 & 0.568 & -0.228 & 0.723 & 0.276 & -0.491 \\
\hline ED_Q60 & 0.540 & 0.695 & 0.686 & 0.667 & -0.530 & 0.721 & 0.698 & 0.484 & -0.201 & 0.583 & 0.363 & -0.470 \\
\hline
\end{tabular}




\section{Appendix B - Table 1: Inter-Item Correlation Matrix}

\begin{tabular}{|c|c|c|c|c|c|c|c|c|c|c|c|c|}
\hline ITEMS & RE_Q13 & RE_Q14 & $F L Q 15$ & RE_Q16 & FA Q17 & CO Q18 & $A D \_$Q19 & ER_Q20 & Cl Q21 & \begin{tabular}{|l|} 
MO_Q22 \\
\end{tabular} & RE_Q23 & FA_Q24 \\
\hline$\overline{A D \_Q 1}$ & -0.101 & 0.075 & 0.740 & -0.541 & 0.725 & 0.754 & 0.822 & -0.638 & 0.768 & -0.672 & 0.148 & 0.715 \\
\hline $\mathrm{CO} Q 2$ & 0.099 & 0.327 & 0.863 & -0.409 & 0.838 & 0.924 & 0.885 & -0.829 & 0.869 & -0.655 & 0.300 & 0.867 \\
\hline $\mathrm{OB} Q \mathrm{Q3}$ & 0.240 & 0.458 & 0.852 & -0.307 & 0.769 & 0.833 & 0.796 & -0.773 & 0.844 & -0.612 & 0.439 & 0.827 \\
\hline EM Q4 & 0.183 & 0.441 & 0.829 & -0.415 & 0.789 & 0.845 & 0.844 & -0.785 & 0.804 & -0.707 & 0.409 & 0.810 \\
\hline EX Q5 & 0.212 & 0.042 & -0.650 & 0.570 & -0.685 & -0.662 & -0.726 & 0.710 & -0.721 & 0.725 & -0.011 & -0.632 \\
\hline FL Q6 & 0.166 & 0.349 & 0.860 & -0.441 & 0.792 & 0.877 & 0.847 & -0.752 & 0.817 & -0.641 & 0.427 & 0.825 \\
\hline MO_Q7 & 0.376 & 0.503 & 0.792 & -0.338 & 0.765 & 0.783 & 0.792 & -0.666 & 0.797 & -0.628 & 0.593 & 0.843 \\
\hline NJ_Q8 & 0.281 & 0.418 & 0.551 & -0.391 & 0.623 & 0.580 & 0.583 & -0.529 & 0.577 & -0.677 & 0.434 & 0.598 \\
\hline OB_Q9 & 0.437 & 0.409 & -0.205 & 0.502 & -0.248 & -0.123 & -0.224 & 0.277 & -0.214 & 0.225 & 0.368 & -0.024 \\
\hline PA_Q10 & 0.084 & 0.354 & 0.745 & -0.258 & 0.707 & 0.750 & 0.732 & -0.584 & 0.717 & -0.536 & 0.355 & 0.741 \\
\hline RE_Q11 & 0.694 & 0.826 & 0.323 & 0.201 & 0.329 & 0.390 & 0.305 & -0.185 & 0.255 & -0.133 & 0.737 & 0.427 \\
\hline MO_Q12 & -0.153 & -0.296 & -0.486 & 0.371 & -0.463 & -0.500 & -0.520 & 0.517 & -0.496 & 0.726 & -0.378 & -0.465 \\
\hline RE Q13 & 000 & 781 & 0.141 & 0.293 & 0.079 & 0.141 & 0.099 & 0.019 & 0.102 & 0.012 & 0.692 & 0.222 \\
\hline RE Q14 & 0.781 & 000 & 0.318 & 0.215 & 0.286 & 0.370 & 0.279 & -0.252 & 0.297 & -0.127 & .731 & 0.442 \\
\hline FL Q15 & 0.141 & 318 & 1.000 & -0.416 & 0.885 & 0.905 & 0.933 & -0.760 & 0.924 & -0.666 & 0.339 & 0.873 \\
\hline RE Q16 & 0.293 & 215 & -0.416 & 00 & -0.527 & -0.376 & -0.469 & 0.456 & -0.388 & 0.483 & -0.019 & -0.348 \\
\hline FA Q17 & 0.079 & 0.286 & 0.885 & -0.527 & 1.000 & 0.865 & 0.884 & -0.762 & 0.829 & -0.709 & 0.311 & 0.895 \\
\hline $\mathrm{CO} Q 18$ & 0.141 & 370 & 0.905 & -0.376 & 0.865 & 1.000 & 0.929 & -0.786 & 0.895 & -0.658 & 0.383 & 0.901 \\
\hline AD_Q19 & 0.099 & 279 & 0.933 & -0.469 & 0.884 & 0.929 & 1.000 & -0.799 & 0.922 & -0.718 & 0.299 & 0.871 \\
\hline ER_Q20 & 019 & 252 & -0.760 & 0.456 & -0.762 & -0.786 & -0.799 & 1.000 & -0.773 & 0.670 & -0.201 & -0.763 \\
\hline C1 Q21 & 02 & 297 & 0.924 & -0.388 & 0.829 & 0895 & 0922 & -0.773 & 1.000 & -0.655 & 0.281 & 0.864 \\
\hline $\mathrm{MO} Q 22$ & 12 & -0.127 & -0.666 & 0.483 & -0.709 & -0.658 & -0.718 & 0.670 & -0.655 & 1.000 & -0.234 & -0.678 \\
\hline RE_Q23 & 92 & 731 & 0.339 & -0.019 & 0.311 & 0.383 & 0.299 & -0.201 & 0.281 & -0.234 & 1.000 & 0.474 \\
\hline FA_Q24 & 222 & 442 & 873 & 348 & 0.895 & 0.901 & 0.871 & -0.763 & 0.864 & 0.678 & 0.474 & 1.000 \\
\hline CO_Q25 & 284 & 446 & 0.749 & -0.284 & 0.750 & .769 & 0.783 & -0.663 & 0.785 & -0.614 & 0.452 & 0.844 \\
\hline$A D Q 26$ & 321 & 115 & .584 & 0.595 & 0.637 & -0.583 & -0.639 & 0.641 & -0.615 & 0.664 & 0.027 & -0.552 \\
\hline MO_Q27 & 0.073 & -0.096 & -0.799 & 0.627 & -0.829 & -0.788 & -0.834 & 0.743 & -0.799 & 0.837 & -0.202 & -0.784 \\
\hline ED_Q28 & 0.177 & 0.321 & 0.761 & -0.455 & 0.743 & 0.761 & 0.766 & -0.649 & 0.690 & -0.594 & 0.410 & 0.705 \\
\hline AD_Q29 & 0.229 & 0.425 & 0.741 & -0.301 & 0.650 & 0.708 & 0.719 & -0.682 & 0.690 & -0.584 & 0.403 & 0.679 \\
\hline Cl Q30 & 0.141 & 0.374 & 0.898 & -0.358 & 0.852 & 0.919 & 0.886 & -0.795 & 0.912 & -0.631 & 0.338 & 0.914 \\
\hline FL_Q31 & 0.334 & 0.466 & 0.816 & -0.230 & 0.725 & 0.801 & 0.742 & -0.630 & 0.797 & -0.522 & 0.457 & 0.803 \\
\hline
\end{tabular}




\section{Appendix B - Table 1: Inter-Item Correlation Matrix}

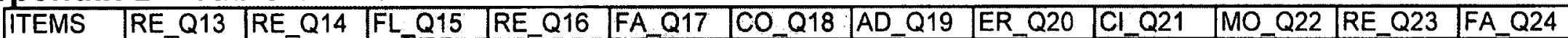

\begin{tabular}{|c|c|c|c|c|c|c|c|c|c|c|c|c|}
\hline & & & & & & & & & & & & \\
\hline NJ_Q32 & 0.499 & 0.454 & -0.272 & 0.643 & -0.346 & -0.244 & $\begin{array}{l}-0.341 \\
\end{array}$ & 0.314 & -0.299 & 0.407 & 0.335 & -0.175 \\
\hline $\mathrm{OP} Q 33$ & 0.356 & 0.303 & -0.403 & 0.599 & -0.457 & -0.338 & -0.445 & 0.271 & -0.416 & 0.506 & 0.084 & -0.328 \\
\hline MO_Q34 & 51 & -0.072 & -0.761 & 0.499 & -0.747 & -0.786 & -0.819 & 0.683 & -0.796 & 0.725 & -0.152 & -0.757 \\
\hline OT_Q35 & 226 & 0.413 & 0.781 & -0.357 & 0.769 & 0.734 & 0.732 & -0.674 & 0.754 & -0.550 & 0.441 & 0.738 \\
\hline PA_Q36 & 158 & 309 & 0.842 & -0.417 & 0.808 & 0.799 & 0.811 & -0.728 & 0.826 & 691 & 0.339 & .811 \\
\hline FL Q37 & 0.200 & 0.377 & 0.824 & -0.383 & 0.769 & 0.837 & 0.803 & -0.758 & 0.798 & -0.679 & 0.389 & 0.814 \\
\hline Cl_Q38 & 0.328 & 0.457 & 0.836 & -0.314 & 0.784 & 0.826 & 0.807 & -0.725 & 0.776 & -0.619 & 0.409 & 0.839 \\
\hline AD Q39 & 182 & 0.375 & 0.852 & -0.393 & 0.807 & 0.848 & 0.806 & -0.740 & 0.802 & -0.661 & .416 & .846 \\
\hline$A D Q Q 40$ & 0.123 & 0.303 & 0.807 & -0.339 & 0.747 & 0.807 & 0.836 & -0.743 & 0.824 & .619 & 234 & .758 \\
\hline FL_Q41 & 0.132 & 0.316 & 0.776 & -0.423 & 0.745 & 0.785 & 0.774 & -0.735 & 0.778 & -0.593 & 288 & 0.772 \\
\hline OPQ42 & 0.004 & 0.141 & 0.751 & -0.406 & 0.692 & 0.720 & 0.788 & -0.660 & 0.757 & -0.621 & 0.186 & 0.710 \\
\hline ST Q43 & 0.255 & 0.528 & 0.565 & -0.228 & 0.523 & 0.596 & 0.545 & -0.573 & 0.528 & -0.349 & 0.492 & 0.615 \\
\hline ST_Q44 & 0.376 & 0.533 & 0.664 & -0.245 & 0.635 & 0.690 & 0.653 & -0.583 & 0.684 & -0.434 & 0.612 & 0.708 \\
\hline ST_Q45 & 0.570 & 0.728 & 0.611 & -0.036 & 0.537 & 0.618 & 0.569 & -0.488 & 0.587 & -0.369 & 0.643 & 0.690 \\
\hline ER_Q46 & 0.328 & 0.512 & 0.738 & -0.229 & 0.655 & 0.773 & 0.738 & -0.647 & 0.750 & -0.485 & 0.506 & 0.763 \\
\hline Cl Q47 & 0.249 & 0.495 & 0.770 & -0.218 & 0.737 & 0.826 & 0.771 & -0.757 & 0.803 & -0.579 & 0.462 & 0.893 \\
\hline ST Q48 & 0.205 & 0.437 & 0.784 & -0.336 & 0.741 & 0.838 & 0.767 & -0.623 & 0.803 & -0.550 & 0.538 & 0.821 \\
\hline AD_Q4 & 0.279 & 0.356 & 0.575 & -0.248 & 0.514 & 0.538 & 0.513 & -0.518 & 0.487 & -0.431 & 0.396 & 0.590 \\
\hline ST Q50 & 0.178 & 0.353 & 0.850 & -0.400 & 0.813 & 0.889 & 0.875 & -0.753 & 0.856 & -0.715 & 0.405 & 0.919 \\
\hline$F L Q 51$ & 0.169 & 0.328 & 0.665 & -0.332 & 0.632 & 0.713 & 0.659 & -0.713 & 0.719 & -0.564 & 0.282 & 0.720 \\
\hline NJ_Q52 & -0.020 & -0.230 & -0.760 & 0.454 & -0.794 & -0.714 & -0.760 & 0.730 & -0.764 & 0.657 & -0.260 & -0.815 \\
\hline $\mathrm{OP} Q 53$ & -0.001 & 0.145 & 0.816 & -0.483 & 0.796 & 0.826 & 0.843 & -0.784 & 0.824 & -0.712 & 0.218 & 0.817 \\
\hline ED_Q54 & 0.162 & 0.304 & 0.526 & -0.407 & 0.542 & 0.587 & 0.557 & -0.551 & 0.583 & -0.555 & 0.258 & 0.516 \\
\hline $\mathrm{EX} \cdot \mathrm{Q55}$ & 0.058 & 0.247 & 0.885 & -0.488 & 0.836 & 0.875 & 0.917 & -0.798 & 0.887 & -0.699 & 0.257 & 0.859 \\
\hline$F L Q 56$ & 0.228 & 0.370 & 0.89 & -0.364 & 0.800 & 0.873 & 0.869 & -0.710 & 0.858 & -0.749 & 0.428 & 0.856 \\
\hline ED Q57 & 0.211 & 0.394 & 0.723 & -0.413 & 0.707 & 0.751 & 0.739 & -0.659 & 0.756 & -0.696 & 0.466 & 0.747 \\
\hline MO Q58 & 0.190 & 0.383 & 0.816 & -0.412 & 0.737 & 0.831 & 0.799 & -0.680 & 0.840 & -0.660 & 0.465 & 0.796 \\
\hline DB Q59 & 0.114 & 0.318 & 0.908 & -0.411 & 0.848 & 0.913 & 0.896 & -0.758 & 0.907 & -0.678 & 0.353 & 0.903 \\
\hline ED Q60 & 0.243 & 0.330 & 0.778 & -0.414 & 0.767 & 0.710 & 0.745 & -0.618 & 0.726 & -0.532 & 0.377 & 0.703 \\
\hline
\end{tabular}


Appendix B - Table 1: Inter-Item Correlation Matrix

\begin{tabular}{|c|c|c|c|c|c|c|c|c|c|c|c|c|}
\hline ITEMS & CO_Q25 & AD_Q26 & MO_Q27 & ED_Q28 & $A D \_Q 29$ & $\mathrm{Cl} Q \mathrm{Q30}$ & $F L \_Q 31$ & NJ_Q32 & OP_Q33 & MO Q34 & OT_Q35 & PA_Q36 \\
\hline$\overline{A D \_Q 1}$ & 0.693 & -0.734 & -0.791 & 0.639 & 0.604 & 0.720 & 0.533 & -0.523 & -0.537 & -0.770 & 0.636 & 0.639 \\
\hline$C O Q 2$ & 0.721 & -0.602 & -0.767 & 0.698 & 0.654 & 0.903 & 0.792 & -0.292 & -0.331 & -0.752 & 0.698 & 0.802 \\
\hline $\mathrm{OB} Q 3$ & 0.726 & -0.500 & -0.682 & 0.676 & 0.691 & 0.823 & 0.743 & -0.174 & -0.236 & -0.623 & 0.730 & 0.773 \\
\hline EM_Q4 & 0.760 & -0.574 & -0.749 & 0.725 & 0.686 & 0.832 & 0.705 & -0.293 & -0.334 & -0.652 & 0.698 & 0.762 \\
\hline EX_Q5 & -0.615 & 0.745 & 0.801 & -0.561 & -0.460 & -0.661 & -0.490 & .576 & 0.558 & .715 & .557 & 0.624 \\
\hline FL Q6 & 0.630 & -0.586 & -0.786 & 0.783 & 0.753 & 0876 & 0.782 & -0.190 & -0.326 & -0.701 & 0.727 & 0.789 \\
\hline MO Q7 & 0.778 & -0.423 & -0.720 & 0.685 & 0.654 & 0.802 & 0.723 & -0.095 & -0.299 & -0.654 & 0.723 & 0.788 \\
\hline NJ_Q8 & 0.533 & -0.521 & -0.637 & 0.489 & 0.568 & 0.517 & 0.449 & -0.290 & -0.272 & -0.535 & 0.565 & 0.605 \\
\hline OB_Q9 & 0.030 & 0.432 & 0.262 & -0.243 & -0.088 & -0.171 & -0.032 & 0.602 & 0.435 & 0.233 & -0.111 & -0.278 \\
\hline PA_Q10 & 0.572 & -0.500 & -0.613 & 0.561 & 0.717 & 0.748 & 0.677 & -0.066 & -0.231 & -0.555 & 0.594 & 0.703 \\
\hline REQ11 & 0.447 & 0.134 & -0.126 & 0.351 & 0.417 & 0.338 & 0.512 & 0.453 & 0.235 & -0.142 & 0.392 & 0.279 \\
\hline $\mathrm{MO} Q 12$ & -0.317 & 0.494 & 0.640 & -0.415 & -0.511 & -0.471 & -0.485 & 0.205 & 0.339 & 0.545 & -0.448 & -0.508 \\
\hline RE Q13 & 0.284 & 0.321 & 0.073 & 0.177 & 0.229 & 0.141 & 0.334 & 0.499 & 0.356 & 0.051 & 0.226 & 0.158 \\
\hline REQQ14 & 0.446 & 0.115 & -0.096 & 0.321 & 0.425 & 0.374 & 0.466 & 0.454 & 0.303 & -0.072 & 0.413 & 0.309 \\
\hline$F L Q 15$ & 0.749 & -0.584 & -0.799 & 0.761 & 0.741 & 0.898 & 0.816 & -0.272 & -0.403 & -0.761 & 0.781 & 0.842 \\
\hline RE_Q16 & -0.284 & 0.595 & 0.627 & -0.455 & -0.301 & -0.358 & -0.230 & 0.643 & 0.599 & 0.499 & -0.357 & -0.417 \\
\hline FA Q17 & 750 & -0.637 & -0.829 & 0.743 & 0.650 & 0.852 & 0.725 & 0.346 & -0.457 & -0.747 & 0.769 & 0.808 \\
\hline CO Q18 & 769 & -0.583 & -0.788 & 0.761 & 0.708 & 0.919 & 0.801 & -0.244 & -0.338 & -0.786 & 0.734 & .799 \\
\hline AD_Q19 & 83 & -0.639 & -0.834 & 0.766 & 0.719 & 0.886 & 0.742 & -0.341 & -0.445 & -0.819 & 0.732 & 0.811 \\
\hline ER Q20 & 663 & 0.641 & 743 & -0.649 & -0.682 & -0.795 & -0.630 & 0.314 & 0.271 & 0.683 & -0.674 & -0.728 \\
\hline Cl_Q21 & 785 & -0.615 & -0.799 & 0.690 & 0.690 & 0.912 & 0.797 & -0.299 & -0.416 & -0.796 & 0.754 & 0.826 \\
\hline MO_Q22 & 314 & 0.664 & 837 & -0.594 & -0.584 & -0.631 & -0.522 & 0.407 & 0.506 & 0.725 & -0.550 & 0.691 \\
\hline RE_Q23 & 152 & 0.027 & -0.202 & 0.410 & 0.403 & 0.338 & 0.457 & 0.335 & 0.084 & -0.152 & 0.441 & .339 \\
\hline FA Q24 & 344 & .552 & -0.784 & 0.705 & 0.679 & 0.914 & 0.803 & -0.175 & -0.328 & -0.757 & 0.738 & 0.811 \\
\hline CO_Q25 & 1.000 & -0.453 & -0.650 & 0.684 & 0.548 & 0.759 & 0.649 & -0.158 & -0.281 & -0.689 & 0.661 & 0.694 \\
\hline$A D Q Q 26$ & 453 & 1.000 & .748 & -0.592 & -0.489 & -0.608 & -0.405 & 0.687 & 0.577 & 0.613 & -0.573 & -0.594 \\
\hline MO Q27 & -0.650 & 0.748 & 1.000 & -0.662 & -0.656 & -0.766 & -0.656 & 0.493 & 0.589 & 0.832 & -0.692 & -0.786 \\
\hline ED_Q28 & 884 & -0.592 & -0.662 & 1.000 & 0.677 & 0.729 & 0.688 & -0.338 & -0.321 & -0.620 & 0.669 & 0.744 \\
\hline AD_Q29 & 548 & -0.489 & -0.656 & 0.677 & 1.000 & 0.709 & 0.657 & -0.163 & -0.187 & -0.554 & 0.651 & 0.725 \\
\hline Cl Q30 & 0.759 & -0.608 & -0.766 & 0.729 & 0.709 & 1.000 & 0.840 & -0.224 & -0.329 & -0.739 & 0.757 & 0.822 \\
\hline$F L \_31$ & 0.649 & -0.405 & -0.656 & 0.688 & 0.657 & 0.840 & 1.000 & 0.016 & -0.187 & -0.619 & 0.673 & 0.760 \\
\hline
\end{tabular}


Appendix B - Table 1: Inter-Item Correlation Matrix

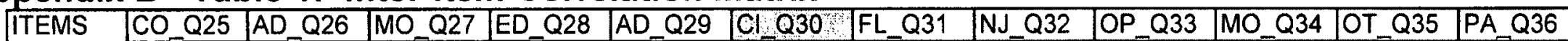

\begin{tabular}{|c|c|c|c|c|c|c|c|c|c|c|c|c|}
\hline & & & & & & & & & & & & \\
\hline NJ_Q32 & -0.158 & 0.687 & 0.493 & -0.338 & -0.163 & -0.224 & 0.016 & 1.000 & 0.649 & 0.422 & -0.242 & -0.320 \\
\hline$O P Q 33$ & -0.281 & 0.577 & 0.589 & -0.321 & -0.187 & -0.329 & -0.187 & 0.649 & 1.000 & 0.529 & -0.173 & -0.367 \\
\hline MOQQ34 & -0.689 & 0.613 & 0.832 & -0.620 & -0.554 & -0.739 & -0.619 & 0.422 & 0.529 & 1.000 & -0.563 & -0.683 \\
\hline OT_Q35 & 0.661 & -0.573 & -0.692 & 669 & 0.651 & 0.757 & 0.673 & -0.242 & -0.173 & -0.563 & 1.000 & 0.722 \\
\hline PA Q36 & 394 & .594 & -0.786 & 744 & 725 & 822 & .760 & -0.320 & -0.367 & -0.683 & 5.722 & 1.000 \\
\hline$F L Q Q 37$ & 0.678 & -0.542 & -0.761 & 749 & 0.773 & 0.839 & 0.784 & -0.223 & -0.266 & -0.679 & 678 & 0.933 \\
\hline $\mathrm{Cl}$ Q38 & 0.681 & -0.501 & -0.696 & 0.779 & 0.687 & $0: 887$ & 0.814 & -0.172 & -0.240 & -0.663 & 0.699 & 819 \\
\hline AD Q39 & 0.694 & -0.542 & -0.726 & .744 & 0.694 & 0.832 & .755 & -0.276 & -0.325 & -0.697 & 0.720 & 386 \\
\hline$A D Q Q 40$ & 0.729 & -0.612 & -0.692 & 0.675 & 747 & 10 & 663 & -0.321 & -0.360 & -0.712 & 706 & 711 \\
\hline$F L Q 41$ & 0.705 & -0.602 & 711 & 708 & 634 & 11 & 41 & -0.258 & -0.293 & 0.655 & .710 & 685 \\
\hline OPQQ42 & 0.740 & -0.599 & -0.651 & 0.624 & 0.533 & 0.726 & 0.465 & -0.458 & -0.476 & -0.661 & 0.591 & .616 \\
\hline ST Q43 & 0.553 & -0.314 & -0.475 & 0.529 & 0.512 & 0.600 & 0.584 & 0.016 & -0.083 & -0.428 & 0.479 & 581 \\
\hline ST Q44 & 0.696 & -0.394 & -0.544 & 0.708 & 0.560 & 0.715 & 0.676 & -0.038 & -0.231 & -0.488 & 0.617 & $\overline{0.692}$ \\
\hline ST_Q45 & 0.692 & -0.103 & -0.393 & 0.528 & 0.508 & 0.646 & 0.646 & 0.166 & -0.010 & -0.443 & 0.513 & 0.578 \\
\hline ER_Q46 & 0.749 & -0.360 & -0.597 & 0.560 & 0.584 & 0.753 & 0.670 & -0.061 & -0.227 & -0.564 & 0.588 & 0.743 \\
\hline Cl_Q47 & 0.801 & -0.424 & -0.646 & \begin{tabular}{l|}
0.571 \\
\end{tabular} & 0.568 & 0.850 & 0.749 & -0.061 & -0.242 & -0.659 & 0.639 & 0.718 \\
\hline ST_Q48 & 0.714 & -0.498 & -0.664 & 0.699 & 0.631 & 0.817 & 0.732 & -0.125 & -0.357 & -0.662 & 0.656 & 0.752 \\
\hline AD_Q4 & 0.488 & -0.315 & -0.538 & 0.508 & 0.535 & 0.582 & 0.590 & -0.067 & -0.120 & -0.395 & 0.559 & 0.587 \\
\hline ST Q50 & 0.829 & -0.580 & -0.804 & 0.729 & 0.617 & 0886 & 0.784 & -0.243 & -0.365 & -0.820 & 0.700 & 0.783 \\
\hline FL_Q51 & 0.595 & -0.556 & -0.675 & 0.579 & 0.515 & 0.768 & 0.650 & -0.214 & -0.156 & -0.556 & 0.706 & 0.614 \\
\hline NJ_Q52 & -0.677 & 0.656 & 0.772 & -0.641 & -0.624 & -0.791 & -0.686 & 0.339 & 0.302 & 0.668 & -0.756 & -0.750 \\
\hline OP Q53 & 0.735 & -0.633 & -0.831 & 0.717 & 0.593 & 0.867 & 0.718 & -0.312 & -0.422 & -0.792 & 0.656 & 0.789 \\
\hline ED_Q54 & 0.477 & -0.404 & -0.541 & 0.416 & 0.386 & 0.568 & 0.511 & -0.248 & -0.318 & -0.488 & 0.446 & 0.527 \\
\hline EX_Q55 & 0.771 & -0.664 & -0.823 & 0.756 & 0.672 & 0.898 & 0.734 & -0.387 & -0.425 & -0.781 & 0.742 & 0.791 \\
\hline FL_Q56 & 0.769 & -0.531 & -0.777 & 0.763 & 0.699 & 0.862 & 0.834 & -0.217 & -0.358 & -0.769 & 0.722 & 0.859 \\
\hline ED Q57 & 0.719 & -0.580 & -0.681 & 0.687 & 0.598 & 0.739 & 0.637 & -0.275 & -0.399 & -0.608 & 0.608 & 0.768 \\
\hline MO_Q58 & 0.708 & -0.569 & -0.755 & 0.771 & 0.706 & 0.832 & 0.813 & -0.219 & -0.312 & -0.660 & 0.699 & 0.831 \\
\hline OB_Q59 & 0.782 & -0.590 & -0.770 & 0.737 & 0.643 & 0.922 & 0.823 & -0.242 & -0.394 & -0.765 & 0.709 & 0.845 \\
\hline ED_Q60 & 0.582 & -0.446 & -0.649 & 0.635 & 0.630 & 0.732 & 0.723 & -0.163 & -0.370 & -0.572 & 0.677 & 0.712 \\
\hline
\end{tabular}




\section{Appendix B - Table 1: Inter-Item Correlation Matrix}

\begin{tabular}{|c|c|c|c|c|c|c|c|c|c|c|c|c|}
\hline ITEMS & $F L Q 37$ & Cl_Q38 & $A D, Q 39$ & $A D \_Q 40$ & FL_Q41 & OP_Q42 & ST_Q43 & ST_Q44 & ST_Q45 & ER_Q46 & CIQ47 & ST_Q48 \\
\hline$A D \_Q 1$ & 0.618 & 0.590 & 0.634 & 0.781 & 0.667 & 0.750 & 0.423 & 0.491 & 0.396 & 0.535 & 0.566 & 0.575 \\
\hline $\mathrm{CO}, \mathrm{Q} 2$ & 0.811 & 0.827 & 0.860 & 0.764 & 0.762 & 0.710 & 0.620 & 0.608 & 0.601 & 0.720 & 0.838 & 0.737 \\
\hline OB_Q3 & 0.773 & 0.790 & 0.790 & 0.739 & 0.728 & 0.690 & 0.615 & 0.676 & 0.703 & 0.757 & 0.788 & 0.753 \\
\hline EM_Q4 & 0.802 & 0.818 & 0.797 & 0.748 & 0.745 & 0.755 & 0.619 & 0.632 & 0.653 & 0.705 & 0.789 & 0.692 \\
\hline EXQQ5 & -0.564 & -0.538 & -0.569 & -0.627 & -0.643 & -0.642 & -0.286 & -0.358 & -0.201 & -0.464 & -0.545 & -0.503 \\
\hline$F L Q 6$ & 0.849 & .835 & 0.823 & 0.720 & 0.813 & 0.633 & 0.586 & 0.707 & 0.570 & 0.705 & 0.743 & 0.815 \\
\hline MO_Q7 & 0.776 & 0.786 & 0.785 & 0.649 & 0.644 & 0.598 & 0.586 & 0.770 & 0.726 & 0.815 & 0.821 & 0.826 \\
\hline NJ_Q8 & 0.599 & 0.548 & 0.558 & 0.546 & 0.500 & 0.468 & 0.398 & 0.467 & 0.415 & 0.505 & 0.478 & 0.529 \\
\hline OB_Q9 & -0.204 & -0.151 & -0.240 & -0.203 & -0.097 & -0.233 & 0.150 & -0.007 & 0.179 & 0.028 & 0.008 & -0.044 \\
\hline PA Q10 & 717 & 0.619 & 0.720 & 0.609 & 0.690 & 0.531 & 0.623 & 0.581 & 0.470 & 0.624 & 0.634 & 0.692 \\
\hline RE_Q11 & 0.348 & 0.411 & 0.346 & 0.319 & 0.273 & 0.133 & 0.440 & 0.447 & 0.651 & 0.464 & 0.407 & 0.392 \\
\hline $\mathrm{MO} Q 12$ & -0.544 & -0.503 & -0.491 & -0.410 & -0.448 & -0.351 & -0.365 & -0.318 & -0.342 & -0.397 & -0.453 & -0.448 \\
\hline REQ13 & 0.200 & 0.328 & 0.182 & 0.123 & 0.132 & 0.004 & 0.255 & 0.376 & 0.570 & 0.328 & 0.249 & 0.205 \\
\hline RE Q14 & 377 & 0.457 & 0.375 & 0.303 & 0.316 & 0.141 & 0.528 & 0.533 & 0.728 & 0.512 & 0.495 & 0.437 \\
\hline$F L Q 15$ & 0.824 & 0.836 & 0.852 & 807 & 0.776 & 0.751 & 0.565 & 0.664 & 0.611 & 0.738 & .770 & 0.784 \\
\hline REQ16 & -0.383 & 314 & -0.393 & -0.339 & -0.423 & -0.406 & -0.228 & -0.245 & -0.036 & -0.229 & -0.218 & -0.336 \\
\hline FA Q17 & 0.769 & 784 & 0.807 & 0.747 & 0.745 & 0.692 & 0.523 & 0.635 & 0.537 & 0.655 & 0.737 & 0.741 \\
\hline CO Q18 & 0.837 & 826 & 0.848 & 0.807 & 0.785 & 0.720 & 0.596 & 0.690 & 0.618 & 0.773 & .826 & 0.838 \\
\hline$A D \_$Q19 & 0.803 & 807 & 0.806 & 0.836 & 0.774 & 0.788 & 0.545 & 0.653 & 0.569 & 0.738 & 0.771 & 0.767 \\
\hline ER_Q20 & -0.758 & -0.725 & -0.740 & -0.743 & -0.735 & -0.660 & -0.573 & -0.583 & -0.488 & -0.647 & -0.757 & -0.623 \\
\hline $\mathrm{Cl}_{\mathrm{O} 21}$ & 0.798 & 776 & 0.802 & 0.824 & 0.778 & 0.757 & 0.528 & 0.684 & 0.587 & 0.750 & 0.803 & 0.803 \\
\hline MO_Q22 & 679 & -0.619 & -0.661 & -0.619 & 0.593 & -0.621 & -0.349 & -0.434 & -0.369 & -0.485 & -0.579 & -0.550 \\
\hline RE Q23 & 0.389 & 409 & 0.416 & 234 & 0.288 & 0.186 & 0.492 & 0.612 & 0.643 & 0.506 & 0.462 & 0.538 \\
\hline FA_Q24 & 0.814 & 839 & 0.846 & 0.758 & 0.772 & 0.710 & 0.615 & 0.708 & 0.690 & 0.763 & 0.893 & 0.821 \\
\hline CO_Q25 & 0.678 & 681 & 0.694 & .729 & 0.705 & 0.740 & 0.553 & 0.696 & 0.692 & 0.749 & 0.801 & 0.714 \\
\hline AD_Q26 & 542 & -0.501 & -0.542 & -0.612 & -0.602 & -0.599 & -0.314 & -0.394 & -0.103 & -0.360 & -0.424 & -0.498 \\
\hline $\mathrm{MO} Q \mathrm{Q} 27$ & -0.761 & -0.696 & -0.726 & -0.692 & -0.711 & -0.651 & -0.475 & -0.544 & -0.393 & -0.597 & -0.646 & -0.664 \\
\hline ED_Q28 & 0.749 & 779 & 0.744 & 0.675 & 0.708 & 0.624 & 0.529 & 0.708 & 0.528 & 0.560 & 0.571 & 0.699 \\
\hline$A D \_$Q29 & 0.773 & 0.687 & 0.694 & 0.747 & 0.634 & 0.533 & 0.512 & 0.560 & 0.508 & 0.584 & 0.568 & 0.631 \\
\hline $\mathrm{Cl} Q 30$ & 0.839 & 0.887 & 0.832 & 0.810 & 0.811 & 0.726 & 0.600 & 0.715 & 0.646 & 0.753 & 0.850 & 0.817 \\
\hline $\mathrm{FL} Q \mathrm{Q} 31$ & 0.784 & 0.814 & 0.755 & 0.663 & 0.641 & 0.465 & 0.584 & 0.676 & 0.646 & 0.670 & 0.749 & 0.732 \\
\hline
\end{tabular}




\section{Appendix B - Table 1: Inter-Item Correlation Matrix}

\begin{tabular}{|l|l|l|l|l|l|l|l|l|l|l|l|l|l|l|}
\hline ITEMS & FL Q37 & Cl Q38 & AD Q39 & AD_Q40 & FL_Q41 & OP_Q42 & ST_Q43 & ST_Q44 & ST_Q45 & ER_Q46 & Cl_Q47 & ST_Q48 \\
\hline
\end{tabular}

\begin{tabular}{|c|c|c|c|c|c|c|c|c|c|c|c|c|}
\hline & & & & & & & & & & & & \\
\hline NJ_Q32 & -0.223 & -0.172 & -0.276 & -0.321 & -0.258 & -0.458 & 0.016 & -0.038 & 0.166 & -0.061 & -0.061 & -0.125 \\
\hline OP Q33 & -0.266 & -0.240 & -0.325 & -0.360 & -0.293 & -0.476 & -0.083 & -0.231 & -0.010 & -0.227 & -0.242 & -0.357 \\
\hline MOQQ34 & -0.679 & -0.663 & -0.697 & -0.712 & -0.655 & -0.661 & -0.428 & -0.488 & -0.443 & -0.564 & -0.659 & -0.662 \\
\hline OT Q35 & 678 & 0.699 & 0.720 & 0.706 & 0.710 & 0.591 & 0.479 & 0.617 & 0.513 & 0.588 & 0.639 & 0.656 \\
\hline$\overline{P A}$ Q36 & 0.933 & 0.819 & 0.886 & 0.711 & 0.685 & 0.616 & 0.581 & 0.692 & 0.578 & 0.743 & 0.718 & 0.752 \\
\hline FLLQ37 & 1.000 & 0.855 & 0.868 & 0.709 & 0.737 & 0.594 & 0.618 & 0.686 & 0.597 & 0.749 & 0.743 & 0.752 \\
\hline Cl_Q38 & 0.855 & 1.000 & 0.831 & 0.724 & 0.764 & 0.663 & 0.563 & 0.670 & 0.700 & 0.683 & 0.762 & 0.720 \\
\hline AD 039 & 0.868 & 0.831 & 1.000 & 0.688 & 0.737 & 0.642 & 0.653 & 0.684 & 0.621 & 0.683 & 0.769 & 0.765 \\
\hline AD Q40 & 0.709 & 0.724 & 0.688 & 1.000 & 0.743 & 0.783 & 0.446 & 0.547 & 0.503 & 0.653 & 0.639 & 0.660 \\
\hline $\mathrm{FL} Q 41$ & 0.737 & 764 & 0.737 & 0.743 & 1.000 & 0.711 & 0.549 & 0.588 & 0.450 & 0.585 & 0.659 & 0.672 \\
\hline OPQ42 & 0.594 & 0.663 & 0.642 & 0.783 & 0.711 & 1.000 & 0.381 & 0.486 & 0.470 & 0.592 & 0.659 & 0.587 \\
\hline ST Q43 & 0.618 & .563 & 653 & 0.446 & 0.549 & .381 & 1.000 & .764 & 0.678 & 637 & 0.618 & 616 \\
\hline ST Q44 & 0.686 & 0.670 & 0.684 & 0.547 & 0.588 & 0.486 & 0.764 & 1.000 & 0.733 & 715 & 0.668 & 785 \\
\hline ST Q45 & 0.597 & 0.700 & 0.621 & 0.503 & 0.450 & 0.470 & 0.678 & 0.733 & 1.000 & 0.732 & 0.736 & 0.631 \\
\hline ER_Q46 & 0.749 & 0.683 & 0.683 & 0.653 & 0.585 & 0.592 & 0.637 & 0.715 & 0.732 & 1.000 & 0.815 & 0.820 \\
\hline Cl2047 & 0.743 & 0.762 & 0.769 & 0.639 & 0.659 & 0.659 & 0.618 & 0.668 & 0.736 & 0.815 & 1.000 & 0.804 \\
\hline ST Q48 & 0.752 & 0.720 & 0.765 & 0.660 & 0.672 & 0.587 & 0.616 & 0.785 & 0.631 & 0.820 & 0.804 & 1.000 \\
\hline$\widehat{A D \_Q 4}$ & 0.641 & 0.627 & 0.626 & 0.465 & 0.609 & 0.424 & 0.522 & 0.480 & 0.482 & 0.560 & 0.591 & 0.524 \\
\hline STRO50 & 0.808 & 0.815 & 0.820 & 0.766 & 0.782 & 0.718 & 0.538 & 0.647 & 0.638 & 0.772 & 0.842 & 0.801 \\
\hline FL_Q51 & 0.684 & 0.702 & 0.656 & 0.629 & 0.784 & 0.557 & 0.445 & 0.524 & 0.449 & 0.534 & 0.667 & 0.566 \\
\hline NJ Q52 & -0.738 & -0.742 & -0.716 & -0.698 & -0.754 & -0.638 & -0.474 & -0.541 & -0.511 & -0.572 & -0.677 & -0.616 \\
\hline OP Q53 & 0.805 & 0.809 & 0.732 & 0.740 & 0.782 & 0.687 & 0.486 & 0.614 & 0.519 & 0.629 & 0.744 & 0.713 \\
\hline ED_Q54 & 0.516 & 0.516 & 0.473 & 0.477 & 0.464 & 0.429 & 0.299 & 0.435 & 0.494 & 0.497 & 0.523 & 0.493 \\
\hline$E X @ 55$ & 0.806 & 0.814 & 0.785 & 0.811 & 0.837 & 0.771 & 0.505 & 0.613 & 0.533 & 0.683 & 0.760 & 0.726 \\
\hline$\overline{F L} Q \overline{Q 56}$ & 0.867 & 0.856 & 0.864 & 0.749 & 0.735 & 0.680 & 0.561 & 0.674 & 0.663 & 0.702 & 0.765 & 0.760 \\
\hline ED Q57 & 0.753 & 0.715 & 0.723 & 0.645 & 0.659 & 0.641 & 0.513 & 0.661 & 0.585 & 0.684 & 0.698 & 0.744 \\
\hline MO_Q58 & 0.870 & 0.761 & 0.792 & 0.686 & 0.724 & 0.574 & 0.647 & 0.785 & 0.590 & 0.742 & 0.709 & 0.838 \\
\hline OBQ59 & 0.841 & 0.839 & 0.851 & 0.770 & 0.751 & 0.727 & 0.566 & 0.700 & 0.599 & 0.745 & 0.837 & 0.840 \\
\hline ED Q60 & 0.661 & 0.745 & 0.689 & 0.703 & 0.603 & 0.601 & 0.410 & 0.547 & 0.557 & 0.559 & 0.606 & 0.614 \\
\hline
\end{tabular}




\section{Appendix B - Table 1: Inter-Item Correlation Matrix}

\begin{tabular}{|c|c|c|c|c|c|c|c|c|c|c|c|c|}
\hline TEMS & AD_Q49 & ST_Q50 & FL_Q51 & NJ_Q52 & OP_Q53 & ED_Q54 & EX Q55 & $F L, Q 56$ & ED_Q57 & MO_Q58 & OB Q59 & ED_Q60 \\
\hline$\overline{A D \_Q 1}$ & 0.384 & 0.734 & 0.532 & -0.704 & 0.721 & 0.466 & 0.800 & 0.693 & 0.616 & 0.655 & 0.727 & 0.540 \\
\hline CO_Q2 & 534 & 0.850 & 0.706 & -0.733 & 0.809 & 0.598 & 0.857 & 0.838 & .740 & 0.779 & 0.891 & 0.695 \\
\hline$\overline{O B Q 3}$ & 565 & 771 & 0.678 & -0.702 & 0.722 & 0.604 & 798 & 0.800 & .762 & 0.783 & 821 & .686 \\
\hline EM_Q4 & 0.589 & 793 & .663 & .720 & 0.783 & 0.617 & 840 & 820 & .800 & 779 & 0.833 & 0.667 \\
\hline EX Q5 & -0.299 & -0.684 & -0.572 & 0.617 & -0.712 & -0.538 & -0.765 & -0.645 & -0.621 & -0.597 & -0.667 & -0.530 \\
\hline FLQ6 & 0.642 & 848 & 0.734 & -0.723 & 0.828 & 0.466 & 0.846 & 0.824 & 0.705 & 0.837 & 0.840 & 0.721 \\
\hline MO_Q7 & 0.596 & 824 & 0.625 & -0.663 & 0.751 & 0.516 & 0.769 & 8.818 & 0.754 & 812 & .813 & 0.698 \\
\hline NJ_Q8 & 0.327 & 542 & 0.440 & -0.586 & 0.472 & 0.582 & 0.554 & 607 & 0.696 & 642 & 0.568 & 0.484 \\
\hline$\widehat{O B Q Q 9}$ & 0.120 & -0.102 & -0.122 & 0.185 & -0.272 & -0.167 & -0.212 & -0.152 & -0.147 & -0.100 & -0.228 & 0.201 \\
\hline PA Q10 & 0.491 & 653 & 0.481 & -0.675 & 0.608 & 0.461 & 0.696 & 0.750 & 0.617 & 0.745 & 0.723 & 0.583 \\
\hline REQ11 & 0.329 & 0.356 & 0.180 & -0.257 & 0.157 & 0.208 & 0.235 & 0.407 & 0.318 & 341 & 0.276 & 0.363 \\
\hline $\mathrm{MO} Q 12$ & -0.410 & -0.505 & -0.438 & 0.511 & -0.462 & -0.575 & -0.489 & -0.582 & -0.621 & -0.572 & -0.491 & -0.470 \\
\hline RE_Q13 & 0.279 & 0.178 & 0.169 & -0.020 & -0.001 & 0.162 & 0.058 & 0.228 & 0.211 & 0.190 & 0.114 & 0.243 \\
\hline RE_Q14 & 0.356 & 353 & 0.328 & -0.230 & 0.145 & 0.304 & 0.247 & 0.370 & 0.394 & 0.383 & 0.318 & 0.330 \\
\hline FL Q15 & 0.575 & 0.850 & 0.665 & -0.760 & 0.816 & 0.526 & 0.885 & 089 & 0.723 & 0.816 & 0.908 & 0.778 \\
\hline RE Q16 & -0.248 & -0.400 & -0.332 & 0.454 & -0.483 & -0.407 & -0.488 & -0.364 & -0.413 & -0.412 & -0.411 & -0.414 \\
\hline FA Q17 & 0.514 & 0.813 & 0.632 & -0.794 & 0.796 & 0.542 & 0.836 & 0.800 & 0.707 & 0.737 & 0.848 & 0.767 \\
\hline COQQ18 & 0.538 & 0.889 & 0.713 & -0.714 & 0.826 & 0.587 & 0.875 & 0.873 & 0.751 & 0.831 & 0.913 & 0.710 \\
\hline AD_Q19 & 0.513 & 0.875 & 0.659 & -0.760 & 0.843 & 0.557 & 0.917 & 0.869 & 0.739 & 0.799 & 0.896 & 0.745 \\
\hline ER_Q20 & -0.518 & -0.753 & -0.713 & 0.730 & -0.784 & -0.551 & -0.798 & -0.710 & -0.659 & -0.680 & -0.758 & -0.618 \\
\hline CI_Q21 & 0.487 & 0.856 & 0.719 & -0.764 & 0.824 & 0.583 & 0.887 & 0.858 & 0.756 & 0.840 & 0.907 & 0.726 \\
\hline MO_Q22 & 431 & -0.715 & -0.564 & 0.657 & -0.712 & -0.555 & -0.699 & -0.749 & -0.696 & -0.660 & -0.678 & -0.532 \\
\hline RE_Q23 & 0.396 & 405 & 0.282 & -0.260 & 0.218 & 0.258 & 0.257 & 0.428 & 0.466 & 0.465 & 0.353 & 0.377 \\
\hline FA Q24 & 0.590 & 0.919 & 0.720 & -0.815 & 0.817 & 0.516 & 0.859 & 0.856 & 0.747 & 0.796 & 0.903 & 0.703 \\
\hline $\mathrm{CO} Q 25$ & 0.488 & 829 & 0.595 & -0.677 & 0.735 & 0.477 & 0.771 & 0.769 & 0.719 & 0.708 & 0.782 & 0.582 \\
\hline$\overline{\mathrm{AD} \mathrm{Q} 26}$ & -0.315 & -0.580 & -0.556 & 0.656 & -0.633 & -0.404 & -0.664 & -0.531 & -0.580 & -0.569 & -0.590 & -0.446 \\
\hline $\mathrm{MO} Q 27$ & -0.538 & -0.804 & -0.675 & 0.772 & -0.831 & -0.541 & -0.823 & -0.777 & -0.681 & -0.755 & -0.770 & -0.649 \\
\hline ED_Q28 & 0.508 & 729 & 0.579 & -0.641 & 0.717 & 0.416 & 0.756 & 0.763 & 0.687 & 0.771 & 0.737 & 0.635 \\
\hline$A D Q 29$ & 0.535 & 617 & 0.515 & -0.624 & 0.593 & 0.386 & 0.672 & 0.699 & 0.598 & 0.706 & 0.643 & 0.630 \\
\hline CI_Q30 & 0.582 & 0.886 & 0.768 & -0.791 & 0.867 & 0.568 & 0.898 & 0.862 & 0.739 & 0.832 & 0.922 & 0.732 \\
\hline FL_Q31 & 0.590 & 0.784 & 0.650 & -0.686 & 0.718 & 0.511 & 0.734 & 0.834 & 0.637 & 0.813 & 0.823 & 0.72 \\
\hline
\end{tabular}


Appendix B - Table 1: Inter-Item Correlation Matrix

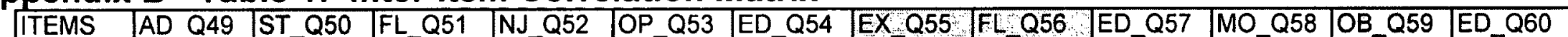

\begin{tabular}{|c|c|c|c|c|c|c|c|c|c|c|c|c|}
\hline & & & & & & & & & & & & \\
\hline NJ Q32 & -0.067 & -0.243 & -0.214 & 0.339 & -0.312 & -0.248 & -0.387 & -0.217 & -0.275 & -0.219 & -0.242 & -0.163 \\
\hline OP Q33 & -0.120 & -0.365 & -0.156 & 0.302 & -0.422 & -0.318 & -0.425 & -0.358 & -0.399 & -0.312 & -0.394 & -0.370 \\
\hline MO_Q34 & -0.395 & -0.820 & -0.556 & 0.668 & -0.792 & -0.488 & -0.781 & -0.769 & -0.608 & -0.660 & -0.765 & -0.572 \\
\hline DT Q35 & 559 & 0.700 & 0.706 & -0.756 & 0.656 & 0.446 & 0.742 & 0.722 & 608 & 0.699 & 0.709 & 0.677 \\
\hline PA Q36 & 587 & 783 & 0.614 & -0.750 & 789 & 0.527 & 0.791 & 0.859 & 0.768 & .831 & .845 & 0.712 \\
\hline FL Q37 & 641 & 0.808 & 0.684 & -0.738 & 0.805 & 0.516 & 0.806 & 0.867 & 0.753 & 0.870 & .841 & 0.661 \\
\hline CI Q38 & 627 & 0.815 & 0.702 & -0.742 & 0.809 & 0.516 & 0.814 & 0.856 & 0.715 & 0.761 & 0.839 & 0.745 \\
\hline $\mathrm{AD}$ Q39 & 0.626 & 0.820 & 0.656 & -0.716 & 0.732 & 0.473 & 0.785 & 0.864 & 0.723 & 0.792 & 0.851 & 0.689 \\
\hline $\mathrm{AD} Q 40$ & 65 & 766 & 0.629 & -0.698 & 0.740 & 0.477 & 0.811 & 0.749 & 0.645 & 0.686 & 0.770 & 0.703 \\
\hline$\overline{F L ~ Q 41}$ & 0.609 & 0.782 & 0.784 & -0.754 & 0.782 & 0.464 & 0.837 & 0.735 & 0.659 & 0.724 & 0.751 & $\overline{0.603}$ \\
\hline $\mathrm{OP} Q 42$ & 0.424 & 0.718 & 0.557 & -0.638 & 0.687 & 0.429 & 0.771 & 0.680 & 0.641 & .574 & 0.727 & 0.601 \\
\hline ST_Q43 & 0.522 & 0.538 & 0.445 & -0.474 & 0.486 & 0.299 & 0.505 & 0.561 & 0.513 & .647 & 0.566 & 0.410 \\
\hline ST Q44 & 0.480 & 0.647 & 0.524 & -0.541 & 0.614 & 0.435 & 0.613 & 0.674 & 0.661 & 0.785 & .700 & .547 \\
\hline ST Q45 & 0.482 & 0.638 & 0.449 & -0.511 & 0.519 & 0.494 & 0.533 & 0.663 & 0.585 & 0.590 & 0.599 & 0.557 \\
\hline ER Q46 & 0.560 & 0.772 & 0.534 & -0.572 & 0.629 & 0.497 & 0.683 & 0.702 & 0.684 & 0.742 & 0.745 & 0.559 \\
\hline Cl_Q47 & 0.591 & 0.842 & 0.667 & -0.677 & 0.744 & 0.523 & 0.760 & 0.765 & 0.698 & 0.709 & 0.837 & 0.606 \\
\hline ST_Q48 & 0.524 & 0.801 & 0.566 & -0.616 & 0.713 & 0.493 & 0.726 & 0.760 & 0.744 & 0.838 & 0.840 & 0.614 \\
\hline$\overline{A D \_Q 4}$ & 1.000 & 0.615 & 0.551 & -0.601 & 0.526 & 0.326 & 0.570 & 0.604 & 0.407 & 0.594 & 0.511 & 0.498 \\
\hline ST Q50 & 0.615 & 1.000 & 0.769 & -0.793 & 0.871 & 0.549 & 091 & 0.884 & 0.716 & 0.824 & 0.901 & 0.680 \\
\hline FL Q51 & 0.551 & 0.769 & 1.000 & -0.674 & 0.744 & 0.508 & 0.745 & 0.695 & 0.602 & 0.676 & 0.698 & 0.595 \\
\hline NJ_Q52 & -0.601 & -0.793 & -0.674 & 1.000 & -0.788 & -0.529 & -0.835 & -0.755 & -0.656 & -0.738 & -0.765 & -0.628 \\
\hline $\overrightarrow{\mathrm{OP}} \mathrm{Q} 53$ & 0.526 & 0.871 & 0.744 & -0.788 & 1.000 & 0.590 & 0.897 & 0.840 & 0.723 & 0.787 & 0.874 & 0.709 \\
\hline ED_Q54 & 0.326 & 0.549 & 0.508 & -0.529 & 0.590 & 1.000 & 0.592 & 0.656 & 0.691 & 0.606 & 0.591 & 0.567 \\
\hline EX Q55 & 0.570 & 0.91 & 0.745 & -0.835 & 0.897 & 0.592 & 1.000 & 0.868 & 0.730 & 0.835 & 0.895 & $\overline{0.698}$ \\
\hline FLQ Q56 & 0.604 & 0.884 & 0.695 & -0.755 & 0.840 & 0.656 & 0.868 & 1.000 & 0.781 & 0.875 & 0.9 & 0.763 \\
\hline ED_Q57 & 0.407 & 0.716 & 0.602 & -0.656 & 0.723 & 0.691 & 0.730 & 0.781 & 1.000 & 0.784 & 0.808 & 0.677 \\
\hline MO_Q58 & 0.594 & 0.824 & 0.676 & -0.738 & 0.787 & 0.606 & 0.835 & 0.875 & 0.784 & 1.000 & 0.870 & 0.658 \\
\hline OB_Q59 & 0.511 & 0.901 & 0.698 & -0.765 & 0.874 & 0.591 & 0.895 & ras 0.9 & 0.808 & 0.870 & 1.000 & 0.752 \\
\hline ED_Q60 & 0.498 & 0.680 & 0.595 & -0.628 & 0.709 & 0.567 & 0.698 & 0.763 & 0.677 & 0.658 & 0.752 & 1.00 \\
\hline
\end{tabular}




\section{Appendix B - Table 2: Final Inter-Item Correlation Matrix}

Note - 14 items have been removed

\begin{tabular}{|c|c|c|c|c|c|c|c|c|c|c|c|c|}
\hline ITEMS & AD_Q1 & OB_Q3 & EM_Q4 & EX_Q5 & MO_Q7 & NJ_Q8 & OB_Q9 & PA_Q10 & RE_Q11 & MO_Q12 & RE_Q13 & RE_Q14 \\
\hline$\overline{A D \_Q 1}$ & 1.000 & .645 & .715 & -.602 & .576 & .541 & -.273 & .569 & .144 & -.432 & -.042 & .110 \\
\hline OB_Q3 & .645 & 1.000 & .863 & -.577 & .784 & .608 & -.078 & .629 & .320 & -.489 & .204 & .412 \\
\hline EM_Q4 & .715 & .863 & 1.000 & -.651 & .772 & .680 & -.187 & .616 & .371 & -.598 & .156 & .401 \\
\hline EX_Q5 & -.602 & -.577 & -.651 & 1.000 & -.494 & -.523 & .348 & -.454 & -.018 & .489 & .203 & .046 \\
\hline MO_Q7 & .576 & .784 & .772 & -.494 & 1.000 & .624 & -.041 & .593 & .446 & -.520 & .369 & .489 \\
\hline NJ_Q8 & .541 & .608 & .680 & -.523 & .624 & 1.000 & -.066 & .500 & .386 & -.717 & .298 & .431 \\
\hline OB_Q9 & -.273 & -.078 & -.187 & .348 & -.041 & \begin{tabular}{l|}
.066 \\
\end{tabular} & 1.000 & .038 & .372 & .033 & .396 & .379 \\
\hline PA_Q10 & .569 & .629 & .616 & -.454 & .593 & .500 & .038 & 1.000 & .413 & -.462 & .083 & .338 \\
\hline RE_Q11 & .144 & .320 & .371 & .018 & .446 & .386 & .372 & .413 & 1.000 & -.252 & .712 & .832 \\
\hline MO_Q12 & -.432 & -.489 & -.598 & .489 & -.520 & -.717 & .033 & -.462 & -.252 & 1.000 & -.130 & -.265 \\
\hline RE_Q13 & -.042 & .204 & .156 & .203 & .369 & .298 & .396 & .083 & .712 & -.130 & 1.000 & .799 \\
\hline RE_Q14 & .110 & .412 & .401 & .046 & .489 & .431 & .379 & .338 & .832 & -.265 & .799 & 1.000 \\
\hline RE_Q16 & -.479 & -.283 & -.388 & .536 & -.279 & -.342 & .487 & -.249 & .223 & .324 & .315 & .238 \\
\hline AD_Q19 & .786 & .792 & .838 & -.696 & .799 & .598 & -.199 & .705 & .308 & -.540 & .104 & .276 \\
\hline ER_Q20 & -.592 & -.769 & -.782 & .664 & -.679 & -.538 & .262 & -.540 & -.179 & .511 & .014 & -.241 \\
\hline MO_Q22 & -.658 & -.570 & -.660 & .669 & -.612 & -.670 & .209 & -.494 & -.188 & .678 & -.055 & -.178 \\
\hline RE_Q23 & .157 & .427 & .407 & -.040 & .594 & .459 & .365 & .357 & .737 & -.389 & .673 & .721 \\
\hline FA_Q24 & .670 & .810 & .798 & -.632 & .843 & .616 & -.006 & .709 & .434 & -.494 & .222 & .430 \\
\hline $\mathrm{CO} \_$Q25 & .674 & .706 & .745 & -.584 & .772 & .549 & .057 & .572 & .452 & -.362 & .286 & .438 \\
\hline$A D \_Q 26$ & -.711 & -.488 & -.549 & .699 & -.416 & -.513 & .400 & -.479 & .107 & .489 & .284 & .092 \\
\hline MO_Q27 & -.745 & -.668 & -.731 & .754 & -.698 & -.620 & .210 & -.604 & -.115 & .666 & .087 & -.071 \\
\hline ED_Q28 & .637 & .648 & .696 & -.522 & .682 & .505 & -.235 & .521 & .384 & -.401 & .224 & .355 \\
\hline$A D \_Q 29$ & .589 & .672 & .663 & -.410 & .646 & .568 & -.050 & .706 & .399 & -.532 & .223 & .409 \\
\hline FL_Q31 & .517 & .734 & 699 & -.466 & .735 & .474 & -.004 & .653 & .496 & -.520 & .318 & .446 \\
\hline NJ_Q32 & -.498 & -.155 & -.294 & .529 & -.105 & -.303 & .566 & -.063 & .388 & .209 & .450 & .409 \\
\hline OP_Q33 & -.518 & -.247 & -.347 & .515 & -.323 & -.290 & .400 & -.188 & .194 & .351 & .324 & .276 \\
\hline MO_Q34 & -.716 & -.606 & -.632 & .683 & -.633 & -.529 & .177 & -.559 & -.137 & .579 & .062 & -.057 \\
\hline OT_Q35 & .628 & 699 & .675 & -.534 & .720 & .582 & -.089 & .575 & .422 & -.466 & .259 & .428 \\
\hline PA_Q36 & .559 & .744 & .749 & -.647 & .759 & .599 & -.239 & .694 & .275 & -.527 & .126 & .274 \\
\hline Cl_Q38 & .569 & .782 & .809 & -.514 & .795 & .568 & -.126 & .595 & .407 & -.523 & .316 & .445 \\
\hline AD_Q40 & .763 & .729 & .740 & -.579 & .654 & .555 & -.176 & .596 & .320 & -.433 & .132 & .301 \\
\hline
\end{tabular}




\section{Appendix B - Table 2: Final Inter-Item Correlation Matrix}

\begin{tabular}{|c|c|c|c|c|c|c|c|c|c|c|c|c|}
\hline ITEMS & AD_Q1 & OB_Q3 & EM_Q4 & EX_Q5 & MO_Q7 & NJ_Q8 & OB_Q9 & PA_Q10 & RE_Q11 & MO_Q12 & RE_Q13 & RE_Q14 \\
\hline FL_Q41 & .637 & .723 & .740 & -.625 & .650 & .509 & -.087 & .673 & .283 & -.454 & .147 & .318 \\
\hline OP_Q42 & .716 & .678 & .745 & -.614 & .607 & .485 & -.196 & .508 & .143 & -.396 & -.001 & .131 \\
\hline ST_Q43 & .422 & .603 & .607 & -.284 & .582 & .410 & .165 & .615 & .439 & -.387 & .253 & .514 \\
\hline ST_Q44 & .442 & .677 & .642 & -.388 & .770 & .482 & .000 & .559 & .430 & -.339 & .336 & .496 \\
\hline ST_Q45 & .365 & .702 & .655 & -.234 & .735 & .439 & .183 & .459 & .626 & -.368 & .529 & .689 \\
\hline ER_Q46 & .490 & .739 & .689 & -.480 & .803 & .521 & .053 & .597 & .443 & -.440 & .288 & .470 \\
\hline ST_Q48 & .517 & .756 & .697 & -.520 & .821 & .527 & -.026 & .649 & .360 & -.479 & .166 & .382 \\
\hline AD_Q49 & .361 & .580 & .593 & -.313 & .610 & .340 & .132 & .475 & .310 & -.440 & .254 & .328 \\
\hline$F L \_Q 51$ & .530 & .666 & .655 & -.523 & .635 & .459 & -.090 & .475 & .194 & -.470 & .179 & .326 \\
\hline NJ_Q52 & -.700 & -.675 & -.694 & .565 & -.670 & -.602 & .149 & -.647 & -.291 & .534 & -.072 & -.260 \\
\hline OP_Q53 & .684 & .724 & .782 & -.677 & .758 & .486 & -.240 & .587 & .157 & -.491 & .001 & .138 \\
\hline ED_Q54 & .432 & .584 & .615 & -.544 & .517 & .589 & -.152 & .464 & .234 & -.572 & .171 & .303 \\
\hline ED_Q57 & .563 & .752 & .784 & -.619 & .750 & .688 & -.107 & .594 & .302 & -.649 & .177 & .351 \\
\hline MO_Q58 & .602 & .784 & .780 & -.588 & .819 & .649 & -.085 & .699 & .325 & -.580 & .167 & .355 \\
\hline ED_Q60 & .489 & .696 & .676 & -.518 & .713 & .493 & -.182 & .524 & .326 & -.483 & .194 & .286 \\
\hline
\end{tabular}




\section{Appendix B - Table 2: Final Inter-Item Correlation Matrix}

\begin{tabular}{|c|c|c|c|c|c|c|c|c|c|c|c|c|}
\hline ITEMS & RE_Q16 & $A D \_Q 19$ & ER_Q20 & MO_Q22 & RE_Q23 & FA_Q24 & CO_Q25 & AD_Q26 & MO_Q27 & ED_Q28 & $A D \_Q 29$ & FL_Q31 \\
\hline$A D \_Q 1$ & -.479 & .786 & -.592 & -.658 & .157 & .670 & .674 & -.711 & -.745 & .637 & .589 & .517 \\
\hline OB_Q3 & -.283 & .792 & -.769 & -.570 & .427 & .810 & .706 & -.488 & -.668 & .648 & .672 & .734 \\
\hline EM_Q4 & -.388 & .838 & -.782 & -.660 & .407 & .798 & .745 & -.549 & -.731 & .696 & .663 & .699 \\
\hline EX_Q5 & .536 & -.696 & .664 & .669 & -.040 & -.632 & -.584 & .699 & .754 & -.522 & -.410 & -.466 \\
\hline MO_Q7 & -.279 & .799 & -.679 & -.612 & .594 & .843 & .772 & -.416 & -.698 & .682 & .646 & .735 \\
\hline NJ_Q8 & -.342 & .598 & -.538 & -.670 & .459 & .616 & .549 & -.513 & -.620 & .505 & .568 & .474 \\
\hline OB_Q9 & .487 & -.199 & .262 & .209 & .365 & -.006 & .057 & .400 & .210 & -.235 & -.050 & -.004 \\
\hline PA_Q10 & -.249 & .705 & -.540 & -.494 & .357 & .709 & .572 & -.479 & -.604 & .521 & .706 & .653 \\
\hline RE_Q11 & .223 & .308 & -.179 & -.188 & .737 & .434 & .452 & .107 & -.115 & .384 & .399 & .496 \\
\hline $\mathrm{MO} \_\mathrm{Q} 12$ & .324 & -.540 & .511 & .678 & -.389 & -.494 & -.362 & .489 & .666 & -.401 & -.532 & -.520 \\
\hline RE_Q13 & .315 & .104 & .014 & -.055 & .673 & .222 & .286 & .284 & .087 & .224 & .223 & .318 \\
\hline RE_Q14 & .238 & .276 & -.241 & -.178 & .721 & .430 & .438 & .092 & -.071 & .355 & .409 & .446 \\
\hline$R E \_Q 16$ & 1.000 & -.424 & .404 & .424 & .001 & -.302 & -.244 & .565 & .584 & -.400 & -.261 & -.182 \\
\hline$A D \_Q 19$ & -.424 & 1.000 & -.796 & -.696 & .320 & .873 & .787 & -.631 & -.825 & .754 & .720 & .756 \\
\hline$E R \_Q 20$ & .404 & -.796 & 1.000 & .610 & -.212 & -.747 & -.648 & .595 & .704 & -.620 & -.674 & -.640 \\
\hline MO_Q22 & .424 & -.696 & .610 & 1.000 & -.266 & -.675 & -.602 & .672 & .785 & -.622 & -.544 & -.503 \\
\hline RE_Q23 & .001 & .320 & -.212 & -.266 & 1.000 & .494 & .468 & .000 & -.214 & .429 & .406 & .468 \\
\hline FA_Q24 & -.302 & .873 & -.747 & -.675 & .494 & 1.000 & .843 & -.557 & -.778 & .702 & .668 & .806 \\
\hline CO_Q25 & -.244 & .787 & -.648 & -.602 & .468 & .843 & 1.000 & -.454 & -.659 & .675 & .562 & .665 \\
\hline AD_Q26 & .565 & -.631 & .595 & .672 & .000 & -.557 & -.454 & 1.000 & .737 & -.596 & -.474 & -.400 \\
\hline MO_Q27 & .584 & -.825 & .704 & .785 & -.214 & -.778 & -.659 & .737 & 1.000 & -.627 & -.654 & -.661 \\
\hline ED_Q28 & -.400 & .754 & -.620 & -.622 & .429 & .702 & .675 & -.596 & -.627 & 1.000 & .646 & .670 \\
\hline AD_Q29 & -.261 & .720 & -.674 & -.544 & .406 & .668 & .562 & -.474 & -.654 & .646 & 1.000 & .671 \\
\hline$F L \_Q 31$ & -.182 & .756 & -.640 & -.503 & .468 & .806 & .665 & -.400 & -.661 & .670 & .671 & 1.000 \\
\hline NJ_Q32 & .595 & -.333 & .305 & .394 & .287 & -.184 & -.165 & .643 & .461 & -.335 & -.147 & -.002 \\
\hline OP_Q33 & .531 & -.450 & .276 & .507 & .043 & -.353 & -.290 & .566 & .573 & -.339 & -.175 & -.212 \\
\hline MO_Q34 & .464 & -.810 & .646 & .687 & -.175 & -.756 & -.695 & .615 & .842 & -.589 & -.561 & -.626 \\
\hline OT_Q35 & -.304 & .732 & -.642 & -.577 & .464 & .748 & .673 & -.581 & -.684 & .683 & .638 & .674 \\
\hline PA_Q36 & -.393 & .797 & -.695 & -.645 & .352 & .807 & .690 & -.574 & -.777 & .697 & .694 & .743 \\
\hline Cl_Q38 & -.268 & .816 & -.734 & -.599 & .426 & .839 & .689 & -.493 & -.687 & .763 & .693 & .824 \\
\hline AD_Q40 & -.299 & .837 & -.739 & -.591 & .248 & .750 & .735 & -.594 & -.687 & .661 & .752 & .677 \\
\hline
\end{tabular}




\section{Appendix B - Table 2: Final Inter-Item Correlation Matrix}

\begin{tabular}{|c|c|c|c|c|c|c|c|c|c|c|c|c|}
\hline ITEMS & RE_Q16 & $A D \_Q 19$ & ER_Q20 & $M O \_Q 22$ & RE_Q23 & FA_Q24 & CO_Q25 & AD_Q26 & MO_Q27 & ED_Q28 & $A D \_Q 29$ & $F L \_Q 31$ \\
\hline FL_Q41 & -.388 & .776 & -.728 & -.571 & .300 & .768 & .706 & -.585 & -.697 & .694 & .633 & .646 \\
\hline OP_Q42 & -.362 & .791 & -.644 & -.614 & .216 & .723 & .742 & -.601 & -.663 & .617 & .530 & .491 \\
\hline ST_Q43 & -.206 & .554 & -.553 & -.366 & .502 & .624 & .567 & -.335 & -.490 & .534 & .515 & .589 \\
\hline ST_Q44 & -.224 & .662 & -.596 & -.414 & .612 & .715 & .689 & -.385 & -.541 & .682 & .552 & .679 \\
\hline ST_Q45 & -.016 & .589 & -.509 & -.365 & .646 & .703 & .693 & -.118 & -.404 & .522 & .517 & .660 \\
\hline ER_Q46 & -.198 & .745 & -.632 & -.492 & .518 & .779 & .746 & -.387 & -.614 & .554 & .581 & .680 \\
\hline ST_Q48 & -.298 & .769 & -.621 & -.517 & .528 & .822 & .708 & -.490 & -.674 & .662 & .618 & .736 \\
\hline$A D \_Q 49$ & -.215 & .533 & -.526 & -.411 & .396 & .604 & .504 & -.320 & -.555 & .492 & .546 & .609 \\
\hline FL_Q51 & -.281 & .671 & -.709 & -.540 & .299 & .719 & .614 & -.539 & -.676 & .569 & .539 & .672 \\
\hline NJ_Q52 & .382 & -.762 & .702 & .664 & -.291 & -.815 & -.693 & .653 & .762 & -.652 & -.627 & -.698 \\
\hline OP_Q53 & -.434 & .848 & -.785 & -.666 & .233 & .814 & .740 & -.610 & -.824 & .690 & .605 & .735 \\
\hline ED_Q54 & -.375 & .559 & -.540 & -.535 & .277 & .527 & .489 & -.387 & -.532 & .413 & .381 & .513 \\
\hline ED_Q57 & -.367 & .747 & -.644 & -.664 & .472 & .763 & .723 & -.580 & -.700 & .659 & .597 & .655 \\
\hline MO_Q58 & -.366 & .806 & -.696 & -.620 & .471 & .798 & .701 & -.550 & -.738 & .741 & .697 & .816 \\
\hline ED_Q60 & -.362 & .748 & -.641 & -.489 & .378 & .703 & .573 & -.425 & -.634 & .603 & .616 & .728 \\
\hline
\end{tabular}




\section{Appendix B - Table 2: Final Inter-Item Correlation Matrix}

\begin{tabular}{|c|c|c|c|c|c|c|c|c|c|c|c|c|}
\hline ITEMS & NJ_Q32 & $O P \_Q 33$ & MO_Q34 & OT_Q35 & PA_Q36 & Cl_Q38 & $A D \_Q 40$ & FL_Q41 & OP_Q42 & ST_Q43 & ST_Q44 & ST_Q45 \\
\hline AD_Q1 & -.498 & -.518 & -.716 & 628 & .559 & .569 & .763 & .637 & .716 & .422 & .442 & .365 \\
\hline OB_Q3 & -.155 & -.247 & -.606 & 699 & .744 & .782 & .729 & .723 & .678 & .603 & .677 & .702 \\
\hline EM_Q4 & -.294 & -.347 & -.632 & .675 & .749 & .809 & .740 & .740 & .745 & .607 & .642 & .655 \\
\hline EX_Q5 & .529 & .515 & .683 & -.534 & -.647 & -.514 & -.579 & -.625 & -.614 & -.284 & -.388 & -.234 \\
\hline MO_Q7 & -.105 & -.323 & -.633 & .720 & .759 & .795 & .654 & .650 & .607 & .582 & .770 & .735 \\
\hline NJ_Q8 & -.303 & -.290 & -.529 & .582 & .599 & .568 & .555 & .509 & .485 & .410 & .482 & .439 \\
\hline OB_Q9 & .566 & .400 & .177 & -.089 & -.239 & -.126 & -.176 & -.087 & -.196 & .165 & .000 & .183 \\
\hline PA_Q10 & -.063 & -.188 & -.559 & .575 & .694 & .595 & .596 & .673 & .508 & .615 & .559 & .459 \\
\hline RE_Q11 & .388 & .194 & -.137 & \begin{tabular}{l|l}
.422 \\
\end{tabular} & .275 & .407 & .320 & .283 & .143 & .439 & .430 & .626 \\
\hline MO_Q12 & .209 & .351 & .579 & -.466 & -.527 & -.523 & -.433 & -.454 & -.396 & -.387 & -.339 & -.368 \\
\hline RE_Q13 & .450 & .324 & .062 & .259 & .126 & .316 & .132 & .147 & -.001 & .253 & .336 & .529 \\
\hline RE_Q14 & .409 & .276 & -.057 & .428 & .274 & .445 & .301 & .318 & .131 & .514 & .496 & .689 \\
\hline RE_Q16 & .595 & .531 & .464 & -.304 & -.393 & -.268 & -.299 & -.388 & -.362 & -.206 & -.224 & -.016 \\
\hline AD_Q19 & -.333 & -.450 & -.810 & .732 & .797 & .816 & .837 & .776 & .791 & .554 & .662 & .589 \\
\hline ER_Q20 & .305 & .276 & .646 & -.642 & -.695 & -.734 & -.739 & -.728 & -.644 & -.553 & -.596 & -.509 \\
\hline MO_Q22 & .394 & .507 & .687 & -.577 & -.645 & -.599 & -.591 & -.571 & -.614 & -.366 & -.414 & -.365 \\
\hline RE_Q23 & .287 & .043 & -.175 & .464 & .352 & .426 & 248 & .300 & .216 & .502 & .612 & .646 \\
\hline FA_Q24 & -.184 & -.353 & -.756 & .748 & .807 & .839 & .750 & .768 & .723 & .624 & .715 & .703 \\
\hline CO_Q25 & -.165 & -.290 & -.695 & .673 & .690 & .689 & .735 & .706 & .742 & .567 & .689 & .693 \\
\hline AD_Q26 & .643 & .566 & .615 & -.581 & -.574 & -.493 & -.594 & -.585 & -.601 & -.335 & -.385 & -.118 \\
\hline MO_Q27 & .461 & .573 & .842 & -.684 & -.777 & -.687 & -.687 & -.697 & -.663 & -.490 & -.541 & -.404 \\
\hline ED_Q28 & -.335 & -.339 & -.589 & 683 & .697 & .763 & .661 & .694 & .617 & .534 & .682 & .522 \\
\hline AD_Q29 & -.147 & -.175 & -.561 & .638 & .694 & .693 & .752 & .633 & .530 & .515 & .552 & .517 \\
\hline FL_Q31 & -.002 & -.212 & -.626 & .674 & .743 & .824 & .677 & .646 & .491 & .589 & .679 & .660 \\
\hline NJ_Q32 & 1.000 & .655 & .393 & -.247 & -.316 & -.179 & -.312 & -.238 & -.464 & .006 & -.055 & .147 \\
\hline OP_Q33 & .655 & 1.000 & .509 & -.207 & -.358 & -.262 & -.355 & -.277 & -.512 & -.107 & -.246 & -.038 \\
\hline MO_Q34 & .393 & .509 & 1.000 & -.568 & -.689 & -.658 & -.702 & -.643 & -.671 & -.448 & -.491 & -.456 \\
\hline OT_Q35 & -.247 & -.207 & -.568 & 1.000 & .704 & .697 & .700 & .704 & .604 & .498 & .605 & .517 \\
\hline PA_Q36 & -.316 & -.358 & -.689 & .704 & 1.000 & .796 & .689 & .676 & .618 & .578 & .698 & .586 \\
\hline Cl_Q38 & -.179 & -.262 & -.658 & .697 & .796 & 1.000 & .730 & .762 & .671 & .567 & .679 & .714 \\
\hline AD_Q40 & -.312 & -.355 & -.702 & .700 & .689 & .730 & 1.000 & .744 & .772 & .454 & .548 & .512 \\
\hline
\end{tabular}


Appendix B - Table 2: Final Inter-Item Correlation Matrix

\begin{tabular}{|c|c|c|c|c|c|c|c|c|c|c|c|c|}
\hline ITEMS & NJ_Q32 & OP_Q33 & MO_Q34 & OT_Q35 & PA_Q36 & Cl_Q38 & AD_Q40 & FL_Q41 & OP_Q42 & ST_Q43 & ST_Q44 & ST_Q45 \\
\hline FL_Q41 & -.238 & -.277 & -.643 & .704 & .676 & .762 & .744 & 1.000 & .694 & .551 & .593 & 466 \\
\hline OP_Q42 & -.464 & -.512 & -.671 & .604 & .618 & 671 & .772 & .694 & 1.000 & .402 & 498 & .484 \\
\hline ST_Q43 & .006 & -.107 & -.448 & .498 & .578 & .567 & .454 & .551 & .402 & 1.000 & .750 & .674 \\
\hline ST_Q44 & -.055 & -.246 & -.491 & .605 & .698 & .679 & .548 & .593 & .498 & .750 & 1.000 & 745 \\
\hline ST_Q45 & .147 & -.038 & \begin{tabular}{l|}
-.456 \\
\end{tabular} & .517 & .586 & .714 & .512 & .466 & .484 & .674 & .745 & 1.000 \\
\hline ER_Q46 & -.075 & -.265 & -.593 & .599 & .744 & .691 & .642 & .581 & .619 & .642 & .717 & .739 \\
\hline$\overline{S T} Q 48$ & -.115 & -.366 & -.667 & .645 & .751 & .718 & .654 & 671 & .600 & .611 & .784 & .643 \\
\hline AD_Q49 & -.046 & -.131 & -.420 & .558 & .588 & .636 & .479 & .618 & .439 & .527 & .494 & .503 \\
\hline$F L \_51$ & -.212 & -.173 & -.562 & .705 & .599 & .713 & .647 & .781 & .566 & .456 & .525 & .464 \\
\hline NJ_Q52 & .331 & .322 & .666 & -.773 & -.718 & -.743 & -.702 & -.745 & -.649 & -.494 & -.531 & -.518 \\
\hline OP_Q53 & -.298 & -.418 & -.782 & .649 & .774 & .816 & .747 & .782 & .689 & .491 & .624 & .539 \\
\hline ED_Q54 & -.258 & -.310 & -.483 & .457 & .544 & .516 & .479 & .473 & .432 & .307 & 447 & 500 \\
\hline ED_Q57 & -.258 & -.409 & -.636 & .615 & .771 & .719 & .641 & 655 & .661 & .526 & .667 & .603 \\
\hline MO_Q58 & -.217 & -.329 & -.651 & .682 & .812 & .772 & .685 & .721 & .586 & .637 & .794 & .615 \\
\hline ED_Q60 & -.173 & -.397 & -.559 & .645 & .690 & .751 & .692 & .595 & .612 & .404 & .568 & .577 \\
\hline
\end{tabular}




\section{Appendix B - Table 2: Final Inter-Item Correlation Matrix}

\begin{tabular}{|c|c|c|c|c|c|c|c|c|c|c|}
\hline ITEMS & ER_Q46 & ST_Q48 & $A D \_Q 49$ & FL_Q51 & NJ_Q52 & OP_Q53 & ED_Q54 & ED_Q57 & MO_Q58 & ED_Q60 \\
\hline AD_Q1 & .490 & .517 & .361 & .530 & -.700 & .684 & .432 & .563 & .602 & .489 \\
\hline OB_Q3 & .739 & .756 & .580 & .666 & -.675 & .724 & .584 & .752 & .784 & .696 \\
\hline EM_Q4 & .689 & .697 & .593 & .655 & -.694 & .782 & .615 & .784 & .780 & .676 \\
\hline EX_Q5 & -.480 & -.520 & -.313 & -.523 & .565 & -.677 & -.544 & -.619 & -.588 & -.518 \\
\hline MO_Q7 & .803 & .821 & .610 & .635 & -.670 & .758 & .517 & .750 & .819 & .713 \\
\hline NJ_Q8 & .521 & .527 & .340 & .459 & -.602 & .486 & .589 & .688 & .649 & .493 \\
\hline OB_Q9 & .053 & -.026 & .132 & -.090 & .149 & -.240 & -.152 & -.107 & -.085 & -.182 \\
\hline PA_Q10 & .597 & .649 & .475 & .475 & -.647 & .587 & .464 & .594 & .699 & .524 \\
\hline RE_Q11 & .443 & .360 & .310 & .194 & -.291 & .157 & .234 & .302 & .325 & .326 \\
\hline MO_Q12 & -.440 & -.479 & -.440 & -.470 & .534 & -.491 & -.572 & -.649 & -.580 & -.483 \\
\hline RE_Q13 & .288 & .166 & .254 & .179 & -.072 & .001 & .171 & .177 & .167 & .194 \\
\hline RE_Q14 & .470 & .382 & .328 & .326 & -.260 & .138 & .303 & .351 & .355 & .286 \\
\hline RE_Q16 & -.198 & -.298 & -.215 & -.281 & .382 & -.434 & -.375 & -.367 & -.366 & -.362 \\
\hline AD_Q19 & .745 & .769 & .533 & .671 & -.762 & .848 & .559 & .747 & .806 & .748 \\
\hline ER_Q20 & -.632 & -.621 & -.526 & -.709 & .702 & -.785 & -.540 & -.644 & -.696 & -.641 \\
\hline MO_Q22 & -.492 & -.517 & -.411 & -.540 & .664 & -.666 & -.535 & -.664 & -.620 & -.489 \\
\hline RE_Q23 & .518 & .528 & .396 & .299 & -.291 & .233 & .277 & .472 & .471 & .378 \\
\hline FA_Q24 & .779 & .822 & .604 & .719 & -.815 & .814 & .527 & .763 & .798 & .703 \\
\hline CO_Q25 & .746 & .708 & .504 & .614 & -.693 & .740 & .489 & .723 & .701 & .573 \\
\hline$A D \_Q 26$ & -.387 & -.490 & -.320 & -.539 & .653 & -.610 & -.387 & -.580 & -.550 & -.425 \\
\hline MO_Q27 & -.614 & -.674 & -.555 & -.676 & .762 & -.824 & -.532 & -.700 & -.738 & -.634 \\
\hline ED_Q28 & .554 & .662 & .492 & .569 & -.652 & .690 & .413 & .659 & .741 & .603 \\
\hline AD_Q29 & .581 & .618 & .546 & .539 & -.627 & .605 & .381 & .597 & .697 & .616 \\
\hline FL_Q31 & .680 & .736 & .609 & .672 & -.698 & .735 & .513 & .655 & .816 & .728 \\
\hline NJ_Q32 & .075 & -.115 & -.046 & -.212 & .331 & -.298 & -.258 & -.258 & -.217 & -.173 \\
\hline OP_Q33 & -.265 & -.366 & -.131 & -.173 & .322 & -.418 & -.310 & -.409 & -.329 & -.397 \\
\hline MO_Q34 & -.593 & -.667 & -.420 & -.562 & .666 & -.782 & -.483 & -.636 & -.651 & -.559 \\
\hline OT_Q35 & .599 & .645 & .558 & .705 & -.773 & .649 & .457 & .615 & .682 & .645 \\
\hline PA_Q36 & .744 & .751 & .588 & .599 & -.718 & .774 & .544 & .771 & .812 & .690 \\
\hline CI_Q38 & .691 & .718 & .636 & .713 & -.743 & .816 & .516 & .719 & .772 & .751 \\
\hline AD_Q40 & .642 & .654 & .479 & .647 & -.702 & .747 & .479 & .641 & .685 & .692 \\
\hline
\end{tabular}




\section{Appendix B - Table 2: Final Inter-Item Correlation Matrix}

\begin{tabular}{|c|c|c|c|c|c|c|c|c|c|c|}
\hline ITEMS & ER_Q46 & ST_Q48 & AD_Q49 & FL_Q51 & NJ_Q52 & OP_Q53 & ED_Q54 & ED_Q57 & MO_Q58 & ED_Q60 \\
\hline$F L \_Q 41$ & .581 & .671 & .618 & .781 & -.745 & .782 & .473 & .655 & .721 & .595 \\
\hline OP_Q42 & .619 & .600 & .439 & .566 & -.649 & .689 & .432 & .661 & .586 & .612 \\
\hline ST_Q43 & .642 & .611 & .527 & .456 & -.494 & .491 & .307 & .526 & 637 & .404 \\
\hline ST_Q44 & .717 & .784 & .494 & .525 & -.531 & .624 & .447 & .667 & .794 & .568 \\
\hline ST_Q45 & .739 & .643 & .503 & .464 & -.518 & 539 & .500 & .603 & .615 & .577 \\
\hline ER_Q46 & 1.000 & .818 & .575 & .539 & -.585 & .635 & .494 & .714 & .748 & .576 \\
\hline ST_Q48 & .818 & 1.000 & .557 & .570 & -.610 & .723 & .495 & .763 & .838 & .633 \\
\hline AD_Q49 & .575 & .557 & 1.000 & .565 & -.603 & .550 & .334 & .448 & .610 & .516 \\
\hline$F L \_Q 51$ & .539 & .570 & .565 & 1.000 & -687 & .753 & .509 & .608 & .676 & .594 \\
\hline NJ_Q52 & -.585 & -.610 & -.603 & -.687 & 1.000 & -.779 & -.527 & -.660 & -.721 & -.609 \\
\hline OP_Q53 & .635 & .723 & .550 & .753 & -.779 & 1.000 & .588 & .730 & .794 & .718 \\
\hline ED_Q54 & .494 & .495 & .334 & .509 & -.527 & .588 & 1.000 & .677 & .598 & .548 \\
\hline ED_Q57 & .714 & .763 & .448 & .608 & -.660 & .730 & .677 & 1.000 & .785 & .682 \\
\hline MO_Q58 & .748 & .838 & .610 & .676 & -.721 & .794 & .598 & .785 & 1.000 & .685 \\
\hline ED_Q60 & .576 & .633 & .516 & .594 & -.609 & .718 & .548 & .682 & .685 & 1.000 \\
\hline
\end{tabular}




\section{Appendix C: Component Abbreviations}

The survey questions were given item labels that would provide understanding and facilitate data analysis activities when assessing the results tables. The question item labels included the component abbreviation and the question sequence number, e.g. AD-

Q1 was the label for the first question in the survey that was aligned with Adventurous. The following table contains the abbreviations used in the question item labels.

\section{Component Abbreviations}

\begin{tabular}{|c|l|c|}
\hline$\#$ & \multicolumn{1}{|c|}{ Component } & Abbreviation \\
\hline 1 & Adventurous & AD \\
\hline 2 & Confidence & CO \\
\hline 3 & Cultural Intelligence & CI \\
\hline 4 & Education & ED \\
\hline 5 & Emotional Resilience & ER \\
\hline 6 & Empathy & EM \\
\hline 7 & Experience & EX \\
\hline 8 & Facilitator & FA \\
\hline 9 & Flexibility & FL \\
\hline 10 & Motivation & MO \\
\hline 11 & Non-Judgmental & NJ \\
\hline 12 & Observant & OB \\
\hline 13 & Open & OP \\
\hline 14 & Optimistic & OT \\
\hline 15 & Personal Autonomy & PA \\
\hline 16 & Respectful & PR \\
\hline 17 & Strategic & RE \\
\hline
\end{tabular}




\section{Appendix D: Summary of the Data Analysis Results for the Research Items}

\begin{tabular}{|c|c|c|c|c|}
\hline Question/Item & Label & Component & Results & Discussion \\
\hline $\begin{array}{l}\text { tend to seek out local foods } \\
\text { as my first choice when I'm } \\
\text { in foreign countries. }\end{array}$ & AD_Q1 & Adventurous & Retained & $\begin{array}{l}\text { Factor } 1 \text { in both EFA and CFA } \\
\text { High EFA at } .790 \\
\text { High CFA at } .718\end{array}$ \\
\hline $\begin{array}{l}\text { In terms of knowing how to } \\
\text { navigate new cultures, I see } \\
\text { myself as highly experienced. }\end{array}$ & CO_Q2 & Confidence & $\begin{array}{c}\text { Removed by } \\
\text { correlation } \\
\text { matrix analysis }\end{array}$ & $\begin{array}{l}\text { Multi-collinearity between } .885 \\
\text { and } .924 \text {, other items remained } \\
\text { sin Confidence component }\end{array}$ \\
\hline $\begin{array}{l}\text { Itend to be inquisitive and } \\
\text { research many topics. }\end{array}$ & OB_Q3 & Observant & Retained & $\begin{array}{l}\text { Factor } 1 \text { in both EFA and CFA } \\
\text { High EFA at } .852 \\
\text { High CFA at } .869\end{array}$ \\
\hline $\begin{array}{l}\text { I empathize with people from } \\
\text { other cultures. }\end{array}$ & EM_Q4 & Empathy & Retained & $\begin{array}{l}\text { Factor } 1 \text { in both EFA and CFA } \\
\text { High EFA at } .874 \\
\text { High CFA at } .881\end{array}$ \\
\hline $\begin{array}{l}\text { Culture shock has been a } \\
\text { difficult challenge for me }\end{array}$ & EX_Q5 & Experience & Retained & $\begin{array}{l}\text { Factor } 1 \text { in both EFA and CFA } \\
\text { High EFA at }-.753 \\
\text { High CFA at }-.747\end{array}$ \\
\hline I am flexible, not predictable. & FL_Q6 & Flexibility & $\begin{array}{c}\text { Removed by } \\
\text { correlation } \\
\text { matrix analysis }\end{array}$ & $\begin{array}{l}\text { Multi-collinearity between } .876 \\
\text { and } .877, \text { other items remained } \\
\text { sin Flexibility component }\end{array}$ \\
\hline $\begin{array}{l}\text { I am involved, not } \\
\text { indifferent. }\end{array}$ & MO_Q7 & Motivation & Retained & $\begin{array}{l}\text { Factor } 1 \text { in both EFA and CFA } \\
\text { High EFA at } .844 \\
\text { High CFA at } .872\end{array}$ \\
\hline $\begin{array}{l}\text { I never assume to understand } \\
\text { a new culture. }\end{array}$ & NJ_Q8 & Non-Judgmental & $\begin{array}{l}\text { Removed by } \\
\text { EFA analysis }\end{array}$ & $\begin{array}{l}\text { Factor } 1 \text { EFA however } \\
\text { insignificant in any factor with } \\
711 \text { and } .538 \text { over two factors }\end{array}$ \\
\hline $\begin{array}{l}\text { I tend to see cultures in } \\
\text { groupings, e.g., Western, } \\
\text { Oriental, and African. }\end{array}$ & OB_Q9 & Observant & $\begin{array}{l}\text { Removed by } \\
\text { EFA analysis }\end{array}$ & $\begin{array}{l}\text { Factor I EFA however } \\
\text { insignificant in any factor with } \\
.600 \text { and } .449 \text { over two factors }\end{array}$ \\
\hline $\begin{array}{l}\text { I feel } \mathrm{l} \text { am in control of my } \\
\text { life and career. }\end{array}$ & PA_Q10 & $\begin{array}{l}\text { Personal } \\
\text { Autonomy }\end{array}$ & $\begin{array}{l}\text { Removed by } \\
\text { EFA analysis }\end{array}$ & $\begin{array}{l}\text { Factor 1 EFA however } \\
\text { insignificant in any factor with } \\
\text { range of } .657 \text { to } .543 \text { over four } \\
\text { factors }\end{array}$ \\
\hline $\begin{array}{l}\text { When I have to meet } \\
\text { strangers from another } \\
\text { culture, I carefully plan my } \\
\text { conversation in advance. }\end{array}$ & RE_Q11 & Respectful & $\begin{array}{l}\text { Removed by } \\
\text { regression } \\
\text { analysis }\end{array}$ & $\begin{array}{l}\text { Factor } 2 \text { in both EFA and CFA } \\
\text { High EFA at } .738, \text { High CFA } \\
.930 \\
\text { However, low predictive } \\
\text { strength with Sig. }=.463 .\end{array}$ \\
\hline $\begin{array}{l}\text { It tend to extend my visits } \\
\text { home as long as possible. }\end{array}$ & MO_Q12 & Motivation & $\begin{array}{l}\text { Removed by } \\
\text { EFA analysis }\end{array}$ & $\begin{array}{l}\text { Factor } 1 \text { EFA however } \\
\text { insignificant in any factor with } \\
641 \text { and } .518 \text { over two factors }\end{array}$ \\
\hline
\end{tabular}




\begin{tabular}{|c|c|c|c|c|}
\hline Question/Item & Label & Component & Results & Discussion \\
\hline $\begin{array}{l}\text { I approach new cultures with } \\
\text { caution. }\end{array}$ & RE_Q13 & Respectful & $\begin{array}{l}\text { Removed by } \\
\text { regression } \\
\text { analysis }\end{array}$ & $\begin{array}{l}\text { Factor } 2 \text { in both EFA and CFA } \\
\text { High EFA at } .840, \text { High CFA } \\
.918 \\
\text { However, low predictive } \\
\text { strength with Sig. }=.463 .\end{array}$ \\
\hline $\begin{array}{l}\text { I plan what I say when I am } \\
\text { with a person from a different } \\
\text { culture. }\end{array}$ & RE_Q14 & Respectful & $\begin{array}{c}\text { Removed by } \\
\text { regression } \\
\text { analysis }\end{array}$ & $\begin{array}{l}\text { Factor } 2 \text { in both EFA and CFA } \\
\text { High EFA at } .815, \text { High CFA } \\
.950 \\
\text { However, low predictive } \\
\text { strength with Sig. }=.463 .\end{array}$ \\
\hline $\begin{array}{l}\text { I can easily 'go with the } \\
\text { flow' in cultural situations. }\end{array}$ & FL_Q15 & Flexibility & $\begin{array}{c}\text { Removed by } \\
\text { correlation } \\
\text { matrix analysis }\end{array}$ & $\begin{array}{l}\text { Multi-collinearity between } .885 \\
\text { and } .933, \text { other items remained } \\
\text { sin Flexibility component }\end{array}$ \\
\hline $\begin{array}{l}\text { Generalizations are often } \\
\text { desirable when dealing with } \\
\text { cultural differences. }\end{array}$ & RE_Q16 & Respectful & $\begin{array}{l}\text { Removed by } \\
\text { EFA analysis }\end{array}$ & $\begin{array}{l}\text { Factor I EFA however } \\
\text { insignificant in any factor with } \\
.428 \text { and } .574 \text { over two factors }\end{array}$ \\
\hline $\begin{array}{l}\text { I see myself as a change } \\
\text { agent, helping others with } \\
\text { change. }\end{array}$ & FA_Q17 & Facilitator & $\begin{array}{c}\text { Removed by } \\
\text { correlation } \\
\text { matrix analysis }\end{array}$ & $\begin{array}{l}\text { Multi-collinearity between } .884 \\
\text { and } .895 \text {, other items remained } \\
\text { sin Facilitator component }\end{array}$ \\
\hline $\begin{array}{l}\text { In keeping a conversation } \\
\text { going with someone from } \\
\text { another culture, I deal } \\
\text { successfully with ambiguity } \\
\text { and differences. }\end{array}$ & CO_Q18 & Confidence & $\begin{array}{c}\text { Removed by } \\
\text { correlation } \\
\text { matrix analysis }\end{array}$ & $\begin{array}{l}\text { Multi-collinearity between } .895 \\
\text { and } .924 \text {, other items remained } \\
\text { sin Confidence component }\end{array}$ \\
\hline $\begin{array}{l}\text { I want to experience different } \\
\text { cultures as much as possible } \\
\text { in both my personal and } \\
\text { professional life. }\end{array}$ & $A D \_Q 19$ & Adventurous & Retained & $\begin{array}{l}\text { Factor } 1 \text { in both EFA and CFA } \\
\text { High EFA at } .947 \\
\text { High CFA at } .941\end{array}$ \\
\hline $\begin{array}{l}\text { I am intimidated by new } \\
\text { experiences. }\end{array}$ & ER_Q20 & $\begin{array}{l}\text { Emotional } \\
\text { Resilience }\end{array}$ & Retained & $\begin{array}{l}\text { Factor } 1 \text { in both EFA and CFA } \\
\text { High EFA at }-.854 \\
\text { High CFA at }-.829\end{array}$ \\
\hline $\begin{array}{l}\text { I can easily integrate myself } \\
\text { into a new culture. }\end{array}$ & CI_Q21 & $\begin{array}{l}\text { Cultural } \\
\text { Intelligence }\end{array}$ & $\begin{array}{c}\text { Removed by } \\
\text { correlation } \\
\text { matrix analysis }\end{array}$ & $\begin{array}{l}\text { Multi-collinearity between } .887 \\
\text { and } .912 \text {, other items remained } \\
\text { in Cultural Intelligence } \\
\text { component }\end{array}$ \\
\hline $\begin{array}{l}\text { I am sometimes reluctant to } \\
\text { return abroad after a home } \\
\text { visit. }\end{array}$ & MO_Q22 & Motivation & Retained & $\begin{array}{l}\text { Factor } 1 \text { in both EFA and CFA } \\
\text { High EFA at }-.7573 \\
\text { High CFA at }-.794\end{array}$ \\
\hline $\begin{array}{l}\text { I tend to become somewhat } \\
\text { formal in culturally } \\
\text { ambiguous situations. }\end{array}$ & RE_Q23 & Respectful & $\begin{array}{l}\text { Removed by } \\
\text { EFA analysis }\end{array}$ & $\begin{array}{l}\text { Factor } 1 \text { EFA however } \\
\text { insignificant in any factor with } \\
476 \text { and } .663 \text { over two factors }\end{array}$ \\
\hline $\begin{array}{l}\text { I often play a liaison role } \\
\text { bringing those from other } \\
\text { cultures together. }\end{array}$ & FA_Q24 & Facilitator & Retained & $\begin{array}{l}\text { Factor } 1 \text { in both EFA and CFA } \\
\text { High EFA at } .928 \\
\text { High CFA at } .901\end{array}$ \\
\hline
\end{tabular}




\begin{tabular}{|c|c|c|c|c|}
\hline Question/Item & Label & Component & Results & Discussion \\
\hline $\begin{array}{l}\text { I think along the lines of live } \\
\text { and let live even if it goes } \\
\text { against my core values. }\end{array}$ & CO_Q25 & Confidence & Retained & $\begin{array}{l}\text { Factor } 1 \text { in both EFA and CFA } \\
\text { High EFA at } .845 \\
\text { High CFA at } .795\end{array}$ \\
\hline $\begin{array}{l}\text { I prefer to socialize with } \\
\text { other expatriates on a foreign } \\
\text { assignment. }\end{array}$ & AD_Q26 & Adventurous & $\begin{array}{l}\text { Removed by } \\
\text { EFA analysis }\end{array}$ & $\begin{array}{l}\text { Factor } 1 \text { EFA however } \\
\text { insignificant in any factor with } \\
.659 \text { and } .541 \text { over two factors }\end{array}$ \\
\hline $\begin{array}{l}\text { When on assignment, I tend } \\
\text { to look for any opportunity to } \\
\text { return home for a visit. }\end{array}$ & MO_Q27 & Motivation & Retained & $\begin{array}{l}\text { Factor } 1 \text { in both EFA and CFA } \\
\text { High EFA at }-.888 \\
\text { High CFA at }-.801\end{array}$ \\
\hline $\begin{array}{l}\text { I try to learn the basics of the } \\
\text { languages I encounter. }\end{array}$ & ED_Q28 & Education & Retained & $\begin{array}{l}\text { Factor } 1 \text { in both EFA and CFA } \\
\text { High EFA at } .771 \\
\text { High CFA at } .878\end{array}$ \\
\hline $\begin{array}{l}\text { I get bored when things are } \\
\text { stagnant or consistent. }\end{array}$ & AD_Q29 & Adventurous & Retained & $\begin{array}{l}\text { Factor } 1 \text { in both EFA and CFA } \\
\text { High EFA at } .760 \\
\text { High CFA at } .859\end{array}$ \\
\hline $\begin{array}{l}\text { When it comes to knowing } \\
\text { how to cope with cultural } \\
\text { diversity, others say I am } \\
\text { very knowledgeable. }\end{array}$ & CI_Q30 & $\begin{array}{l}\text { Cultural } \\
\text { Intelligence }\end{array}$ & $\begin{array}{c}\text { Removed by } \\
\text { correlation } \\
\text { matrix analysis }\end{array}$ & $\begin{array}{l}\text { Multi-collinearity between } .876 \\
\text { and } .919, \text { other items remained } \\
\text { in Cultural Intelligence } \\
\text { component }\end{array}$ \\
\hline $\begin{array}{l}\text { I am a good actor, not } \\
\text { reserved. }\end{array}$ & FL_Q31 & Flexibility & Retained & $\begin{array}{l}\text { Factor } 1 \text { in both EFA and CFA } \\
\text { High EFA at } .809 \\
\text { High CFA at } .766\end{array}$ \\
\hline $\begin{array}{l}\text { Stereotyping helps me view } \\
\text { others in some cultural } \\
\text { situations. }\end{array}$ & RE_Q32 & Respectful & $\begin{array}{l}\text { Removed by } \\
\text { CFA analysis }\end{array}$ & $\begin{array}{l}\text { Factor } 2 \text { in both EFA and CFA } \\
\text { High EFA at } .760 \text {, however } \\
\text { insignificant CFA. }\end{array}$ \\
\hline $\begin{array}{l}\text { I prefer to work with people } \\
\text { who are technically very } \\
\text { competent rather than those } \\
\text { from a different culture. }\end{array}$ & OP_Q33 & Open & $\begin{array}{l}\text { Removed by } \\
\text { EFA analysis }\end{array}$ & $\begin{array}{l}\text { Factor } 1 \text { EFA however } \\
\text { insignificant in any factor with } \\
417, .589 \text { and } .451 \text { over three } \\
\text { factors. }\end{array}$ \\
\hline $\begin{array}{l}\text { I look forward to the end of } \\
\text { an assignment so I can return } \\
\text { home. }\end{array}$ & MO_Q34 & Motivation & Retained & $\begin{array}{l}\text { Factor } 1 \text { in both EFA and CFA } \\
\text { High EFA at }-.834 \\
\text { High CFA at }-.883\end{array}$ \\
\hline $\begin{array}{l}\text { People are all basically the } \\
\text { same, no matter where they } \\
\text { are from. }\end{array}$ & OT_Q35 & Optimistic & $\begin{array}{l}\text { Removed by } \\
\text { EFA analysis }\end{array}$ & $\begin{array}{l}\text { Factor } 1 \text { EFA however } \\
\text { insignificant in any factor with } \\
\text { range of } .695 \text { to } .549 \text { over four } \\
\text { factors }\end{array}$ \\
\hline $\begin{array}{l}\text { I accept responsibility for my } \\
\text { life/career decisions. }\end{array}$ & PA_Q36 & $\begin{array}{l}\text { Personal } \\
\text { Autonomy }\end{array}$ & Retained & $\begin{array}{l}\text { Factor } 1 \text { in both EFA and CFA } \\
\text { High EFA at } .874 \\
\text { High CFA at } .843\end{array}$ \\
\hline I am willing to take risks. & FL_Q37 & Flexibility & $\begin{array}{c}\text { Removed by } \\
\text { correlation } \\
\text { matrix analysis }\end{array}$ & $\begin{array}{l}\text { Multi-collinearity with item } 36 \\
\text { (PA_Q36) at .933, other items } \\
\text { sremained in Flexibility } \\
\text { component }\end{array}$ \\
\hline
\end{tabular}




\begin{tabular}{|c|c|c|c|c|}
\hline Question/Item & Label & Component & Results & Discussion \\
\hline $\begin{array}{l}\text { I look for cultural cues when } \\
\text { I encounter those from } \\
\text { another culture }\end{array}$ & CI_Q38 & $\begin{array}{l}\text { Cultural } \\
\text { Intelligence }\end{array}$ & Retained & $\begin{array}{l}\text { Factor } 1 \text { in both EFA and CFA } \\
\text { High EFA at } .893 \\
\text { High CFA at } .771\end{array}$ \\
\hline $\begin{array}{l}\text { lam secure in own skin (I } \\
\text { know my abilities, strengths } \\
\text { and limits). }\end{array}$ & AD_Q39 & Adventurous & $\begin{array}{c}\text { Removed by } \\
\text { correlation } \\
\text { matrix analysis }\end{array}$ & $\begin{array}{l}\text { Multi-collinearity with item } 36 \\
\text { (PA_Q36) at .986, other items } \\
\text { remained in Adventurous } \\
\text { component }\end{array}$ \\
\hline $\begin{array}{l}\text { I prefer a job in a culture } \\
\text { different from my own. }\end{array}$ & AD_Q40 & Adventurous & Retained & $\begin{array}{l}\text { Factor } 1 \text { in both EFA and CFA } \\
\text { High EFA at } .862 \\
\text { High CFA at } .870\end{array}$ \\
\hline $\begin{array}{l}\text { My partner/family is } \\
\text { supportive of my career and } \\
\text { has an open attitude toward } \\
\text { other cultures. }\end{array}$ & FL_Q41 & Flexibility & Retained & $\begin{array}{l}\text { Factor } 1 \text { in both EFA and CFA } \\
\text { High EFA at } .838 \\
\text { High CFA at } .741\end{array}$ \\
\hline $\begin{array}{l}\text { I would rather work with } \\
\text { someone who is from a } \\
\text { culture very different from } \\
\text { my own culture. }\end{array}$ & OP_Q42 & Open & Retained & $\begin{array}{l}\text { Factor } 1 \text { in both EFA and CFA } \\
\text { High EFA at } .782 \\
\text { High CFA at } .822\end{array}$ \\
\hline $\begin{array}{l}\text { I consider myself to be very } \\
\text { sensible and not ruled by my } \\
\text { emotions. }\end{array}$ & PR_Q43 & Pragmatic & $\begin{array}{l}\text { Removed by } \\
\text { EFA analysis }\end{array}$ & $\begin{array}{l}\text { Factor 1 EFA however } \\
\text { insignificant in any factor with } \\
.639 \text { and } .574 \text { over two factors }\end{array}$ \\
\hline $\begin{array}{l}\text { I set clear goals before I start } \\
\text { working with others from } \\
\text { different cultures }\end{array}$ & ST_Q44 & Strategic & $\begin{array}{l}\text { Removed by } \\
\text { EFA analysis }\end{array}$ & $\begin{array}{l}\text { Factor 1 EFA however } \\
\text { insignificant in any factor with } \\
.728 \text { and } .616 \text { over two factors }\end{array}$ \\
\hline $\begin{array}{l}\text { I change the way I interact } \\
\text { depending on the cultural } \\
\text { backgrounds of those around } \\
\text { me. }\end{array}$ & PR_Q45 & Pragmatic & $\begin{array}{l}\text { Removed by } \\
\text { EFA analysis }\end{array}$ & $\begin{array}{l}\text { Factor } 1 \text { EFA however } \\
\text { insignificant in any factor with } \\
756 \text { and } .665 \text { over two factors }\end{array}$ \\
\hline I am not easily offended. & ER_Q46 & $\begin{array}{l}\text { Emotional } \\
\text { Resilience }\end{array}$ & Retained & $\begin{array}{l}\text { Factor } 1 \text { in both EFA and CFA } \\
\text { High EFA at } .788 \\
\text { High CFA at } .788\end{array}$ \\
\hline $\begin{array}{l}\text { I see myself as having a lot of } \\
\text { cultural expertise. }\end{array}$ & CI_Q47 & $\begin{array}{l}\text { Cultural } \\
\text { Intelligence }\end{array}$ & $\begin{array}{c}\text { Removed by } \\
\text { correlation } \\
\text { matrix analysis }\end{array}$ & $\begin{array}{l}\text { Multi-collinearity with item } 24 \\
\text { (FA_24) at .893, other items } \\
\text { remained in Cultural } \\
\text { Intelligence component }\end{array}$ \\
\hline $\begin{array}{l}\text { I always have a Plan B as an } \\
\text { alternative plan in case things } \\
\text { do not work out as } \\
\text { anticipated. }\end{array}$ & ST_Q48 & Strategic & Retained & $\begin{array}{l}\text { Factor } 1 \text { in both EFA and CFA } \\
\text { High EFA at } .824 \\
\text { High CFA at } .851\end{array}$ \\
\hline $\begin{array}{l}\text { I eagerly use new technology } \\
\text { as soon as it is available. }\end{array}$ & $A D \_Q 49$ & Adventurous & $\begin{array}{l}\text { Removed by } \\
\text { CFA analysis }\end{array}$ & $\begin{array}{l}\text { Factor } 1 \text { in both EFA and CFA } \\
\text { High EFA at } .669 \text {, however } \\
\text { insignificant CFA with } 2 \\
\text { factors at } .560 \text { and } .539 .\end{array}$ \\
\hline $\begin{array}{l}\text { I intentionally seek out } \\
\text { foreign work assignments. }\end{array}$ & ST_Q50 & Strategic & $\begin{array}{l}\text { Removed by } \\
\text { correlation } \\
\text { matrix analysis }\end{array}$ & $\begin{array}{l}\text { Multi-collinearity between } .875 \\
\text { and } .919 \text {, other items remained } \\
\text { in Strategic component }\end{array}$ \\
\hline
\end{tabular}




\begin{tabular}{|c|c|c|c|c|}
\hline Question/Item & Label & Component & Results & Discussion \\
\hline $\begin{array}{l}\text { My family is very flexible } \\
\text { with my job relocations; they } \\
\text { do not 'hold me back' from } \\
\text { opportunities. }\end{array}$ & FL_Q51 & Flexibility & Retained & $\begin{array}{l}\text { Factor } 1 \text { in both EFA and CFA } \\
\text { High EFA at } .771 \\
\text { High CFA at } .764\end{array}$ \\
\hline $\begin{array}{l}\text { I sometimes think my } \\
\text { (native) culture is superior to } \\
\text { other cultures. }\end{array}$ & NJ_Q52 & Non-Judgmental & Retained & $\begin{array}{l}\text { Factor } 1 \text { in both EFA and CFA } \\
\text { High EFA at }-.813 \\
\text { High CFA at }-.784\end{array}$ \\
\hline $\begin{array}{l}\text { I have friends from many } \\
\text { cultural backgrounds. }\end{array}$ & OP_Q53 & Open & Retained & $\begin{array}{l}\text { Factor } 1 \text { in both EFA and CFA } \\
\text { High EFA at } .907 \\
\text { High CFA at } .890\end{array}$ \\
\hline $\begin{array}{l}\text { I consider myself well } \\
\text { educated. }\end{array}$ & EF_Q54 & Education & $\begin{array}{l}\text { Removed by } \\
\text { EFA analysis }\end{array}$ & $\begin{array}{l}\text { Factor 1 EFA however } \\
\text { insignificant in any factor with } \\
689 \text { and } .602 \text { over two factors }\end{array}$ \\
\hline $\begin{array}{l}\text { I want to experience living in } \\
\text { many cultures. }\end{array}$ & EX_Q55 & Experience & $\begin{array}{c}\text { Removed by } \\
\text { correlation } \\
\text { matrix analysis }\end{array}$ & $\begin{array}{l}\text { Multi-collinearity between } .875 \\
\text { and } .917, \text { other items remained } \\
\text { sin Experience component }\end{array}$ \\
\hline $\begin{array}{l}\text { I can operate/live in a state of } \\
\text { flux and confusion. }\end{array}$ & FL_Q56 & Flexibility & $\begin{array}{c}\text { Removed by } \\
\text { correlation } \\
\text { matrix analysis }\end{array}$ & $\begin{array}{l}\text { Multi-collinearity between } .884 \\
\text { and } .900, \text { other items remained } \\
\text { sin Flexibility component }\end{array}$ \\
\hline $\begin{array}{l}\text { I actively keep abreast of } \\
\text { global issues and concerns. }\end{array}$ & ED_Q57 & Education & $\begin{array}{l}\text { Removed by } \\
\text { CFA analysis }\end{array}$ & $\begin{array}{l}\text { Factor } 1 \text { in both EFA and CFA } \\
\text { High EFA at } .851 \text {, however } \\
\text { insignificant CFA at } .528\end{array}$ \\
\hline I am energized, not lethargic. & ED_Q58 & Motivation & Retained & $\begin{array}{l}\text { Factor } 1 \text { in both EFA and CFA } \\
\text { High EFA at } .869 \\
\text { High CFA at } .881\end{array}$ \\
\hline $\begin{array}{l}\text { I am confident in my ability } \\
\text { to interpret cultural } \\
\text { behavioural cues. }\end{array}$ & OB_Q59 & Observant & $\begin{array}{c}\text { Removed by } \\
\text { correlation } \\
\text { matrix analysis }\end{array}$ & $\begin{array}{l}\text { Multi-collinearity between } .915 \\
\text { and } .922, \text { other items remained } \\
\text { sin Observant component }\end{array}$ \\
\hline $\begin{array}{l}\text { I have many hobbies and } \\
\text { interests. }\end{array}$ & ED_Q60 & Education & Retained & $\begin{array}{l}\text { Factor } 1 \text { in both EFA and CFA } \\
\text { High EFA at } .791 \\
\text { High CFA at } .810\end{array}$ \\
\hline
\end{tabular}




\section{Appendix E: Transcultural Measurement Scale Survey}

Please select the response that best represents how you feel about each statement.

\begin{tabular}{|c|c|c|c|c|c|c|c|}
\hline \multirow{2}{*}{$\begin{array}{l}\text { How do you feel about the following: } \\
\begin{array}{l}\text { 1. I tend to seek out local foods as my first choice } \\
\text { when I'm in foreign countries. }\end{array} \\
\end{array}$} & \multicolumn{2}{|c|}{$\begin{array}{l}\text { Strongly } \\
\text { Agree }\end{array}$} & \multicolumn{3}{|c|}{ Indifferent } & \multicolumn{2}{|c|}{$\begin{array}{l}\text { Strongly } \\
\text { Disagree }\end{array}$} \\
\hline & 1 & 2 & 3 & 4 & 5 & 6 & 7 \\
\hline $\begin{array}{l}\text { 2. I tend to be inquisitive and research many } \\
\text { topics. }\end{array}$ & 1 & 2 & 3 & 4 & 5 & 6 & 7 \\
\hline 3. I empathize with people from other cultures. & 1 & 2 & 3 & 4 & 5 & 6 & 7 \\
\hline $\begin{array}{l}\text { 4. Culture shock has been a difficult challenge for } \\
\text { me. }\end{array}$ & 1 & 2 & 3 & 4 & 5 & 6 & 7 \\
\hline 5. I am involved, not indifferent. & 1 & 2 & 3 & 4 & 5 & 6 & 7 \\
\hline $\begin{array}{l}\text { 6. I want to experience different cultures as much } \\
\text { as possible in both my personal and professional } \\
\text { life. }\end{array}$ & 1 & 2 & 3 & 4 & 5 & 6 & 7 \\
\hline 7. I am intimidated by new experiences. & 1 & 2 & 3 & 4 & 5 & 6 & 7 \\
\hline $\begin{array}{l}\text { 8. I am sometimes reluctant to return abroad after a } \\
\text { home visit. }\end{array}$ & 1 & 2 & 3 & 4 & 5 & 6 & 7 \\
\hline $\begin{array}{l}\text { 9. I often play a liaison role bringing those from } \\
\text { other cultures together. }\end{array}$ & 1 & 2 & 3 & 4 & 5 & 6 & 7 \\
\hline $\begin{array}{l}\text { 10. I think along the lines of live and let live even if } \\
\text { it goes against my core values. }\end{array}$ & 1 & 2 & 3 & 4 & 5 & 6 & 7 \\
\hline $\begin{array}{l}\text { 11. When on assignment, I tend to look for any } \\
\text { opportunity to return home for a visit. }\end{array}$ & 1 & 2 & 3 & 4 & 5 & 6 & 7 \\
\hline $\begin{array}{l}\text { 12. I try to learn the basics of the languages I } \\
\text { encounter. }\end{array}$ & 1 & 2 & 3 & 4 & 5 & 6 & 7 \\
\hline $\begin{array}{l}\text { 13. I get bored when things are stagnant or } \\
\text { consistent. }\end{array}$ & 1 & 2 & 3 & 4 & 5 & 6 & 7 \\
\hline 14. I am a good actor, not reserved. & 1 & 2 & 3 & 4 & 5 & 6 & 7 \\
\hline $\begin{array}{l}\text { 15. I look forward to the end of an assignment so I } \\
\text { can return home. }\end{array}$ & 1 & 2 & 3 & 4 & 5 & 6 & 7 \\
\hline $\begin{array}{l}\text { 16. I accept responsibility for my life/career } \\
\text { decisions. }\end{array}$ & 1 & 2 & 3 & 4 & 5 & 6 & 7 \\
\hline $\begin{array}{l}\text { 17. I look for cultural cues when I encounter those } \\
\text { from another culture }\end{array}$ & 1 & 2 & 3 & 4 & 5 & 6 & 7 \\
\hline 18. I prefer a job in a culture different from my own. & 1 & 2 & 3 & 4 & 5 & 6 & 7 \\
\hline
\end{tabular}




\begin{tabular}{|c|c|c|c|c|c|c|c|}
\hline \multirow{2}{*}{$\begin{array}{l}\text { How do you feel about the following: } \\
\text { 19. My partner/family is supportive of my career } \\
\text { and has an open attitude toward other cultures. }\end{array}$} & \multicolumn{2}{|c|}{$\begin{array}{l}\text { Strongly } \\
\text { Agree }\end{array}$} & \multicolumn{3}{|c|}{ Indifferent } & \multicolumn{2}{|c|}{$\begin{array}{l}\text { Strongly } \\
\text { Disagree }\end{array}$} \\
\hline & 1 & 2 & 3 & 4 & 5 & 6 & 7 \\
\hline $\begin{array}{l}\text { 20. I would rather work with someone who is from a } \\
\text { culture very different from my own culture. }\end{array}$ & 1 & 2 & 3 & 4 & $J$ & 6 & 7 \\
\hline 21. I am not easily offended. & 1 & 2 & 3 & 4 & 5 & 6 & 7 \\
\hline $\begin{array}{l}\text { 22. I always have a Plan B as an alternative plan in } \\
\text { case things do not work out as anticipated. }\end{array}$ & 1 & 2 & 3 & 4 & 5 & 6 & 7 \\
\hline $\begin{array}{l}\text { 23. My family is very flexible with my job } \\
\text { relocations; they do not 'hold me back' from } \\
\text { opportunities. }\end{array}$ & 1 & 2 & 3 & 4 & 5 & 6 & 7 \\
\hline $\begin{array}{l}\text { 24. I sometimes think my (native) culture is superior } \\
\text { to other cultures. }\end{array}$ & 1 & 2 & 3 & 4 & 5 & 6 & 7 \\
\hline 25. I have friends from many cultural backgrounds. & 1 & 2 & 3 & 4 & 5 & 6 & 7 \\
\hline 26. I am energized, not lethargic. & 1 & 2 & 3 & 4 & 5 & 6 & 7 \\
\hline 27. I have many hobbies and interests. & 1 & 2 & 3 & 4 & 5 & 6 & 7 \\
\hline
\end{tabular}

Please provide any comments:

\section{Thank You}

